CEZAR AUGUSTO BELLEZI

\title{
ANÁLISE NUMÉRICA DE FENÔMENOS DE IMPACTO HIDRODINÂMICO EM PLATAFORMAS OFFSHORE
}

\author{
Dissertação apresentada à Escola \\ Politécnica da Universidade de São Paulo \\ para obtenção do título de Mestre em \\ Engenharia Naval e Oceânica
}

São Paulo

2015 
CEZAR AUGUSTO BELLEZI

\title{
ANÁLISE NUMÉRICA DE FENÔMENOS DE IMPACTO HIDRODINÂMICO EM PLATAFORMAS OFFSHORE
}

\author{
Dissertação apresentada à Escola \\ Politécnica da Universidade de São Paulo \\ para obtenção do título de Mestre em \\ Engenharia Naval e Oceânica \\ Área de Concentração: \\ Engenharia Naval e Ocênica \\ Hidrodinâmica, Dinâmica e Controle de \\ Sistemas Oceânicos \\ Orientador: \\ Prof. Dr. Kazuo Nishimoto
}

São Paulo

2015 
FICHA CATALOGRÁFICA

\section{Bellezi, Cezar Augusto}

Análise numérica de fenômenos de impacto hidrodinâmico em plataformas offshore / C.A. Bellezi. -- São Paulo, 2014. $140 \mathrm{p}$.

Dissertação (Mestrado) - Escola Politécnica da Universidade de São Paulo. Departamento de Engenharia Naval e Oceânica.

1.Estruturas offshore (Simulação numérica) 2.Hidrodinâmica 3.Método de partículas I.Universidade de São Paulo. Escola Politécnica. Departamento de Engenharia Naval e Oceânica II.t. 


\section{AGRADECIMENTOS}

Em primeiro lugar, agradeço a minha companheira Regina Chan pelo apoio contínuo e compreensão diante do exigente período do mestrado. Também agradeço aos meus pais, Augusto e Diva, pelo incentivo ao estudo desde cedo, determinante na minha escolha em continuar meus estudos após a graduação.

Em segundo lugar ao Prof. Dr. Cheng Liang-Yee e ao Prof. Dr. Kazuo Nishimoto, pela paciente orientação e contínuo apoio sem os quais não teria sido possível a realização deste trabalho e pelo privilégio de, na prática, ter as atividade como que orientadas por dois professores.

Agradeço ao Programa de Recursos Humanos da Agência Nacional de Petróleo (PRH-ANP 19) pela bolsa de mestrado, que forneceu o suporte financeiro para que me concentrasse exclusivamente no desenvolvimento da pesquisa. Destaco também o suporte do Prof. Dr. Hernani Brinatti e do PV Jairson de Lima, sempre ao lado dos alunos bolsistas do programa.

Por fim, agradeço aos integrantes da Equipe MPS do Tanque de Provas Numérico da USP: Dr. Márcio Tsukamoto, Me. Fábio Motezuki, Dr. Davi Fernandes, Me. Rubens Amaro e ao Prof. Dr. Fernando Kurokawa. O desenvolvimento do simulador baseado no método de partículas empregado neste trabalho é fruto do trabalho conjunto e contínuo desta equipe coordenada pelo prof. Dr. Cheng LiangYee e foi possível graças ao finaciamento da Petrobras SA. 


\section{RESUMO}

O presente trabalho é focado no estudo dos violentos fenômenos de impacto hidrodinâmico que podem prejudicar a operação de plataformas offshore. São três os fenômenos abordados neste trabalho: o green water, o wave runup e o sloshing. O fenômeno de wave runup consiste na projeção vertical de uma coluna de água devido ao impacto de ondas em estruturas transversais. O fenômeno de green water consiste no embarque de água no convés, podendo danificar os equipamentos da planta de produção. Por fim, o sloshing consiste no movimento violento de fluído em tanques parcialmente preenchidos, resultando em perigosos carregamentos em suas paredes.

Tais fenômenos possuem natureza altamente não linear e sua análise, considerando-se toda a sua complexidade, ainda constitui um desafio para a engenharia naval e oceânica. Os métodos de partículas têm se destacado no tratamento de tais fenômenos envolvendo interação fluído-estruturas, grandes deformações e fragmentação de superfície livre. Desta maneira, optou-se pelo emprego do método de partículas Moving Particles Semi-Implicit (MPS) neste trabalho para o estudo dos fenômenos de impacto hidrodinâmico. O MPS é um método totalmente lagrangeano para escoamentos incompressíveis.

Para os três fenômenos abordados neste trabalho há uma primeira etapa de validação, na qual os resultados numéricos são comparados a resultados experimentais da literatura. Uma segunda etapa é baseada na aplicação do método numérico na análise de ferramentas para a mitigação dos esforços resultantes do impacto hidrodinâmico. Nesta etapa é investigada a influência do formato da proa no fenômeno de green water e a utilização de anteparas fixas e flutuantes para a mitigação de sloshing em tanques. 


\section{ABSTRACT}

The present work is focused in the study of the violent hydrodynamic impact phenomenon which could jeopardize the offshore platforms operation. In this work three different phenomena involving hydrodynamic impact are studied: green water, wave runup and sloshing. The wave runup consists in the vertical projection of a water column due to wave impact on a transversal structure, such as submersible columns. The green water consists in the water boarding on the deck which could damage the equipment over the oil platform deck. Finally, the sloshing phenomenon is the violent movement of fluid in partially filled tanks, resulting in dangerous impact loads at its walls.

The hydrodynamic impact phenomenon has strongly non linear nature and is still a challenge for the naval and offshore engineering its analysis considering all its complexity. The particle methods present advantages in the analysis of phenomena involving fluid structure interaction, large free surface deformation, fragmentation and merging. Therefore, in the present study the Moving Particles Semi-Implicit (MPS) method is used. The MPS is a fully lagrangian method for the simulation of incompressible flows.

For the three phenomena studied in the present work a first step of validation is performed. In the validation step the numerical results obtained by the particle method are compared to experimental data presented in the literature. The second step consists in the application of the numerical method to investigate simple mechanisms to mitigate the hydrodynamic impact loads. For example, the effect of the bow shape in the green water phenomenon is studied. Also in this step the use of fixed and floating baffles in order to suppress the sloshing phenomenon are investigated. 


\section{IV. ÍNDICE DE ILUSTRAÇÕES}

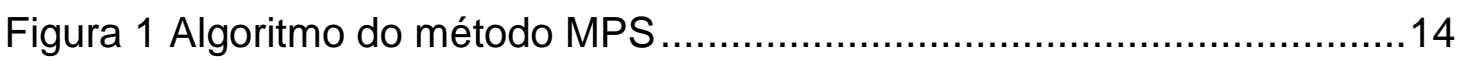

Figura 2 Modelagem do sólido no MPS ....................................................15

Figura 3 Dimensões e configuração do caso de Dam Break ...........................20

Figura 4 Posicionamento dos sensores de superfície livre ............................21

Figura 5 Posicionamento dos sensores de pressão no bloco .........................22

Figura 6 Série temporal de pressão no sensor P1 .....................................22

Figura 7 Série temporal de pressão no sensor P2 ......................................23

Figura 8 Série temporal de pressão no sensor P3 ....................................23

Figura 9 Série temporal da elevação de superfície livre no sensor H4 ….......24

Figura 10 Série temporal da elevação de superfície livre no sensor H2 .........25

Figura 11 Snapshots da simulação com o método de partículas - Dam Break

Figura 12 Dimensões do tanque de provas numérico para calibração de onda 29

Figura 13 Redução da amplitude da onda ao longo do tanque - Condição de onda 7 .30

Figura 14 Dimensões do tanque de provas numérico 31

Figura 15 Dimensões principais dos modelos (Lee, et al., 2012) ..................32

Figura 16 Posição dos sensores de pressão (Lee, et al., 2012) .....................33

Figura 17 Série temporal de pressão no sensor P11 - MPS x experimental (Lee, et al., 2012) - MPS não filtrado (a) MPS filtrado (b) - condição de onda 9......33

Figura 18 Série temporal de pressão no sensor P21 - MPS x experimental (Lee, et al., 2012) - MPS não filtrado (a) MPS filtrado (b) - condição de onda 9......34

Figura 19 Série temporal de pressão no sensor P31 - MPS x experimental (Lee, et al., 2012) - MPS não filtrado (a) MPS filtrado (b) - condição de onda 9......35 
Figura 20 Pressão no sensor P11 - $($ Rect $0-\lambda=375 \mathrm{~cm}-A=11,25 \mathrm{~cm}-$ onda 9)

Figura 21 Pressão no sensor P11 - (Rect5 $-\lambda=375 \mathrm{~cm}-\mathrm{A}=11,25 \mathrm{~cm}-$ onda 9) .36

Figura 22 Pressão no sensor P11 - (Round $-\lambda=375 \mathrm{~cm}-\mathrm{A}=11,25 \mathrm{~cm}-$ onda 9) .36

Figura 23 Pressão no sensor P21 ( $\lambda=375 \mathrm{~cm}-\mathrm{A}=11.25 \mathrm{~cm}-$ onda 9$)$ .37

Figura 24 Pressão no sensor P31 $(\lambda=375 \mathrm{~cm}-\mathrm{A}=11.25 \mathrm{~cm}-$ onda 9$)$ 37

Figura 25 Snapshots da simulação numérica - velocidade das partículas de superfície livre (esquerda) pressão no convés e antepara (direita) - condição de onda 9 38

Figura 26 Modelos com diferentes formatos de proa .40

Figura 27 Força longitudinal na antepara - Condição de onda 3 - (a) proas em formato prabólico, (b) proas em forma de cunha em $\mathrm{V}$ e (c) proa chanfrada. .42

Figura 28 Força longitudinal na antepara - Condição de onda 7 - (a) proas em formato prabólico, (b) proas em forma de cunha em $V$ e (c) proa chanfrada ......44

Figura 29 Força longitudinal na antepara - Condição de onda 6 - (a) proas em formato prabólico, (b) proas em forma de cunha em $\mathrm{V}$ e (c) proa chanfrada ......45

Figura 30 Volume de água embarcada no convés - Modelos com proa chanfrada - (a) Condição de onda 1, (b) condição de onda 3, (c) Condição de onda 6 e (d) Condição de onda 7

Figura 31 Configuração das células sobre o convés .48

Figura 32 Altura da superfície livre nas células - Proa em cunha - Condição de onda 6 49

Figura 33 Velocidade longitudinal média do fluído sobre a região das células Proa em cunha - Condição de onda 6 . 49

Figura 34 Altura da superfície livre nas células - Proa inclinada - Condição de onda 3 .50 
Figura 35 Velocidade longitudinal média na região sobre as células - Proa inclinada - Condição de onda 3

Figura 36 Snapshots da simulação numérica com o método de partículas Green water com diferentes geometrias de proa .52

Figura 37 Dimensões do modelo .54

Figura 38 Vista superior dos tanques de provas numéricos .56

Figura 39 Movimento da estrutura flutuante - onda 9 .58

Figura 40 Snapshots da simulação numérica $-\alpha=45^{\circ}$ (esquerda) $\alpha=90^{\circ}$ (direita) - onda 9 .59

Figura 41 Componente longitudinal da força nas anteparas - onda 9 60

Figura 42 Componente transversal da força nas anteparas - onda 9 61

Figura 43 Força resultante nas anteparas - onda 9 61

Figura 44 Componente longitudinal da força nas anteparas - onda 9. .63

Figura 45 Componente transversal da força nas anteparas - onda $9-\alpha=90^{\circ}$ .63

Figura 46 Dimensões em escala real da seção de plataforma (a), modelo com seção trasnversal da coluna quadrada (b) e modelo com a seção transversal da coluna circular (c) .68

Figura 47 Runup nas colunas do modelo fixo (modelo A) - (a) coluna 1 e (b) coluna 2 - Onda média 71

Figura 48 Série temporal da pressão de impacto nas coluas do modelo fixo (modelo A) - (a) coluna 1, sensor de pressão P1 e (b) coluna 2, sensor de pressão P2 - Onda média .71

Figura 49 Snapshots da simulação do modelo flutuante (modelo B) - Onda curta (esquerda), onda média (centro) e onda longa (direita) .72

Figura 50 Movimento de (a) pitch e (b) heave do modelo flutuante (modelo B) 
Figura 51 Runup nas colunas - (a) onda curta, (b) onda média e (c) onda longa

Figura 52 Distribuição de pressão nas colunas em um ciclo de onda - (a) onda curta e (b) onda longa

Figura 53 Snapshots da simulação de partículas - Onda curta - (a) $t=5,48 \mathrm{~s}$. (b) $t=6.12 \mathrm{~s}$.

Figura 54 Snapshots da simulação de partículas - Onda longa - (a) $t=7,19 \mathrm{~s}$. (b) $t=8,11 \mathrm{~s}$. .78

Figura 55 Força de arrasto nas colunas - (a) onda curta e (b) onda longa ....79

Figura 56 Configuração do tanque e principais variáveis do movimento (Arai et. al., 1992a) .82

Figura 57 Dimensões e tipos de tanque .83

Figura 58 Eevação de superfície livre nas paredes (a) esquerda e (b) direita 85

Figura 59 Snapshot das simulações de convergência com o método de partículas - Distância entre partículas de (a) $B / d s=15$, (b) $B / d s=30$ e (c) $B / d s=6085$

Figura 60 Posição dos sensores de pressão para o Caso A e o Caso B 86

Figura 61 Pressão ns sensores (a) P1 e (b) P2 no Caso A 87

Figura 62 Amplitude do runup em função da resolução .88

Figura 63 Pressão dinâmica nos sensores P1 e P2 em função da resolução 88

Figura 64 Posição dos sensores de pressão para o Caso C - tanque com antepara .89

Figura 65 Pressão no tanque A $(h=450 \mathrm{~mm})$ - Sensores P4 (abaixo), P5 (centro) e P6 (acima) - MPS x experimental - adaptado de (Arai, et al., 1992) .......90

Figura 66 Pressão no Caso D - Sensores P1 (abaixo), P2 (centro) e P3 (acima) - MPS x experimental - adaptado de (Arai, et al., 1992) .90

Figura 67 Pressão hidrodinâmica em função da frequência (Caso $C, \theta=6^{\circ}, \varphi$ $\left.=33,7^{\circ}\right)-$ MPS x experimental (adaptado de Arai et. al., 1992) .92 
Figura 68 Modelos de tanque para o estudo de supressão de sloshing Modelo sem antepara (a), modelo com antepara no fundo (Modelo A) (b), modelo com antepara no centro (Modelo B)(c), modelo com antepara no topo (Modelo C) e modelo com antepara flutuante (e)

Figura 69 Distribuição dos sensores de pressão .96

Figura 70 Modos naturais de sloshing bidimensional (a) $n=1$ (b) $n=2$ (c) $n=$ 3

Figura 71 Diagrama de pressão dinâmica - nível de preenchimento de 25\% $\mathrm{P} 1$ .97

Figura 72 Snapshots da simulação por método de partículas - nível de preenchimento de $25 \%$ 98

Figura 73 Série temporal de pressão no sensor P1- nível de preenchimento $25 \%$ - frequência $0,7 \mathrm{~Hz}$

Figura 74 Série temporal da pressão máxima (a) e posição vertical no tanque de ocorrência da pressão máxima (b) - nivel de preenchimento $25 \%$ 100

Figura 75 Snapshots da simulação por método de partículas - nível de preenchimento de $25 \%$ - frequência $0,7 \mathrm{~Hz}$ - (a) sem antepara (b) antepara fixa no fundo (c) antepara flutuante 101

Figura 76 Diagrama de pressão dinâmica - nível de preenchimento de 33\% $\mathrm{P} 1$ 102

Figura 77 Série temporal de pressão - sensor P1 - nível de preenchimento $33 \%$ - frequência $0,75 \mathrm{~Hz}$ 103

Figura 78 Série temporal da pressão máxima (a) e posição vertical no tanque de ocorrência da pressão máxima (b) - nivel de preenchimento $33 \%$ 103

Figura 79 Diagrama de pressão dinâmica - nível de preenchimento de 50\% $\mathrm{P} 1$ 104

Figura 80 Série temporal de pressão no sensor P1- nível de preenchimento $50 \%$ - frequência $0,8 \mathrm{~Hz}$ 105 
Figura 81 Série temporal da pressão máxima (a) e posição vertical no tanque de ocorrência da pressão máxima (b) - nivel de preenchimento $50 \%$ 105

Figura 82 Snapshots da simulação por método de partículas - nível de preenchimento de $50 \%$ - frequência $0,8 \mathrm{~Hz}$ - (a) sem antepara (b) antepara fixa no centro (c) antepara flutuante 106

Figura 83 Diagrama de pressão dinâmica - nível de preenchimento de 67\% 107

Figura 84 Série temporal de pressão - sensor P1 - nível de preenchimento $67 \%$ - frequência $0,85 \mathrm{~Hz}$ 108

Figura 85 Série temporal da pressão máxima - frequência de 0,85 Hz- nível de preenchimento $67 \%$ 108

Figura 86 Diagrama de pressão dinâmica - nível de preenchimento de 75\% $\mathrm{P} 1$ 109

Figura 87 Série temporal de pressão - sensor P1 - nível de preenchimento $75 \%$ - frequência $0,85 \mathrm{~Hz}$ 110

Figura 88 Série temporal da pressão máxima - frequência de $0,85 \mathrm{~Hz}-$ nível de preenchimento $75 \%$ 110

Figura 89 Snapshots da simulação por método de partículas - nível de preenchimento de $75 \%$ - frequência $0,85 \mathrm{~Hz}$ - (a) sem antepara (b) antepara fixa no fundo (c) antepara flutuante 111 


\section{V. ÍNDICE DE TABELAS}

Tabela 1 Parâmetros numéricos de simulação ...............................................21

Tabela 2 Parâmetros das ondas (Lee, et al., 2012) ....................................28

Tabela 3 Parâmetros de geração de onda...................................................30

Tabela 4 Parâmetros numéricos de simulação ....................................................31

Tabela 5 Dimensões principais dos modelos..................................................41

Tabela 6 Parâmetros numéricos de simulação …………………………....... 41

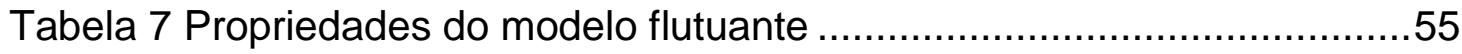

Tabela 8 Parâmetros numéricos de simulação .............................................55

Tabela 9 Dados dos tanques de prova numéricos........................................56

Tabela 10 Características das ondas e do movimiento do batedor .................70

Tabela 11 Parâmetros da análise de convergência .......................................84

Tabela 12 Frequência de movimento do Caso C..........................................

Tabela 13 Combinação dos modelos de tanque e níveis de preenchimento..94

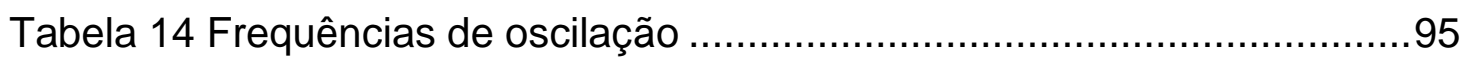




\section{SUMÁRIO}

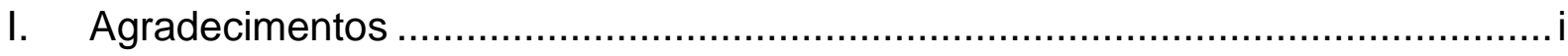

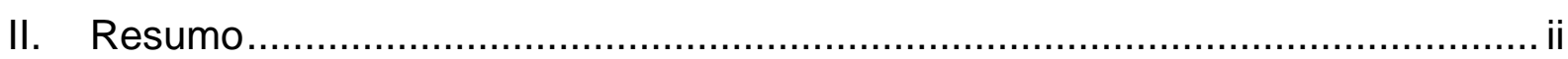

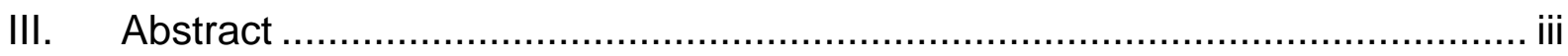

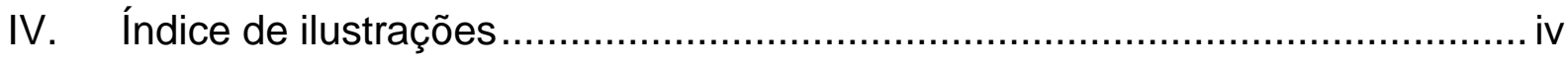

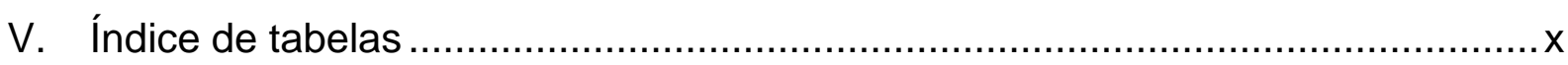

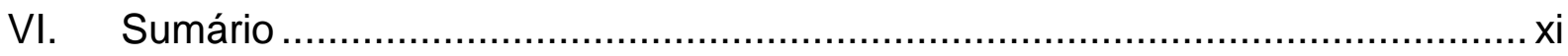

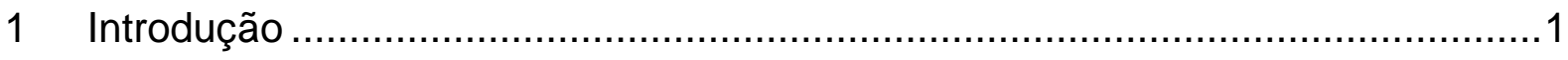

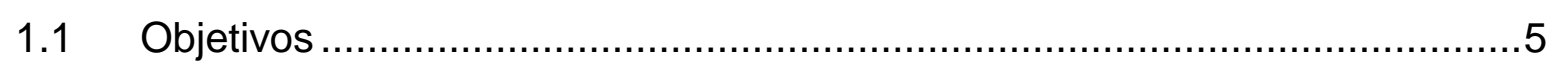

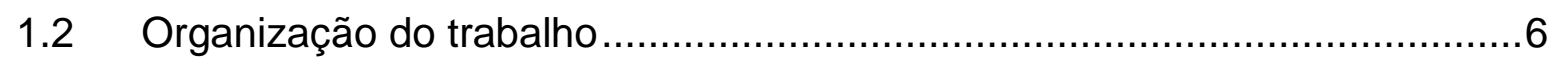

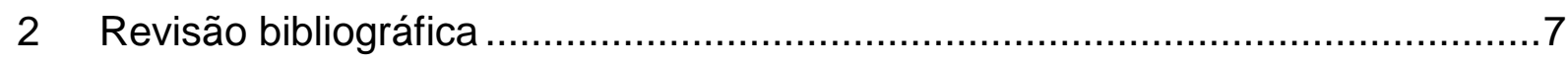

2.1 Métodos numéricos para dinâmica dos fluídos ........................................

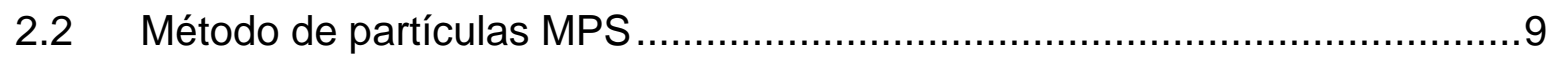

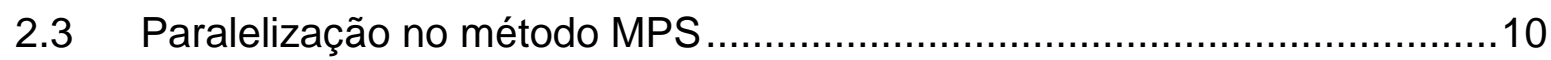

2.4 Formulação matemática do método MPS ….........................................11

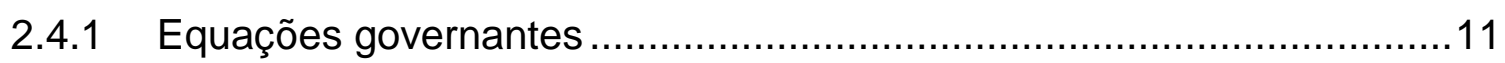

2.4.2 Modelo de interação entre partículas...............................................12

2.4.3 Algoritmo do escoamento incompressível .........................................13

2.4.4 Condição de contorno de superfície livre...............................................14

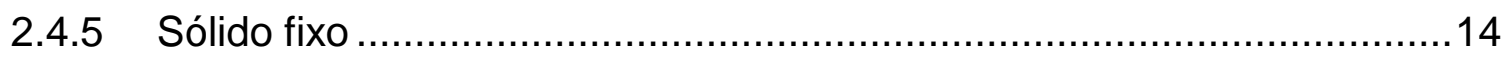

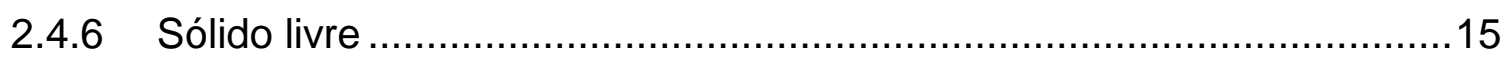

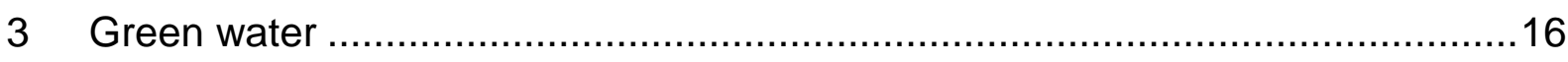

3.1 Introdução e Revisão Bibliográfica....................................................16

3.2 Validação - Caso de dam-break .........................................................20

3.3 Validação - Caso de Green water ..........................................................28

3.3.1 Calibração numérica da onda incidente.............................................28

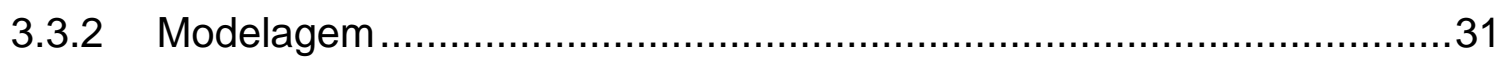

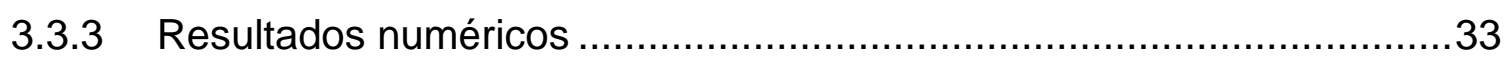

3.4 Análise do efeito da proa no fenômeno de green water ..............................40

3.4.1 Resultados numéricos ................................................................ 
4 Green water para diferentes ângulos de aproamento ................................53

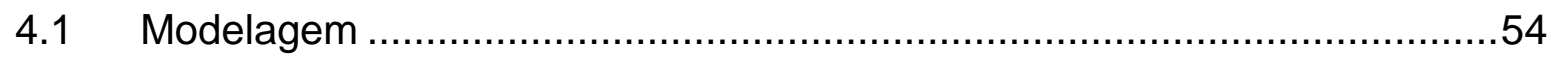

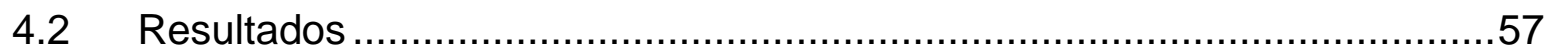

4.2.1 Resultados: análise do ângulo de aproamento.................................57

4.2.2 Resultados: modelo fixo e modelo flutuante ....................................62

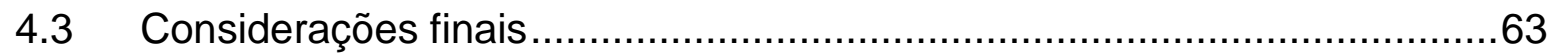

5 Wave runup nas colunas de plataforma semi-submersível ...........................66

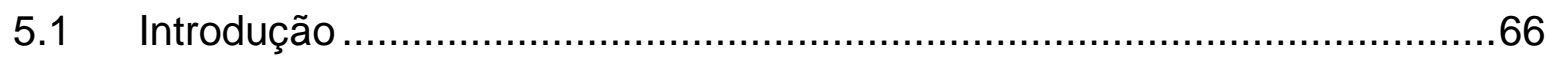

5.2 Modelo e calibração de onda ........................................................67

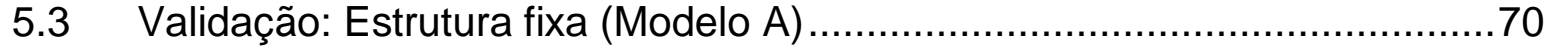

5.4 Análise do comportamento hidrodinâmico: estrutura flutuante (Modelo B) .72

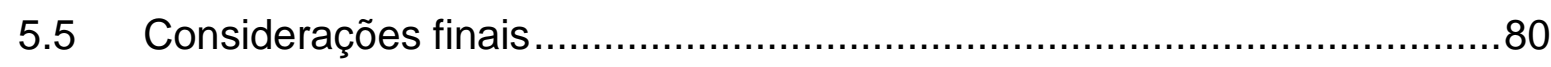

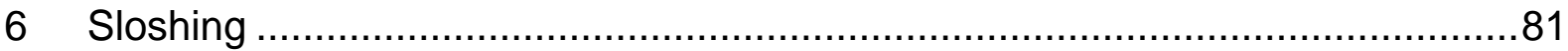

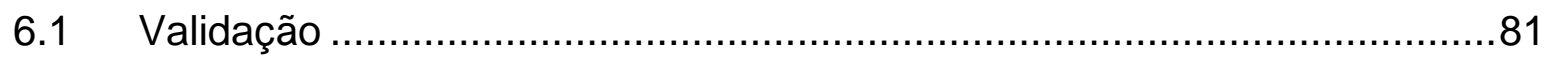

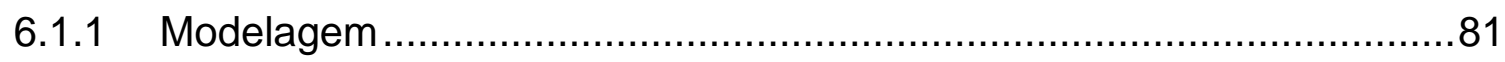

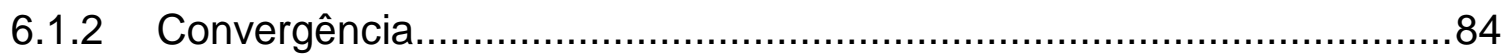

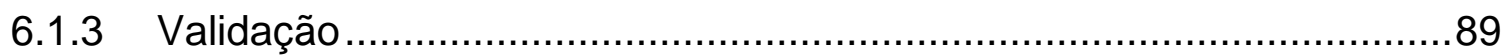

6.2 Estudo de supressor de sloshing com anteparas fixas .........................92

6.3 Considerações finais ..................................................................... 112

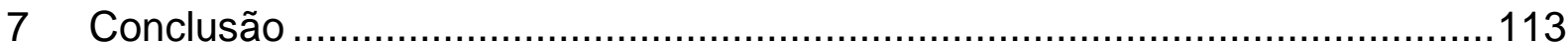

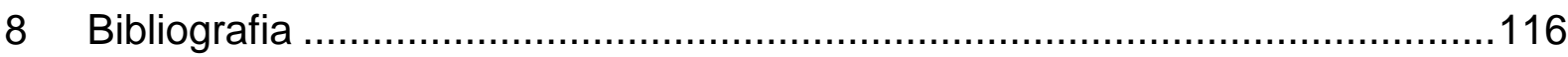




\section{INTRODUÇÃO}

A descoberta e início da exploração de petróleo na região do Pré-Sal brasileiro se dá em águas profundas e ultra-profundas. Ela é realizada por estruturas flutuantes tais como plataformas dos tipos semi-submersível e Floating, Production, Storage and Offloading (FPSOs). As plataformas tipo FPSO consistem em estruturas na forma de embarcação nas quais a planta de exploração se localiza sobre o convés, com amplo espaço para armazenamento na parte inferior do casco. Já as plataforma semi-submersíveis consistem em uma planta de produção disposta sobre um convés superior, sustentado por colunas ligadas ao seu casco, estruturas submersas denominadas pontões. Ambas são estruturas flutuantes empregadas para a exploração de petróleo em águas profundas.

Na região do Pré-Sal atualmente operam 28 plataformas do tipo FPSO, mais que qualquer outro lugar do mundo. E a PETROBRAS é a segunda maior operadora de plataformas deste tipo no mundo, com 10 navios, atrás apenas da China National Offshore Oil Company (CNOOC), que opera 12 navios (Wood Group Mustang, 2013). Outro tipo de estrutura comum na exploração do Pré-Sal são as plataformas do tipo semi-submersível, com 19 unidades operadas pela PETROBRAS, das quais 13 operam na Bacia de Campos e 2 na de Santos (Wood Group Mustang, 2011).

Tais estruturas flutuantes se encontram sob a ação de diversos agentes climáticos, como as correntes, os ventos e as ondas. Em condições climáticas severas, a ação das ondas gera diversos fenômenos de impacto hidrodinâmico que podem prejudicar a operação das plantas de produção. Neste estudo são investigados os fenômenos de impacto hidrodinâmico: o green water, o wave runup e o sloshing.

O fenômeno de wave runup é a projeção ascendente de fluído ao longo de estruturas sujeitas ao impacto das ondas. Um exemplo é quando ocorre o choque de uma onda contra a coluna de uma plataforma semi-submersível e água se eleva ao longo dessa coluna. O fenômeno de wave runup pode ser seguido por outros fenômenos de impacto hidrodinâmico, como o green water e o wave-in-deck impact. 
O fenômeno de green water, também conhecido como shipping water, ocorre quando a altura da onda incidente na estrutura é superior à borda livre da embarcação ou FPSO e ocorre o embarque de água no convés, que pode danificar o equipamento da planta de produção. A investigação do green water adquire importância na medida em que a borda livre das embarcações é limitada por critérios estruturais, de peso e de estabilidade e, em condições climáticas severas, pode ocasionar embarque de água significativo.

Outro fenômeno de impacto hidrodinâmico é wave-in-deck impact, que ocorre quando uma onda se choca contra o convés inferior de estruturas flutuantes como plataformas semi-submersíveis e jaqueta. Pode ocorrer como resultado de uma onda de altura superior ao air gap entre o convés inferior e a superfície livre das ondas ou após o wave runup em estruturas transversais á direçãod e propagação da onda, como as colunas. Esse fenômeno resulta em grandes carregamentos hidrodinâmicos para os quais usualmente o convés inferior destas plataformas não foi projetado.

Os três fenômenos de impacto hidrodinâmico citados são consequência direta do impacto de onda em estruturas flutuantes; já o sloshing é indiretamente afetado pela ação das ondas nas plataformas. O sloshing consiste no movimento violento de fluído dentro de tanques parcialmente preenchidos, sendo que o movimento do fluído dentro do tanque é estimulado pelo movimento da embarcação devido às ondas.

Todos os fenômenos de impacto hidrodinâmico abordados neste estudo apresentam natureza altamente não linear, envolvendogeometria complexas, grandes deslocamentos de superfície livre, fragmentação e junção de fluído e interação fluído-estrutura. Estas características tornam complicada a modelagem destes fenômenos por métodos analíticos ou mesmo métodos numéricos tradicionais, baseados em uma descrição euleriana do domínio computacional. Os métodos analíticos fornecem estimativas permeadas por diversas simplificações que, por sua vez, comprometem a precisão dos resultados. Por fim, a análise experimental apresenta os resultados mais precisos, porém apresenta alguns efeitos de escala, carece de flexibilidade e apresenta altos custos. As análises experimentais também apresentam limitação na tomada de dados relativa à 
quantidade de sensores disponíveis, imprecisões próprias dos sensores e efeitos de escala para os ensaios em escala reduzida. Diante deste quadro, uma alternativa que se demonstra promissora é o emprego de métodos numéricos lagrangeanos, nos quais o domínio computacional é discretizado em partículas. Estes métodos não padecem das mesmas dificuldades dos métodos tradicionais e, em contrapartida, oferecem maior flexibilidade e menores custos e em relação às análises experimentais.

No presente estudo propõe-se a utilização do método Moving Particles SemiImplicit, também conhecido como Moving Particles Simulation (MPS) na análise de fenômenos de impacto hidrodinâmico envolvidos no impacto de ondas em estruturas offshore. O MPS é um método completamente lagrangeano para a modelagem do escoamento incompressível inicialmente proposto por Koshizuka et al. (1995) e Koshizuka \& Oka (1996). No MPS os operadores diferenciais são substituídos por operadores algébricos baseados de um modelo de interação entre partículas e o algoritmo é baseado em um esquema de passos fracionados, com a pressão sendo calculada de forma implícita. O método de partículas, em relação aos métodos tradicionais baseados em malhas, apresenta vantagens na modelagem de fenômenos envolvendo grandes deformações de superfície livre, fragmentação, junção, interação fluído-estrutura, geometrias complexas e fenômenos multifísicos e envolvendo multi-corpos. Já a desvantagem destes métodos reside em um maior custo computacional e nas oscilações de natureza numérica da pressão calculada. Tais dificuldades vêm sendo contornadas pela constante evolução da capacidade de processamento e pelo desenvolvimento de diversas técnicas para a suavização das flutuações de pressão.

As simulações serão realizadas empregando-se um software desenvolvido no Tanque de Provas Numérico (TPN-USP) baseado no método MPS. A implementação original do simulador se dá em memória compartilhada, o que permite a aceleração do processamento por meio do emprego de diversos processadores compartilhando a memória de um nó do cluster computacional. A versão de processamento paralelo em memória compartilhada do simulador permite a simulação de modelos numéricos de até 2 milhões de partículas, pois a memória 
disponível é limitada à capacidade de um nó do cluster. Esta quantidade de partículas não é suficiente para a simulação de problemas de alta complexidade.

Com o objetivo de realizar simulações mais sofisticadas, envolvendo modelos com dezenas de milhões de partículas, foi desenvolvida a versão de processamento paralelo em memória híbrida do simulador baseado no método MPS (dMPS) por Fernandes (2013). A versão com processamento paralelo em memória híbrida combina a memória compartilhada, que permite a utilização de mais de um processador por nó, com a utilização de memória distribuída, que permite o emprego de mais de um nó em uma mesma simulação. A distribuição do processo em diversos nós do cluster se dá pela divisão do domínio computacional em diversos subdomínios que, individualmente, são alocados em nós exclusivos. Esta técnica permite que a memória de diversos nós seja combinada e aumente a escalabilidade dos modelos numéricos simulados com o software.

O trabalho será dividido em duas etapas principais.

A primeira etapa consiste na validação do software para cada um dos fenômenos de impacto hidrodinâmico. A validação para o fenômeno de green water é dividida em duas partes; a primeira para a validação do método para fenômenos de impacto hidrodinâmico, com a simulação de um caso de benchmark de dam break (Kleefsman, et al., 2005a)(Issa \& Violeau, 2006); e a segunda com a simulação de green water em escala reduzida baseado nos resultados experimentais de Lee et al. (2012). A validação de sloshing será a partir dos resultados experimentais e numéricos de Arai et al. (1992) para o sloshing em tanques retangulares simples e com uma antepara. Por fim, a validação de wave runup será pela simulação do impacto de ondas em um modelo em escala reduzida de uma plataforma semi-submersível, com uma seção que contém duas coluna alinhadas, baseada nos resultados apresentados em Iwanowski et al. (2009).

A segunda etapa do estudo contempla a investigação e solução de problemas de engenharia reais relacionados a cada um dos fenômenos de impacto hidrodinâmico analisados. Para o fenômeno de green water será analisado o efeito da forma da proa no volume de água embarcado e no carregamento hidrodinâmico em estruturas sobre o convés. Para o fenômeno de wave runup nas colunas de plataformas semi-submersíveis será investigada a influência da forma na coluna no 
runup e nos carregamentos hidrodinâmicos nas colunas. Para os fenômenos de green water e wave runup, para os quais na análises experimentais geralmente são baseadas em estruturas fixas, serão simulados também casos com estruturas móveis e os resultados comparados à aqueles obtidos com as estruturas fixas. Nestes dois diferentes fenômenos também será investigado o comportamento diante de diversas condições de onda. Por fim, a aplicação na análise de sloshing é focada na avaliação de supressores, primeiramente com o emprego de supressores horizontais fixos em diferentes posições do tanque e, em seguida, a análise da aplicação de um supressor flutuante.

\subsection{Objetivos}

O objetivo deste estudo é a investigação de fenômenos de impacto hidrodinâmico presentes na operação de estruturas offshore. A aplicação do simulador baseado no método de partículas se insere neste tema desafiador na área de engenharia naval e offshore, na qual os métodos tradicionais apresentam dificuldade em prover resultados precisos e com bom custo-benefício.

Para se chegar a este objetivo o trabalho se divide nas etapas de validação e de aplicação, sendo que cada uma destas etapas apresenta os seus objetivos específicos. O objetivo da etapa de validação é a constatação da capacidade do método numérico em representar adequadamente o fenômeno estudo, comparando os resultados obtidos a resultados experimentais presentes na literatura. A etapa de aplicação tem por objetivo explorar a flexibilidade da ferramenta numérica, estudando aspectos do fenômeno de impacto hidrodinâmico ou avaliando soluções simples de engenharia para os problemas encontrados.

Para o fenômeno de green water a etapa de aplicação envolve diversos estudos, cada uma com o seu objetivo.

1. O primeiro estudo envolve a análise da influência do formato da proa no volume do embarque de água no convés. São investigados 5 formatos de proa com modelos fixos sob a ação de mar de proa. 0 objetivo é determinar a geometria que corresponda ao menor ebarque de água no convés. 
2. Na segunda análise são comparados modelos fixos e flutuantes colocados sob diferentes condições de mar: de proa, de bochecha e de través. Um dos objetivos é o estudo das condições de mar mais críticas. Outro objetivo é estabelecer a importância do movimento relativo entre a superfície livre da onda e a estrutura flutuante para o embarque de água.

A aplicação para o estudo do fenômeno de sloshing consiste na avaliação do emprego de estruturas fixas horizontais para a supressão de sloshing e no teste de uum conceito de supressão de sloshing baseado em uma antepara flutuante.

\subsection{Organização do trabalho}

O texto para a qualificação está dividido em 5 capítulos, a saber:

O Capítulo 1 contempla a introdução do tema e a definição do escopo; assim como os principais objetivos do trabalho, a sua organização textual.

O Capítulo 2 consiste em uma breve revisão de literatura sobre as ferramentas para análise de dinâmica dos fluídos computacional, com foco na evolução dos métodos de partículas e a formulação do método MPS.

O Capítulo 3 é focado na análise do fenômeno de green water. Este capítulo apresenta uma breve revisão bibliográfica sobre o estado-da-arte do fenômeno, validação para o caso de dam-break e validação de green water em modelo fixo. Também é apresentada uma análise de convergência e simulação em alta resolução, a comparação entre os resultados obtidos para um modelo fixo e um modelo flutuante, a análise do formato da proa no fenômeno de green water e, por fim, análise do fenômeno de green water para diferente ângulos de aproamento.

O Capítulo 4 aborda a análise do fenômeno de wave runup na coluna de plataforma semi-submersível, com uma breve revisão de literatura do fenômeno, validação, comparação do impacto de onda em coluna de diferentes geometrias e comparação entre o impacto em estrutura fixa e estrutura flutuante.

O Capítulo 5 é focado na análise do fenômeno de sloshing, com revisão de literatura, validação de caso bidimensional e tridimensional, análise de supressão de sloshing com o emprego de anteparas fixas e com antepara flutuante. 


\section{REVISÃO BIBLIOGRÁFICA}

\subsection{Métodos numéricos para dinâmica dos fluídos}

Nesta seção é elaborada uma breve evolução histórica dos métodos numéricos para Dinâmica dos Fluídos Computacional (CFD); concluída, nesta retrospectiva, no desenvolvimento dos métodos de partículas totalmente lagrangeanos, ferramentas empregadas no presente estudo. Vale lembrar que diferentes métodos numéricos coexistem atualmente, cada um deles apresentando melhores resultados para determinados tipos de aplicações.

Os trabalhos considerados como precursores do CFD foram Richardson (1910), que propôs uma solução numérica por método iterativo para a Equação de Laplace, e Liebmann (1918) que resolveu a equação de Laplace pelo método de Gauss-Siedel. O primeiro a resolver o escoamento viscoso foi Thom (1933), através de diferenças finitas e um método iterativo. Todos estes métodos anteriores ao desenvolvimento dos computadores digitais.

Apenas ao final da década de 40 surgiram os primeiros métodos numéricos que descreviam o estado do fluído ao longo do tempo, com os métodos de Crank \& Nicholson (1947) e o Alternate Direction Iterative Method (ADI) de Peaceman \& Rachford (1955), um método de diferenças finitas. Posteriormente foi desenvolvido o método Marker and Cell (MAC) de Harlow \& Welch (1965), que utilizava partículas marcadoras para determinar a superfície livre.

Uma série de métodos baseados no MAC foram posteriormente propostos, como o SMAC (simplified MAC) de Amsden \& Harlow (1968), o método SOLA de Hirt \& Cook (1972) e o SOLA-SURF, uma versão do método SOLA que trabalha com superfície livre, apresentado por Nichols \& Hirt (1973). Patankar (1980) propôs o método Semi-Implicit Pressure-Linked Equations (SIMPLE), um método semiimplícito para o cálculo da pressão utilizado em um grande número de métodos atuais.

Todos os métodos aqui apresentados são baseados em uma descrição euleriana do domínio computacional e um dos grandes problemas desses métodos é relativa à difusão numérica do termo convectivo. Harlow et al. (1964) propôs o 
método Particle in Cell (PIC), que calcula o escoamento por diferenças finitas em uma malha e utiliza partículas para calcular o termo convectivo. Derivado do PIC, foi proposto por Blackbill et al. (1988) o método Fluid Impact Particle (FLIP), para a resolução de escoamentos incompressíveis, mas com grandes instabilidades no cálculo.

Um método totalmente lagrangeano para a simulação de dinâmica dos fluídos é o Smooth Particle Hydrodynamics (SPH), inicialmente desenvolvido por Gingold \& Monaghan (1977) para a modelagem de problemas astrofísicos. A modelagem para o escoamento compressível foi apresentada por Monaghan \& Gingold (1983). Outro método de totalmente lagrangeano é o método Moving Particles Semi-Implicit (MPS), apresentado por Koshizuka et al. (1995) e Koshizuka \& Oka (1996), para a modelagem do escoamento incompressível. Atualmente, na simulação de CFD envolvendo métodos de partículas, o SPH e o MPS são os métodos mais empregados.

$\mathrm{O}$ SPH e MPS apresentam algumas diferenças. O SPH originalmente foi desenvolvido para a modelagem de escoamentos compressíveis, enquanto o MPS para escoamentos incompressíveis. A versão original do SPH utiliza um método inteiramente explícito, no qual a pressão é calculada por meio de uma equação de estado. No MPS a pressão é calculada implicitamente por meio de um sistema linear da Equação de Poisson.

É possível observar na formulação do método MPS a influência de diversos dos trabalhos anteriormente citados. O método do passo fracionado para 0 acoplamento pressão-velocidade na equação de Navier-Stokes foi proposto por Chorin (1968) e também utilizados por Patankar (1980) no método SIMPLE. A condição de contorno de superfície livre aplicada no MPS de Koshizuka et al. (1995) é baseada no trabalho de Harlow \& Welch (1965) com o PIC.

Desenvolveu-se também uma versão do SPH para escoamentos incompressíveis (Cummins \& Rudman, 1999), baseada no algoritmo de passo fracionado do próprio MPS. Neste caso, outra diferença notável entre os métodos está na modelagem dos operadores diferenciais; enquanto no SPH ela se dá pela derivação exata de uma função aproximada, a função núcleo (kernel function); no MPS os próprios operadores diferenciais são discretizados e as contribuições das 
partículas dentro da vizinhança são ponderadas por uma função peso (weight function). Este último ponto resulta em uma preocupação maior dos usuários do SPH em relação à função núcleo do que dos usuários do MPS em relação á função peso. As diferenças e relações entre a função peso do MPS e a função núcleo do $\mathrm{SPH}$ e a consistência dos métodos é analisada em profundidade por Souto-Iglesias et al. (2013).

Neste trabalho optou-se pela utilização do método MPS por haver sido desenvolvido especialmente para o escoamento incompressível e possuir um longo histórico de aplicação em problemas de engenharia naval, como em Shibata et al. (2007), Shibata \& Koshizuka (2007), Shibata et al. (2009), e Shibata et al. (2012). No entanto, o SPH também foi aplicado com sucesso em diversas aplicações de engenharia naval, como em Colicchio et al. (2002), Calagrossi \& Landrini (2003) e Rudman et al. (2008).

\subsection{Método de partículas MPS}

O método MPS apresentou um desenvolvimento gradual. Em Koshizuka \& Oka (1996) o método passa a ser chamado de MPS e é melhorada a estabilidade do método através da alteração da função peso (weight function) e do modelo de incompressibilidade. Em Koshizuka \& Oka (1997) são propostos modelos de interação fluído-gás e fluído-sólido. O estudo de Koshizuka et al. (1998a) apresenta melhoras no cálculo de vizinhança e reduzindo o tempo de cálculo da ordem de $n^{2}$ para $n^{1,5}$, onde $n$ é o número de partículas do modelo. Em Koshizuka et al. (1998b) são apresentados os primeiros casos tridimensionais empregando o método MPS. Sueyoshi \& Naito (2002a) e Sueyoshi \& Naito (2002b) aplicam o método MPS em casos de interesse naval e obtêm resultados realistas para a análise bidimensional.

O método MPS apresenta vantagens em relação aos métodos eulerianos na simulação de fenômenos envolvendo superfície livre e violentos fenômenos de impacto hidrodinâmico. O MPS tem facilidade para modelar a interação fluídoestrutura, além de fenômenos envolvendo violentas deformações fragmentação e junção de superfície livre. As desvantagens são as oscilações de pressão próprias do método e o alto custo computacional. 
O cálculo implícito da Equação de Poisson da pressão no método MPS apresenta violentas oscilações que podem afetar a estabilidade numérica. Diversos trabalhos propõem técnicas para a mitigação da oscilação numérica de pressão. Hibi \& Yabushita (2004), Sueyoshi (2006) e Kondo \& Koshizuka (2010) propuseram a resolução de uma equação de Poisson adicional, o que aumenta de forma considerável o custo computacional e não apresenta resultados suficientemente estáveis. Khayyer \& Gotoh (2008) e Khayyer \& Gotoh (2009) propuseram melhoras no método para garantir a conservação do momento. Khayyer \& Gotoh (2012) propõe o emprego de um Laplaciano de alta ordem derivado do divergente do gradiente do modelo de interação entre partículas para a redução da oscilação de pressão. Tanaka \& Matsunaga(2010) propõem uma nova condição de incompressibilidade dividida em duas partes: um termo baseado na condição de densidade do número de partículas e outro termo irrotacional (divergente nulo). Bellezi et al. (2009) elabora um estudo em série que relaciona os parâmetros numéricos de simulação à oscilação numérica do cálculo da pressão e propõe uma relação entre os mesmos obtidos por regressão que minimize a oscilação numérica para casos bidimensionais.

O desenvolvimento mais recente do método é apresentado por Tamai et al. (2013), por meio do Least Squares Moving Particle Semi-Implicit (LSMPS), no qual é empregado um novo esquema de discretização espacial dos operadores diferenciais em um técnica alta ordem de mínimos quadrados. Koh et al. (2012) utiliza técnica similar na proposta de um novo método de partículas de alta ordem, o Consistent Particle Method (CPM), no qual os operadores diferenciais são modelados por meio de expansão de Taylor de alta ordem.

\subsection{Paralelização no método MPS}

Em Premoze et al. (2003) conclui-se que o gargalo do processamento do método MPS é a solução da equação de Poisson da pressão e sugere a paralelização deste trecho do código.

Em Tsukamoto (2006) é empregado um simulador MPS com memória compartilhada que apresenta ganhos significativos no processamento em relação a versão serial. A simulação de um modelo tridimensional do impacto de onda em um 
casco de embarcação com o método MPS é apresentada em Shibata \& Koshizuka (2007), que aplica a divisão do domínio em subdomínio para acelerar o cálculo de um modelo cerca de 350 mil partículas.

Em Ikari \& Gotoh (2008) mostra-se que a decomposição por domínio é mais eficiente do ponto de vista computacional do que a decomposição por partículas, este estudo também propõe uma divisão e domínio baseada no centro de massa de cada subdomínio.

Gotoh (2009) utilizou a decomposição de domínio com fronteiras dinâmicas, que mantêm os domínios com quantidades de partículas similares, com resultados bastante satisfatórios, mas também levanta bastante pontos a serem desenvolvidos.

Por fim, em Iribe et al. (2010) é implementado em um cluster um MPS com memória distribuída e determina-se que o gargalo da simulação está na comunicação entre os diferentes subdomínios, sugerindo um novo processo de rotulagem das partículas nos subdomínios.

Com base em todos estes estudos precedentes, Fernandes (2013) implementou um framework computacional e desenvolveu o simulador baseado no método MPS com memória híbrida, baseado no simulador de memória compartilhada desenvolvido por Tsukamoto (2006) e implementando a memória distribuída por meio de uma técnica de paralelização por partíção dinâmica do domínio computacional.

\subsection{Formulação matemática do método MPS}

\subsubsection{Equações governantes}

As equações governantes do escoamento incompressível são as equações de conservação de massa e conservação de quantidade de movimento, respectivamente, a equação de continuidade (Eq. (1)) e a equação de Navier-Stokes (Eq. (2)).

$$
\begin{gathered}
\frac{D \rho}{D t}=-\rho(\nabla \cdot \vec{u})=0 \\
\frac{D \vec{u}}{D t}=\frac{1}{\rho} \nabla \mathrm{P}+\vartheta \nabla^{2} \vec{u}+\frac{\vec{f}}{\rho}+\vec{g}
\end{gathered}
$$


onde $\rho$ é a densidade do fluído, $\vec{u}$ é o vetor velocidade, $P$ a pressão, $\vec{g}$ a aceleração gravitacional, $\vec{f}$ as forças atuantes, $\vartheta$ a viscosidade cinemática e to tempo.

\subsubsection{Modelo de interação entre partículas}

No método MPS, os operadores diferenciais são substituídos por operadores algébricos baseados em um modelo de interação entre partículas. O modelo de interação entre partículas é fundamentado na ponderação das contribuições pela função peso apresentada na Eq. (3).

$$
\omega(r)=\left\{\begin{array}{c}
\frac{r_{e}}{r}-1 \text { para }\left(0 \leq r<r_{e}\right) \\
0 \text { para }\left(r_{e} \leq r\right)
\end{array}\right.
$$

na qual $r=\left|\vec{r}_{j}-\vec{r}_{i}\right|$ é a distância entre duas partículas $i$ e $j$, e $r_{e}$ é um raio de vizinhança pré-estabelecido.

A densidade do número de partículas (pnd), é apresentada na Eq. (4). O pnd é proporcional à densidade do fluído e a incompressibilidade do sistema é satisfeita mantendo-se constante seu valor.

$$
[p n d]_{i}=\sum_{j \neq i} \omega\left(\left|\vec{r}_{j}-\vec{r}_{l}\right|\right)
$$

O operador gradiente (Eq. (5)) e o operador laplaciano (Eq. (6)) de uma função escalar $\Phi$ são dados por:

$$
\begin{gathered}
{[\nabla \Phi]_{i}=\frac{d}{p n d^{0}} \sum_{j \neq i}\left[\frac{\left(\Phi_{j}-\Phi_{i}^{\prime}\right)}{\left|\vec{r}_{j}-\vec{r}_{l}\right|^{2}}\left(\vec{r}_{j}-\vec{r}_{l}\right) \omega\left(\left|\vec{r}_{j}-\vec{r}_{l}\right|\right)\right]} \\
{\left[\nabla^{2} \Phi\right]_{i}=\frac{2 d}{p n d^{0} \delta} \sum_{j \neq i}\left[\left(\Phi_{j}-\Phi_{i}\right) \omega\left(\left|\vec{r}_{j}-\vec{r}_{l}\right|\right)\right]}
\end{gathered}
$$

onde a constante $\delta$ é dada por:

$$
\delta=\frac{\int_{V} \omega(r) r^{2} d v}{\int_{V} \omega(r) d v}
$$

onde $d$ é o número de dimensões e $p n d^{0}$ o valor inicial da densidade do número de partículas. 


\subsubsection{Algoritmo do escoamento incompressível}

O método MPS adota um algoritmo semi-implícito, no qual o acoplamento entre pressão e velocidade na equação de conservação do momento é feito a partir de um método de passo fracionado, como em Chorin (1968). Nos métodos de passos fracionados, ou projeção, o passo de cálculo é dividido em duas etapas: uma primeira na qual se calcula uma velocidade intermediária levando-se em conta os termos da equação de Navier-Stokes que envolvem apenas a velocidade; e uma segunda etapa na qual se calcula a pressão. Ao final do passo de cálculo a velocidade intermediária é corrigida adicionando-se a contribuição do gradiente de pressão.

No método MPS a primeira etapa é calculada explicitamente, enquanto a segunda etapa é composta pelo cálculo implícito da pressão. O cálculo implícito da pressão é feito por meio da solução de um sistema linear da equação de Poisson, derivado da conservação de massa e mostrado na Eq. (8).

$$
\left[\nabla^{2} P^{n+1}\right]_{i}=\frac{\rho}{\Delta t^{2}} \frac{\left[p n d^{*}\right]_{i}-p n d^{0}}{p n d^{0}}
$$

onde $p n d^{*}$ é o valor do pnd estimado na parte explícita do cálculo. Com o valor das pressões é calculado o gradiente da pressão e a velocidade estimada na etapa explícita de cálculo é corrigida.

O algoritmo do método MPS é apresentado no fluxograma da Figura 1. 


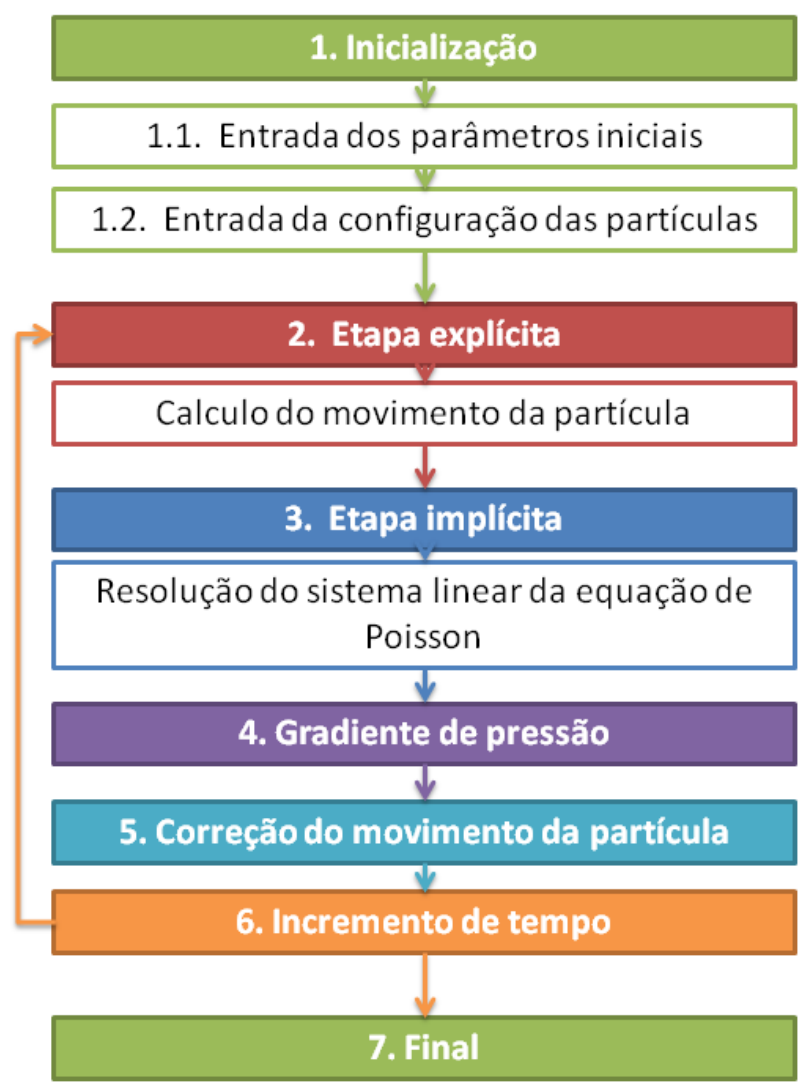

Figura 1 Algoritmo do método MPS

\subsubsection{Condição de contorno de superfície livre}

A condição de contorno de superfície livre empregada neste trabalho é baseada em Lee et al. (2010). Esta formulação difere daquela inicialmente proposta em Koshizuka et al. (1995) e Koshizuka \& Oka (1996) por introduzir o número de partículas dentro do raio de vizinhança como parâmetro adicional para identificação das partículas de superfície livre. Uma partícula é identificada como de superfície livre quando o seu pnd é inferior a $\beta_{1 . p n d}$ e quando o número de partículas vizinhas é inferior a $\beta_{2} . N^{0}$. O parâmetro $p n d^{0}$ é o pnd de uma partícula completamente submersa na distribuição inicial e $N^{0}$ é o número de partículas dentro do raio de vizinhança para esta mesma condição. Neste trabalho é adotado $\beta_{1}=0,97$ e $\beta_{2}=0,85$, de acordo com Lee et al. (2010).

\subsubsection{Sólido fixo}

As paredes do sólido fixo são modeladas de acordo com Koshizuka et al. (1995), por meio de três camadas de partículas. O esquema das camadas de 
partículas do sólido fixo é apresentado na Figura 2 A primeira camada é composta pelas partículas que entram em contato com as partículas do fluído; estas partículas são consideradas durante o cálculo de pressão. As duas outras camadas adjacentes não entram em contato com o fluído e não participam do cálculo de pressão; são empregadas apenas para o correto cálculo da pnd da primeira camada de partículas de sólido.

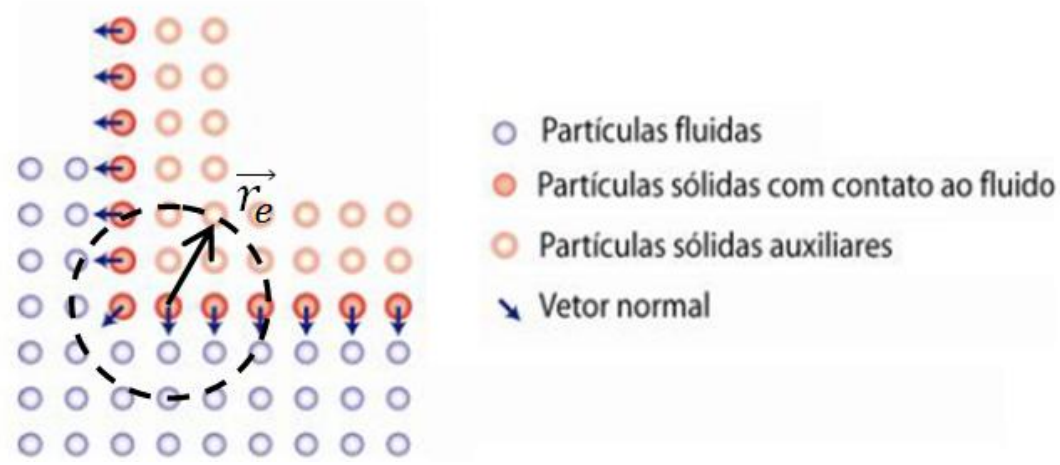

Figura 2 Modelagem do sólido no MPS

\subsubsection{Sólido livre}

A implementação do sólido livre, também chamado neste trabalho de sólido flutuante, é baseada naquela apresentada em Sueyoshi \& Naito (2002b) e empregada em Lee et al. (2010) para a simulação do comportamento de corpos flutuantes em análise de problemas de engenharia naval.

A modelagem das paredes do sólido livre é similar à do sólido fixo, com uma camada em contato com o fluído na qual a pressão é calculada e duas camadas adjacentes de partículas auxiliares (dummy particles) que não entram no cálculo da pressão, porém possuem papel fundamental no cálculo do pnd da primeira camada. O cálculo da normal das partículas de parede do sólido flutuante é feito por meio do somatório dos vetores posição das partículas de sólido e sólido auxiliar dentro do raio de vizinhança. As componentes da velocidade das partículas do sólido livre são calculadas na etapa explícita do método. As velocidades são calculadas pela equação do movimento, na qual as forças e momentos resultantes no corpo são obtidas a partir da integração da pressão nas partículas sólidas em contato com o fluído. Neste acoplamento a massa e os momentos de inércia do corpo flutuante são dados de entrada do programa. 


\section{GREEN WATER}

\subsection{Introdução e Revisão Bibliográfica}

A exploração de petróleo em águas profundas e ultra profundas nas bacias do Pré-Sal pode ser realizada apenas por meio de estruturas flutuantes, tais como as plataformas do tipo FPSO e semi-submersíveis. As plataformas do tipo FPSO consistem em estruturas oceânicas de forma similar ao casco de embarcações, nas quais a planta de produção de petróleo e gás é posicionada sobre o convés.

No caso das plataformas do tipo FPSO, a borda livre, que consiste na distância entre a linha d'água e o convés, é limitada de acordo com restrições estruturais e de estabilidade. Em condições de mar severas, quando a amplitude da onda supera a borda livre da embarcação, pode ocorrer o embarque de água no convés. Este fenômeno é conheicdo como green water e pode causar danos aos equipamentos da planta de exploração.

O fenômeno de green water é um fenômeno de impacto hidrodinâmico de natureza complexa e altamente não linear. $\mathrm{Ni}$ et al. (2011) realizou uma revisão sobre o estado da arte na análise de green water, contemplando estudos analíticos, experimentais e numéricos. Os estudos analíticos levam em conta essencialmente os efeitos lineares e apresentam limitações para determinar o comportamento tridimensional do fluído. A abordagem analítica predominante consiste na analogia entre a coluna de água que embarca no convés a coluna d'água de um fenômeno de dam-break, abordagem aplicada po Greco(2001).

Devido às limitações da abordagem analítica, o fenômeno passa a ser estudado majoritariamente por meio de experimentos. No entanto, com o desenvolvimento das ferramentas numéricas computacionais ao longo das últimas décadas, a abordagem numérico-computacional passa a ser o mecanismo preponderante para a análise do fenômeno de green water e desloca os estudos experimentais para o importante papel de validação e calibração dos modelos numéricos. Dentre importantes estudos experimentais sobre green water destacam-se Greco (2001), Buchner (2002), Ryu et al. (2007), Lee et al. (2012) e Xiao et al. (2014). Apesar de os métodos experimentais serem um meio mais preciso para investigar o complexo fenômeno de 
impacto hidrodinâmico, é uma alternativa cara e com pouca flexibilidade para a avaliação de diferentes parâmetros. Outras desvantagens são os efeitos de escala da simulação em modelos de escala reduzida e a limitação dos pontos de medição pelo número e posicionamento dos sensores.

Diversos métodos numéricos podem ser aplicados em diversas abordagens para o estudo de green water. Algumas ferramentas simplificadas são ideais para os estágios preliminares de projeto de sistemas flutuantes e são focadas na determinação da ocorrência de green water e nos principais carregamentos de natureza linear do problema. Schiller et al. (2014a) e Schiller et al. (2014b) utilizam um método potencial para estimar o movimento relativo entre o convés da embarcação e as ondas, a partir da coluna d'água detectada é aplicada uma abordagem analítica da teoria de dam-break com componentes não lineares para estimar o carregamento nas estruturas sobre o convés. Outras abordagens combinando métodos potenciais e técnicas analíticas e empíricas são utilizados para este escopo.

No entanto, para uma modelagem do comportamento tridimensional do escoamento sobre o convés é necessária a utilização de métodos de CFD, que constituem uma alternativa para evitar a simplificação dos métodos analíticos e superar as limitações da abordagem experimental. A modelagem por métodos de CFD do fenômeno de green water se dá de duas formas: a primeira apenas o fenômeno local do escoamento sobre o convés e a segunda pela modelagem completa da interação entre embarcação e ondas (Silva \& Rossi, 2014). Neste trabalho é adotada a segunda abordagem, por meio da modelagem do fenômeno em um tanque de provas numérico, que fornece uma modelagem mais completa, no entanto tem como desvantagem a necessidade de um domínio computacional mais extenso e, consequentemente, um maior custo computacional. Outro trabalhos com abordagem similar são Shibata et al. (2012), empregando o método MPS, e Lu et al. (2010), empregando um método VOF.

Dentre os diversos métodos numéricos para simulação de dinâmica dos fluídos, optou-se por utilizar neste estudo o método numérico baseado em partículas Moving Particles Semi-Implicit (MPS). Shibata e Koshizuka (2007) e Shibata et al. (2009) 
obtiveram resultados numéricos em concordância com os resultados experimentais para a simulação de casos de green water empregando o método MPS.

Visando combinar o baixo custo de processamento dos métodos de painéis das ferramentas numéricas mais simples e os resultados do comportamento tridimensional obtidos pelos métodos de CFD, diversos métodos acoplados estão em desenvolvimento para a análise do fenômeno de green water. Kleefsman et al. (2005b) acopla um método potencial a uma ferramenta VOF (Comflow@). Pakozdi et al. (2014) utiliza uma ferramente baseada em teoria potencial e teoria de dam-break (Kinema3C) acoplada a uma técnica VOF (Star-ccm+C). Nestes dois trabalhos a interação entre embarcação e onda e a altura relativa entre superfície livre e convés são calculadas pelo método potencial, enquanto a ferramenta de CFD se ocupa apenas do escoamento sobre o convés. Le Touzé et al. (2010) utiliza uma abordagem diferente, na qual o campo próximo, incluindo a interação entre embarcação e onda, os fenômenos de impacto hidrodinâmico no casco e o embarque de água no convés, é modelado pelo método SPH. Apenas o campo distante é modelado com uma teoria potencial.

No presente estudo, o método MPS foi empregado na simulação do fenômeno de green water em modelos de plataforma FPSO por meio da modelagem de tanques de prova numéricos. O estudo sobre o fenômeno de green water é dividido em três partes.

A primeira etapa consiste na validação para o fenômeno de impacto hidroedinâmico por meio da simulação de um caso de benchmark de dam-break (Kleefsman, et al., 2005a) e a validação para o fenômeno de Green water baseado nos resultados experimentais de Lee et al. (2012) para modelos em escala reduzida. A validação se dá pela comparação entre os resultados numéricos e experimentais do comportamento tridimensional do fluído sobre o convés e da série temporal de pressão em pontos sobre o convés.

A segunda parte é composta por um caso de aplicação do simulador a um problema de engenharia relacionado ao fenômeno de green water. O caso de aplicação contemplará a análise do fenômeno para diferentes formatos de proa. Todos os casos simulados em tanques de prova numéricos e em modelos fixos em escala reduzida. São analisadas proas com o tradicional formato em "caixote", um 
modelo com um chanfro na proa, modelos prismáticos hidrodinâmicos em forma de cunha, circular e parabólico. A proposta de proas parabólicas é baseada em Cheng (1995) que, na análise do fenômeno de slamming, propõe o emprego de perfil parabólico para que ocorra uma distribuição mais uniforme do esforço impulsivo em comparação ao perfil circular. Os resultados são avaliados por meio da comparação do esforço impulsivo em uma antepara localizada sobre o convés; e dos valores de pressão, altura da coluna d'água e velocidade média da água em pontos distribuídos ao longo do convés.

Em todas as etapas anteriores foi considerada condição de mar de proa. No quinto e último tópico do estudo de green water é analisado o fenômeno de green water em diferentes condições de aproamento. As condições particulares de certas fronteiras de exploração de petróleo e o modo de aproamento das embarcações leva a operação das plataformas em condição de ondas oblíquas. Para tais situações a análise apenas do mar de proa é insuficiente; é necessária a simulação de green water para mar de bochecha e mar de través. A terceira etapa compreende a simulação do fenômeno de green water para diferentes ângulos de aproamento em modelo flutuante. 


\subsection{Validação - Caso de dam-break}

O primeiro caso de validação consiste em um caso de benchmark de dam-break (quebra de barragem) baseado nos resultados apresentados em Kleefsman et al. (2005a). O caso do dam-break apresenta semelhanças significativas com o fenômeno de green water, principalmente com a etapa de invasão de água no convés, conforme observado por Greco et el. (2005) e Buchner (2002). Além disso, a modelagem analítica predominante para o fenômeno de embarque de água no convés modela a coluna de água embarcada como o fenômeno de dam-break (Greco, 2001). Silva e Rossi (2014) simulam o embarque de água no convés pelo software comercial $\mathrm{CFX} \odot$ e a validação também é realizada por este mesmo caso de dam-break. A configuração e dimensões principais do modelo de validação são apresentadas na Figura 3.
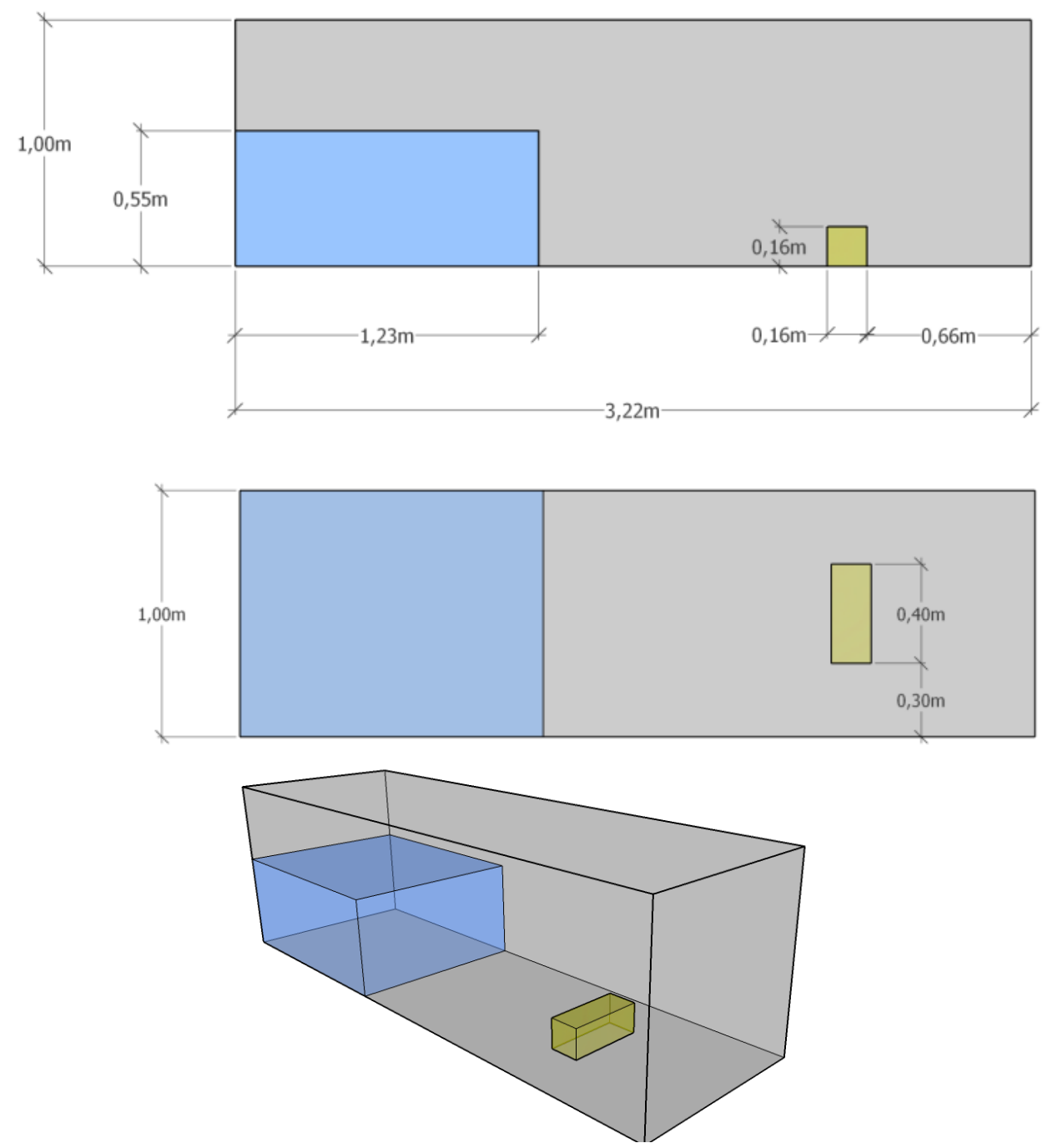

Figura 3 Dimensões e configuração do caso de Dam Break 
Neste estudo de validação duas diferentes resoluções são avaliadas. A primeira delas emprega uma distância entre partículas de 18,3 milímetros e é baseada no espaçamento da malha empregada na simulação numérica de Kleefsman et al. (2005a), o qual emprega um método de volumes finitos. A segunda resolução apresenta um modelo de maior resolução, com distância entre partículas de 10 milímetros. Os parâmetros numéricos de simulação são apresentados na Tabela 1.

Tabela 1 Parâmetros numéricos de simulação

\begin{tabular}{cccc}
\hline $\begin{array}{c}\text { Distância entre } \\
\text { partículas }\end{array}$ & $\begin{array}{c}\text { Número de } \\
\text { partículas }\end{array}$ & $\begin{array}{c}\text { Incremento } \\
\text { de tempo }\end{array}$ & $\begin{array}{c}\text { Constante suavizadora } \\
\text { de pressão }\end{array}$ \\
\hline $18,3 \mathrm{~mm}$ & 250.000 & $0,001 \mathrm{~s}$ & 0,075 \\
$10 \mathrm{~mm}$ & 1.135 .000 & $0,0005 \mathrm{~s}$ & 0,05 \\
\hline
\end{tabular}

A constante suavizadora de pressão consiste em um parâmetro numérico de simulação empregado por Bellezi et al. (2009) para a mitigação da oscilação numérica de pressão. É um constante que multiplica o termo do lado direito da Eq. (8) para o cálculo da pressão por meio do sistema linear da equação de Poisson.

A comparação entre os resultados numéricos e os resultados experimentais são realizadas em termos da série temporal da pressão em sensores localizados no bloco amarelo ao centro do tanque e pela série temporal de elevação da superfície livre em determinados pontos ao longo do tanque. A posição do sensores de superfície livre é apresentada na Figura 4 e o posicionamento dos sensores de pressão no bloco é apresentado na Figura 5.

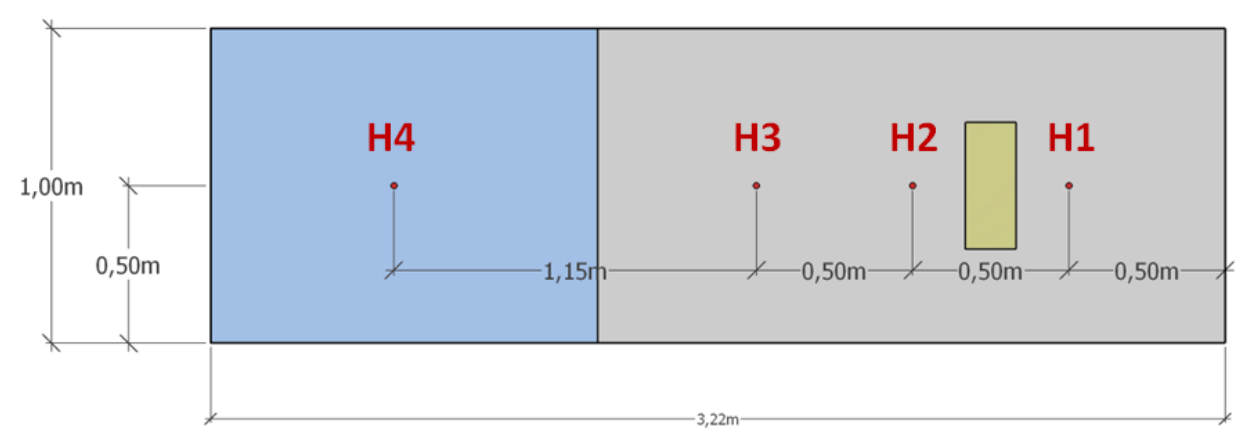

Figura 4 Posicionamento dos sensores de superfície livre 


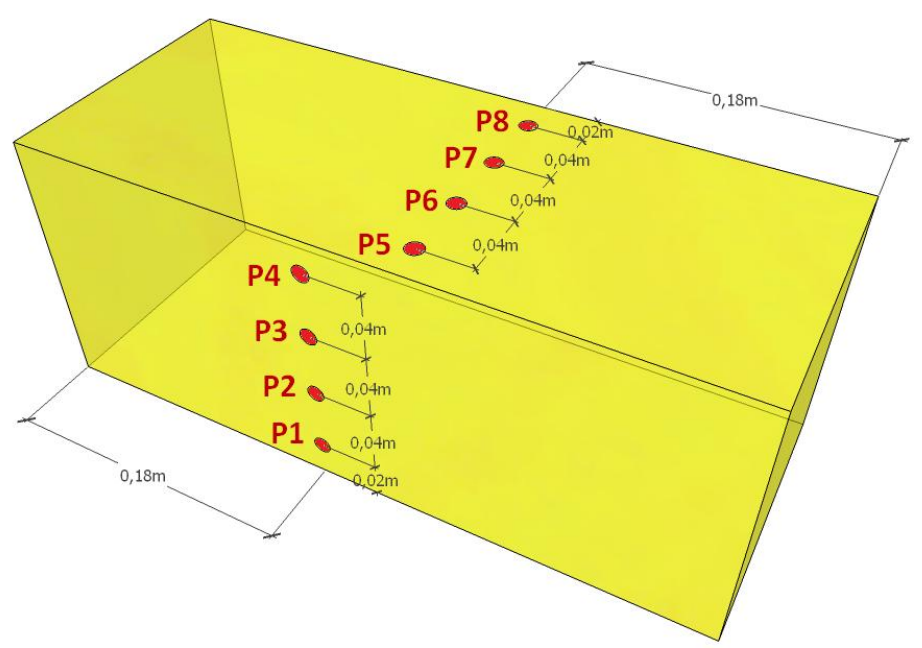

Figura 5 Posicionamento dos sensores de pressão no bloco

Da Figura 6 a Figura 8 são mostradas as séries temporais da pressão nos sensores P1, P2 e P3. Em preto está o resultados experimental, em azul o resultado numérico empregando-se a resolução mais grosseira, com cerca de 250.000 partículas, e em vermelho o resultado para o modelo de alta resolução, com cerca de 1,150,000 partículas.

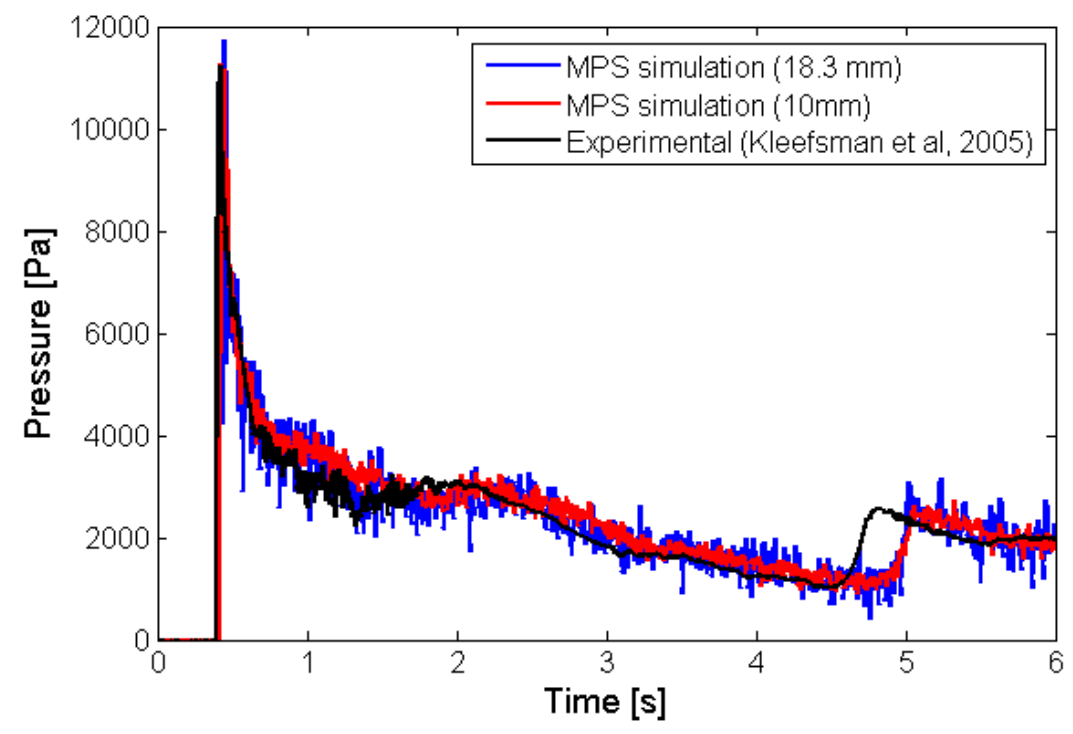

Figura 6 Série temporal de pressão no sensor P1 


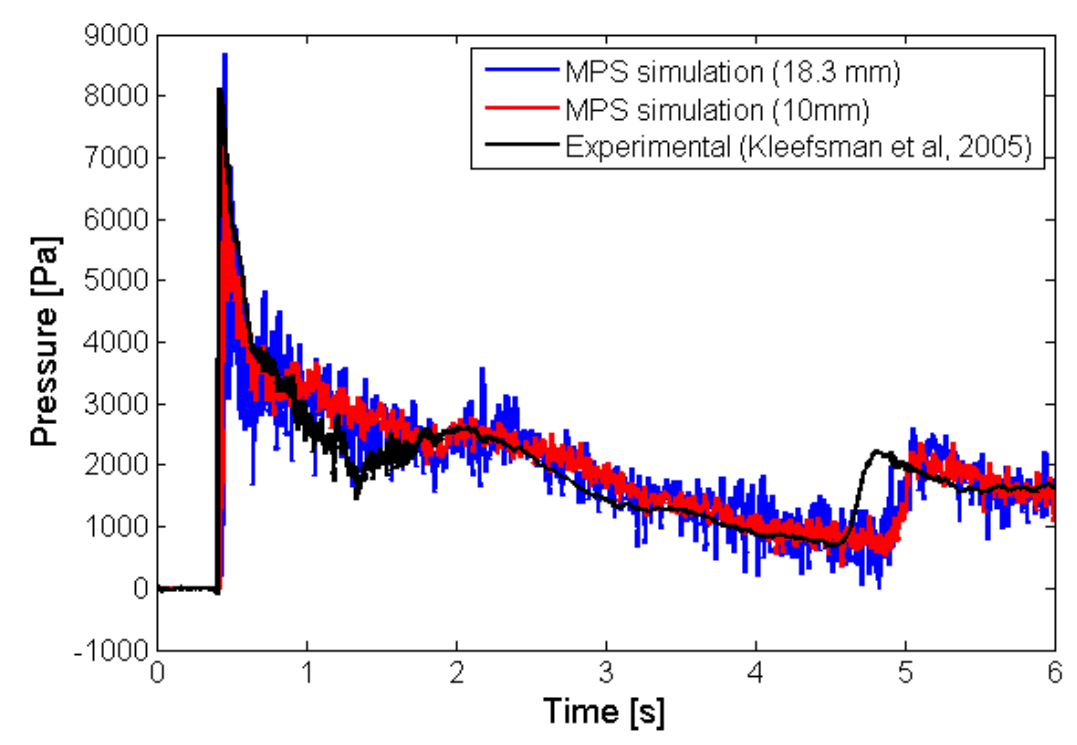

Figura 7 Série temporal de pressão no sensor P2

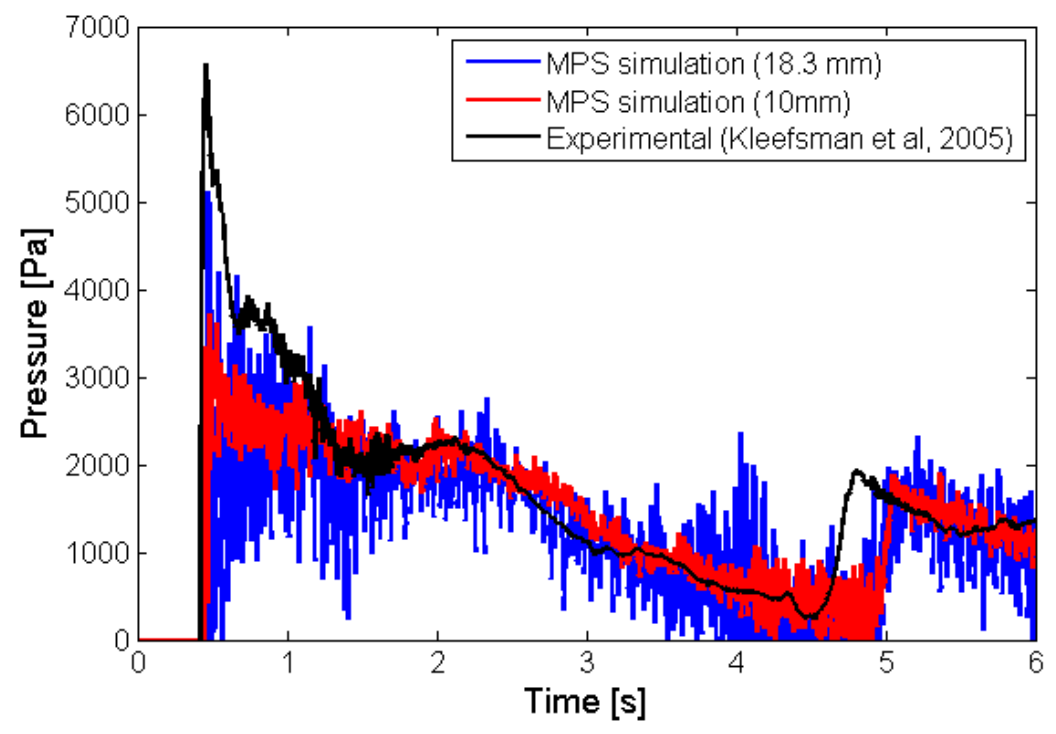

Figura 8 Série temporal de pressão no sensor P3

Para os sensores de pressão P1, P2 e P3 os resultados obtidos numericamente apresentam boa aderência aos resultados experimentais (Kleefsman, et al., 2005a). Os resultados numéricos apresentam uma oscilação de pressão, característica do próprio método de partículas. No entanto, a amplitude da oscilação numérica de pressão não é significativo em relação à magnitude dos valores de pressão registrados e o comportamento médio da curva é muito próximo à curva experimental, mesmo para o modelo com a resolução mais grosseira.

A principal diferença observada nos resultados obtidos por meio das duas diferentes resoluções está no fato do modelo de maior resolução apresentar uma 
curva mais suave, com uma amplitude da oscilação numérica menor. É importante salientar que, no método MPS, a magnitude das oscilações numéricas de pressão não são relacionadas apenas à resolução empregada, mas a uma combinação entre ela e os demais parâmetros numéricos de pressão: o incremento de tempo e uma constante suavizadora de pressão (Bellezi, et al., 2009). O pico de pressão registrado no sensor $\mathrm{P} 1$ é próximo ao valor experimental enquanto o pico de pressão para o sensor P3 é subestimado pelo método numérico.

A Figura 9 e a Figura 10 mostram os resultados para os sensores de superfície livre $\mathrm{H} 4$ e $\mathrm{H} 2$, respectivamente. Novamente, os resultados numéricos apresentam boa aderência aos resultados experimentais. No entanto, diferentemente do registro de pressão, não aparece diferença significativa entre os resultados obtidos com as duas resoluções.

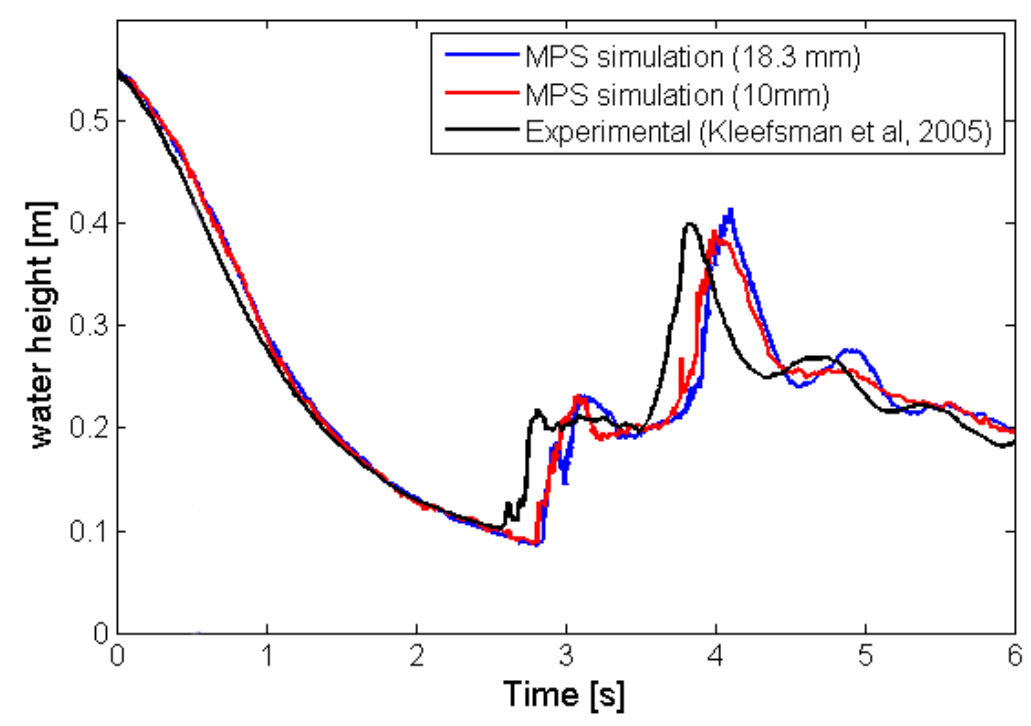

Figura 9 Série temporal da elevação de superfície livre no sensor H4 


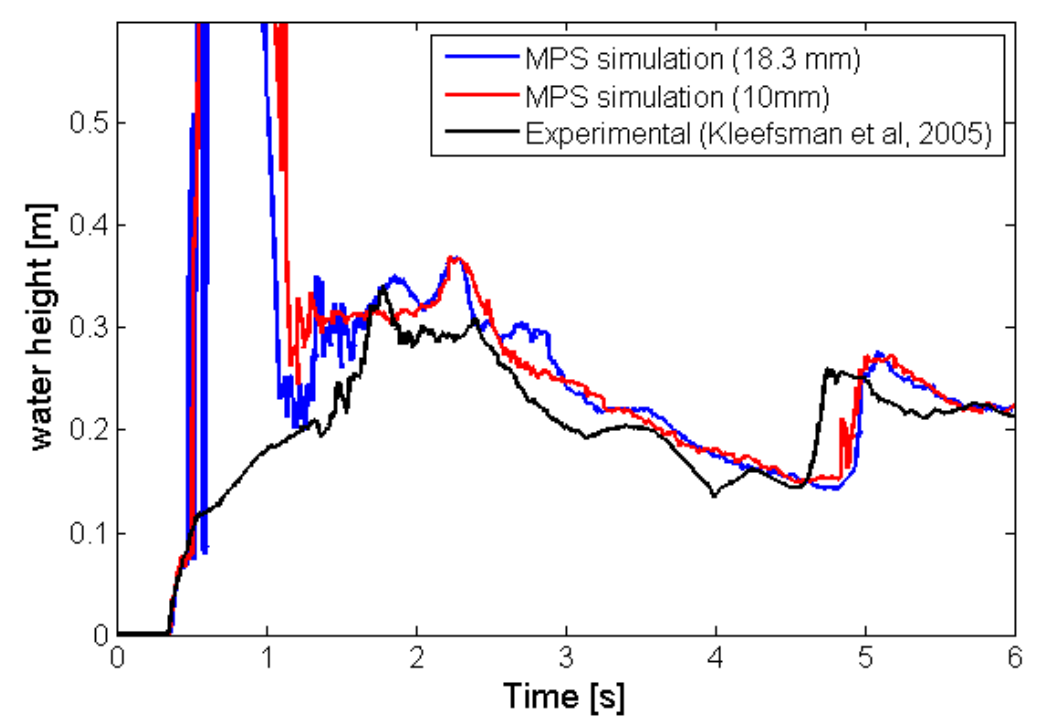

Figura 10 Série temporal da elevação de superfície livre no sensor H2

Os resultados apresentados na Figura 9 e na Figura 10 mostram que 0 comportamento do fluído obtido numericamente se aproxima daquele obtido experimentalmente, para ambas as resoluções avaliadas. Em ambos os resultados ocorre um atraso na curva numérica em relação a curva experimental, esta possivelmente devio a um amortecimento de origem numérica próprio do método de partículas.

$\mathrm{Na}$ Figura 10, a diferença entre o resultado numérico e experimental no trecho entre 0,5 e 1,5 segundos se dá devido ao sensor de detecção de superfície livre empregado. A ferramenta considera todas as partículas de superfície livre, incluindo aquelas resultantes da fragmentação de fluído após o choque com o bloco. Essa diferença se torna significativa no sensor de superfíci livre $\mathrm{H} 2$, aquele situado na região próxima ao bloco.

A Figura 11 mostra os snapshots da simulação por método de partículas e a comparação entre as duas resoluções simuladas. 


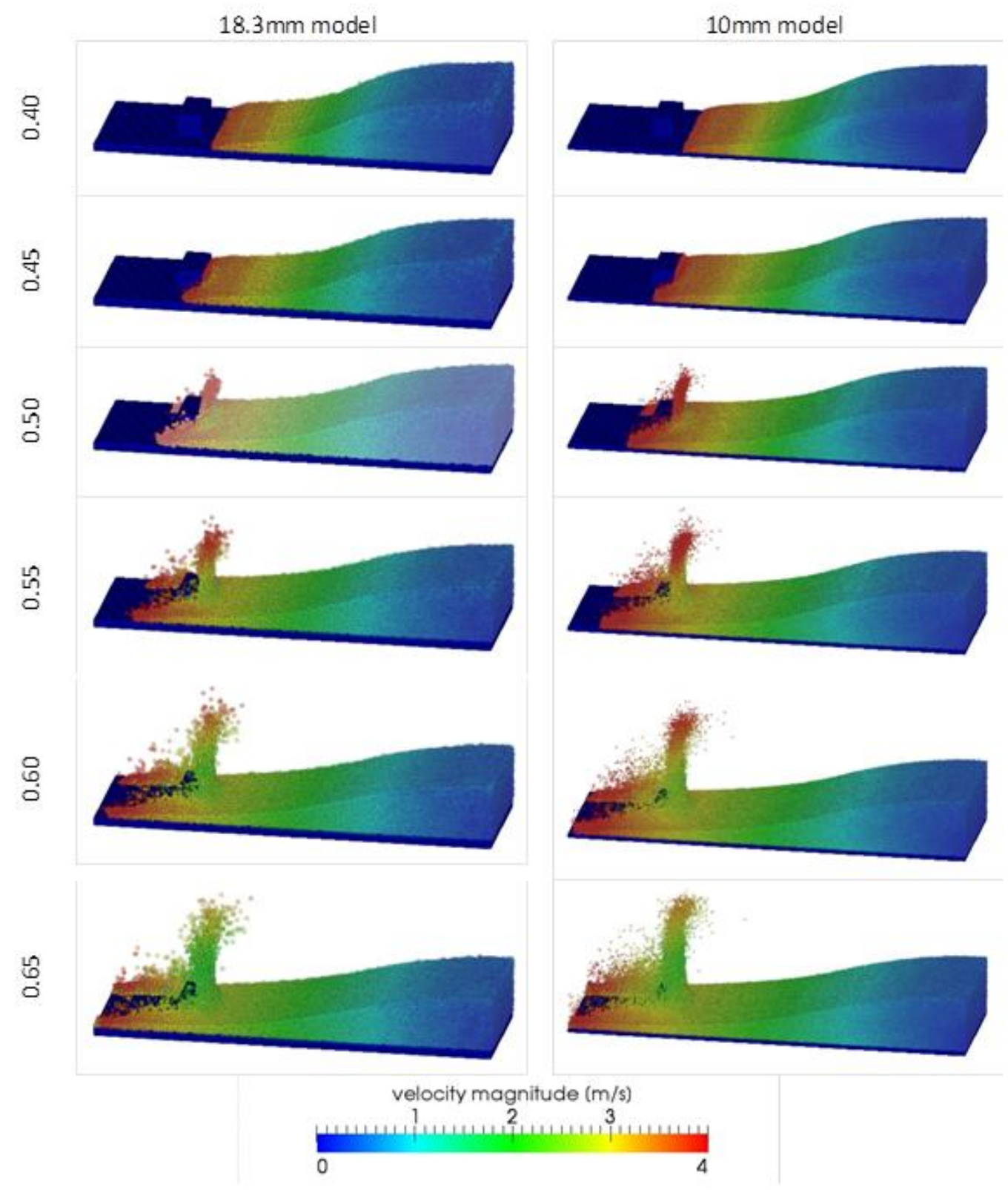

Figura 11 Snapshots da simulação com o método de partículas - Dam Break

A coluna da esquerda mostra os resultados do modelo de resolução mais grosseira enquanto a coluna da direita mostra os resultados para o modelo de maior resolução. A escala de cores representa o módulo da velocidade das partículas. O comportamento do escoamento tridimensional observado nos snapshots está de acordo com os experimentos.

Em ambas as simulações ocorre grande fragmentação de fluído após o impacto com o bloco e, excetuando-se que o splash após o impacto é maior para o modelo 
de maior resolução, nenhuma outra diferença significativa é observada entre os dois modelos.

A validação do método numérico para a simulação de fenômenos de impacto hidrodinâmico, por meio de uma caso de benchmark de dam-break tridimensional mostra que a modelagem por meio do método de partículas reproduz de maneira adequada um fenômeno de impacto hidrodinâmico envolvendo grande deformação de superfície livre, frangmentação e junção. 


\subsection{Validação - Caso de Green water}

\subsubsection{Calibração numérica da onda incidente}

A primeira etapa do estudo de impacto de ondas empregando-se a ferramenta numérica MPS consiste na calibração da onda incidente. Neste estudo são simuladas as 9 condições de onda presentes em Lee et al. (2012), obtidas a partir da combinação entre 3 valores de declividade de onda e 3 valores de comprimento de onda. Os comprimentos de onda são de $\lambda / L=0,75, \lambda / L=1,0$ e $\lambda / L=1,25$, onde $L=3,0$ m é o comprimento do modelo em escala reduzida. Os valores de declividade são de $H / \lambda=0,04, H / \lambda=0,05$ e $H / \lambda=0,06$, onde $H$ é a altura da onda. As condições de onda são apresentadas na Tabela 2:

Tabela 2 Parâmetros das ondas (Lee, et al., 2012)

\begin{tabular}{ccccc}
\hline $\begin{array}{c}\text { Condição de } \\
\text { onda }\end{array}$ & $\begin{array}{c}\text { Comprimento de } \\
\text { onda }\end{array}$ & $\begin{array}{c}\text { Período da } \\
\text { onda }\end{array}$ & Amplitude & Declividade \\
\hline 1 & $225 \mathrm{~cm}$ & $1,28 \mathrm{~s}$ & $4,500 \mathrm{~cm}$ & 0,04 \\
2 & $225 \mathrm{~cm}$ & $1,28 \mathrm{~s}$ & $5,625 \mathrm{~cm}$ & 0,05 \\
3 & $225 \mathrm{~cm}$ & $1,28 \mathrm{~s}$ & $6,750 \mathrm{~cm}$ & 0,06 \\
4 & $300 \mathrm{~cm}$ & $1,39 \mathrm{~s}$ & $6,000 \mathrm{~cm}$ & 0,04 \\
5 & $300 \mathrm{~cm}$ & $1,39 \mathrm{~s}$ & $7,500 \mathrm{~cm}$ & 0,05 \\
6 & $300 \mathrm{~cm}$ & $1,39 \mathrm{~s}$ & $9,000 \mathrm{~cm}$ & 0,06 \\
7 & $375 \mathrm{~cm}$ & $1,55 \mathrm{~s}$ & $7,500 \mathrm{~cm}$ & 0,04 \\
8 & $375 \mathrm{~cm}$ & $1,55 \mathrm{~s}$ & $9,375 \mathrm{~cm}$ & 0,05 \\
9 & $375 \mathrm{~cm}$ & $1,55 \mathrm{~s}$ & $11,250 \mathrm{~cm}$ & 0,06 \\
\hline
\end{tabular}

A configuração e as dimensões do tanque de provas numérico utilizado na calibração de onda são apresentadas na Figura 12. 


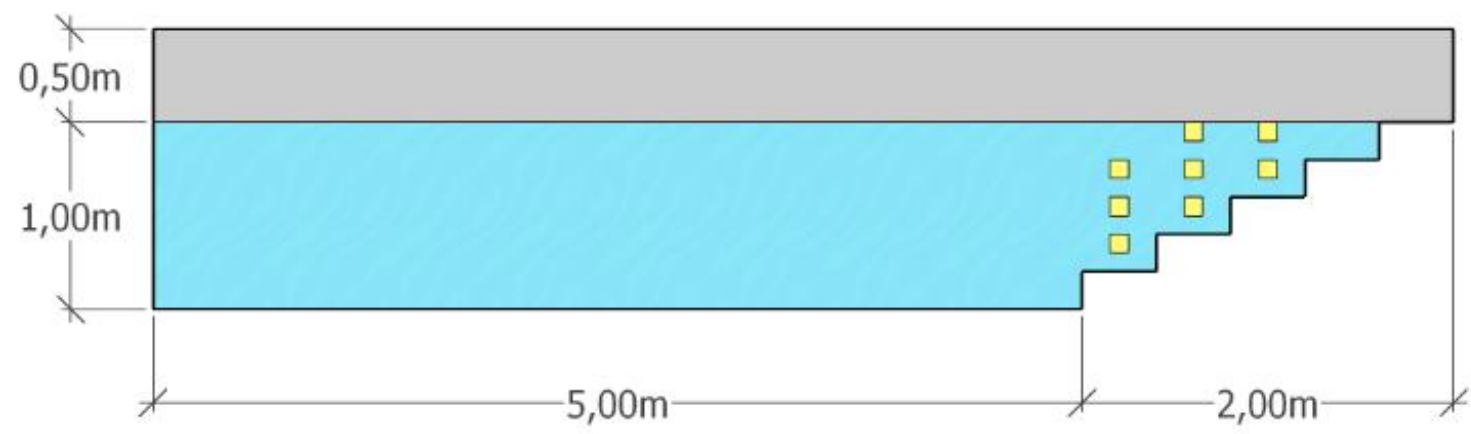

Figura 12 Dimensões do tanque de provas numérico para calibração de onda

O tanque é composto por um batedor de ondas do tipo pistão na sua extremidade esquerda e por uma praia em degraus de declividade aproximada de $30^{\circ}$ e dissipadores passivos na sua extremidade direita. Neste estudo se adotou um batedor do tipo pistão devido a sua função de transferência para águas rasas, mais eficiente que aquela de um pistão do tipo flap (Dean \& Dalrymple, 1991).

Apesar de uma das vantagens do emprego de um método lagrangeano estar relacionada a não ocorrer difusão numérica devido ao termo convectivo, pelo fato de a convecção ser determinada a partir do movimento das próprias partículas, ocorrem nestes métodos amortecimentos numéricos de outras naturezas.

Desta maneira, no caso do método numérico empregado neste estudo ocorre uma redução significativa da amplitude da onda ao longo do tanque, como resultado de amortecimento numérico. Devido a este amortecimento, na etapa de calibração de onda deve-se determinar inclusive a posição ao longo do tanque onde a onda possui as características desejadas, além da amplitude e do período de movimento do batedor.

Na Figura 13 é mostrado um exemplo de redução da amplitude da onda ao longo do tempo. A linha tracejada indica a amplitude de onda desejada e a linha contínua a amplitude da onda em função da distância do batedor. O ponto de encontro das duas curvas indica a posição no tanque onde a onda possui as características desejadas. 


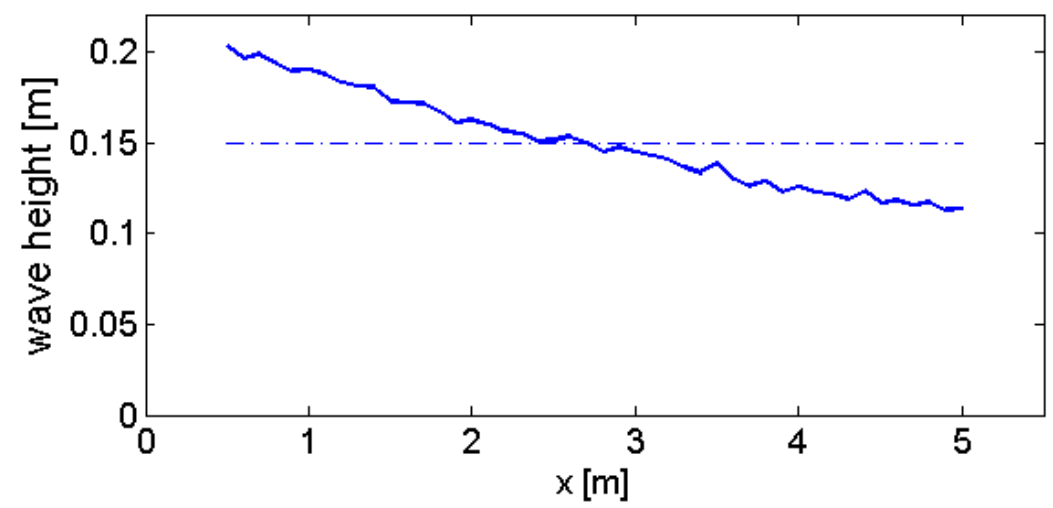

Figura 13 Redução da amplitude da onda ao longo do tanque - Condição de onda 7

A calibração do comprimento da onda gerada é baseada no período do movimento do batedor de ondas e a calibração da amplitude da onda se baseia na amplitude do movimento realizado pelo batedor. O resultado final das características do movimento do batedor e da distância na qual é posicionado o modelo para cada uma das condições de onda é apresentada na Tabela 3.

Tabela 3 Parâmetros de geração de onda

\begin{tabular}{|c|c|c|c|}
\hline $\begin{array}{l}\text { Condição } \\
\text { de onda }\end{array}$ & $\begin{array}{c}\text { Período do } \\
\text { movimento do } \\
\text { batedor }\end{array}$ & $\begin{array}{l}\text { Amplitude do } \\
\text { movimento do } \\
\text { batedor }\end{array}$ & $\begin{array}{c}\text { Distância entre o } \\
\text { modelo e o batedor } \\
\text { de ondas }\left(x_{0}\right)\end{array}$ \\
\hline 1 & $1,28 \mathrm{~s}$ & $0,04 \mathrm{~m}$ & $2,2 \mathrm{~m}$ \\
\hline 2 & $1,28 \mathrm{~s}$ & $0,05 \mathrm{~m}$ & $2,2 \mathrm{~m}$ \\
\hline 3 & $1,28 \mathrm{~s}$ & $0,06 \mathrm{~m}$ & $2,2 \mathrm{~m}$ \\
\hline 4 & $1,39 \mathrm{~s}$ & $0,05 \mathrm{~m}$ & $2,2 \mathrm{~m}$ \\
\hline 5 & $1,39 \mathrm{~s}$ & $0,06 \mathrm{~m}$ & $2,0 \mathrm{~m}$ \\
\hline 6 & $1,39 \mathrm{~s}$ & $0,08 \mathrm{~m}$ & $2,7 \mathrm{~m}$ \\
\hline 7 & $1,55 \mathrm{~s}$ & $0,07 \mathrm{~m}$ & $3,1 \mathrm{~m}$ \\
\hline 8 & $1,55 \mathrm{~s}$ & $0,08 \mathrm{~m}$ & $2,7 \mathrm{~m}$ \\
\hline 9 & $1,55 \mathrm{~s}$ & $0,10 \mathrm{~m}$ & $3,0 \mathrm{~m}$ \\
\hline
\end{tabular}




\subsubsection{Modelagem}

A calibração numérica da onda foi realizada empregando-se um tanque de provas bidmensional, com objetivo de redução do custo computacional. Para o estudo de green water é empregado um tanque de provas tridimensional com as dimensões apresentadas na Figura 14. O tanque é composto por um batedor de ondas do tipo pistão no seu início e por uma praia em degraus com declividade de $30^{\circ}$ e dissipadores passivos ao seu final.
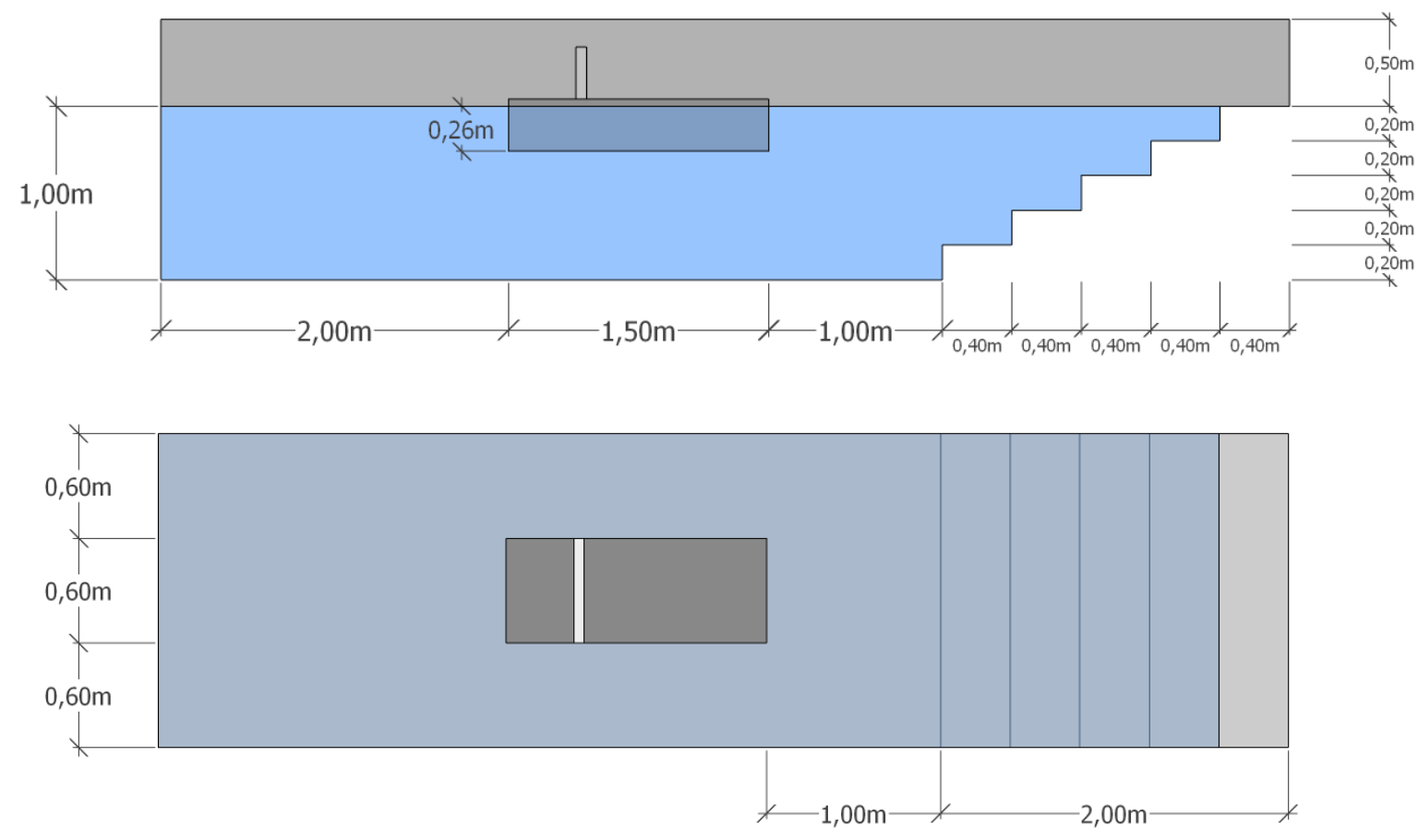

Figura 14 Dimensões do tanque de provas numérico

Os parâmetros numéricos de simulação empregados estão apresentados na Tabela 4. A resolução empregada resulta em um modelo de pouco menos de 2 milhões de partículas, valor próximo ao limite de memória disponível nocomputador utilizado para simulações empregando o simulador de memória compartilhada. Assim, não ocorreu análise de convergência numérica nesta primeira análise.

Tabela 4 Parâmetros numéricos de simulação

\begin{tabular}{cccc}
\hline $\begin{array}{c}\text { Distância entre } \\
\text { partículas }\end{array}$ & $\begin{array}{c}\text { Número de } \\
\text { partículas }\end{array}$ & $\begin{array}{c}\text { Incremento } \\
\text { de tempo }\end{array}$ & $\begin{array}{c}\text { Constante suavizadora } \\
\text { de pressão }\end{array}$ \\
\hline $20 \mathrm{~mm}$ & $\approx 1.700 .000$ & $0,001 \mathrm{~s}$ & 0,075 \\
\hline
\end{tabular}


Para a simulação do fenômeno de green water serão utilizados modelos em escala reduzida de 1:100 com três diferentes formatos da proa: o Modelo 0, em formato de caixote, e os modelos A e B, com proas parabólicas hidrodinâmicas. Os modelos estão apresentados na Figura 15.

\section{Modelo Rect0}
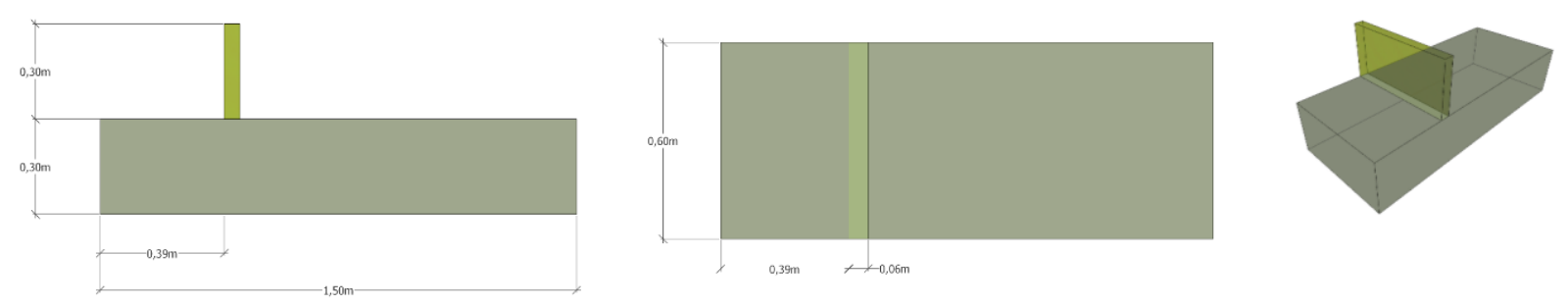

\section{Modelo Rect5}
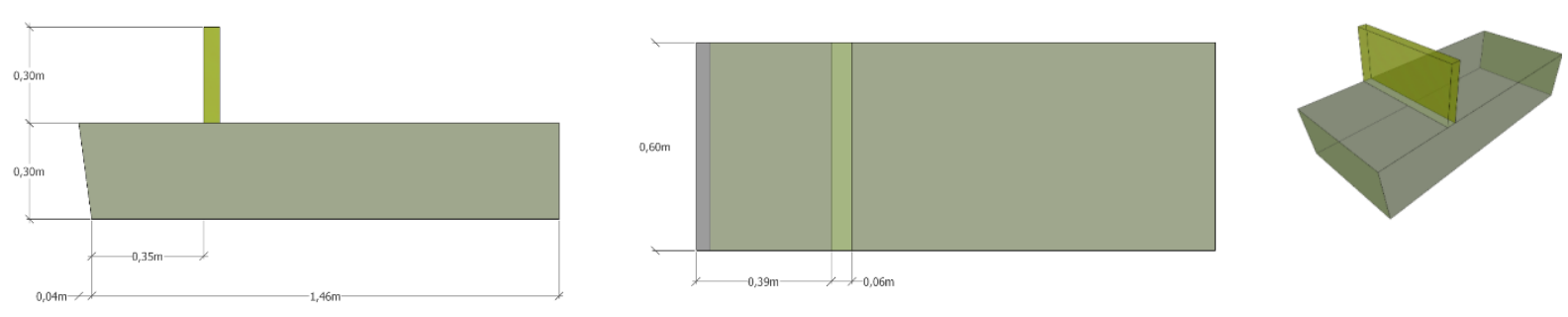

\section{Modelo Round}
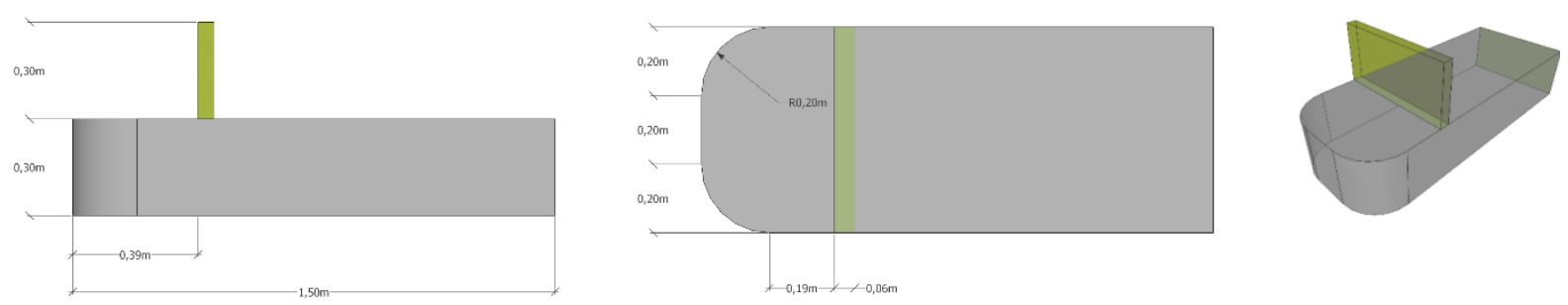

Figura 15 Dimensões principais dos modelos (Lee, et al., 2012)

A validação do simulador baseado no método MPS se dá pela comparação com resultados experimentais com os resultados numéricos para a pressão em sensores posicionados sobre o convés. Os resultados experimentais são baseados nos experimentos de Lee et al. (2012), que consistem no impacto de 9 diferentes ondas regulares de proa em 3 modelos em escala reduzida fixos de plataforma FPSO. Nesta validação são comparados apenas os resultados obtidos para o modelo em forma de paralelepípedo, o Rect0. A posição dos sensores de pressão é mostrada na Figura 16. 


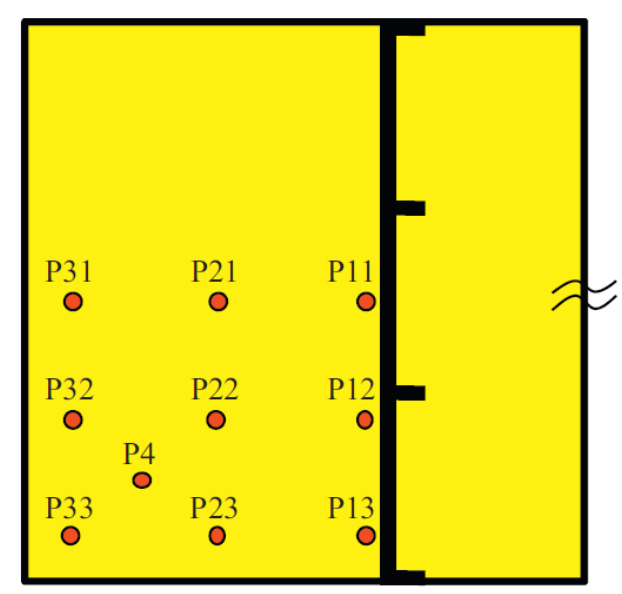

Figura 16 Posição dos sensores de pressão (Lee, et al., 2012)

\subsubsection{Resultados numéricos}

Os resultados da validação são apresentados nas Figura 17, Figura 18 e Figura 19, para os sensores de pressão P11, P21 e P31, respectivamente. Todos os resultados são relativa a condição de onda 9 , com comprimento de onda de $375 \mathrm{~cm}$ e amplitude de $11,25 \mathrm{~cm}$. Nas três figuras, o resultado apresentado à esquerda contempla a série temporal não filtrada obtida com o método de partículas MPS, mostrando toda a oscilação de pressão própria do método. Já os resultados apresentados à direita mostram a série temporal filtrada, para uma melhor visualização do comportamento da curva de pressão.

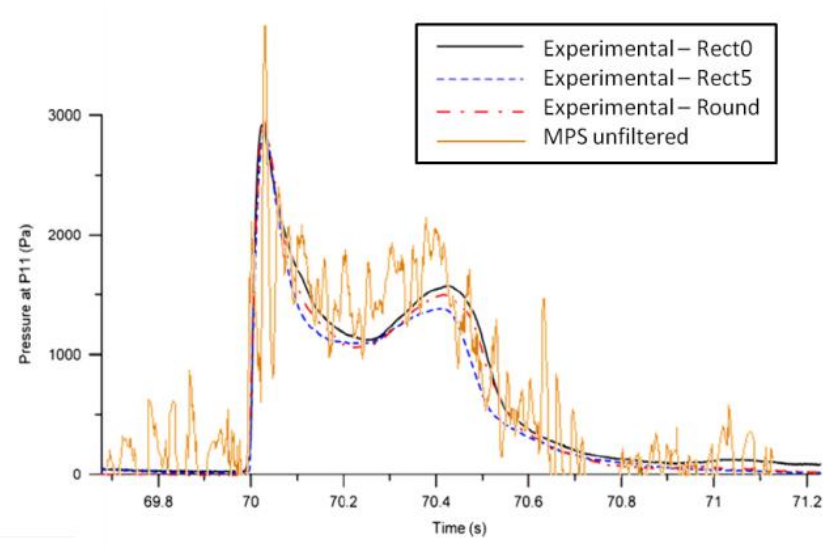

(a)

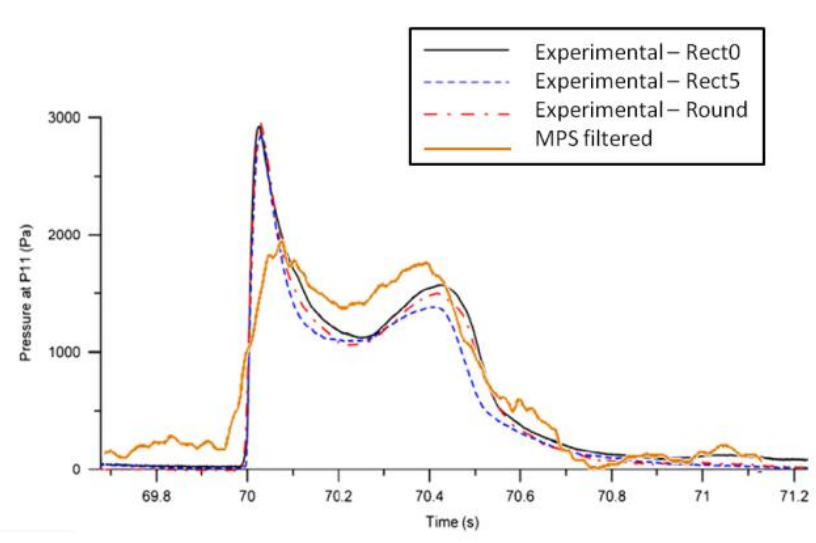

(b)

Figura 17 Série temporal de pressão no sensor P11 - MPS x experimental (Lee, et al., 2012) - MPS não filtrado (a) MPS filtrado (b) - condição de onda 9

Na Figura 17-(a), para o sinal não filtrado de pressão obtido para o sensor P11, é possível perceber que o resultado obtido pelo método de partículas segue bem a 
tendência do resultado experimental; a oscilação de pressão ocorre ao redor da curva experimental. O método de partículas é capaz de simular o pico de pressão relativo ao impacto hidrodinâmico. O primeiro pico de pressão é superestimado, resultado possivelmente associado a oscilação numérica de pressão. Nos resultados de Lee et al. (2012) o pico de pressão em P11 varia significativamente, possuindo um valor médio de $2498 \mathrm{~Pa}$, com máximo de $3182 \mathrm{~Pa}$ e mínimo de $1883 \mathrm{~Pa}$.

$\mathrm{Na}$ Figura 17-(b) observa-se que a curva obtida pelo método numérico apresenta comportamento muito próximo ao experimental, com a presença dos dois picos de pressão associados a duas fases do fenômeno de green water; o primeiro associado a fase de ingresso e o segundo a fase de drenagem. A diferença para o primeiro pico se dá pelo próprio processo de filtragem por media locais, no qual se perde o valor dos picos de alta frequência.

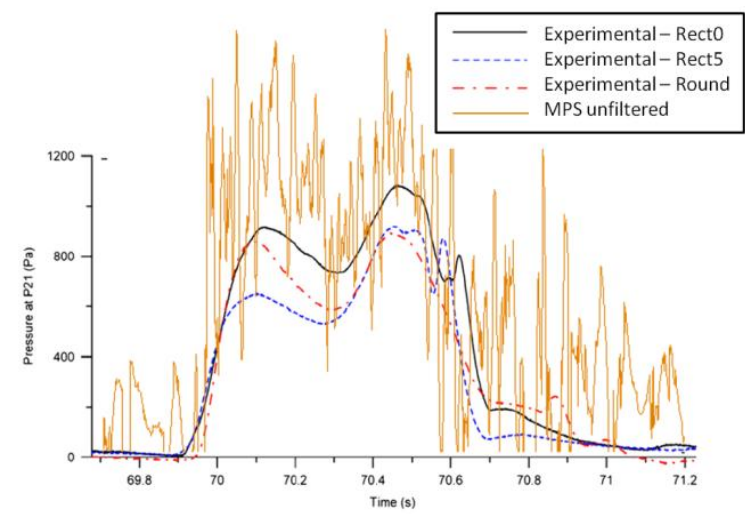

(a)

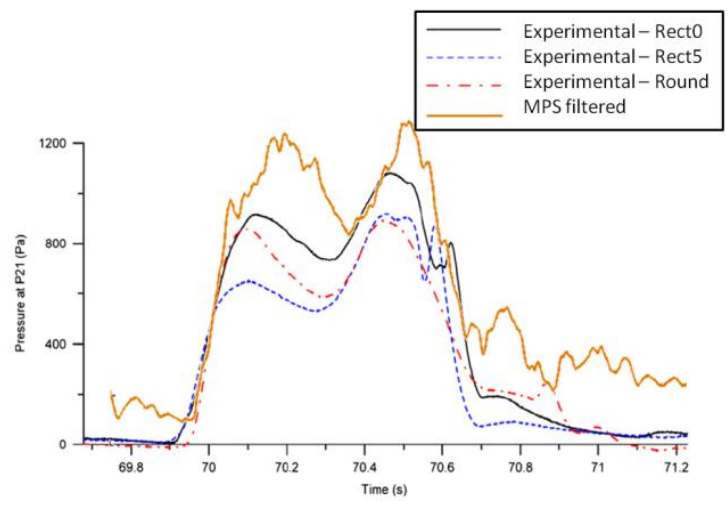

(b)

Figura 18 Série temporal de pressão no sensor P21 - MPS x experimental (Lee, et al., 2012) - MPS não filtrado (a) MPS filtrado (b) - condição de onda 9

A pressão no sensor P21 é apresentada na Figura 18. O valor não filtrado mostra que a oscilação numérica de pressão passa a ser maior, proporcionalmente, do que aquela registrada para o sensor P11, no qual o impacto é mais intenso e as pressões envolvidas são maiores. O resultado filtrado mostrado na Figura 18-b indica que o método de partículas superestima ligeiramente a pressão neste ponto e que a diferença de amplitude entre o primeiro e segundo pico não é tão nítida quanto nos resultados experimentais. Porém os resultados obtidos ainda são próximos dos experimentais, já que a pressão do pico em P21 varia entre 808 Pa e 1308 Pa nos experimentos de Lee et al. (2012). 


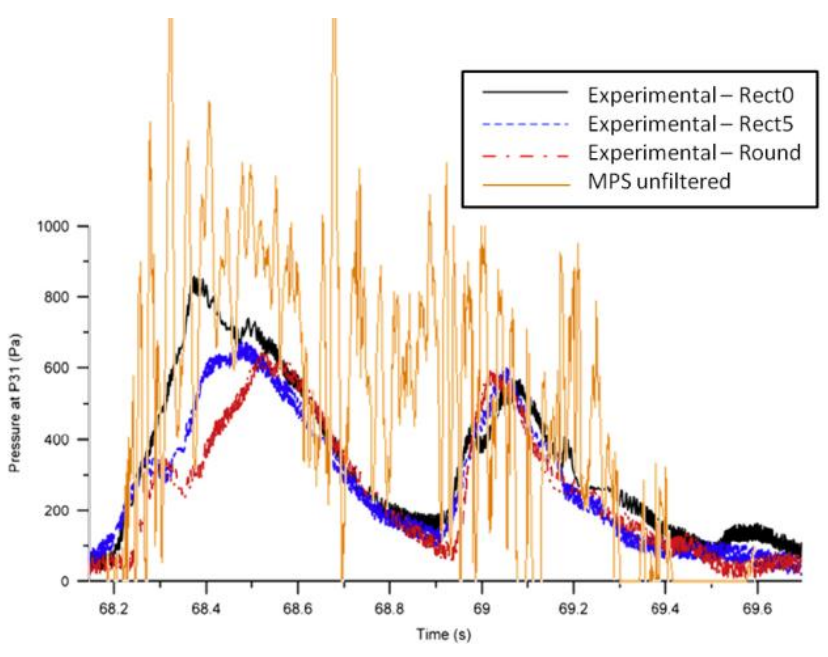

(a)

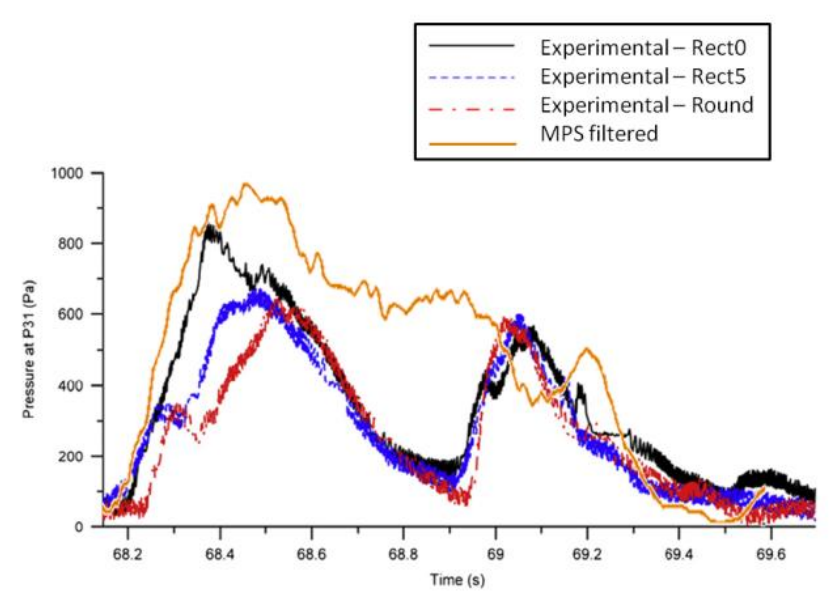

(b)

Figura 19 Série temporal de pressão no sensor P31 - MPS x experimental (Lee, et al., 2012) - MPS não filtrado (a) MPS filtrado (b) - condição de onda 9

Já para o sensor P31, com os resultados mostrados na Figura 19, envolve pressões menores ainda que aquelas presentes no sensor P21 e a oscilação numérica de pressão torna-se relativamente maior em relação ao valor médio registrado. Neste resultado a pressão chega a ser da mesma magnitude que o segundo pico de pressão, de modo que se torna imperceptível a queda de pressão presente entre os dois picos, como pode ser observado no resultado filtrado, em Figura 19-(b).

A partir da análise dos resultados dos sensores de pressão observa-se que a melhor estimativa obtida pelo método de partículas, para a resolução empregada, se dá na região próxima à antepara, na qual ocorre o impacto hidrodinâmico mais violento. Desta forma, para o escopo do presente estudo, focado na análise do embarque de água e dos efeitos do green water em equipamentos sobre o convés, a resolução empregada se mostra adequada pois os resultados numéricos se aproximam dos experimentais justamente na região do impacto hidrodinâmico entre o fluído embarcado e uma estrutura sobre o convés. Em outras analises similares a este trabalho, como nas simulações numéricas de Zhang et al. (2013) baseadas nos experimentos de Greco (2001), leva-se em conta apenas as pressões registradas sobre as anteparas. 
Na Figura 20, Figura 21 e Figura 22 são apresentadas as séries temporais não filtradas no sensor P11 para a condição de onda 9 dos modelos Rect0, Rect5 e Round, respectivamente.

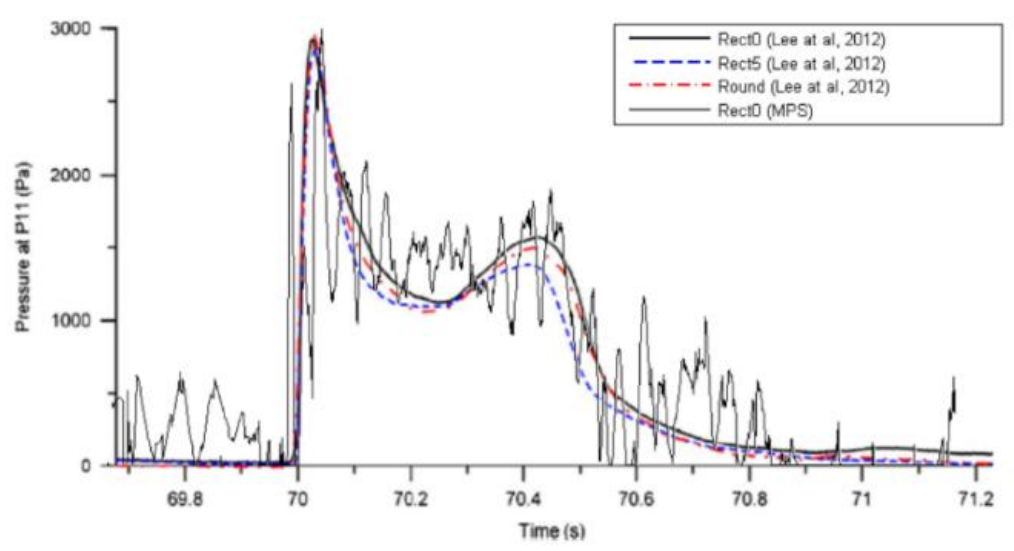

Figura 20 Pressão no sensor P11 $-($ Rect $0-\lambda=375 \mathrm{~cm}-A=11,25 \mathrm{~cm}-$ onda 9$)$

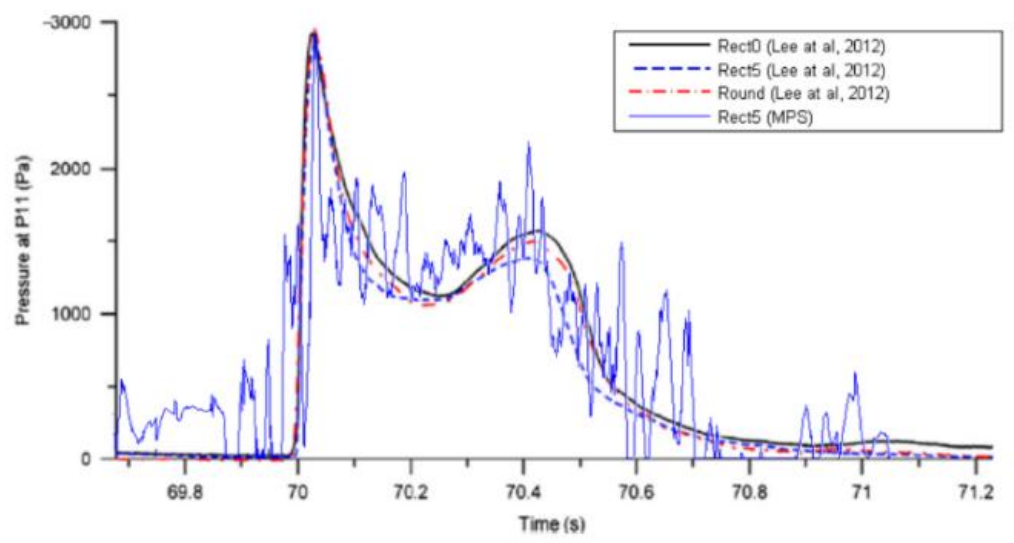

Figura 21 Pressão no sensor P11 - (Rect5 $-\lambda=375 \mathrm{~cm}-\mathrm{A}=11,25 \mathrm{~cm}-$ onda 9$)$

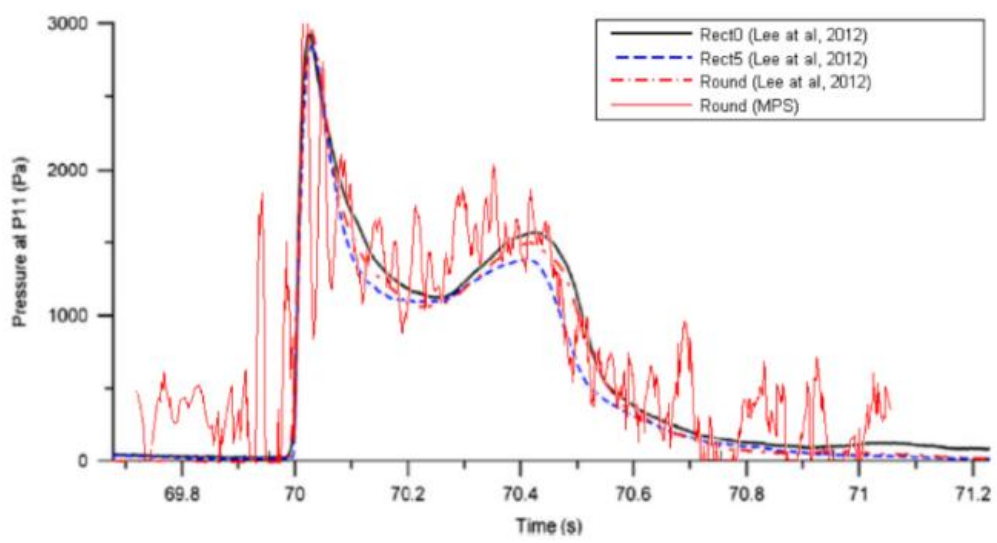

Figura 22 Pressão no sensor P11 - (Round $-\lambda=375 \mathrm{~cm}-\mathrm{A}=11,25 \mathrm{~cm}-$ onda 9$)$ 
A magnitude da oscilação de pressão é maior que as ligeiras diferenças observadas entre os modelos nos testes experimentais. Desta forma, com a resolução empregada, torna-se difícil observar diferenças signifcativas entre modelos com pequenas diferenças de geometria.

A Figura 23 e a Figura 24 mostram a série temporal da pressão nos sensores P21 e P31, respectivemente, para as três geometrias simuladas. Conforme já observado na Figura 18 e na Figura 19, a oscilação numérica de pressão se torna relativamente maior em relação ao valor médio nos pontos distantes da região do impacto hidrodinâmico; desta maneira, mesmo pelos resultados filtrados, não se pode observar as diferenças entre os modelos com a resolução empregada. Porém, o comportamento da curva de pressão obtido numericamente apresenta boa aderência ao resultados experimental, registrando os dois picos de pressão (da fase de ingresso e da fase de drenagem) e com magnitudes próximas das registradas experimentalmente.

Experimental (Lee, et al., 2012)

Resultado numérico (MPS)
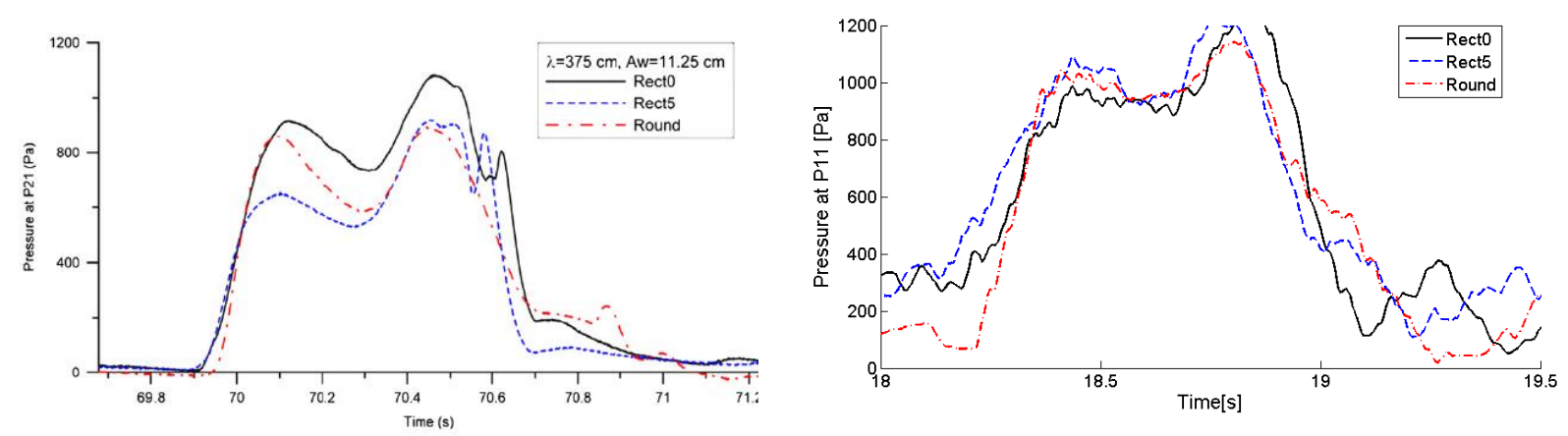

Figura 23 Pressão no sensor P21 $(\lambda=375 \mathrm{~cm}-A=11.25 \mathrm{~cm}$ - onda 9)

Experimental (Lee, et al., 2012)

Resultado numérico (MPS)
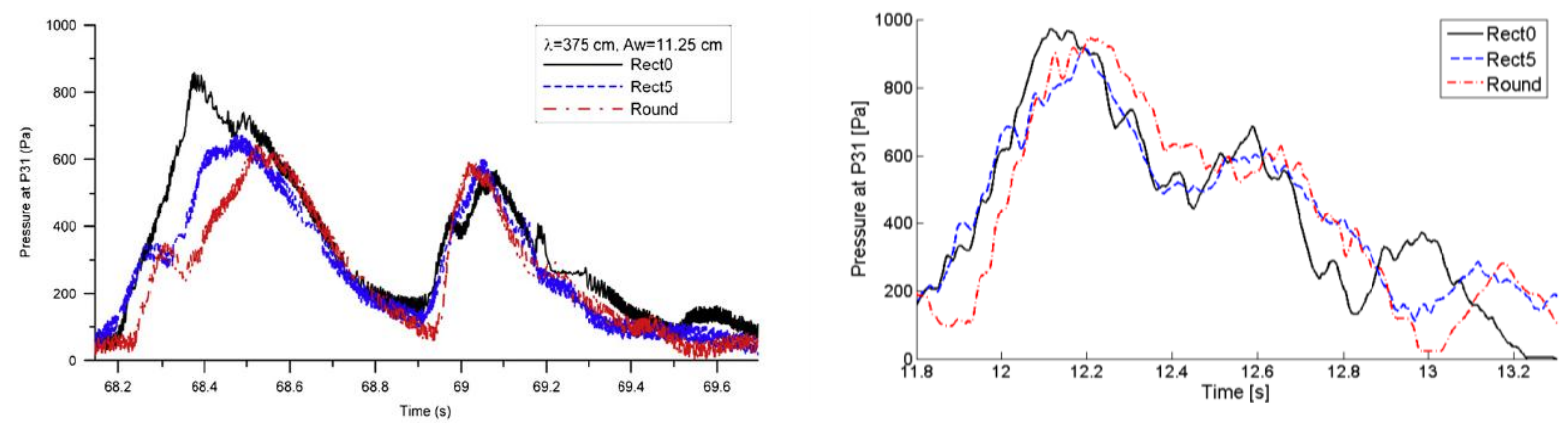

Figura 24 Pressão no sensor P31 $(\lambda=375 \mathrm{~cm}-\mathrm{A}=11.25 \mathrm{~cm}-$ onda 9) 
Tempo

Memória distribuída

Memória híbrida

5,40
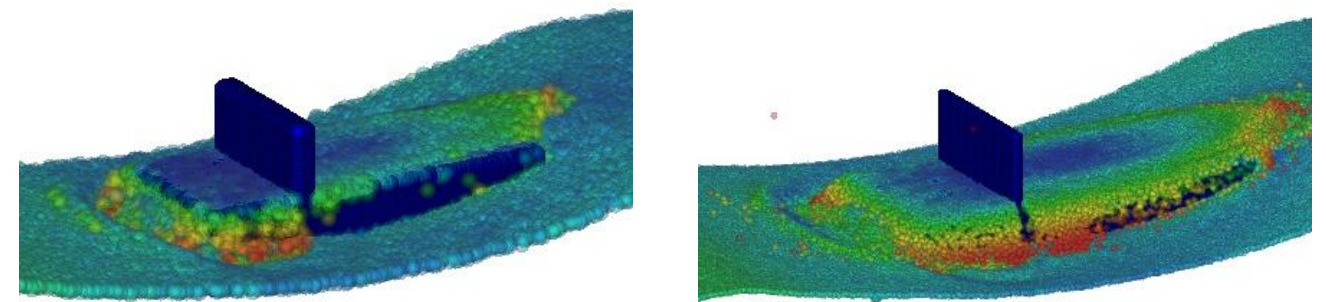

5,60
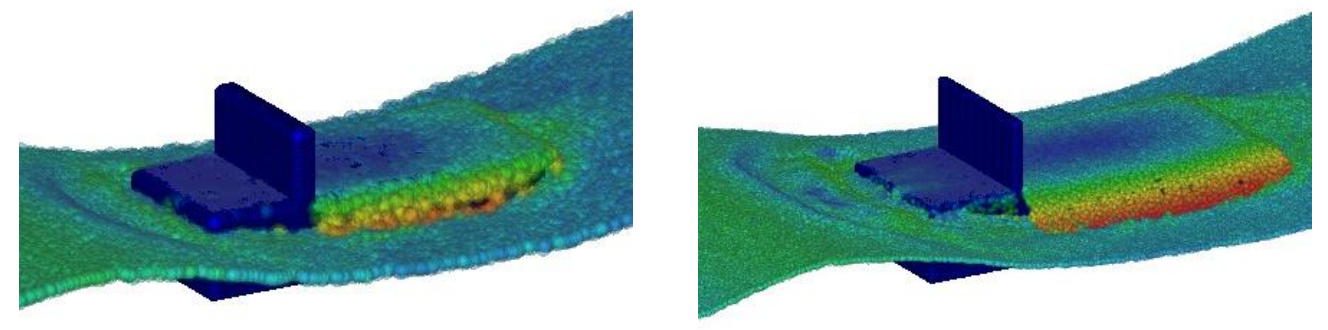

5,80
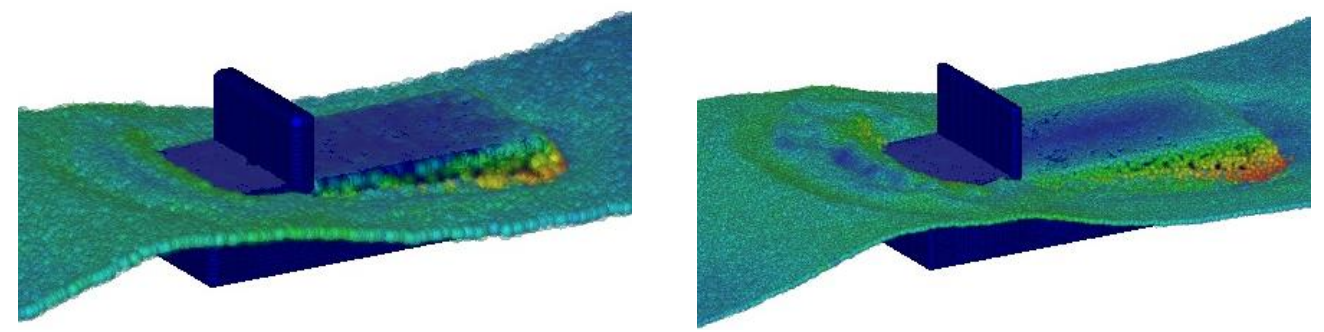

6,00
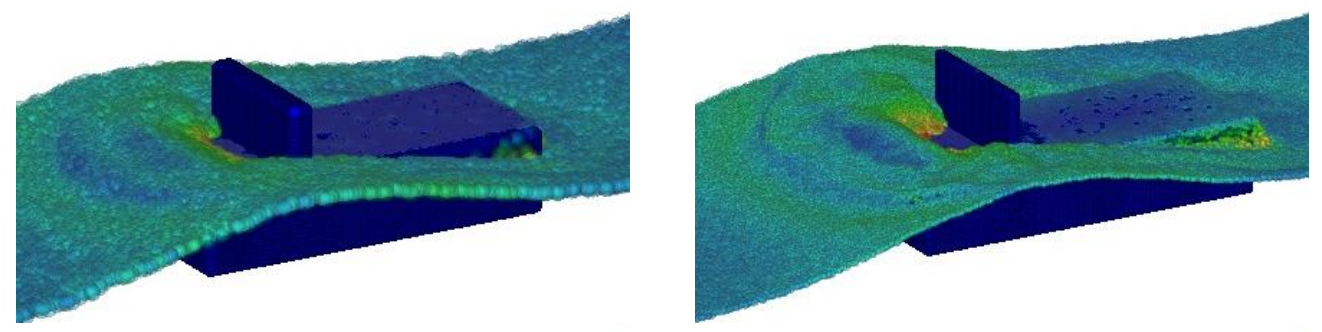

6,20
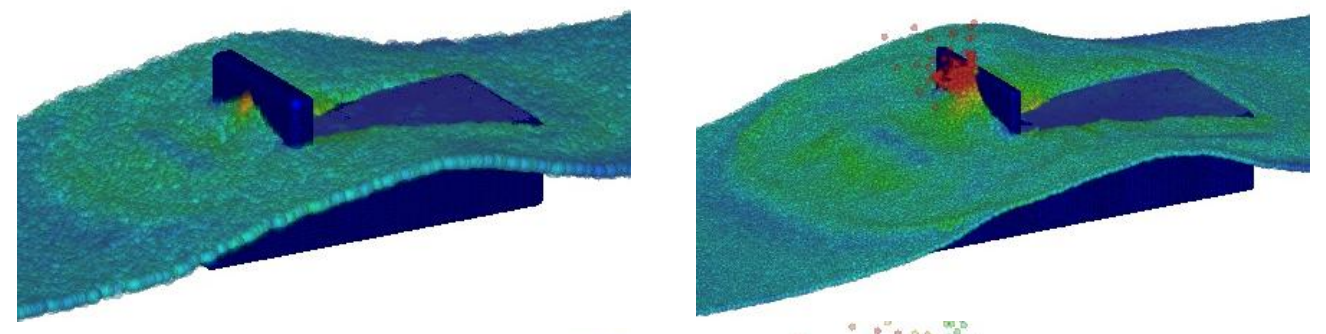

6,40
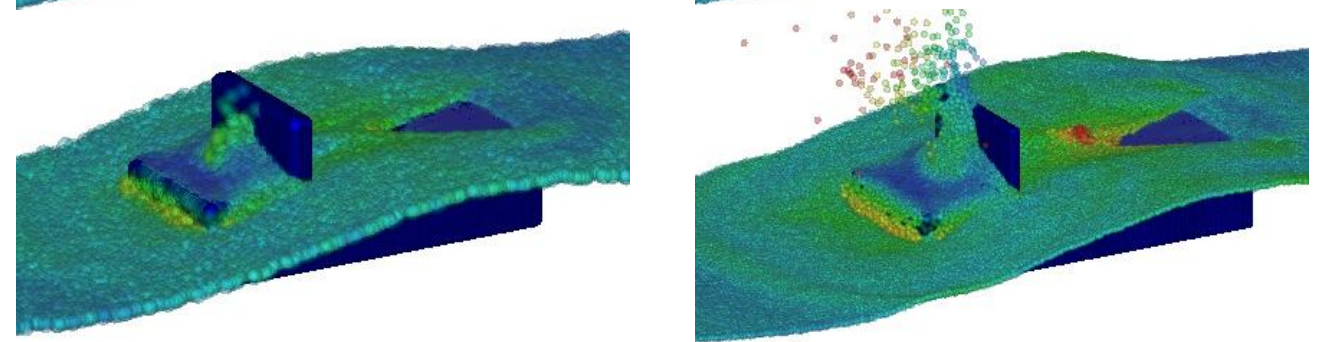

Figura 25 Snapshots da simulação numérica - velocidade das partículas de superfície livre (esquerda) pressão no convés e antepara (direita) - condição de onda 9

A Figura 25 apresenta os snapshots da simulação empregando-se a resolução com distância entre partículas de 20 milímetros, empregando-se o software de memória compartilhada, e da simulaão empregando o modelo com 
resolução de distância entre partículas de 10 milímetros, com o software de memória híbrida.

Na Figura 25 o comportamento do escoamento das simulações é próximo aos snapshots dos resultados numéricos apresentados em (Lee, et al., 2012), porém é possível observar ligeiras diferenças no comportamento tridimensional do escoamento durante a etapa de ingresso do fenômeno de green water. Uma diferença está no perfil da superfície livre da região próxima ao modelo durantes as fases iniciais do ingresso. Além disso, observa-se um perfil mais desenvolvido para o modelo de maior resolução, devido a reflexão da onda na estrutura fixa. Outra diferença significativa é a maior fragmentação e runup ocorrido na antepara, também para o modelo de maior resolução. Esta última diferença também foi oservada na simulação do fenômeno de dam break da seção 3.2.

Conforme apresentado nos resultados desta seção, mesmo com a resolução grosseira empregada nesta primeira análise, já é possível observar que o comportamento médio das curvas de pressão obtidas numericamente apresenta boa aderência aos resultados experimentais. Em pontos mais distantes da antepara na qual ocorre o impacto hidrodinâmico a amplitude das oscilações de pressão se torna relativamente maior em relação ao valor médio. Desta maneira, com objetivo de aumentar a precisão dos resultados e reduzir a oscilação numérica de pressão serão simulados modelos de alta resolução na segunda etapa deste estudo, com número de partículas superior a 2 milhões, apenas possíveis empregando-se o simulador com paralelização em memória distribuída. 


\subsection{Análise do efeito da proa no fenômeno de green water}

Neste tópico da análise do fenômeno de green water será analisado o efeito do formato da proa da estrutura para as ondas de proa, com os modelos fixos. As dimensões principais dos modelos em escala reduzida continuam baseadas naquelas apresentadas em Lee et al. (2012) e são mostrada na Tabela 5.

São avaliados modelos com sete diferentes geometrias de proa. $\mathrm{O}$ modelo 0 compreende o formato tradicional, em paralelepípedo. Os modelos $C$ e $D$ possuem formato prismático de cunha em $V$ de $30^{\circ}$ e $45^{\circ}$, respectivamente. Por fim, os modelos $\mathrm{E}$ e $\mathrm{F}$ apresentam as proas planas, com inclinação na direção do pontal, partindo do convés para a quilha. As inclinações da proa nos modelo $E$ e $F$ são, respectivamente, $30^{\circ}$ e $45^{\circ}$. As geometrias das proas são aqui apresentadas na Figura 26.

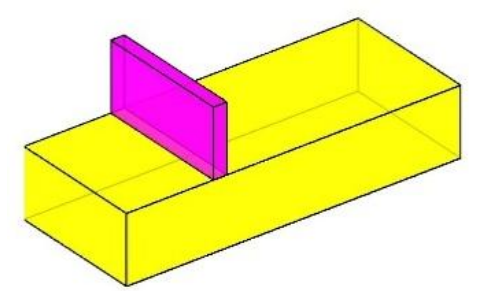

Modelo 0 - Paralelepípedo
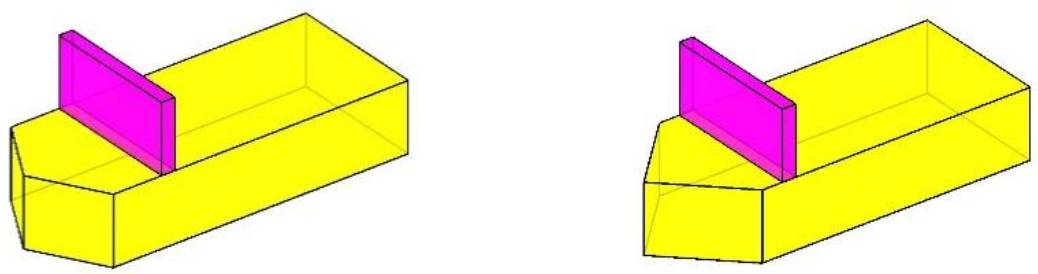

Modelo C - Cunha em V de $30^{\circ} \quad$ Modelo D - Cunha em V de $45^{\circ}$

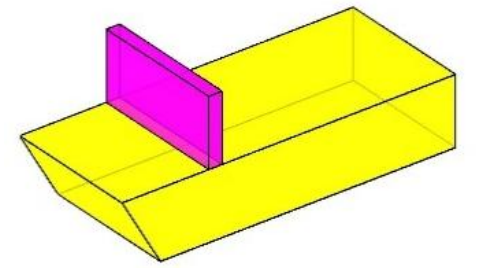

Modelo E - Chanfro de $30^{\circ}$

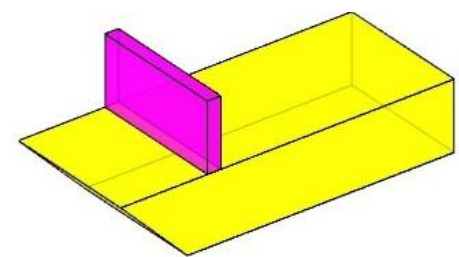

Modelo F - Chanfro de 45은 Figura 26 Modelos com diferentes formatos de proa 
Tabela 5 Dimensões principais dos modelos

Comprimento

Boca

Pontal

Calado

Altura da antepara

Posição da antepara (a partir da proa)
$1,5 \mathrm{~m}$

$0,6 \mathrm{~m}$

$0,3 \mathrm{~m}$

$0,26 \mathrm{~m}$

$0,3 \mathrm{~m}$

$0,39 \mathrm{~m}$

Os parâmetros numéricos computacionais utilizados nas simulações deste trabalho são mostrados na Tabela 6.

Tabela 6 Parâmetros numéricos de simulação

Distância entre partículas $\quad 0,02 \mathrm{~m}$

Incremento de tempo $\quad 0,001 \mathrm{~s}$

Constante suavizadora de pressão $\quad 0,075$

A resolução empregando partículas de 0,02 metros resulta em modelos de aproximadamente 1.600 .000 partículas. Julga-se esta resolução como ponto de partida por ser a mínima a partir da qual se pode diferenciar entre as diferentes geometrias de proa de forma adequada. Desta maneira, neste estudo não foi realizado estudo de convergência para determinação da resolução empregada devido ao grande número de partículas do modelo, que se aproxima do limite de memória do computador empregado, que limita os modelo a, no máximo, aproximadamente 2 milhões de partículas.

Para cerca de 30 segundos de simulação são necessários entre 3 e 4 dias de processamento computacional utilizando uma CPU Nehalen de 8 cores e 2,8 GHz, com 24GB de memória RAM. 


\subsubsection{Resultados numéricos}

Este estudo é focado na análise do efeito da geometria da proa no fenômeno de green water. $O$ desafio nos estudos de green water apresentam como objetivos a redução do volume de água embarcada e a redução da força de impacto hidrodinâmico nas estruturas localizadas ao longo do convés. Esta análise é realizada, primeiro, por meio da análise da força longitudinal de impacto na antepara localizada sobre o convés, considerando as condições de onda 3,6 e 7 . Os resultados são organizados de acordo com a amplitude da condição de onda, partindo da menor amplitude dentre estas (condição de onda 3) para a maior delas (condição de onda 6).

A Figura 27 mostra a força de impacto longitudinal na antepara para a condição de onda 3. O primeiro compara o formato tradicional (modelo 0) aos modelos com proa parabólica, o segundo aos modelos com proa em forma de cunha e, Figura 27-(c), aos modelos com proa chanfrada.

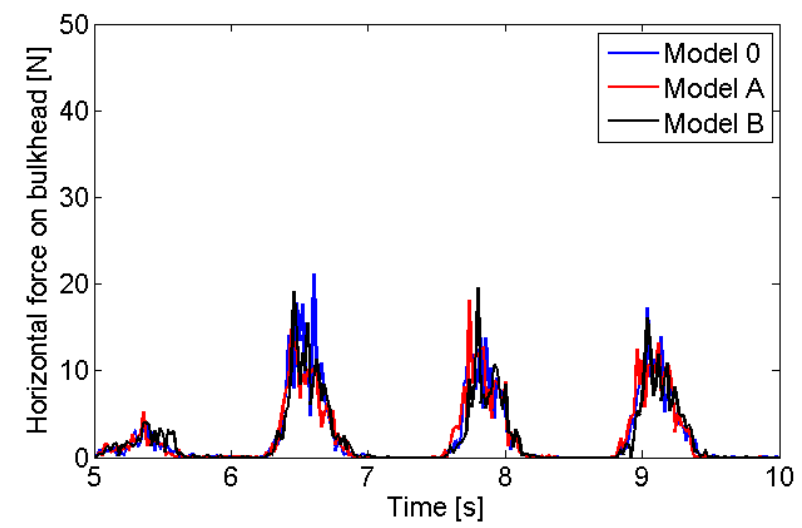

(a)

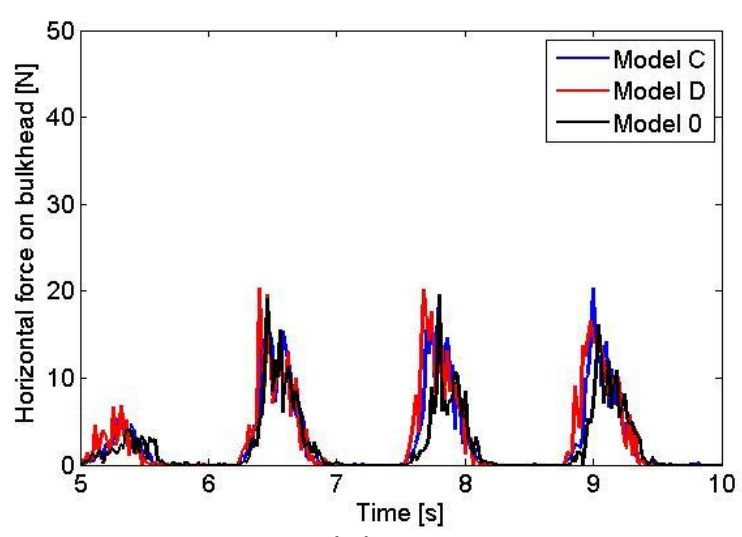

(b)

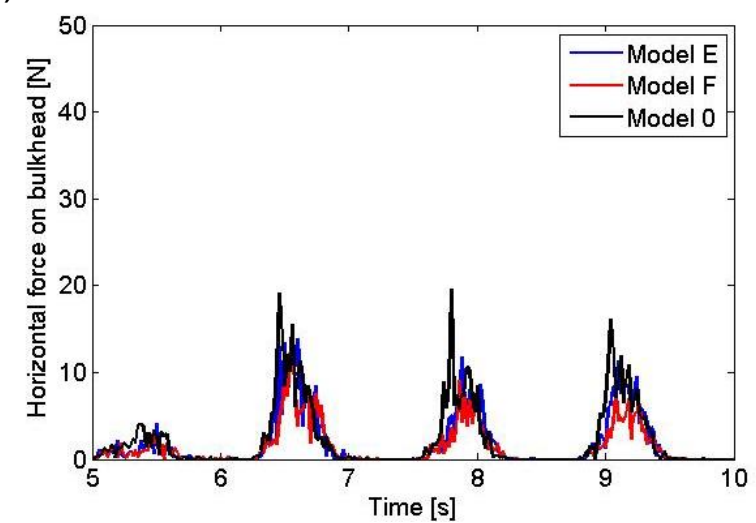

(c)

Figura 27 Força longitudinal na antepara - Condição de onda 3 - (a) proas em formato prabólico, (b) proas em forma de cunha em $\mathrm{V}$ e (c) proa chanfrada 
A condição onda 3 apresenta amplitude de 6,75 centímetros e comprimento de onda de 225 centímetros. A amplitude da onda excede a borda livre do modelo em 2,75 centímetros. A Figura 27-(b) mostra que a diferença entre o modelo 0 e as proas em forma de cunha em $\mathrm{V}$ é desprezível para a condição de onda dada. Os três modelos apresentam o mesmo comportamento e picos das força de impacto hidrodinâmico similares, em torno de $20 \mathrm{~N}$. Na Figura 27-(a), para as proas em formato parabólico, os resultados são bastante similares aos apresentado na Figura $27-(b)$.

Por outro lado, na Figura 27-(c), pela comparação entre a proa do modelo tradicional e as proas chanfradas, a força de impacto nestas últimas é inferior ao registrado no modelo 0 . Os picos da força longitudinal na antepara para os modelo $E$ e F são de $15 \mathrm{~N}$ e $12 \mathrm{~N}$, respectivamente, inferiores aos $20 \mathrm{~N}$ observado no modelo 0 e nos demais modelos na Figura 27-(a) e na Figura 27-(b). Este resultado mostra que o aumento da inclinação da proa nos modelos chanfrados é relacionado a uma redução na força de impacto.

A condição onda 7 apresenta amplitude de 7,5 centímetros e comprimento de onda de 375 centímetros. A amplitude da onda excede a borda livre do modelo em 3,5 centímetros. A Figura 28 mostra a força de impacto longitudinal na antepara para a condição de onda 7 , sendo dividida em três gráficos. O primeiro compara 0 formato tradicional (modelo 0) aos modelos com proa parabólica, o segundo aos modelos com proa em forma de cunha e, o terceiro, aos modelos com proa chanfrada. 


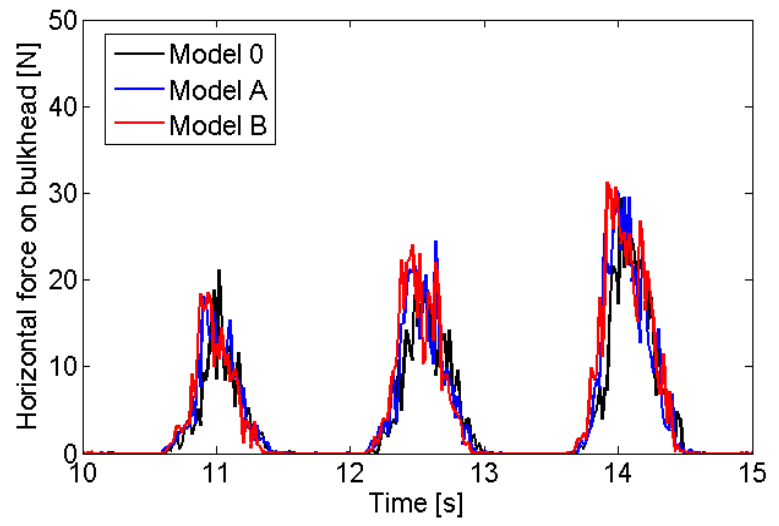

(a)

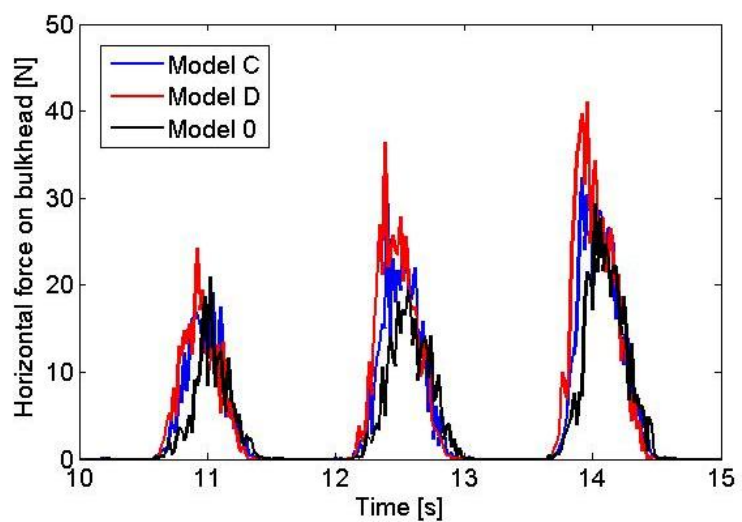

(b)

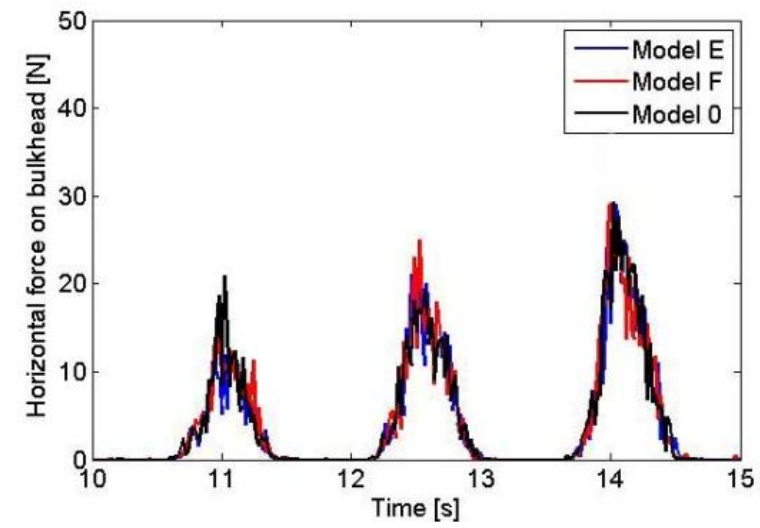

(c)

Figura 28 Força longitudinal na antepara - Condição de onda 7 - (a) proas em formato prabólico, (b) proas em forma de cunha em $\mathrm{V}$ e (c) proa chanfrada

De acordo com os resultados numéricos apresentados na Figura 28-(b), o modelo $\mathrm{D}$, com a cunha em $\mathrm{V}$ de $45^{\circ}$, apresenta uma maior força de impacto hidrodinâmico na antepara que o Modelo C, a cunha de $30^{\circ}$, que por sua vez mostra uma força de impacto maior que o modelo em forma de "caixote". Na Figura 28-(a), a proa parabólica B (modelo B) apresenta força de impacto maior que a proa parabólica $A$ (modelo $A$ ), que também apresenta força de impacto maior que o modelo 0. Estes resultados apontam para a tendência de modelos mais hidrodinâmicos apresentarem uma força de impacto hidrodinâmico na antepara maior. Já de acordo com a Figura 28-(c), não se verifica nenhum diferença significativa na força de impacto na antepara entre o modelo 0 e os modelos com proa chanfrada.

A condição onda 6 apresenta amplitude de 9,0 centímetros e comprimento de onda de 300 centímetros. A amplitude da onda excede a borda livre do modelo em 5,0 centímetros. A Figura 29 mostra a força de impacto longitudinal na antepara para a condição de onda 7 , sendo dividida em três gráficos. 0 primeiro compara 0 
formato tradicional (modelo 0) aos modelos com proa parabólica, o segundo aos modelos com proa em forma de cunha e, o terceiro, aos modelos com proa chanfrada.

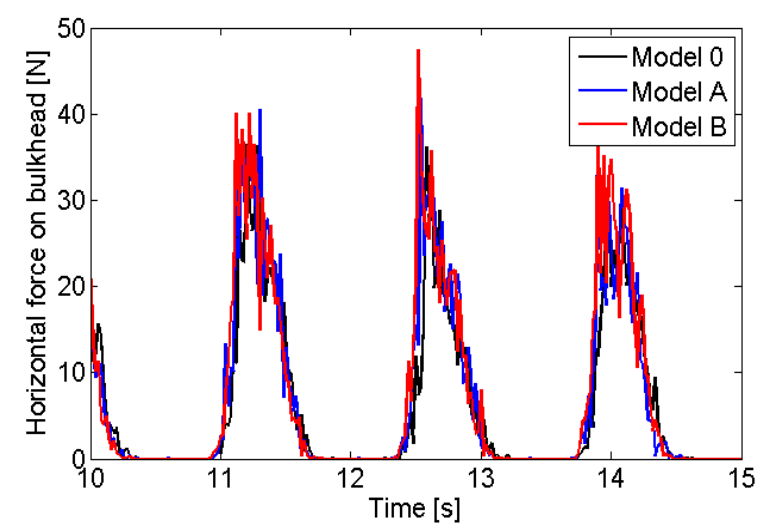

(a)

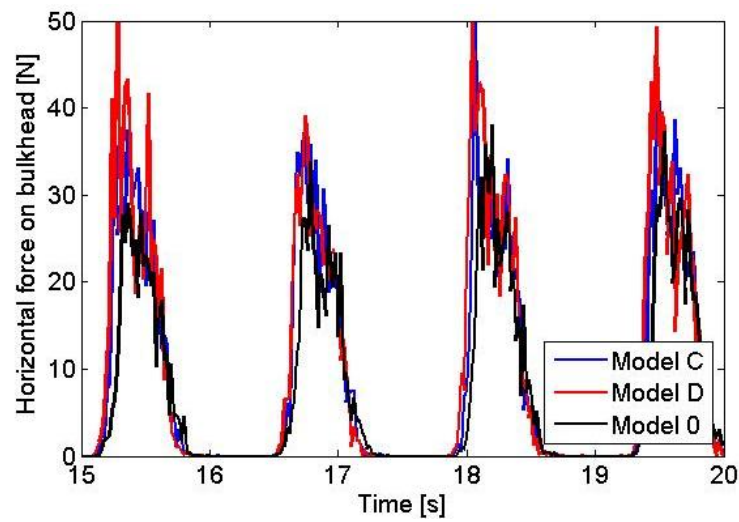

(b)

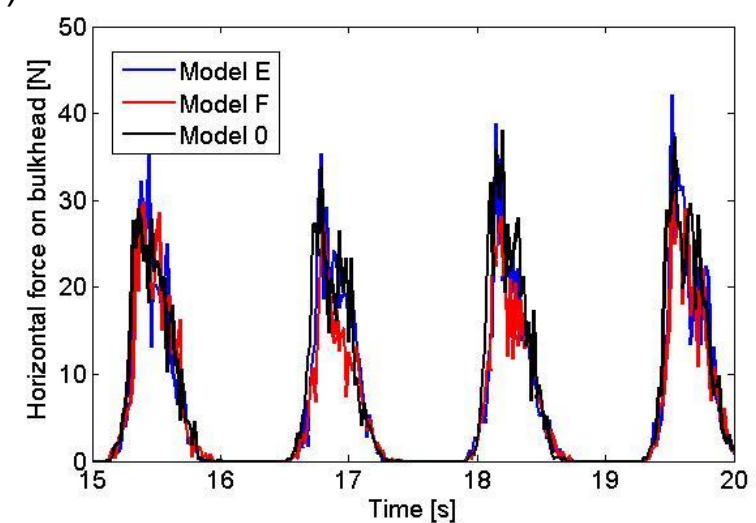

(c)

Figura 29 Força longitudinal na antepara - Condição de onda 6 - (a) proas em formato prabólico, (b) proas em forma de cunha em $\mathrm{V}$ e (c) proa chanfrada

$\mathrm{Na}$ Figura 29-(a) e Figura 29-(b) observa-se que os modelos com proa parabólica e proa em forma de cunha em $\mathrm{V}$ apresentam maior força de impacto na antepara que o modelo em paralelepípedo para a condição de onda 6 , assim como já observado para a condição de onda 7. Para as proas chanfradas, na Figura 29(c), não é observada diferença significativa na força de impacto na antepara entre os modelos $\mathrm{E}$ e $\mathrm{F}$ e o modelo 0.

De acordo com os resultados apresentados na Figura 27, na Figura 28 e na Figura 29, separaremos a análise final dos resultados em dois grupos; o primeiro grupo será composto pelas geometrias de proa hidrodinâmicas, englobando a proas eem forma de cunha em $V$; o segundo grupo será o composto pelas proas chanfradas. 
Nas proas em forma de cunha, nas ondas de menor amplitude, nas quais a amplitude da onda supera pouco a borda livre e o embarque de fluído é pequeno, não se observa diferença significativa na força de impacto na antepara em relação ao modelo em paralelepípedo. Este fato pode ser explicado por um amortecimento ao longo do convés maior que a energia da coluna de água que embarca no fenômeno de green water, desta forma o fluído que atinge a antepara já perdeu uma parcela de sua energia ao percorrer o convés. No entanto, para as ondas de maior amplitude, estes modelos apresentam forças de impacto maiores do que o modelo tradicional.

Já as proas do segundo grupo, para as ondas de menor amplitude apresentam uma menor força de impacto em relação ao modelo de "caixote". Para as ondas de maior amplitude a diferença passa a ser desprezível entre os modelos do segundo grupo e o modelo de paralelepípedo.

Comparando os resultados, a partir da condição de onda 3 para a condição de onda 6, da menor para a maior amplitude, observa-se que a força de impacto na antepara é proporcional à amplitude da onda incidente. Uma maior amplitude da onda incidente é associada a uma maior coluna d'água embarcada que irá colidir com a antepara. Em Greco et al. (2005) investigou-se a semelhança entre o fenômeno de green water e o fenômeno de dam break. De acordo com a similaridade entre os dois fenômenos, a altura da onda e, consequentemente, da coluna d'água, é proporcional ao quadrado da velocidade da frente de onda e esta, por sua vez, é proporcional a pressão de impacto e, consequentemente, à força de impacto (Lee, et al., 2012).

Uma segunda comparação se dá em termos do volume de água embarcado no convés, com o objetivo de entender como os modelos com a proa chanfrada apresentam força de impacto menor para as ondas de menor amplitude. Nesta seção são comparados os resultados do modelo em paralelepípedo apenas aos modelos com a proa chanfrada, por possuíres a mesma área de convés antes da antepara. A Figura 30 mostra a serie temporal do volume de água embarcado para o modelo 0 e os modelos $E$ e F, nas condições de onda 1, 3 , 6 e 7 . 


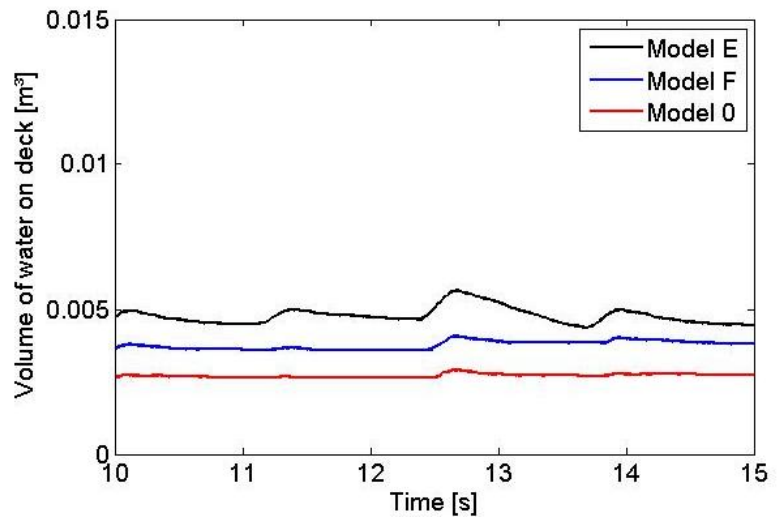

(a)

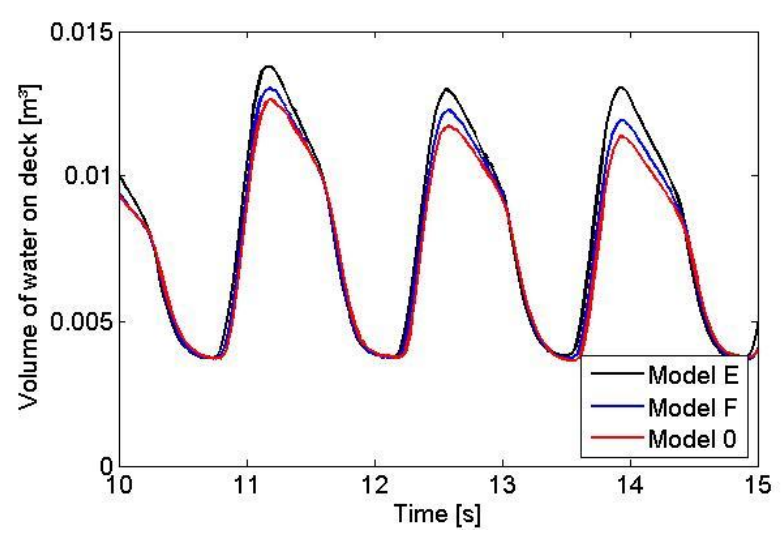

(c)

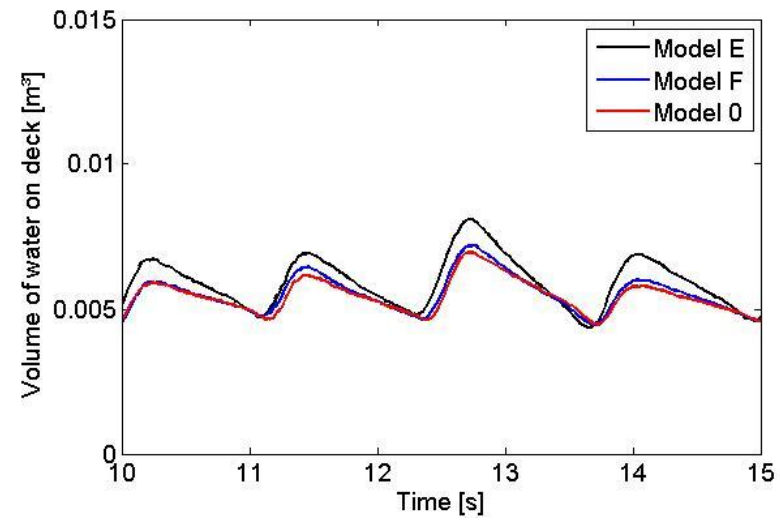

(b)

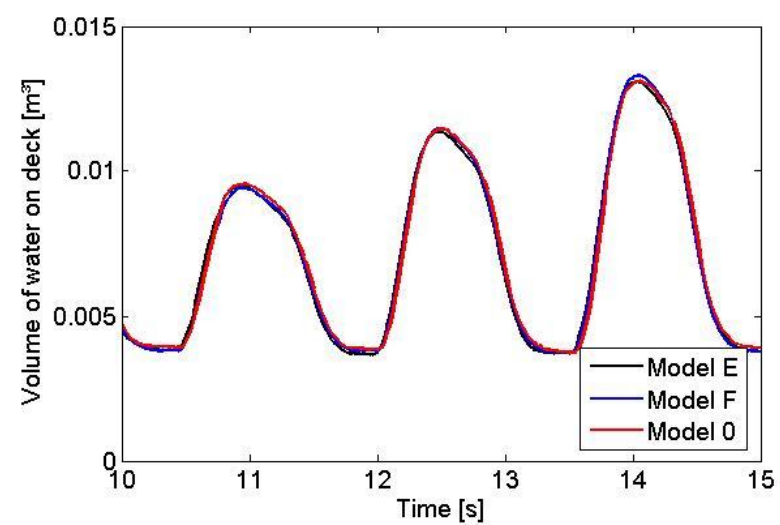

(d)

Figura 30 Volume de água embarcada no convés - Modelos com proa chanfrada - (a) Condição de onda 1, (b) condição de onda 3, (c) Condição de onda 6 e (d) Condição de onda 7

Para as condições de onda 1,3 e 6 , os modelos com a proa chanfrada apresentam um volume de água embarcado inferior ao modelo tradicional, o modelo 0 . As séries temporais em Figura 30-(a) e Figura 30-(b) mostram que, para as ondas de menor amplitude, a diferença entre o volume de água embarcada é relativamente maior em relação ao volume total embarcado do que nas ondas de maior amplitude, como em Figura 30-(c) e Figura 30-(d).

Lembrando que, na Figura 30-(a) e na Figura 30-(b) o comprimento de onda é de 225 centímentros, na Figura 30-(c) é de 300 centímetros e na Figura 30-(d) é de 375 centímentros. Não se observa diferença significativa no volume de água embarcado para a condição de onda 9, na qual a altura da onda supera significativamente a borda livre, com uma onda suficientemente grande para o efeito da geometria da proa ser desprezível no embarque de água.

A forma das curvas, para os diferentes comprimentos de onda, também mostra as diferença no comportamento do green water para ondas longas, médias e 
curtas. Nas ondas curtas, as fases de ingresso e de drenagem são visíveis, com o ingresso do próximo período de onda se iniciando antes do término da drenagem do período anterior. Já nas ondas longas, a drenagem do período anterior se encerra antes da etapa de ingresso do próximo período de onda. A curva em ondas longas tem um perfil aproximadamente parabólico, enquanto a curva nas ondas curtas se assemelha a duas retas, um ascendete na etapa de ingresso e uma descendente na etapa de drenagem.

Para comparar as características do escoamento para modelos com diferentes áreas no convés antes da antepara, será feita a comparação da velocidade média do fluído e da altura da coluna d'água em diversos pontos do convés. Na Figura 31 é apresentada a divisão da região do convés em 54 "células", sendo 6 colunas e 9 linhas. Nela também são indicadas as células que serão empregadas nas análises, principalmente a célula $\mathrm{R} 2$, na região central do convés e logo a frente da antepara, e a célula $\mathrm{R} 3$, na região próxima ao costado e em frente à antepara.

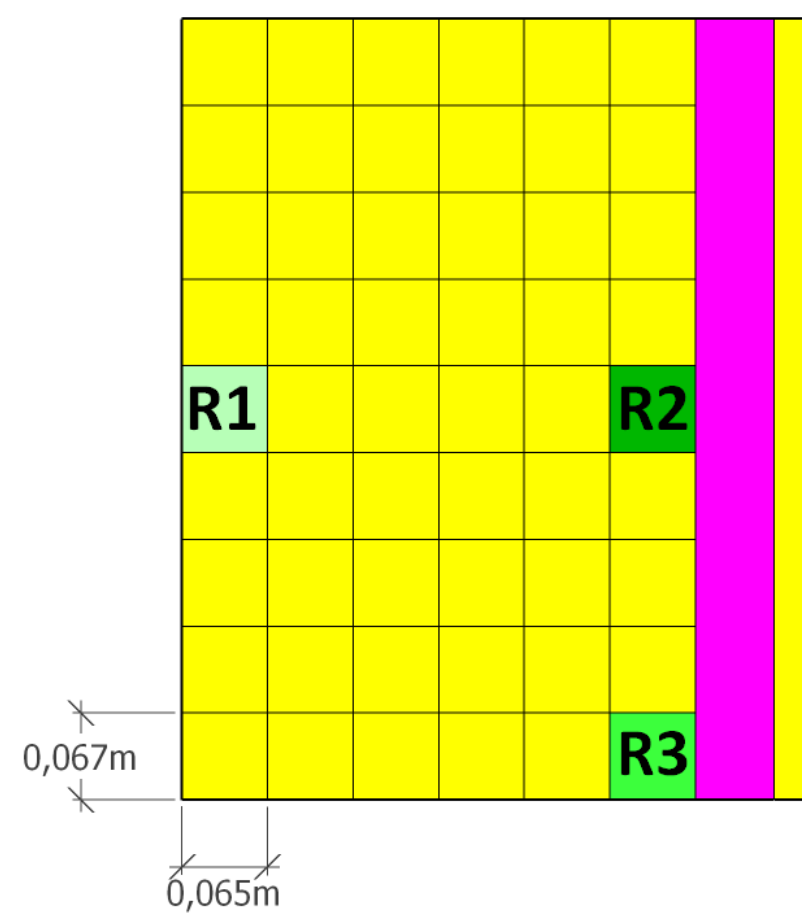

Figura 31 Configuração das células sobre o convés

A Figura 32 mostra as séries temporais da elvação de superfície livre nas células $\mathrm{R} 2$ e R3 para o modelo 0 e os modelos $C$ e $D$ (com proa em formato de cunha), na condição de onda 6 . A Figura 33 apresenta a velocidade longitudinal 
média do fluído sobre as regiões R2 e R3 para os mesmo modelos e condição de onda.

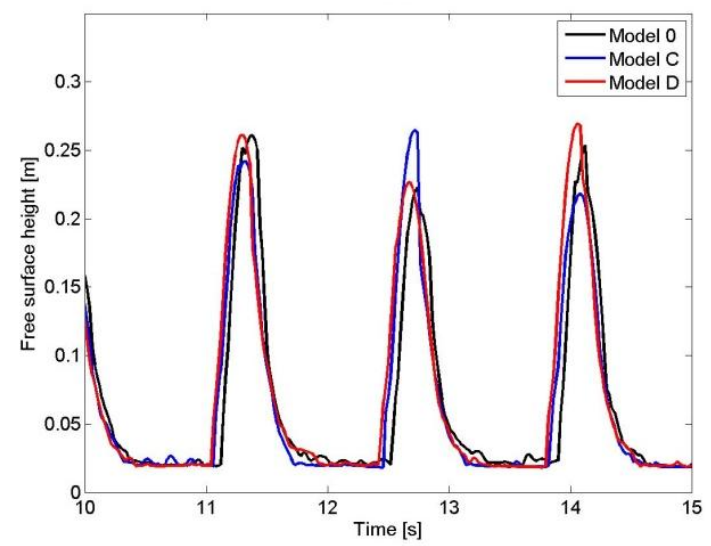

R2 cell

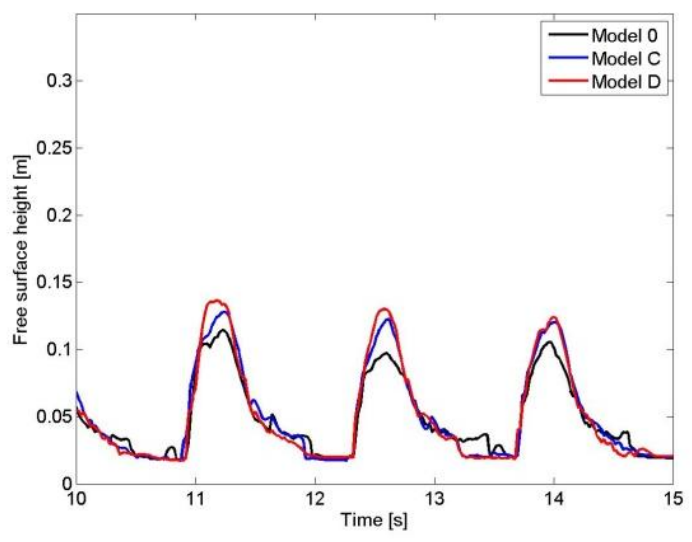

R3 cell

Figura 32 Altura da superfície livre nas células - Proa em cunha - Condição de onda 6

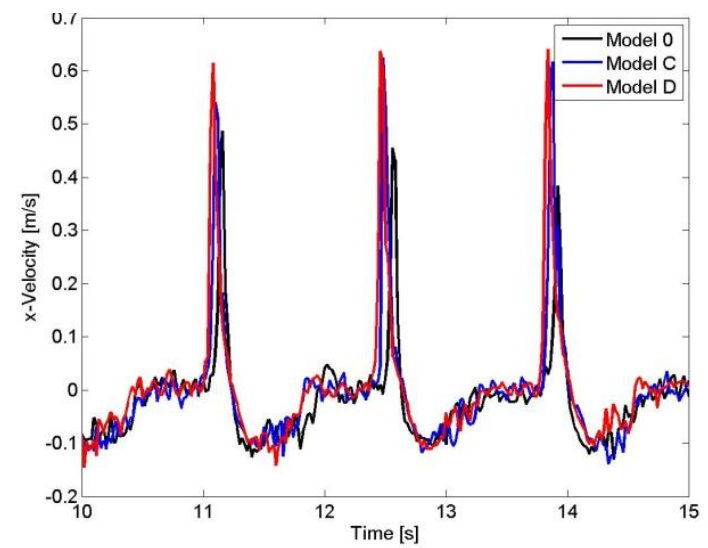

$\mathrm{R} 2$ cell

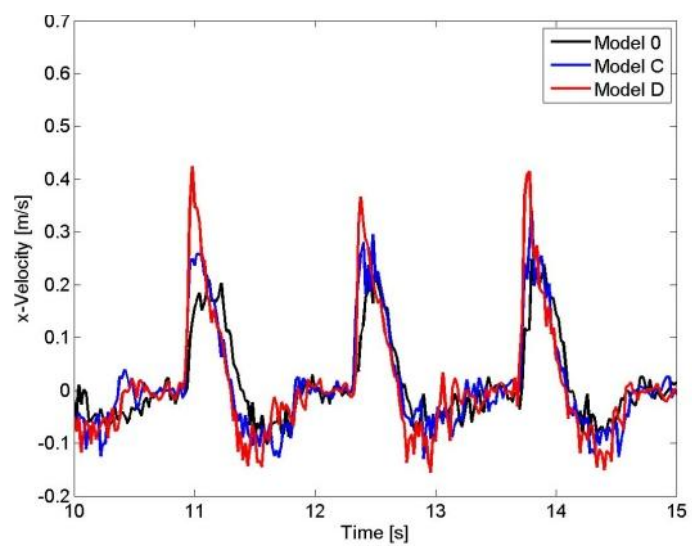

R3 cell

Figura 33 Velocidade longitudinal média do fluído sobre a região das células - Proa em cunha Condição de onda 6

A Figura 32 mostra que o pico da curva da coluna d'água na célula R3, na região próxima ao costado do modelo, é maior no modelo com proa em cunha do que no modelo em paralelepípedo. A comparação entre a velocidade longitudinal mpedia da água na célula R3 também mostra valores maiores para os modelos com a proa em forma de cunha. Os resultados apresentados na Figura 32 e na Figura 33 estão de acordo com aquele apresentado na Figura 29-(b), na qual se observa um maior impacto hidrodinâmico na antepara para os modelos com a proa em forma de cunha. 
A diferença observada pode ser explicada pela distância menor entre a extremidade do convés e a antepara, na direção de propagação da onda, nas regiões próximas ao costado. Isto resulta em um menor trecho pelo qual a coluna de água embarcada se propaga no convés antes de atingir a antepara, resultando em uma menor velocidade da frente de onda devido às perdas de energia por atrito.

A Figura 34 mostra as séries temporais da elevação de superfície livre nas células R2 e R3 para o modelo 0 e os modelos E e $F$ (com proa inclinada), na condiçãod e onda 3. A Figura 35 apresenta a velocidade longitudinal média do fluído sobre as regiões $\mathrm{R} 2$ e R3 para os mesmo modelos e condição de onda.

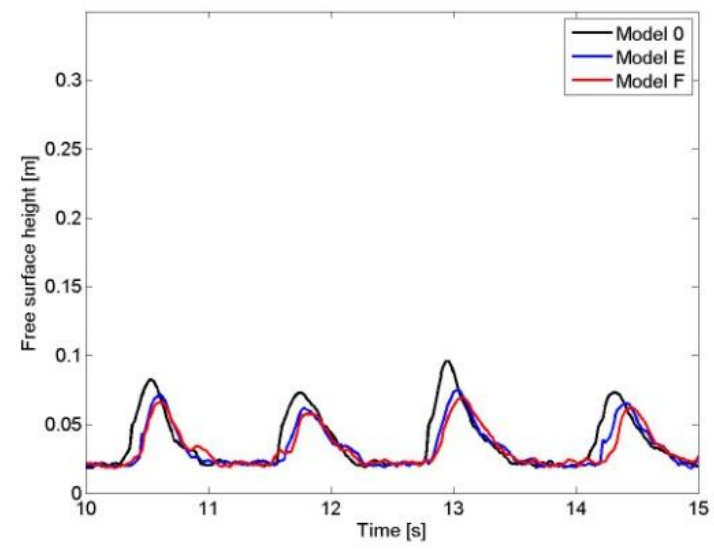

$\mathrm{R} 2$ cell

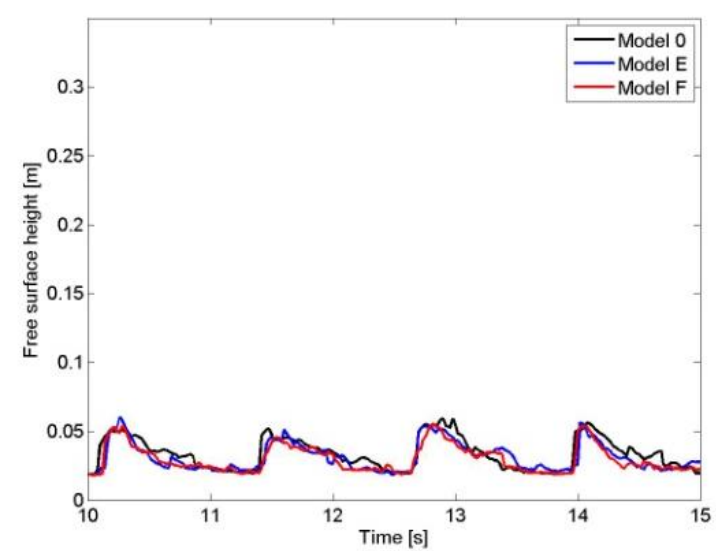

R3 cell

Figura 34 Altura da superfície livre nas células - Proa inclinada - Condição de onda 3

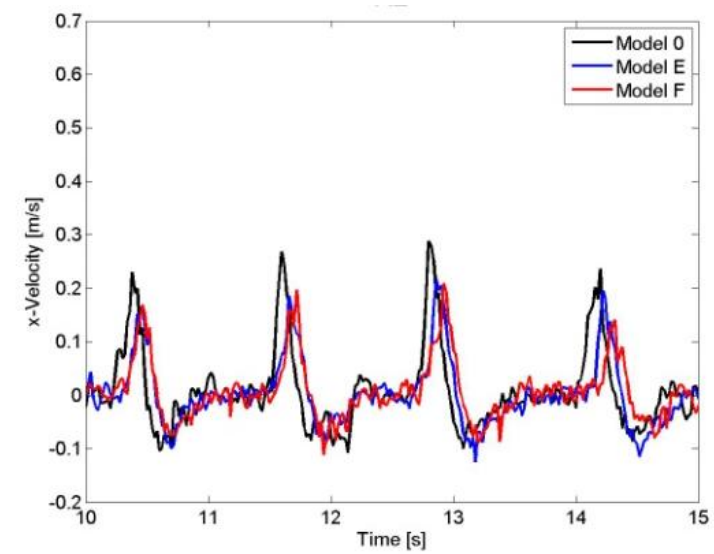

R2 cell

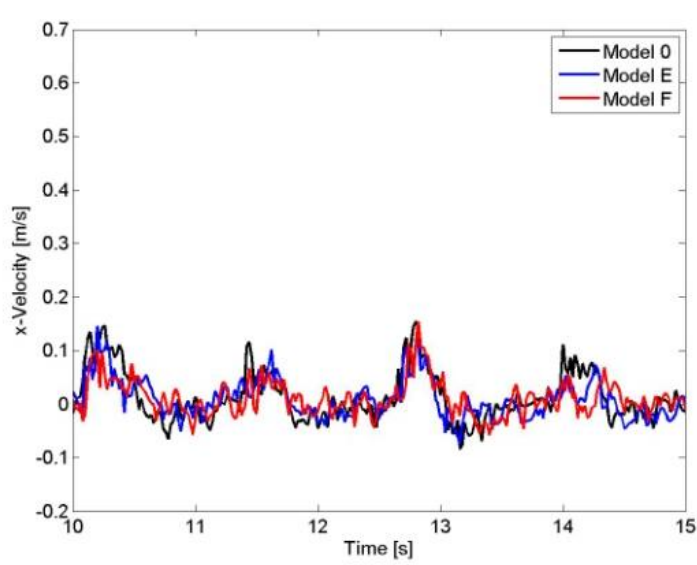

R3 cell

Figura 35 Velocidade longitudinal média na região sobre as células - Proa inclinada - Condição de onda 3 
De acordo com os resultados da Figura 34, o pico da elevação de superfície livre na célula $R 2$, ao centro do convés na região logo à frente da antepara, é menor nos modelo com a proa chanfrada do que no modelo em paralelepípedo. A mesma tendência é observada para a velocidade média longitudinal da água na mesma célula, onde o pico é maior no modelo 0 . A amplitude maior observada na região central é devida á junção do fluído que embarca pela frente e pelas laterais. A diferença nas laterais ou nas regiões internas avaliadas individualmente pode ser desprezível, mas se torna significativa na medida em que se somam e convergem na região central do convés. Os resultados apresentados na Figura 34 e na Figura 35 estão de acordo com aquele apresentado na Figura 29-(c), na qual se observa um maior impacto hidrodinâmico na antepara para o modelo tradicional,em forma de "caixote".

Os snapshots da simulação com o método de partículas, para os modelos 0 , $\mathrm{D}$ e $\mathrm{F}$, na condição de onda 8, são mostrados na Figura 36. Em $t=8,8$ segundos, o convés do modelo $D$ está completamente invadido por água. No entanto, para os modelo 0 e $\mathrm{F}$ é possível observar que ainda há uma pequena parcela do convés ainda "seca", na região central, logo à frente da antepara. Neste instante é possível observar também claramente as três frentes de ondas convergindo para a região central, as frentes resultantes das laterais e a frente da onda proveniente da proa. Em 8,96 segundos, a junção das frentes de coluna d'pagua ocorre antes para o modelo $D$ do que nos modelos 0 e $F$. Esse comportamento também é observado na Figura 28-(b), que contempla as séries temporais da força nas anteparas para a condição de onda 7 para os modelos com proa em cunha, nas qual o crescimento da curva do Modelo $\mathrm{D}$ ocorre antes do que para o modelo 0 . Em $t=9,12$ segundos se forma uma coluna d'água de forma triangular na frente da região central da antepara fruto da junção das três colunas d'água incidentes. Os snapshots de $t=9,12 \mathrm{e} t=$ 9,28 segundos mostram a fase de drenagem do fenômeno de green water, com o escoamento da água do convés para o mar. 


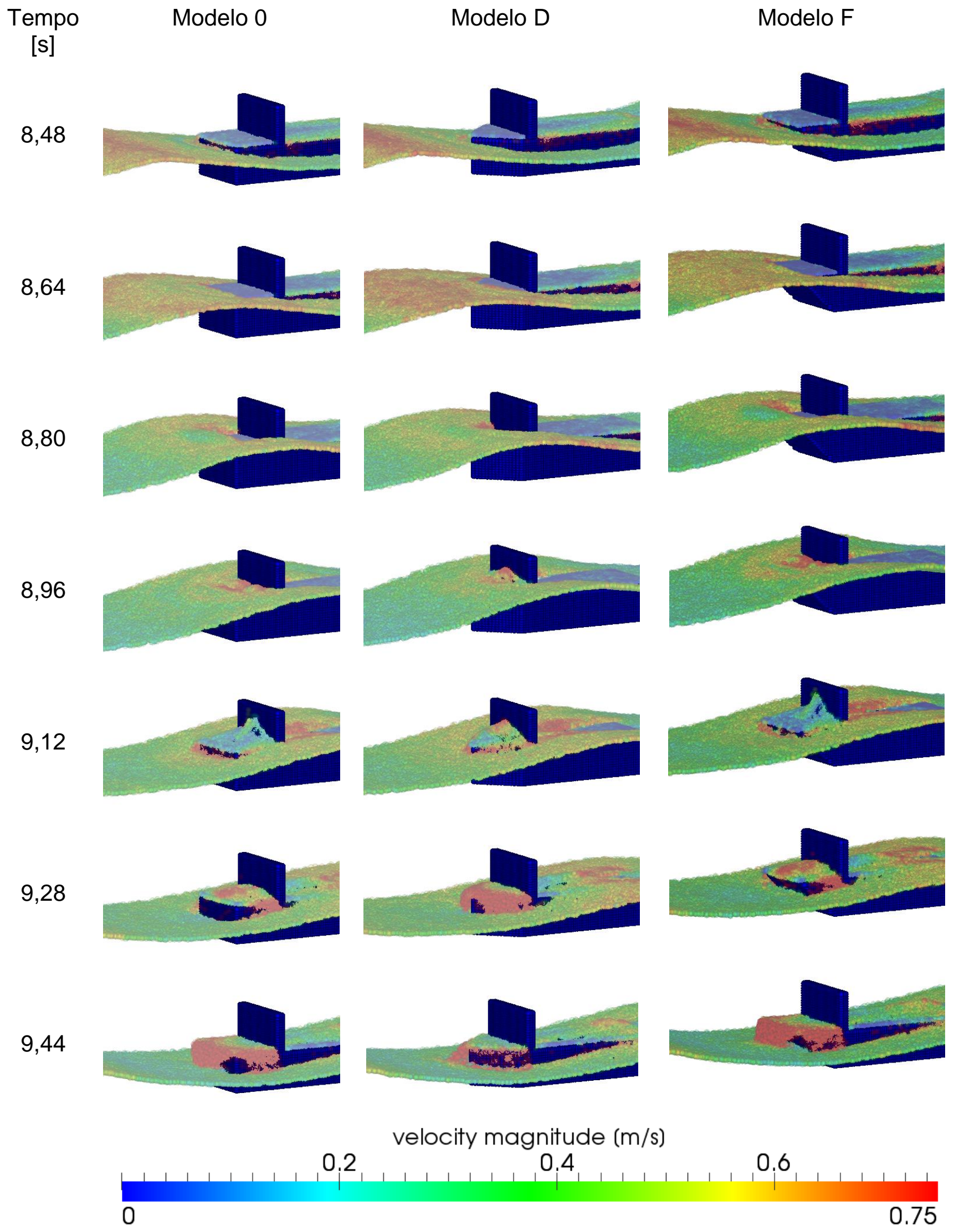

Figura 36 Snapshots da simulação numérica com o método de partículas - Green water com diferentes geometrias de proa 


\section{GREEN WATER PARA DIFERENTES ÂNGULOS DE APROAMENTO}

As plataformas do tipo FPSO apresentam geralmente duas formas de amarração, em turret ou spread mooring. Quando amarrada em turret é permitida uma maior rotação da plataforma, de modo que a mesma possa se alinhar a condição climática mais severa. Para este caso a plataforma geralmente opera com mar de proa, o que fez grande parte da literatura se ocupar apenas desta situação, como Faltinsen et al. (2002) e Shibata et al. (2009). No entanto, em áreas nas quais a condição de mar não é tão bem definida ou quando a amarração é da forma spread mooring, o movimento da plataforma é limitado e podem ocorrer situações perigosas como mar de través ou ondas oblíquas.

São poucos os estudos que se ocupam da análise de green water para diferentes ângulos de aproamento. Xiao et al. (2014) baseia seu estudo nas condições encontradas na Baía de Bohai na China, onde ocorre exploração de petróleo em águas rasas e as plataformas se encontram sujeitas a ondas oblíquas. Também na Bacia de Santos as estruturas podem operar com ondas oblíquas, devido a uma condição de mar bi-direcional associado ao vento de leste e ao sweel do sul (Vogel, et al., 2010). Silva e Rossi (2014) modelam o fenômeno de green water para uma FPSO com mar de través na Bacia de Santos por meio de um software comercial de CFD.

Neste trabalho o fenômeno de green water é estudado empregando-se um modelo em escala reduzida em um tanque de provas numérico. Simulações com ângulos de aproamento e condições de onda diferentes são realizadas. $O$ desafio adicional decorrente disso é um número muito maior de partículas necessárias para modelar o tanque de provas numérico do que os tanques de provas numéricos empregados em estudos anteriores, para a condição de mar de proa. Para isso, uma versão do simulador para memória distribuída baseado em uma técnica de processamento paralelo utilizando partição dinâmica do domínio computacional e é adotado neste estudo. O MPS, combinado com uma técnica diferente de paralelização, também foi usado por Zhang et al. (2013) para estudar o fenômeno 
de green water, no entanto, com uma ordem inferior em quantidade de partículas, na casa das centenas de milhares.

Neste trabalho, tanto o modelo fixo quanto um modelo flutuante livre nos graus de liberdade de heave, pitch e roll são considerados. O green water é avaliado nas mesmas nove condições de onda baseadas em Lee et al. (2012) e já utilizadas nas análises anteriores e em cinco diferentes ângulos de aproamento. Os carregamentos relativos ao green water são avaliados pelas forças longitudinal e transversal em duas estruturas cilíndricas posicionadas sobre o convés. Também são analisados os movimentos da plataforma flutuante para os diferentes ângulos de aproamento.

\subsection{Modelagem}

O modelo empregado para a análise de green water sob diferentes ângulos de aproamento tem formato de caixa e apresenta duas estruturas cilíndricas sob o convés, que serão chamadas de colunas no restante deste trabalho. A geometria e as dimensões principais do modelo são apresentadas na Figura 37.

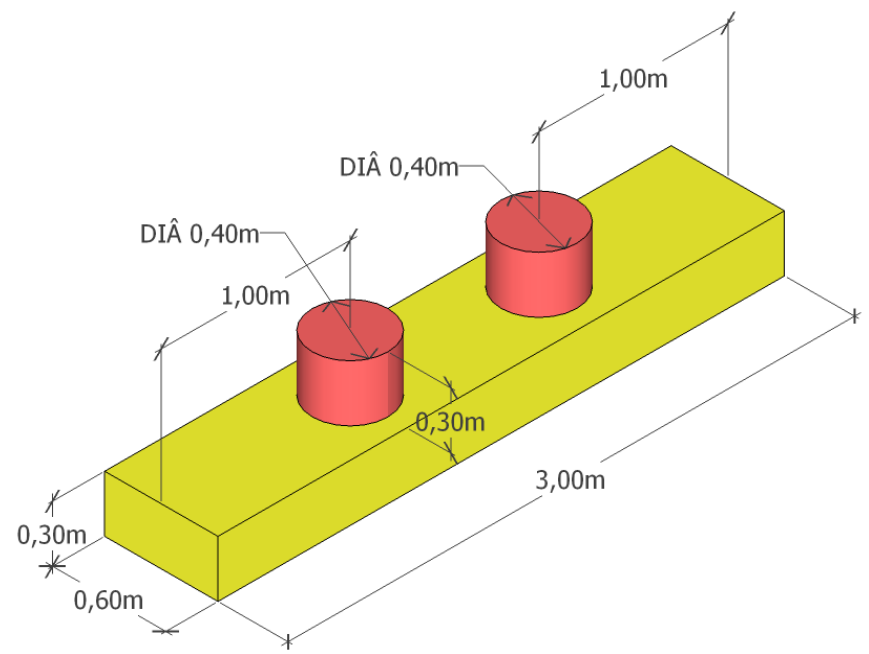

Figura 37 Dimensões do modelo

Nas simulações realizadas considerou-se o modelo fixo assim como o modelo flutuante. O modelo flutuante é livre nos graus de liberdade de heave, pitch e roll. $\mathrm{Na}$ rotina de sólido livre do método de partículas a massa e os momentos de inércia são dados de entrada e apresentados na Tabela 7. 
Tabela 7 Propriedades do modelo flutuante

Massa

$$
\begin{array}{ll}
\text { Momento de inércia de pitch }\left(\mathrm{I}_{\mathrm{yy}}\right) & 44,723 \mathrm{~kg} \cdot \mathrm{m}^{2} \\
\text { Momento de inércia de roll }\left(\mathrm{I}_{\mathrm{xx}}\right) & 8,606 \mathrm{~kg} \cdot \mathrm{m}^{2}
\end{array}
$$

Os parâmetros numéricos de simulação são apresentados pela Tabela 8 .

\begin{tabular}{lc}
\multicolumn{2}{l}{ Tabela 8 Parâmetros numéricos de simulação } \\
\hline Distância entre partículas & $0,02 \mathrm{~m}$ \\
Incremento de tempo & $0,001 \mathrm{~s}$ \\
Tempo de impressão & $0,05 \mathrm{~s}$ \\
Tempo de simulação & $20 \mathrm{~s}$ \\
Nós do cluster & 10 \\
Constante suavizadora de & 0,75 \\
pressão
\end{tabular}

Para a análise do fenômeno de green water são avaliadas 3 diferentes condições de aproamento do modelo: em mar de proa $\left(\alpha=0^{\circ}\right)$, mar de través $\left(\alpha=90^{\circ}\right)$ e mar de "bochecha" $\left(\alpha=45^{\circ}\right)$, onde $\alpha$ é o ângulo entre o eixo $x$ e a direção de propagação da onda $x$ '. No sistema de coordenadas adotado o eixo $x$ é alinhado ao eixo longitudinal do modelo enquanto o eixo $y$ é alinhado ao eixo transversal do modelo. Optou-se por empregar tanques de prova numéricos com largura de três vezes a projeção do modelo na direção transversal à onda. Sendo assim, os modelos para cada uma das situações apresenta número distinto de partículas. A configuração e dimensões principais dos tanques são apresentadas na Figura 38. 


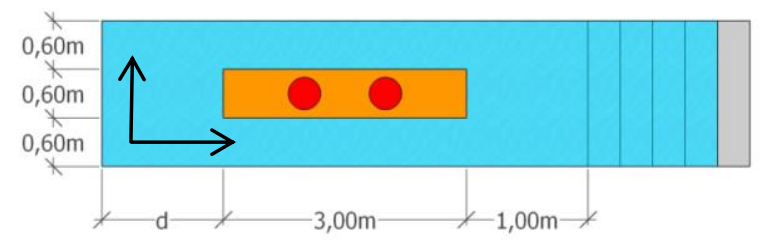

(a) $\alpha=0^{\circ}$

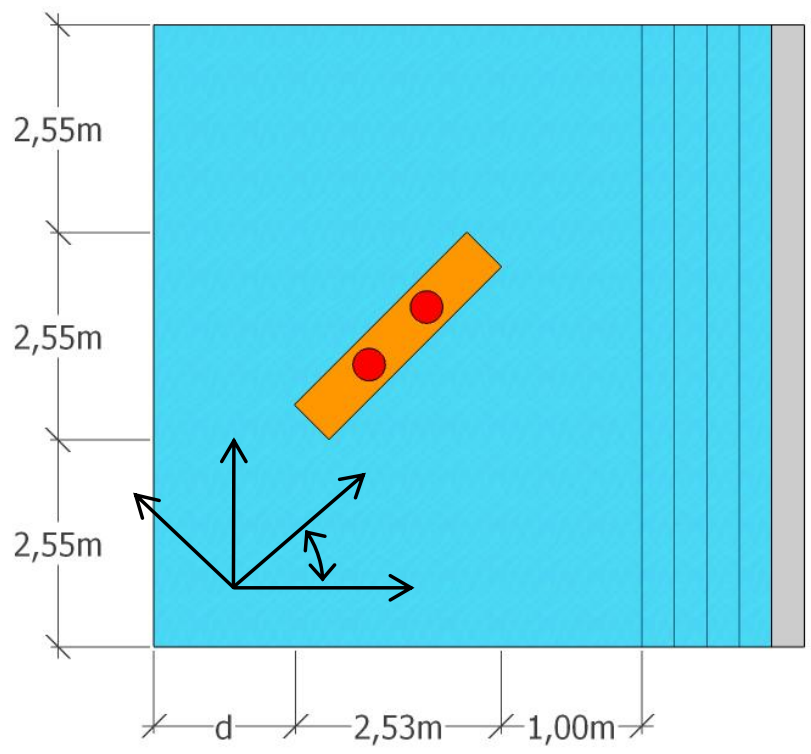

(b) $\alpha=45^{\circ}$

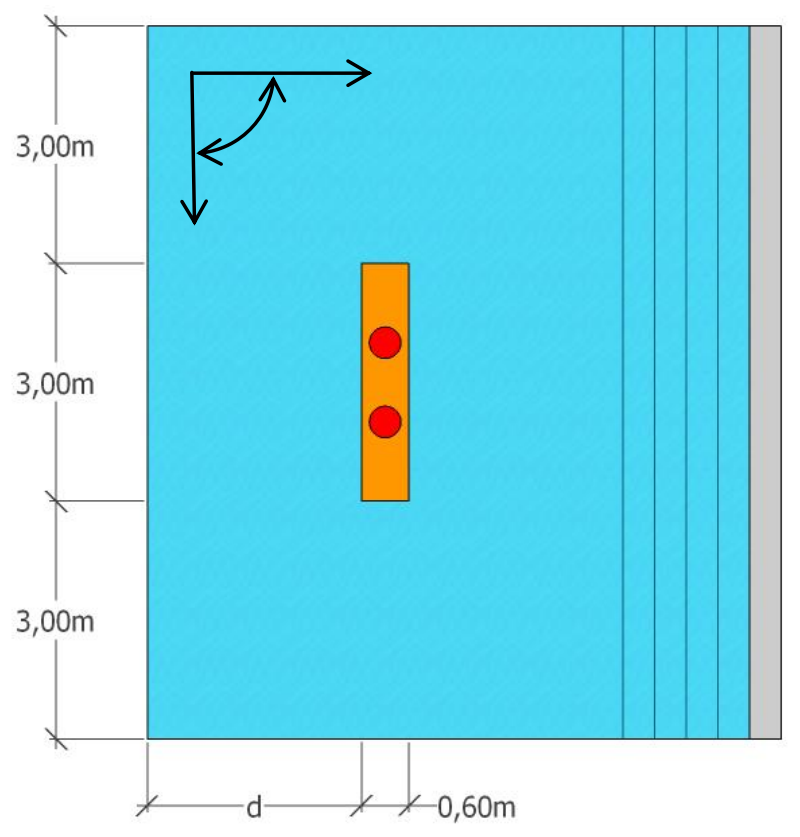

(c) $\alpha=90^{\circ}$

Figura 38 Vista superior dos tanques de provas numéricos

A quantidade partículas e o tempo médio de processamento de cada caso são apresentados na Tabela 9. Em todas as simulações foram empregados 10 nós do cluster computacional do Tanque de Provas Numérico (TPN-USP). Cada nó do cluster possui 20 processadores AMD Shanghai de $2,66 \mathrm{GHz}$ com memória compartilhada de 128GB.

Tabela 9 Dados dos tanques de prova numéricos

\begin{tabular}{cccc}
\hline $\begin{array}{c}\text { Ângulo de } \\
\text { aproamento }(\alpha)\end{array}$ & Largura do tanque & $\begin{array}{c}\text { Quantidade } \\
\text { aproximada de } \\
\text { partículas }\end{array}$ & $\begin{array}{c}\text { Tempo de } \\
\text { processamento } \\
\text { aproximado }\end{array}$ \\
\hline $0^{\circ}$ & $1,80 \mathrm{~m}$ & 1.600 .000 & $2 \mathrm{hrs}$ \\
$45^{\circ}$ & $7,64 \mathrm{~m}$ & 6.800 .000 & $10 \mathrm{hrs}$ \\
$90^{\circ}$ & $9,00 \mathrm{~m}$ & 8.000 .000 & $14 \mathrm{hrs}$ \\
\hline
\end{tabular}




\subsection{Resultados}

A análise de resultados é dividida em duas partes. A primeira consiste na análise do efeito do ângulo de aproamento no fenômeno de green water no modelo flutuante. A segunda é focada na comparação dos resultados empregando um modelo fixo e um modelo flutuante. Os resultados apresentados são baseados no esforços hidrodinâmicos na colunas posicionadas sobre o convés em termos da força resultante, componente longitudinal e componente transversal. Nas seções seguintes são apresentados os resultados para a condição de onda mais severa deste estudo, a onda 9 , com $\lambda=375 \mathrm{~cm}$ e $A=11,25 \mathrm{~cm}$.

\subsubsection{Resultados: análise do ângulo de aproamento}

Os resultados para o movimento do corpo flutuante na condição de onda 9 são apresentados na Figura 39. Observa-se que o maior movimento de heave ocorre para a condição de mar de través $\left(\alpha=90^{\circ}\right)$, chegando a ser cerca de 3 vezes a amplitude do movimento para onda de proa e ondas de bochecha. Conforme mostra a figura, não há pitch para o caso de onda de través $\left(\alpha=90^{\circ}\right)$ e não há roll para onda de proa $\left(\alpha=0^{\circ}\right)$ porque nesta condição, as frentes de ondas são paralelas, respectivamente, às direções longitudinal e transversal do modelo. O movimento de roll é crítico para mar de través. A combinação entre os movimento de pitch e de roll para o caso de mar de bochecha $\left(\alpha=45^{\circ}\right)$ pode levar a grandes movimentos relativos da proa e da popa em relação á superfície livre e afetar o fenômeno de green water. 


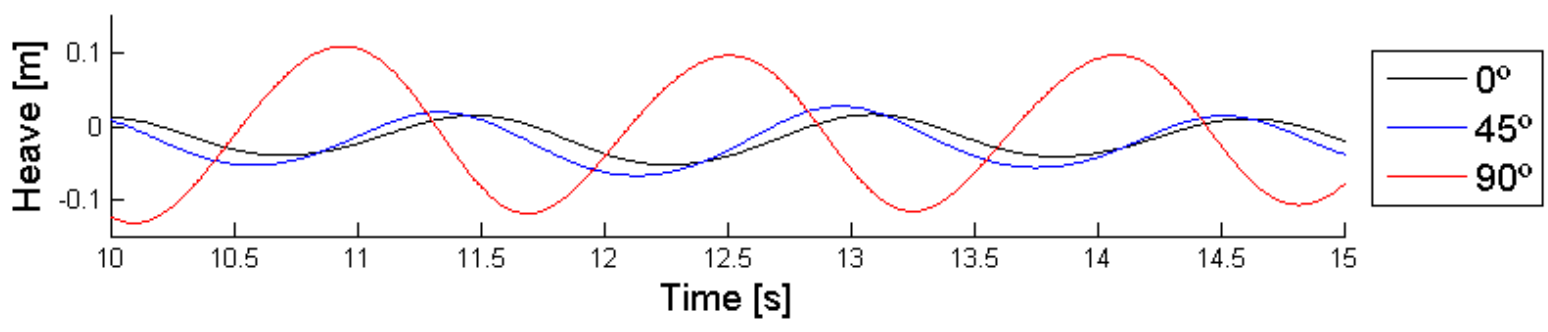

(a) Heave

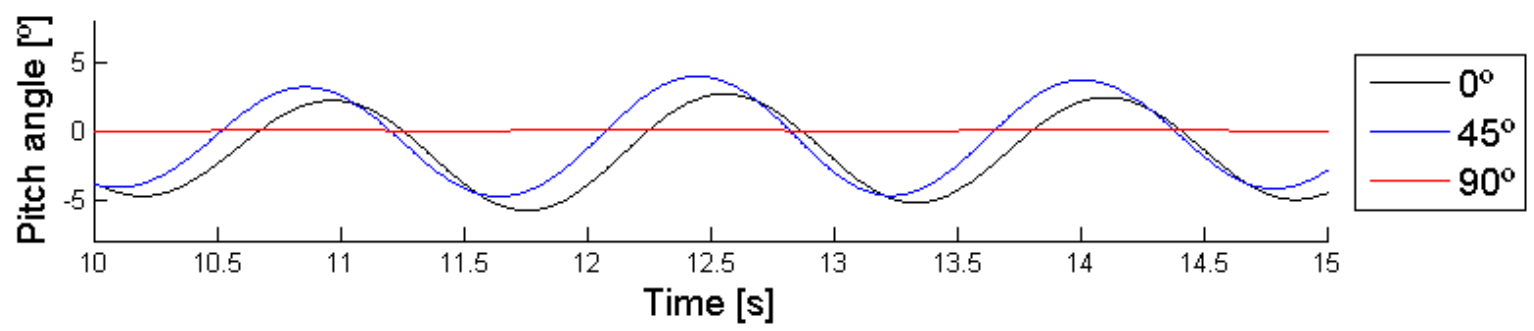

(b) Pitch

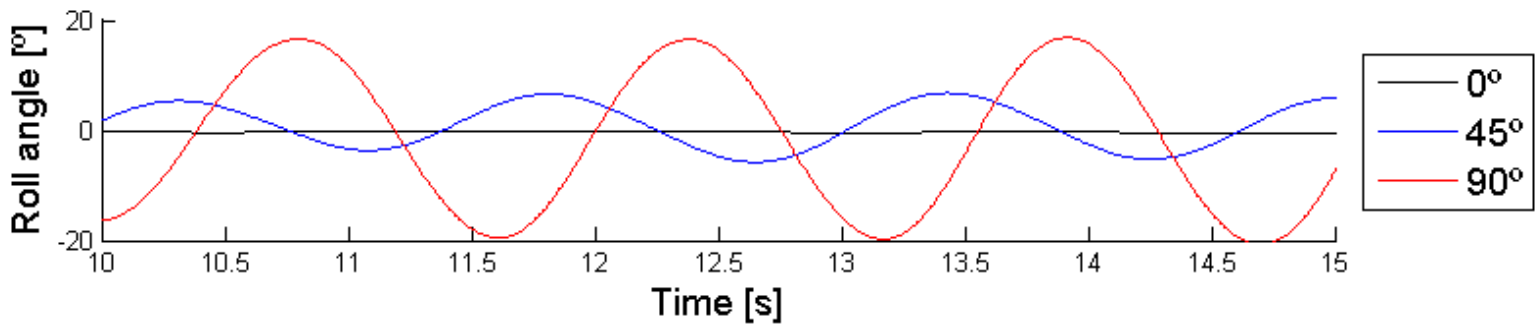

(c) Roll

Figura 39 Movimento da estrutura flutuante - onda 9

$\mathrm{Na}$ Figura 40 são apresentados snapshots da simulação numérica empregando o método MPS. Na sequência de snapshots a escala de cor do fluído representa a magnitude da velocidade, com as regiões em vermelho indicando maiores velocidades e a região em azul as menores velocidades. Nas imagens é possível observar o movimento da estrutura flutuante assim como a difração no casco e nas colunas e o fenômeno de impacto hidrodinâmico nas colunas. 
(a) $5,71 \mathrm{~s}$

(b) $5,91 \mathrm{~s}$
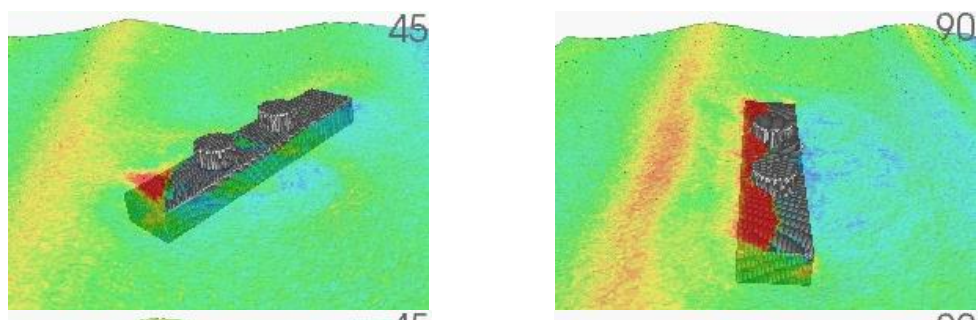

(c) $6,12 \mathrm{~s}$
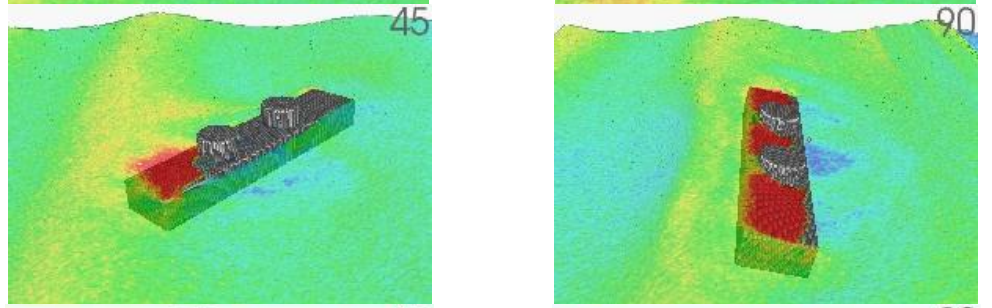

(d) $6,27 \mathrm{~s}$
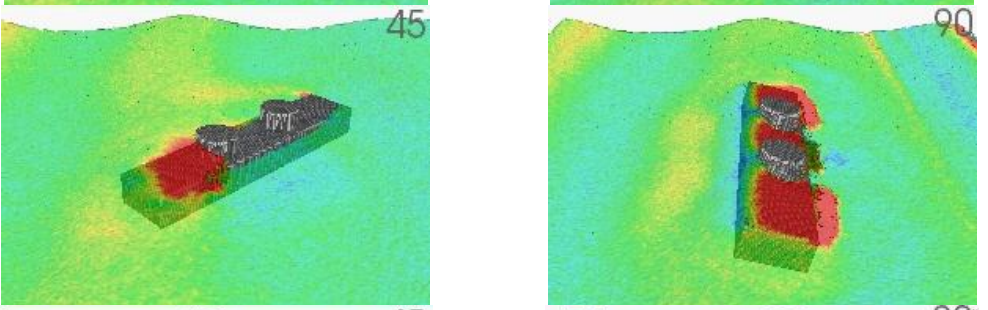

(e) $6,42 \mathrm{~s}$
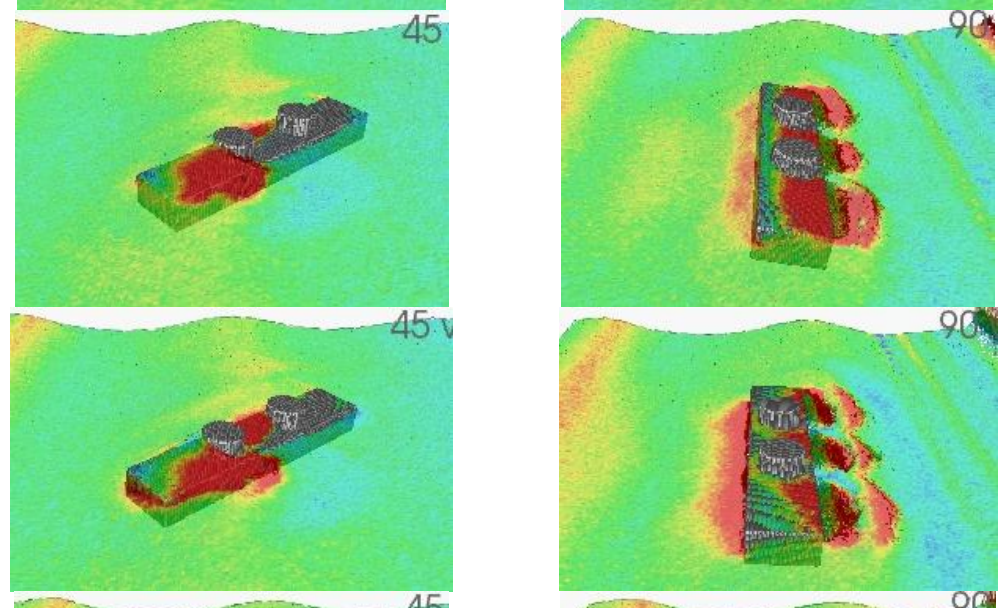

(f) $6,57 \mathrm{~s}$
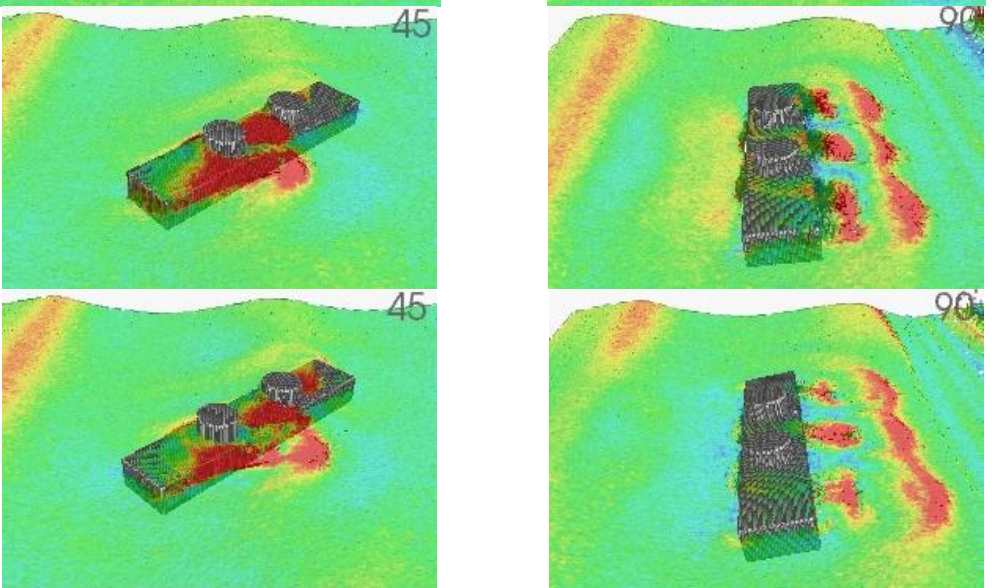

Fluid velocity magnitude $(\mathrm{m} / \mathrm{s})$

(g) $6,72 \mathrm{~s}$

0.4

0.8

1.2

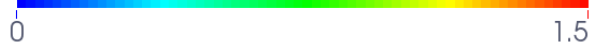

Figura 40 Snapshots da simulação numérica $-\alpha=45^{\circ}$ (esquerda) $\alpha=90^{\circ}$ (direita) - onda 9 
A seguir são analisadas as forças de impacto hidrodinâmico nas colunas posicionadas sobre o convés. A Figura 41 apresenta a componente longitudinal da força de impacto hidrodinâmico nas duas colunas para a condição de mar 9 .

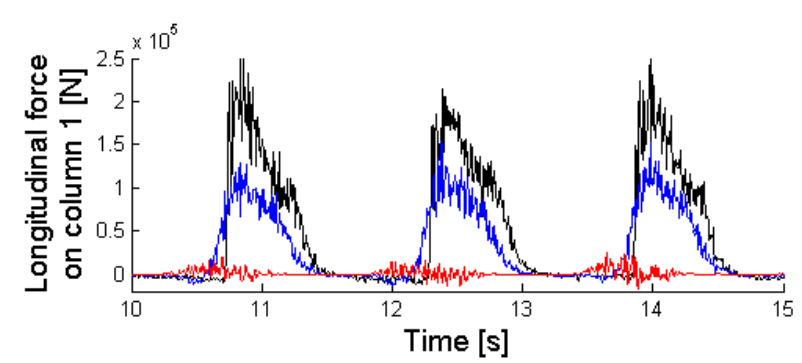

- alpha: $0^{\circ}$ - floating model
alpha: $45^{\circ}$ - floating model
alpha: $90^{\circ}$ - floating model

(a) Coluna 1

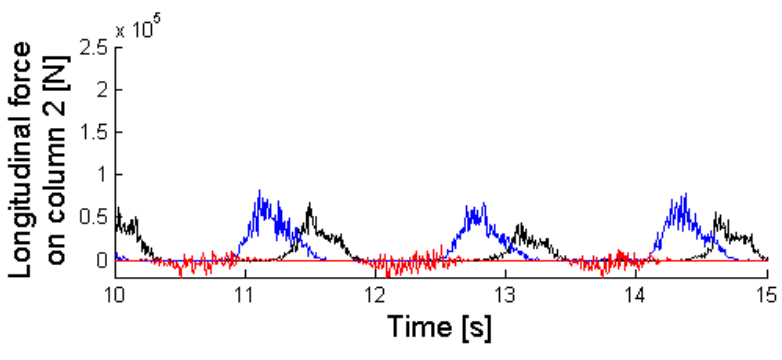

alpha: $0^{\circ}$ - floating model alpha: $45^{\circ}$ - floating model alpha: $90^{\circ}$ - floating model

(b) Coluna 2

Figura 41 Componente longitudinal da força nas anteparas - onda 9

Observa-se que para o mar de proa e mar de bochecha a força longitudinal que atua na primeira coluna é significativamente maior que a força que atua na segunda coluna. De acordo com os snapshots da Figura 40-(a) a Figura 40-(c), para o mar de bochecha o movimento relativo da proa em relação à crista da onda favorece a formação de uma coluna de água maior que embarca no convés, intensificando os carregamentos resultantes do fenômeno de green water. Para esta situação, tal movimento relativo não é observado para a região da segunda coluna, que registra impacto menor.

No caso da onda de bochecha há também uma contribuição da difração da onda incidente, que forma duas frentes de onda a partir da separação da coluna de água na primeira coluna, observadas pelas regiões de alta velocidade (em vermelho) na Figura 40-(c) e Figura 40-(d). Uma destas frentes de alta velocidade colide na segunda coluna e resulta numa pressão maior no mar de bochecha do que para o mar de proa para a segunda coluna. Por outro lado, a componente longitudinal da força de impacto do mar de través é desprezível, pois nesta condição os esforças na direção longitudinal do flutuante são simétricos e cancelam. 


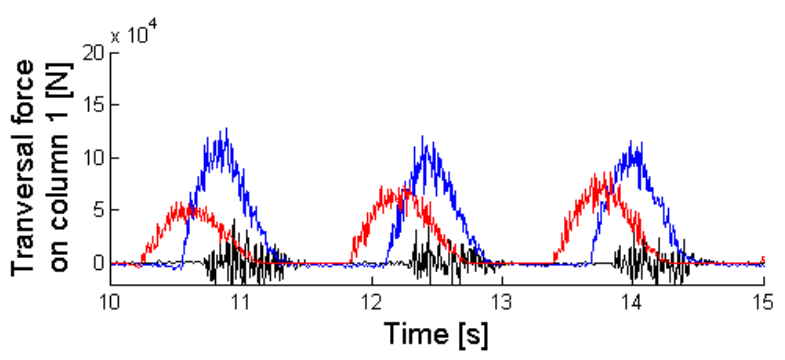

- alpha: $0^{\circ}$ - floating model
alpha: $45^{\circ}$ - floating model
alpha: $90^{\circ}$ - floating model

(a) Coluna 1
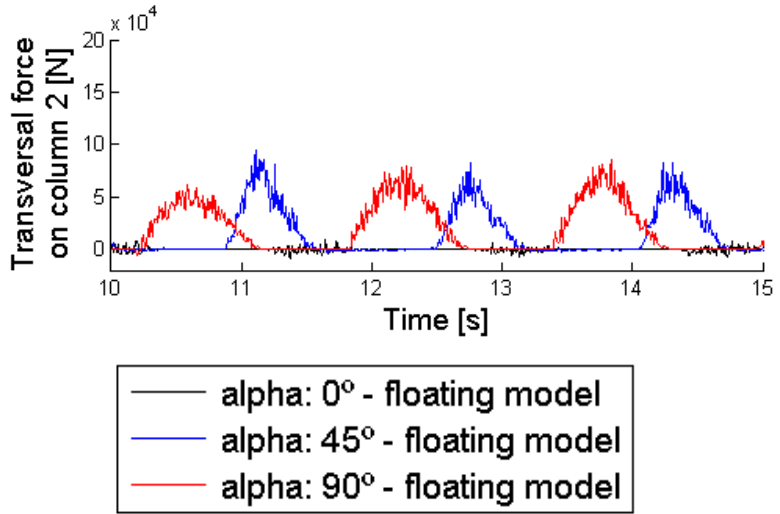

(b) Coluna 2

Figura 42 Componente transversal da força nas anteparas - onda 9

De forma análoga, a componente transversal da força de impacto hidrodinâmico para o mar de proa é desprezível, conforme mostra a Figura 42, que apresentada a componente transversal da força de impacto hidrodinâmicos para a condição de mar 9. Observa-se que a componente transversal, tanto na coluna 1 quanto na coluna 2, é maior para a condição de mar de bochecha do que para o mar de través. Pelos snapshots da simulação numérica apresentadas na Figura 40, o movimento de roll para o mar de través faz com que as colunas sobre o convés se movimentem na mesma direção da propagação da coluna d'água embarcada, ajudando a mitigar o impacto nas estruturas. A componente transversal possui magnitude semelhante nas duas colunas para mar de bochecha.

Por fim, a Figura 43 mostra a força resultante nas duas colunas para a condição de mar mais severa avalida.
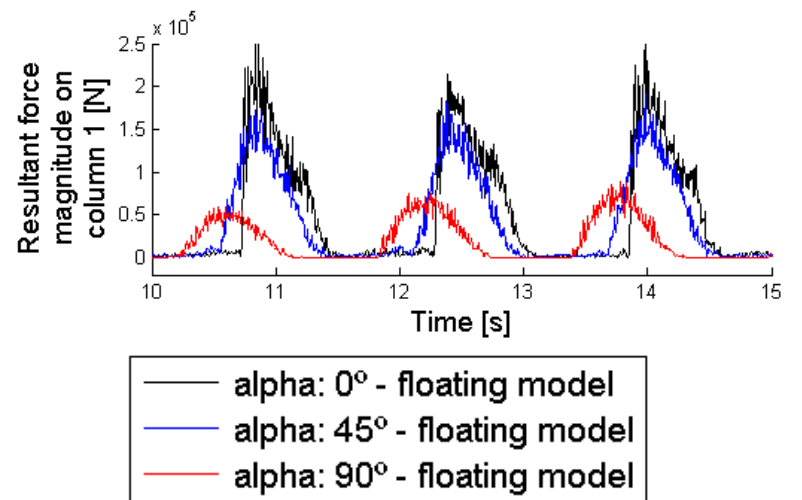

(a) Coluna 1
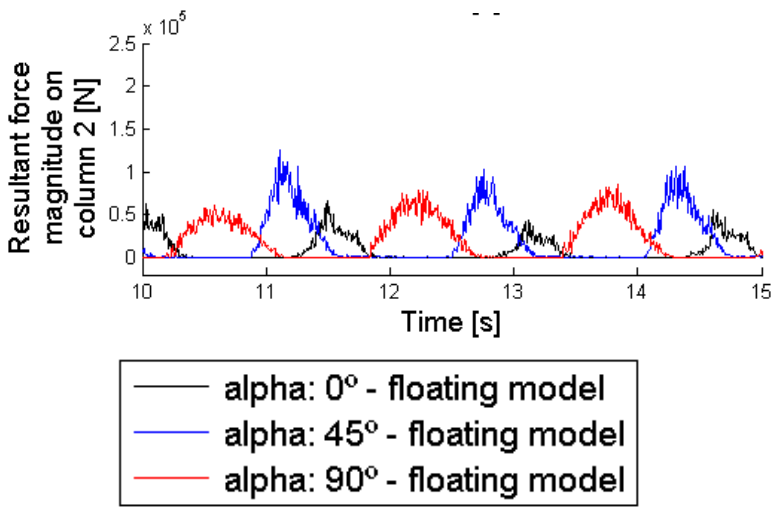

(b) Coluna 2

Figura 43 Força resultante nas anteparas - onda 9

Na coluna 1 o maior impacto hidrodinâmico ocorre para a condição de mar de proa, devido ao impacto da coluna de água que embarca pela proa e se propaga ao longo do convés, ganhando velocidade. No entanto, com a contribuição da 
componente transversal da força de impacto, a magnitude da força de impacto hidrodinâmico na primeira coluna para mar de bochecha se aproxima daquela obtida para o mar de proa. Para a segunda coluna, a situação mais crítica observada ocorre para o mar de bochecha, para o qual o pico da força de impacto chega a ser o dobro daquele observado tanto para o mar de través quanto para o mar de proa.

\subsubsection{Resultados: modelo fixo e modelo flutuante}

A segunda etapa da apresentação dos resultados é focada na comparação entre as forças obtidas para o modelo fixo e o modelo flutuante nos graus de liberdade de heave, pitch e roll. São apresentadas aqui apenas as situações nas quais a mobilidade do modelo flutuante afetam mais significativamente as forças resultantes.

Para o mar de través, a componente longitudinal é desprezível tanto para a abordagem com modelo fixo quanto a abordagem com modelo flutuante. Já para o mar de proa e o mar de bochecha observa-se que as forças registradas na primeira coluna são significativamente maiores para o modelo flutuante. O motivo deste comportamento, a partir da observação do escoamento, ocorre devido ao movimento relativo entre a proa da embarcação, devido ao movimento de pitch, e as ondas. Este movimento tem como resultado a formação de uma coluna d'água maior no convés para o modelo flutuante. A partir de uma analogia com o fenômeno de dambreak, a altura da coluna d'água é proporcional ao quadrado da velocidade de propagação da frente da coluna de água pelo convés que eventualmente se choca com a primeira coluna, produzindo maiores carregamentos devido ao green water. Em outras palavras, para o mar de bochecha, é importante levar em conta o movimento relativo entre o flutuante e a onda na determinação dos esforços longitudinais devido ao green water.

A Figura 44 apresenta a componente longitudinal da força de impacto para a coluna 1, nas condições de mar de proa e mar de bochecha. 


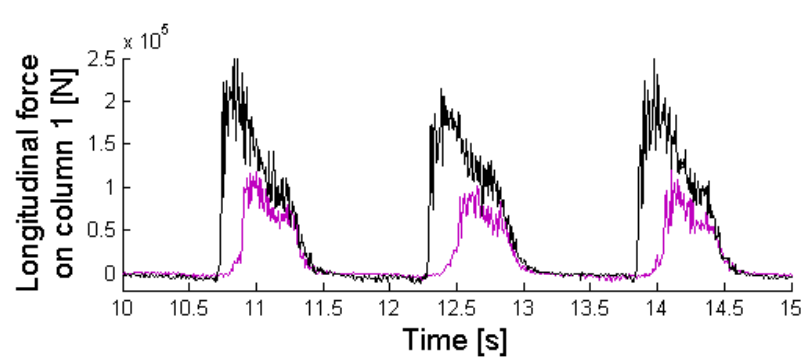

alpha: $0^{\circ}$ - fixed model alpha: $0^{\circ}$ - floating model

(a) Coluna $1-\alpha=0^{\circ}$

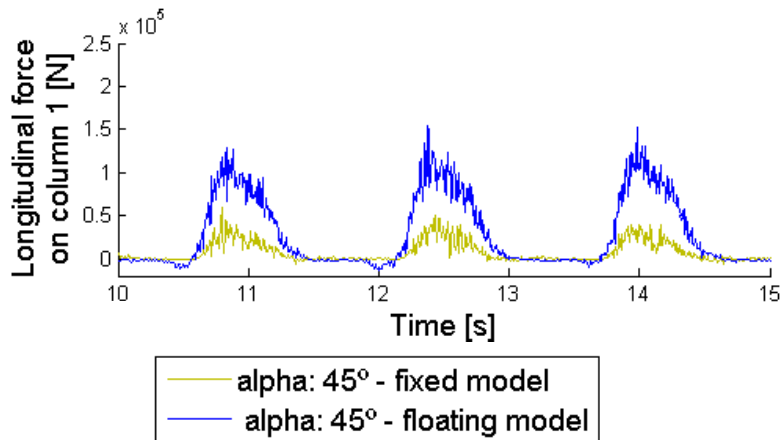

(a) Coluna $1-\alpha=45^{\circ}$

Figura 44 Componente longitudinal da força nas anteparas - onda 9

Para o mar de proa, a componente transversal é desprezível tanto para o modelo flutuante quanto para o modelo fixo. No caso do mar de bochecha não se observa diferença significativa na componente transversal obtida tanto para o modelo fixo quanto o modelo flutuante. Desta forma, apenas para o caso do mar de través se observa uma diferença significativa entre os resultados obtidos para o modelo fixo e o modelo flutuante. A componente transversal para as duas coluna em mar de través é apresentada na Figura 45.

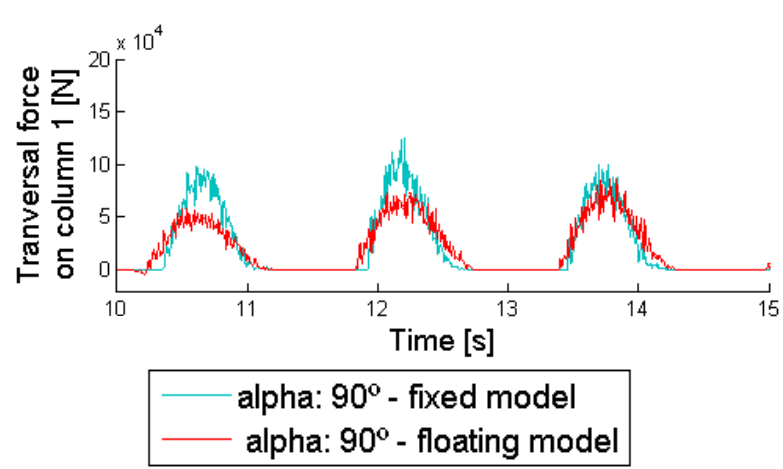

(a) Coluna 1
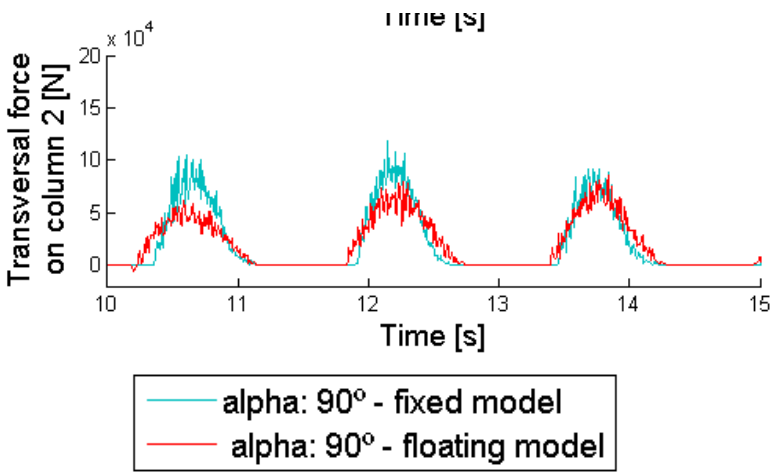

(b) Coluna 2

Figura 45 Componente transversal da força nas anteparas - onda $9-\alpha=90^{\circ}$

Diferentemente da componente longitudinal para mar de proa e mar de bochecha, onde o resultado obtido para o modelo fixo é subestimado, a componente transversal é superestimada pelo modelo fixo para o mar de través. Esta diferença pode ser explicada pelo movimento relativo entre o convés e a frente da coluna de água embarcada devido ao movimento de roll.

\subsection{Considerações finais}

Durante o projeto de estruturas offshore, como plataformas do tipo FLNG e FPSO, a estratégia mais indicada na investigação dos diversos fenômenos hidrodinâmicos envolvidos na operação dos corpos flutuantes é a combinação de 
diversas ferramentas, envolvendo estudos analíticos, experimentais e numéricos $(\mathrm{Ni}$, et al., 2011). Em relação aos fenômenos envolvendo violentos impactos hidrodinâmicos, nos quais uma análise completa levando em conta inclusive importantes efeitos de natureza não linear, os métodos numéricos baseado em partículas, entre eles o método MPS, surgem como alternativas flexíveis e adequadas.

Neste trabalho são apresentados resultados de dois casos de validação, no qual o simulador baseado no método MPS mostrou boa aderência aos resultados experimentais de Lee et al. (2012) para green water e Kleefsman et al. (2005a) para dam-break, apesar do uso de um modelo com resolução grosseira. $O$ comportamento do fluído obtido numericamente é muito próximo ao experimental e o registro de pressão numérico oscila em torno da curva experimental, apresentando resultados mais próximos na região onde ocorre o impacto hidrodinâmico de maneira mais intensa.

A segunda etapa mostra uma aplicação do software na análise do efeito da proa sobre o fenômeno de green water resultante do impacto de ondas de proa. Os resultados numéricos mostram que, a aplicação de perfis hidrodinâmicos como as cunhas em $\mathrm{V}$, resultam em um ligeiro aumento do esforço de impacto hidrodinâmico nas condições de onda intermediárias, dentre aquelas simuladas. Esse resultado se dá devido ao ingresso de água pelas laterais do convés de forma antecipada e acentuada nos modelos de proa parabólica e em cunha. Já para as proas chanfradas, nas ondas simuladas nas quais a altura da superfície livre da onda resulta em embarque moderado de água, o volume de água embarcado e a força de impacto na antepara foram maiores na geometria do casco tradicional, em caixote.

$\mathrm{Na}$ terceira etapa é estudado o fenômeno de green water para um modelo flutuante em diferentes condições de aproamento. As simulações apenas foram possíveis com o emprego de uma versão do simulador paralelizado com base na partição dinâmica do domínio, que permite lidar casos com dezenas de milhões de partículas. Explorando as vantagens da simulação por método de partículas, diversos aspectos não lineares do fenômeno de green water envolvendo difração, interação fluído-estrutura, grandes deformações, fragmentação e junção de superfície livre foram reproduzidas. A desvantagem da abordagem numérica por 
CFD com a modelagem completa do escoamento ao redor dos modelos está no alto custo computacional. No entanto, a utilização do simulador paralelizado permite a simulação de modelo com dezenas de milhões de partículas em um intervalo de horas, o que torna o simulador baseado no MPS uma ferramenta de aplicação prática a problemas de engenharia.

O caso da simulação para diferentes ângulos de aproamento se mostra interessante no contexto da exploração de petróleo no Pré-Sal da Bacia de Santos por plataformas FPSO. A utilização de amarração do tipo spread mooring e o estado de mar bi-direcional podem levar a operação da estrutura flutuante sob ondas oblíquas. Os resultados apresentados neste trabalho mostraram que para a condição de mar de bochecha os carregamentos devido ao green water nas estruturas posicionadas próxima à popa da embarcação (coluna 2) são maiores do que para o mar de proa e inclusive o mar de través. Para as estruturas posicionadas próximas a proa (coluna 1), os carregamentos devido ao green water são perigosos para mar de proa e mar de bochecha devido ao movimento relativo da embarcação.

A comparação entre os resultados obtidos para os modelos flutuantes e os modelos fixos mostrou que a abordagem mais simples, com emprego de modelos fixos e desconsiderando a interação fluído-estrutura, pode apresentar diferenças significativas para certas situações. Para o mar de proa a abordagem com modelo fixo subestima os carregamentos devido ao green water nas estruturas próximas a proa. Por outro lado, para o mar de través, os carregamentos são superestimados pelo mesmo modelo fixo. Sendo assim, é importante levar em conta o movimento relativo entre o flutuante e a onda na determinação dos esforços longitudinais devido ao green water. 


\section{WAVE RUNUP NAS COLUNAS DE PLATAFORMA SEMI- SUBMERSÍVEL}

\subsection{Introdução}

Plataformas do tipo semi-submersível são comumente utilizadas na exploração de petróleo em águas profundas e ultra-profundas, como das reservas do Pré-Sal brasileiro. Essas estruturas operam sobre a influência de agentes climáticos, como os carregamentos causados por ondas, ventos e correntes. $O$ foco deste tópico é a investigação das forças de impacto nas colunas de plataforams semi-submersíveis devido a ondas de grande amplitude relacionadas a condições climáticas severas.

Mais especificamente, neste tópico, é analisado o fenômeno de runup que ocorre após o impacto de ondas nas estruturas transversais das plataformas offshore. O runup ocorre quando há a projeção de fluído no sentido transversal ao escoamento e paralelo à estrutura; e, por sua vez, pode resultar em embarque de água (green water) ou impacto em estruturas do convés inferior de plataformas do tipo semi-submersível (wave-in-deck impact). Ambos os fenômenos citados impõem grande carregamentos hidrodinâmicos para os quais as estruturas offshore geralmente não são projetadas.

Tradicionalmente, a resposta de plataformas sobre a ação de ondas de pequena amplitude é calculada por meio de métodos analíticos, os quais proporcionam resultados adequados para fenômenos com características predominantemente lineares. No entanto, para ondas de grandes amplitudes, pode ocorrer impacto hidrodinâmico e as análises se tornam complexas. Nestas situações, os métodos numéricos se tornam as ferramentas mais apropriadas para auxiliar nas etapas preliminares do projeto estrutural.

Para modelar a complexa interação fluído-estrutura de um corpo flutuante em ondas, é adotada uma ferramenta numérica baseada no método de partículas MPS Koshizuka et al. (1995) e Koshizuka e Oka (1996). O MPS é um método de partículas para o escoamento incompressível e se destaca em relação aos métodos tradicionais na modelagem de fenômenos envolvendo grandes deformações de 
superfície livre, fragmentação e junção. O MPS já foi empregado com sucesso na análise de problemas de engenharia naval e offshore em Sueyoshi e Naito (2002a), Shibata et al. (2007), Shibata et al. (2009), Shibata et al. (2012) e Zhang et al. (2013).

No presente estudo a análise do fenômeno de runup é realizada por meio de um modelo em escala reduzida de 1:50 da seção de uma plataforma semisubmersível, com duas colunas alinhadas, baseado nos resultados experimentais e numéricos de Iwanowski et al. (2009). São analisadas três condições de ondas de grandes amplitudes cujo sentido de propagação fica no alinhamento das colunas. $O$ impacto de ondas é realizado em um tanque de provas numérico com um batedor do tipo flap no seu início e uma praia em forma de degraus com dissipadores passivos na outra extremidade. Assim como no estudo de green water da seção anterior, a primeira etapa consiste na calibração da onda incidente, onde se lida com o amortecimento numérico da onda propagada. A segunda etapa contempla a validação do método numérico, por meio da comparação com resultados experimentais para o impacto em modelo fixo. Por último, o tópico final consiste na análise do comportamento hidrodinâmico de uma estrutura flutuante nas mesmas condições de onda.

\subsection{Modelo e calibração de onda}

Neste estudo é empregado um modelo na escala de 1:50 baseado em Iwanowski et al. (2009). As dimensões para o modelo em escala real são apresentadas na Figura 46-(a). Para a validação é empregado apenas o modelo fixo e com a coluna de seção tranversal quadrada, assim como nos experimentos, conforme apresentado na Figura 46-(b). Na etapa subsequente, para a análise do comportamento hidrodinâmico de estrutura flutuante, é empragado o modelo flutuante e de coluna com seção quadrada circular mostrado em Figura 46-(c). 

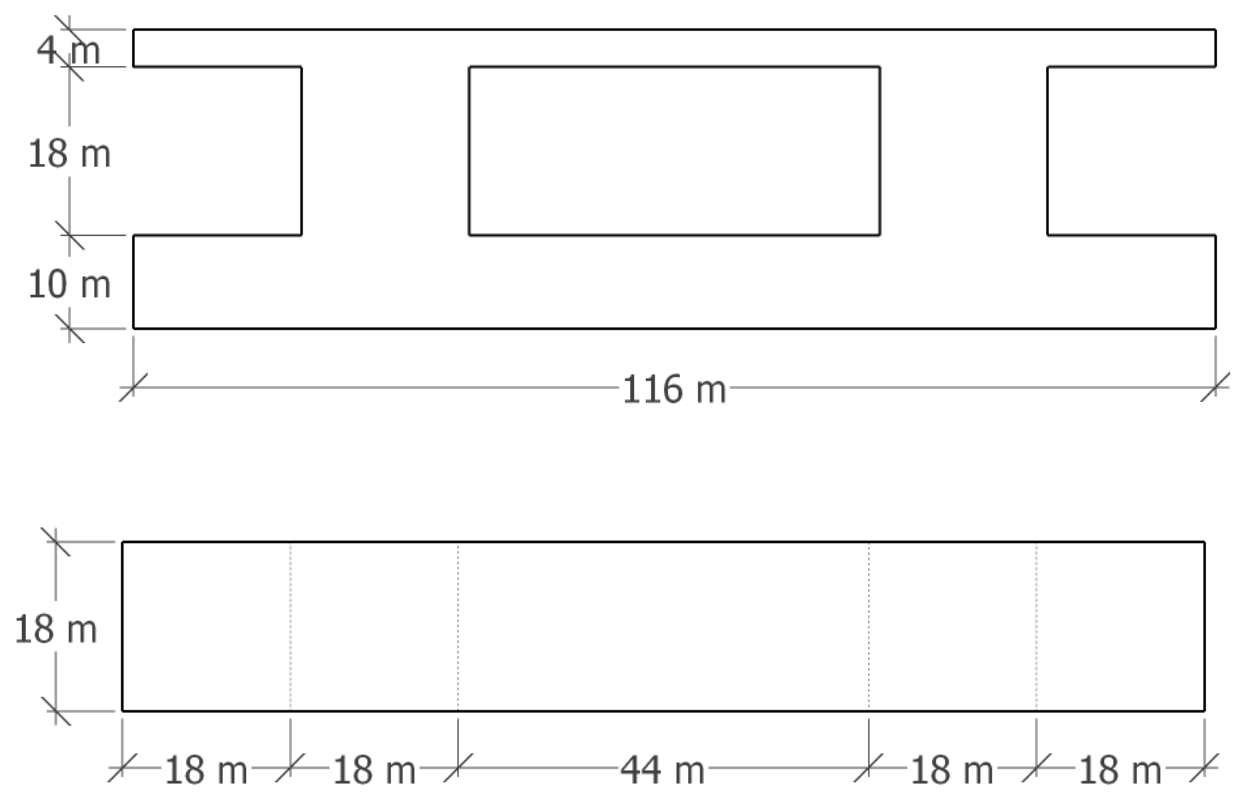

(a)

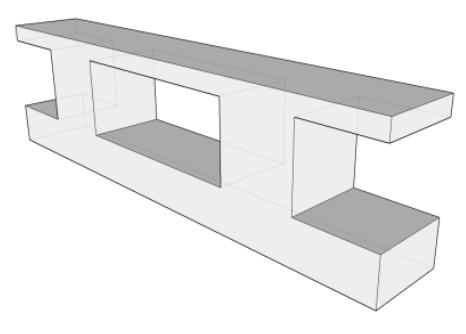

Modelo A (b)

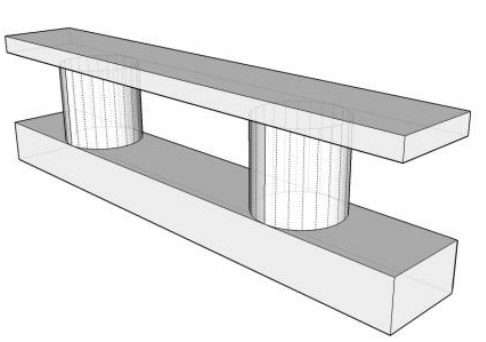

Modelo B (c)

Figura 46 Dimensões em escala real da seção de plataforma (a), modelo com seção trasnversal da coluna quadrada (b) e modelo com a seção transversal da coluna circular (c)

Neste estudo o fluído é tratado como invíscido e possui densidade de 1.000 $\mathrm{kg} / \mathrm{m}^{3}$. A massa e o momento de inércia para o modelo $\mathrm{B}$, com a coluna de seção transversal circular, são de 191,7 kg e 93,6 kg.m², respectivamente. Apenas para efeito de análise preliminar, o corpo flutuante é considerado com distribuição de massa homogênea e o centro de gravidade do mesmo corresponde ao seu centro geométrico.

O tanque de provas numérico é composto por um batedor de ondas do tipo flap, o qual é modelado como um sólido de movimento forçado.. Ao fim do tanque é posicionada uma praia em degraus com declividade de $30^{\circ}$ para o amortecimento 
das ondas longas e dissipadores passives em formato cúbico, para a dissipação de ondas curtas. O tanque de porvas numérico é nos mesmos moldes daquele empregado no estudo de green water da seção anterior e possui dimensões de 5 metros de comprimento até o início da praia e largura de 5 vezes a boca do modelo em escala reduzida, com 1 metro de profundidade.

O domínio computacional é dividido em uma resolução com distância entre partículas de 20 milímetros, que resulta em um modelo de cerca de 2 milhões de partículas. Nesta etapa não foi realizado estudo de convergência pelo modelo com a resolução mais grosseira partir de um número de partículas próximo ao limite de hardware do software com memória compartilhada. O hardware é composto por um CPU Nahalem de 2,8GHz com 8 núcleos de processamento e 24GB de memória RAM. Com um incremento de tempo de 0,001 segundos e 30 segundo de simulação, resulta-se em um tempo de processamento entre 4 e 5 dias. Por fim, o coeficiente de suavização de pressao a ser empregado na Equação de Poisson da pressão é de 0,075 .

As características das ondas incidentes são também baseadas em Iwanowski et al. (2009). São empregadas três diferentes condições de onda: uma onda curta $(\lambda / L \approx 1,0)$, uma onda média $(\lambda / L \approx 1,5)$ e uma onda longa $(\lambda / L \approx 2,0)$. Todas as condições de onda possuem a mesma declividade, em valor significativamente superior a aquele característico de onda lineares de pequena amplitude, como objetivo de simular condições climáticas severas.

No método partículas, ao menos na formulação aqui empregada, na há garantia total de conservação da energia mecânica ao longo da simulação. Desta forma, o amortecimento de origem numérica é significativo e a onda propagada apresente uma suave redução na amplitude ao longo do tanque. Desta forma, se faz necessária uma etapa preliminar de calibração da onda incidente que, além de determinar a amplitude e o período do movimento do batedor, determina também a posição ao longo do tanque na qual o modelo em escala reduzida deve ser psicionado. A distância entre o batedor e a proa do modelo em escala reduzida, assim como os demais parâmetros de onda e de movimento do batedor, são apresentados na Tabela 10. 
Tabela 10 Características das ondas e do movimiento do batedor

\begin{tabular}{|c|c|c|c|c|c|c|c|c|}
\hline \multirow{2}{*}{$\begin{array}{c}\text { Tipo do } \\
\text { modelo/ } \\
\text { escala } \\
\text { Tipo de } \\
\text { onda }\end{array}$} & \multicolumn{2}{|c|}{$\begin{array}{l}\text { 1:1 } \\
\text { (Iwanowski } \\
\text { et al., 2009) }\end{array}$} & \multicolumn{2}{|c|}{$\begin{array}{c}\text { 1:50 } \\
\text { (Iwanowski } \\
\text { et al., 2009) }\end{array}$} & \multicolumn{2}{|c|}{ 1:50 (MPS) } & $\begin{array}{l}\text { Amplitude } \\
\text { do batedor }\end{array}$ & $\begin{array}{c}\text { Distância } \\
\text { modelo/ } \\
\text { batedor }\end{array}$ \\
\hline & $H[\mathrm{~m}]$ & $T[\mathrm{~s}]$ & $H[\mathrm{~m}]$ & $T[\mathrm{~s}]$ & $H[\mathrm{~m}]$ & $T[\mathrm{~s}]$ & $\theta$ [rad] & [m] \\
\hline Cuta & 7,6 & 9,0 & 0,152 & 1,29 & 0,16 & 1,29 & 0,1 & 0,76 \\
\hline Média & 15,0 & 11,0 & 0,3 & 1,6 & 0,32 & 1,6 & 0,25 & 2,36 \\
\hline Longa & 20,5 & 13,0 & 0,4 & 1,89 & 0,41 & 1,89 & 0,4 & 2,96 \\
\hline
\end{tabular}

\subsection{Validação: Estrutura fixa (Modelo A)}

Conforme mencionado acima, a validação do método numérico empregado se dá por meio da simulação do impacto de onda em um modelo em escala reduzida de semi-submersível fixo e com duas colunas de seção transversal quadrada alinhadas. Os resultados numéricos obtidos com o MPS são comparados aos resultados experimentais e numéricos com emprego do Comflowß, disponíveis em Iwanowski et al. (2009).

A Figura 47 mostra a comparação do runup nas colunas 1 (Figura 47-(a)) e 2 (Figura 47-(b)) para o modelo A na condição de onda média. Os resultados obtidos numericamente com o método de partículas apresentam boa aderência tanto aos resultados experimentais com o resultado do método numérico de volumes finitos. $\mathrm{O}$ resultado de runup obtido pelo método de partículas é ligeiramente inferior na região de pico, na qual ocorre impacto do fluído com o convés inferior do modelo, devido a uma partícularidade do método de detecção de superfície livre do sólido: o resultado se dá em termos do centro da partícula de superfície livre de maior altura, portanto, ao menos 20 milímetros (uma distância entre partículas) abaixo da posição vertical do convés inferior. Desta maneira, a diferença pode ser mitigada alterando-se o referencial para a tomda da medida ou aumentando a resolução do modelo. Seguindo também essa tendência, curvas mais suaves podem ser obtidas com modelos de maior resolução. 


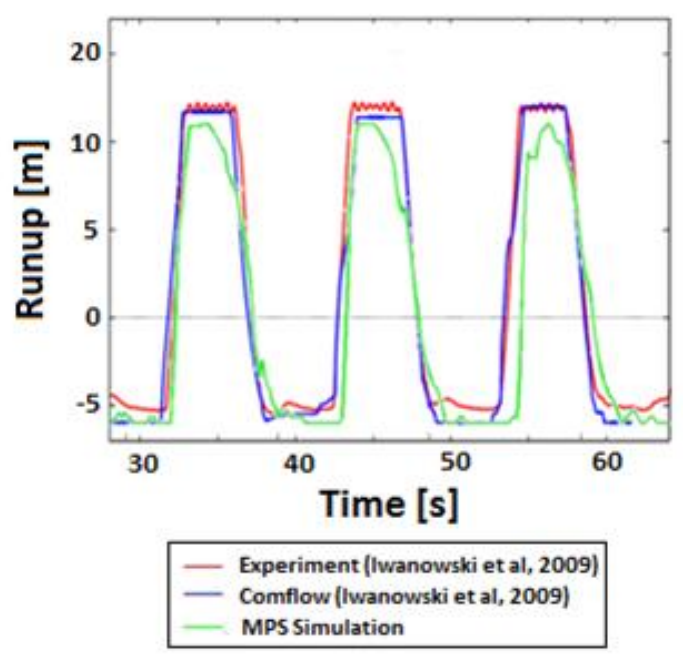

(a)

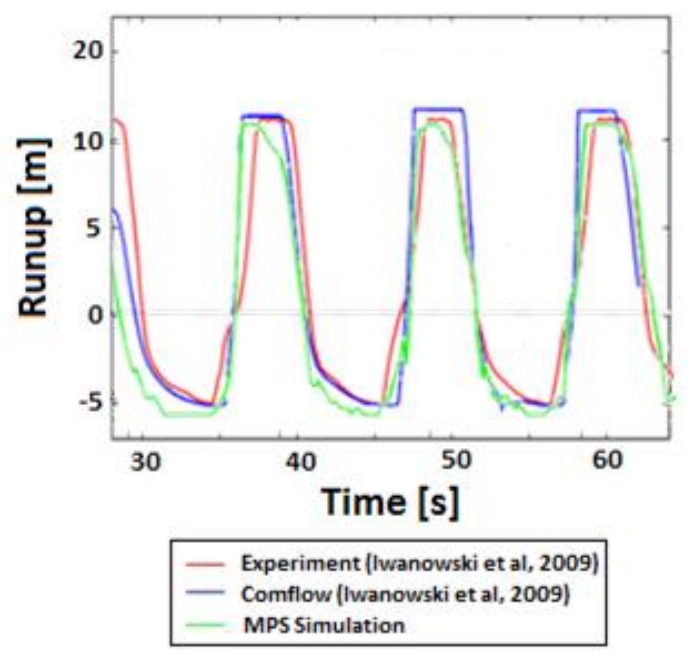

(b)

Figura 47 Runup nas colunas do modelo fixo (modelo A) - (a) coluna 1 e (b) coluna 2 - Onda média

As séries temporais da pressão de impacto nas colunas do modelo A sobre ondas médias e apresentada na Figura 48. São posicionados sensores de pressão na linha de centro das colunas, a 0,072 metros da base da coluna (ponto de junção entre a coluna e o pontoon) e 0,272 metros da quilha do modelo. O sensor de pressão P1 é posicionado na primeira coluna, enquanto o sensor de pressão P2 é posicionado na segunda coluna. A comparação com os resutados presentes na literatura mostram que, apesar de um pico de pressão ligeiramente superestimado para o resultado com o MPS para a coluna 1 , os resultados apresentam ótima aderência aos resultados experimentais na determinação de carregamentos altamente não lineares.

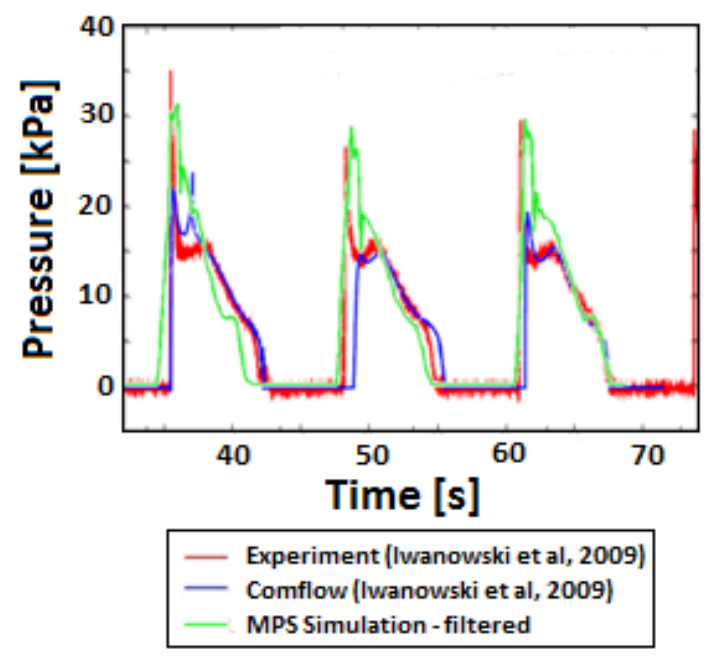

(a)

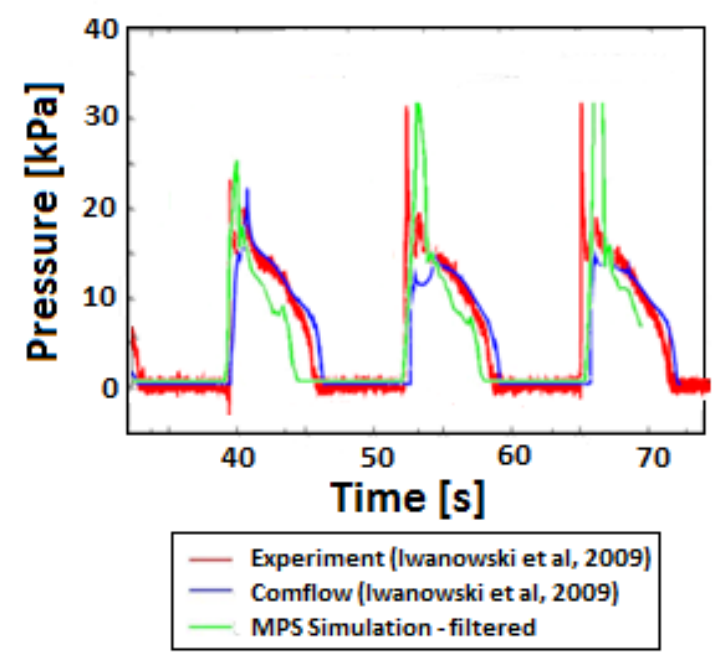

(b)

Figura 48 Série temporal da pressão de impacto nas coluas do modelo fixo (modelo A) - (a) coluna 1, sensor de pressão P1 e (b) coluna 2, sensor de pressão P2 - Onda média 


\subsection{Análise do comportamento hidrodinâmico: estrutura flutuante (Modelo B)}

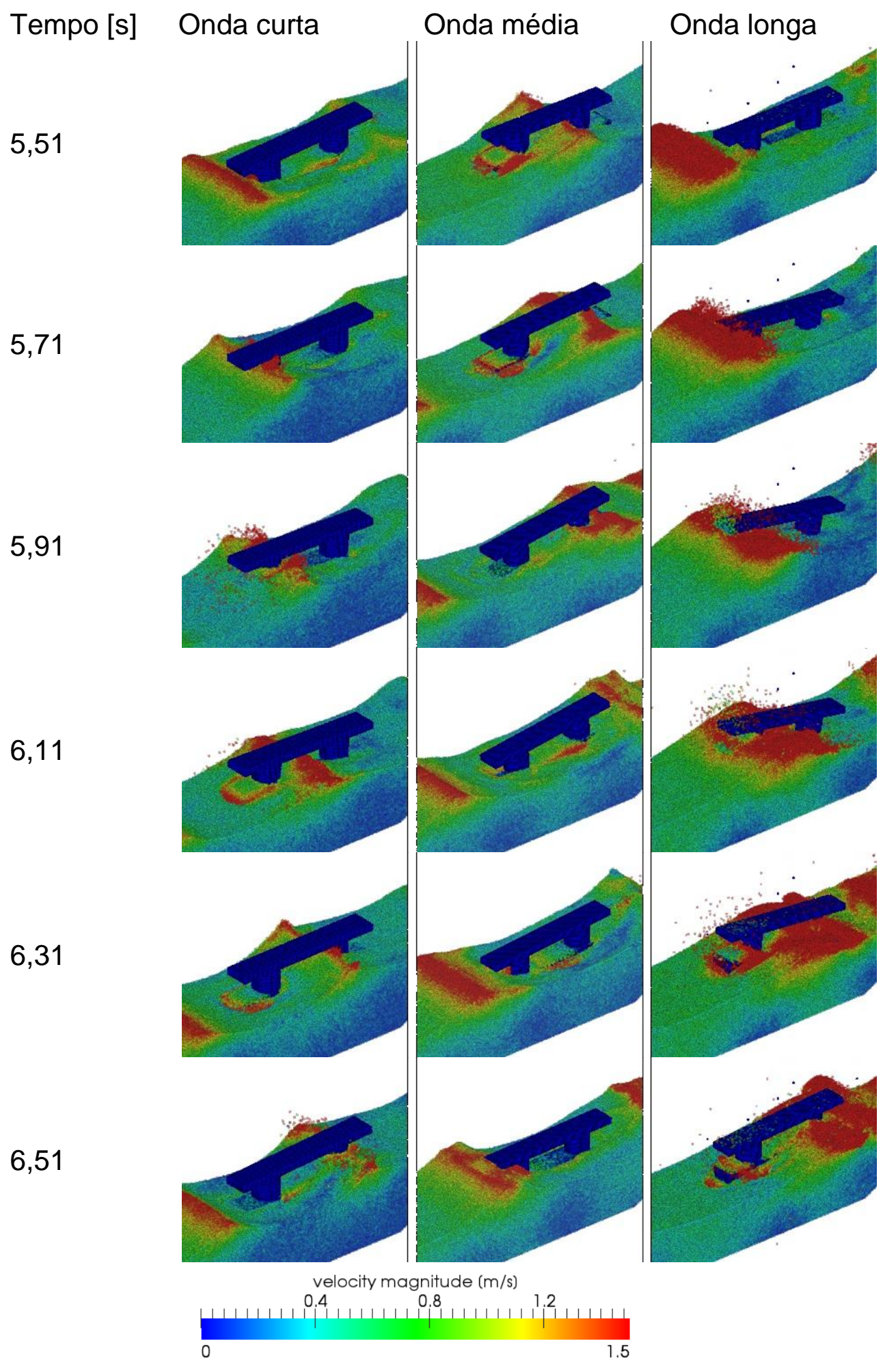

Figura 49 Snapshots da simulação do modelo flutuante (modelo B) - Onda curta (esquerda), onda média (centro) e onda longa (direita) 
A Figura 49 mosta a sequência de snapshots da simulação obtida com emprego do métdo de partículas MPS para o modelo flutuante (modelo B) sob a ação da onda curta (esquerda), média (centro) e longa (direita). A escala de cores representa o módulo da velocidade. Pelos snapshots da simulação pode ser observado o impacto das ondas nas colunas 1 e 2 , assim como o embarque de água no convés (green water, ou shipping water) em algumas situações e a difração da onda.

Os movimentos de pitch e heave sob as três condições de onda são apresentado na Figura 50-(a) e na Figura 50-(b), respectivamente. Em ambos os movimentos, o módulo do pico do movimento senoidal é de amplitude maior que o módulo do cavado, mostrando o comportamento não linear do fenômeno em questão para as três condições de onda.

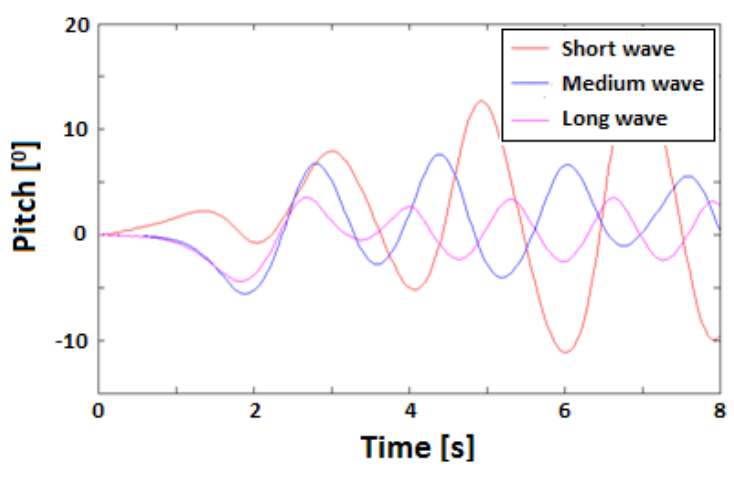

(a)

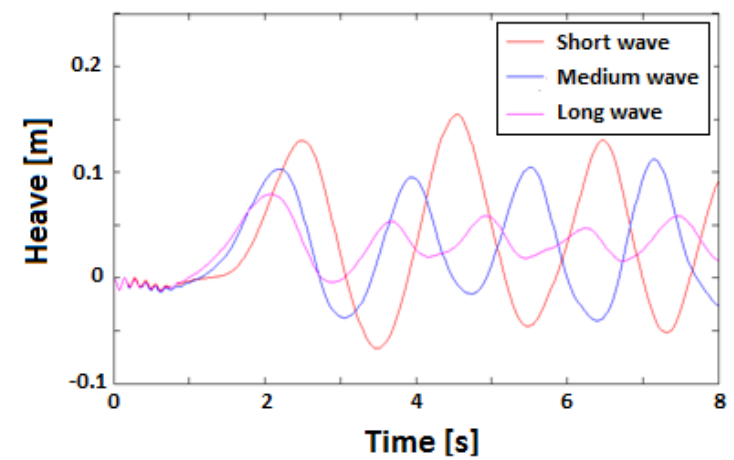

(b)

Figura 50 Movimento de (a) pitch e (b) heave do modelo flutuante (modelo B)

$\mathrm{Na}$ Figura 51 são apresentadas as séries temporais do runup nas colunas, a qual é medida com base em coordenadas locais com origem na base da coluna, para as condições de onda curta, média e longa, respectivamente. A comparação do runup para as três diferentes condições de onda mostra resultados interessantes.

Como a condição de onda curta apresenta comprimento de onda aproximadamente igual ao comprimento do modelo, ocorre no resultado uma alternância no runup entre as duas colunas: enquanto uma das colunas está completamente imersa, com o pico da onda, a outra coluna se encontra quase que totalmente emersa, no cavado da onda, conforme apresenta na Figura 51-(a). O 
runup em uma das colunas se inicia quando o runup na outra coluna é concluído e a duração do runup para as duas colunas é bastante similar.

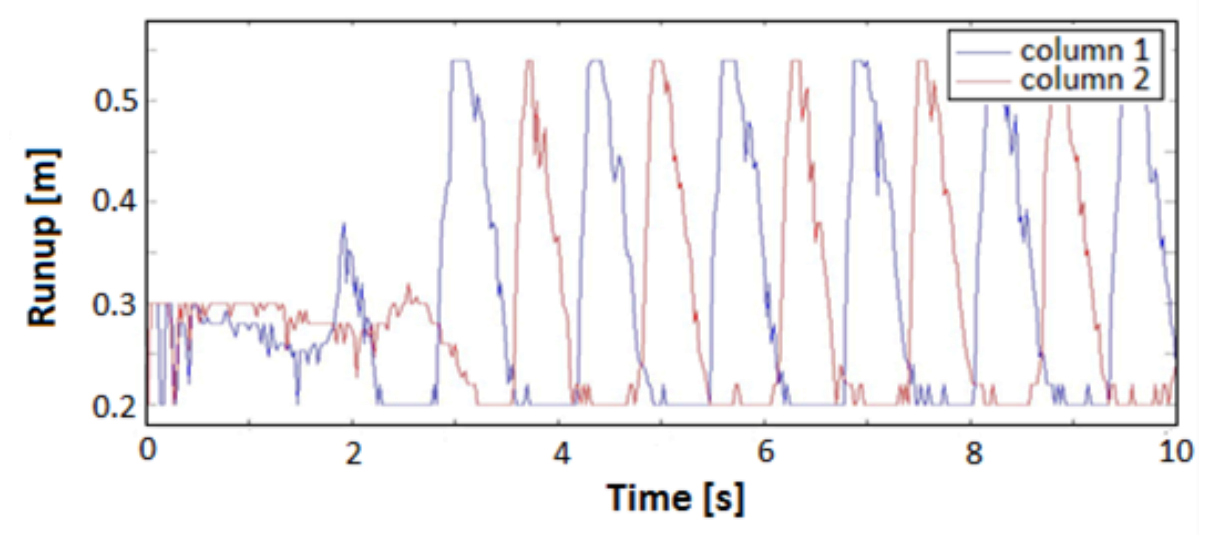

(a)

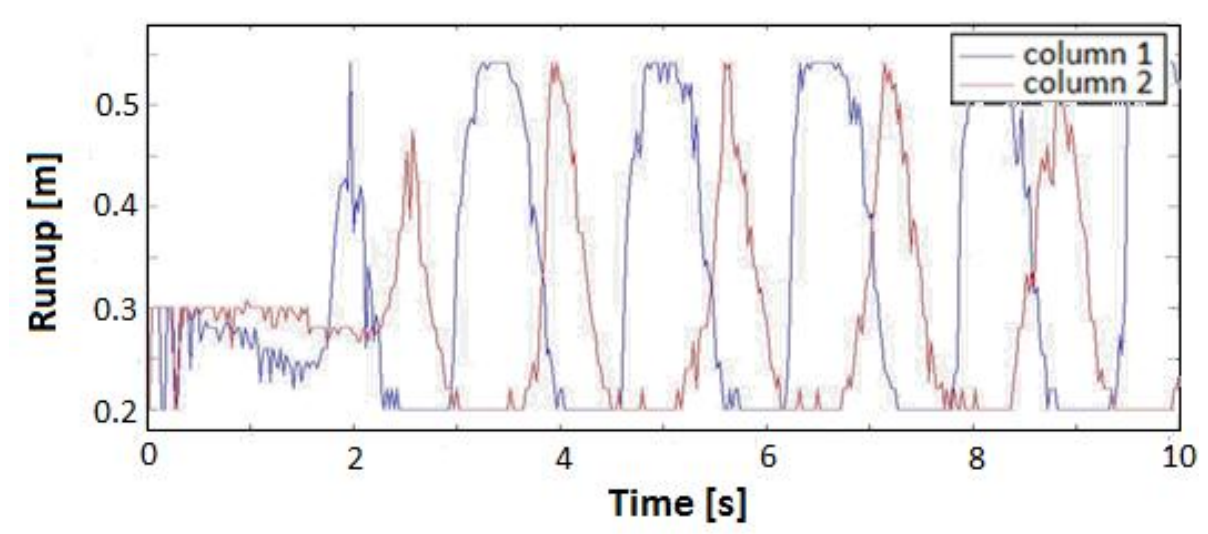

(b)

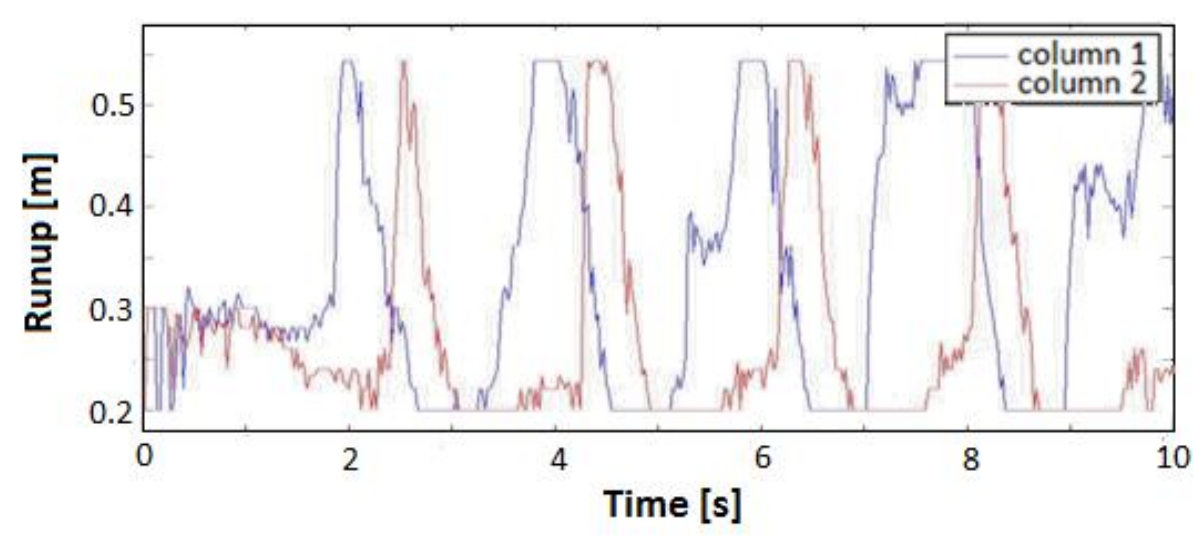

(c)

Figura 51 Runup nas colunas - (a) onda curta, (b) onda média e (c) onda longa 
Por outro lado, de acordo com a Figura 51-(c), para a condição de onda longa, o runup na segunda coluna se inicia antes da conclusão do runup an primeira coluna. Além disso, a dinâmica do fenômeno mostra momentos de alternância entre os quais as duas colunas apresentam runup máximo e mínimo concomitantemente. Esse comportamento é devido ao comprimento da onda ser muito maior que o comprimento do modelo, cerca do dobro, e cerca de quatro vezes maior que a distância entre as duas colunas. Desta maneira, as colunas se encontram simultaneamente na crista da onda em determinados instantes e simultaneamente no cavado da onda em outros instantes. No caso da onda longa também se observa que o runup na segunda coluna é mais rápido. A Figura 51-(b), para a onda média, mostra um comportamento intermediário entre os dois aqui analizados.

A Figura 52 mostra a distribuição de pressão na parte frontal das duas colunas para o quarto ciclo de runup, à esquerda para a condição de onda curta e, a direita, para a condição de onda longa. A Figura 52-(a) mostra a alternância observada no runup entre as duas colunas para a condiçãod e onda curta. Por outro lado, a Figura 52-(b) mostra os momentos de sobreposição de runup máximo e runup mínimo na condição de onda longa. Além disso, em ambos os casos, o runup na segunda coluna apresenta menor duração que o runup na primeira coluna, com uma discrepância de duração maior para a onda longa.

É interessante notar que, no instante de impacto da onda com a coluna para a condiçaõ de onda curta, são observadas duas regiões de pico de pressão: uma na base da coluna e outra um pouco acima, próxima da região central. Essa segunda região acima do ponto de base é relativa ao impacto da crista da onda que quebra e torna-se a região na qual o fluído atinge as maiores velocidades. Este comportamento é observado apenas na onda curta pois a sua amplitude é inferior à altura da coluna, ocorrendo choque da crista com a coluna como pode ser observado nos snapshots da Figura 49. Comportamento similar não é observado na condição de onda longa, na qual se verifica a pressão máxima no instante do impacto apenas no ponto base da coluna, pois a amplitude da mesma supera a altura da coluna de modo que a crista não se choque com a coluna. 


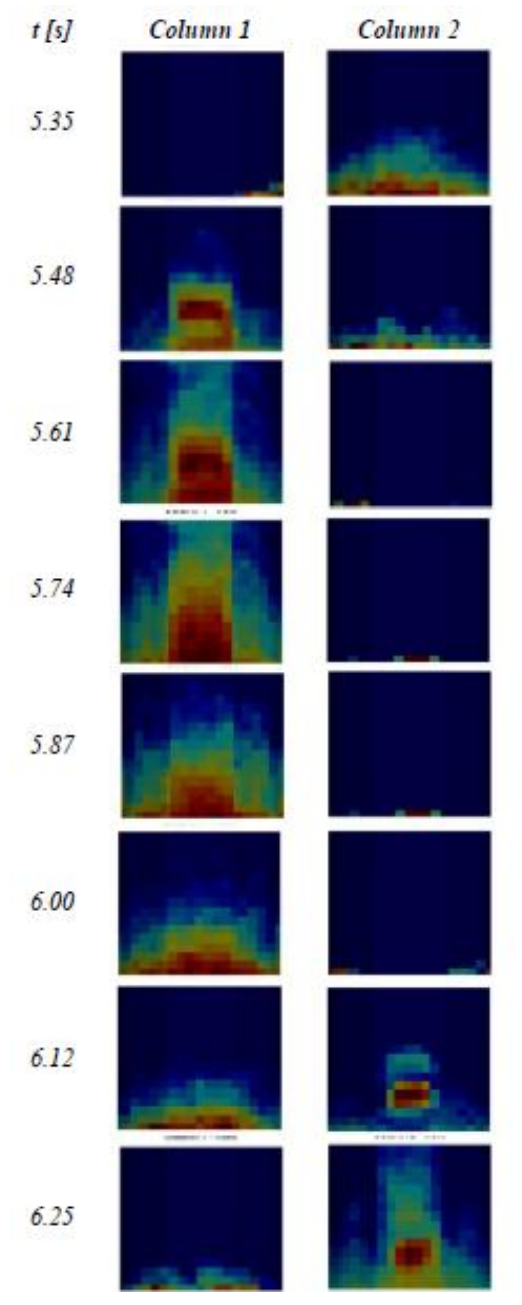

(a)

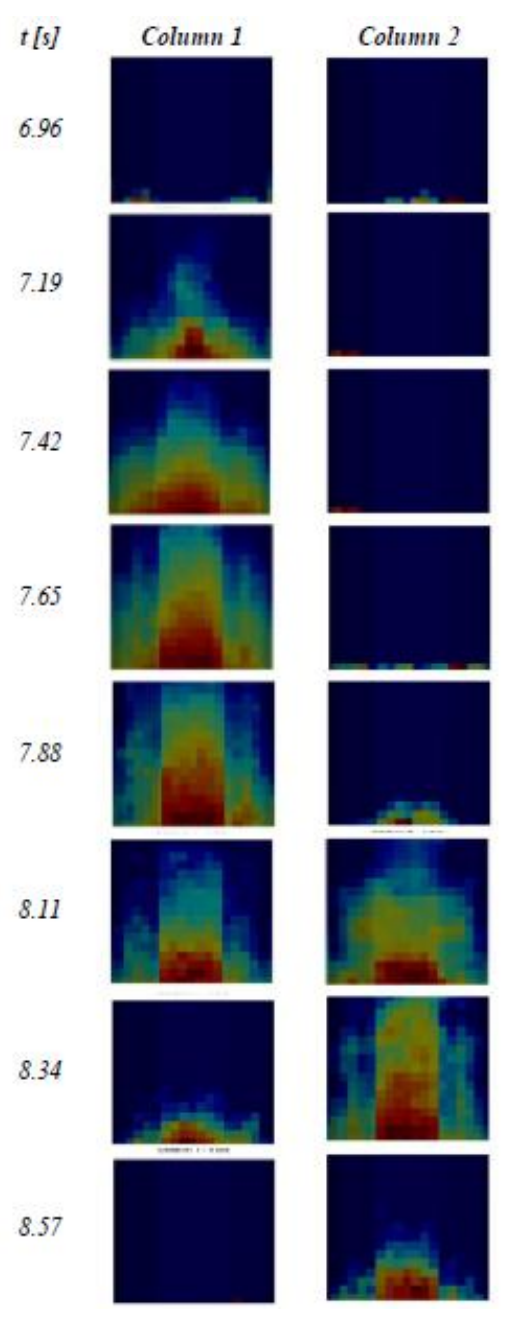

(b)

Figura 52 Distribuição de pressão nas colunas em um ciclo de onda - (a) onda curta e (b) onda longa

Na Figura 53 e na Figura 54 são apresentados snapshots da simulação de partículas nos instantes dos choques da onda nas duas colunas, para as condições de onda curta e longa, respectivamente. A escala de cores do azul para o vermelho mostra a magnitude da velocidade das partículas do fluído, enquanto a escala em preto em branco mostra a pressão nas partículas do modelo. Na Figura 53-(a) e na Figura 53-(b) observa-se a região de pico instantâneo de pressão próxima a onda que quebra. Já na Figura 54-(a) e Figura 54-(b) observa-se que a altura da onda é superior á altura das colunas, de modo que não ocorre quebra da onda na colunas. É interessante observar que na Figura 54-(b) o runup na segunda coluna se inicia enquanto ainda ocorre runup na primeira coluna. 


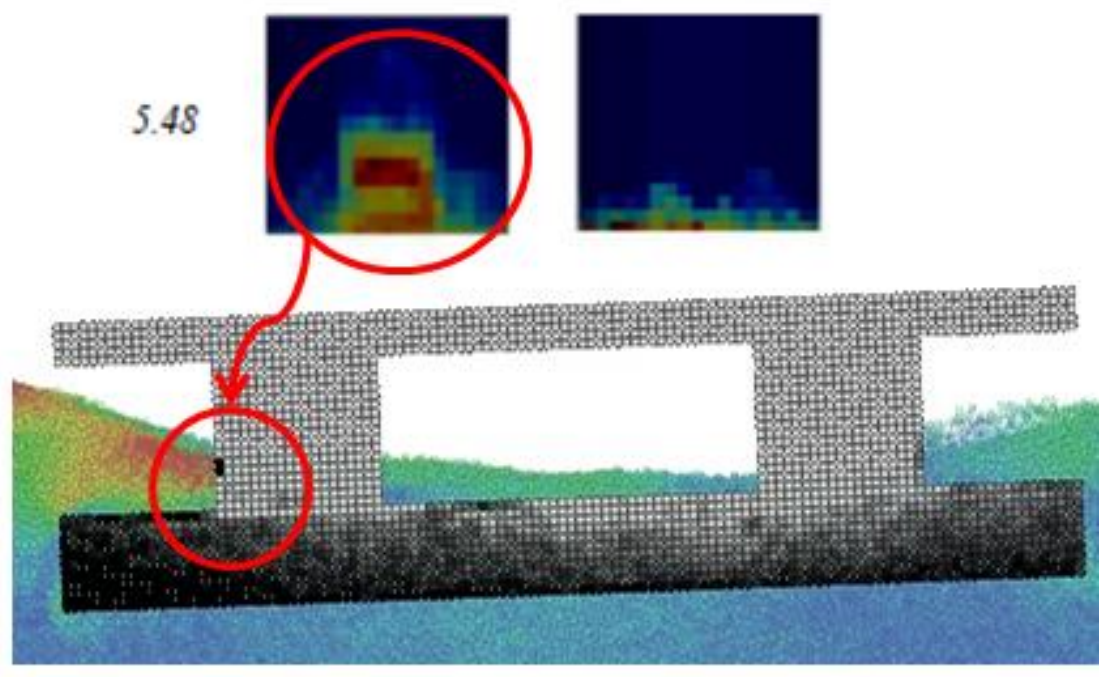

(a)

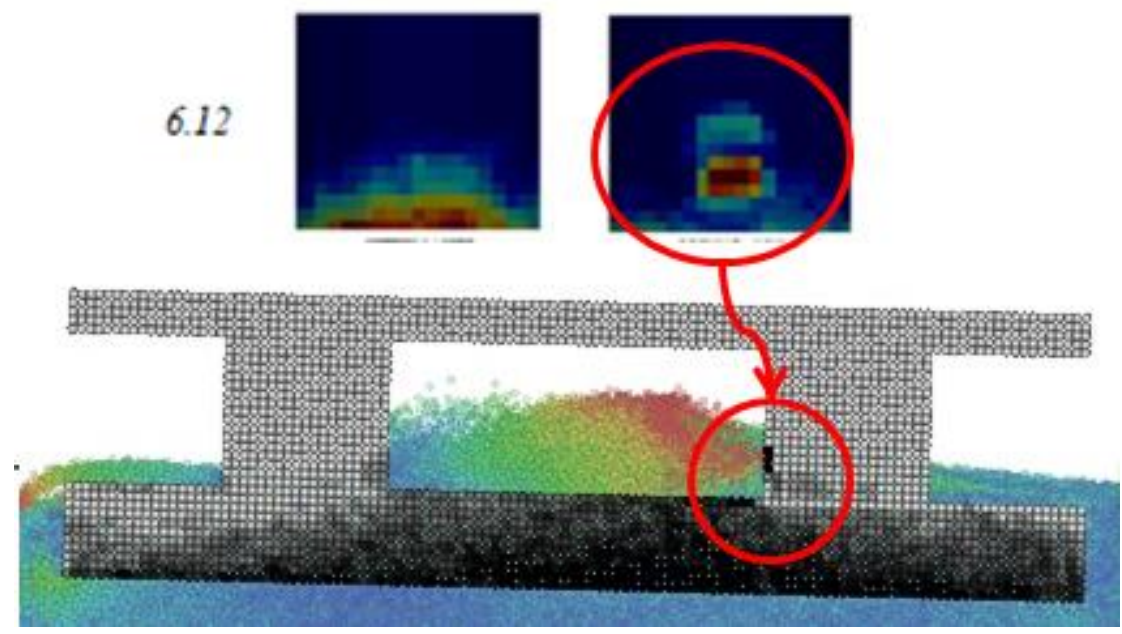

(b)

Fluid velocity magnitude $(\mathrm{m} / \mathrm{s})$

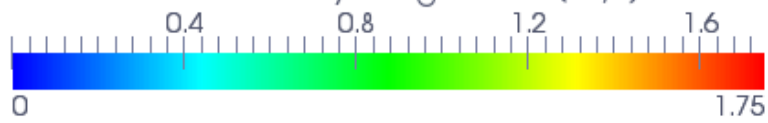

Solid pressure (Pa)

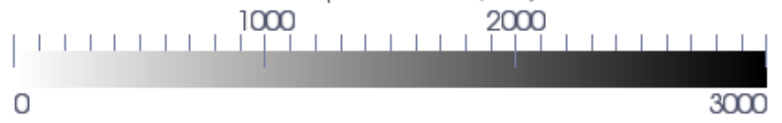

Figura 53 Snapshots da simulação de partículas - Onda curta - (a) $t=5,48 \mathrm{~s}$. (b) $t=6.12 \mathrm{~s}$. 


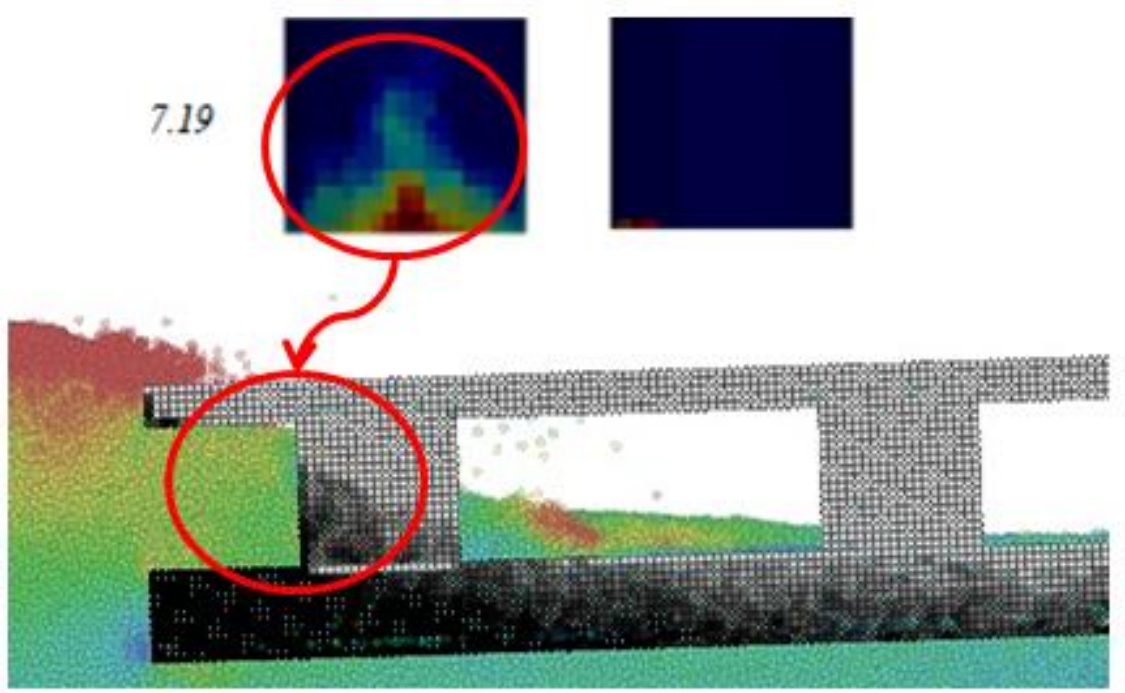

(a)

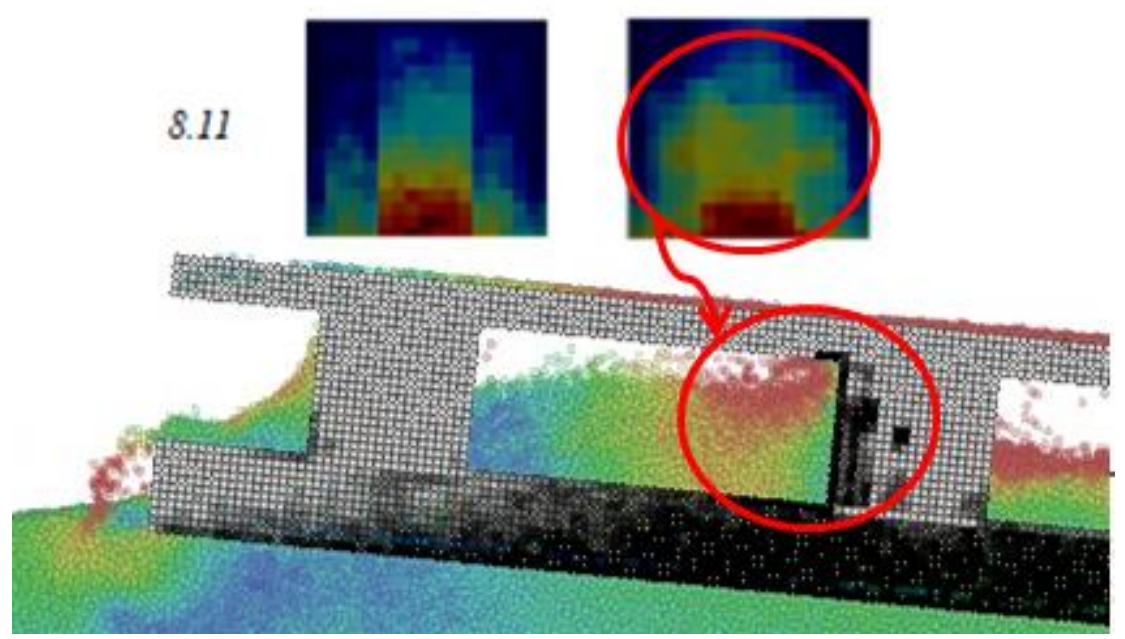

(b)

Fluid velocity magnitude $(\mathrm{m} / \mathrm{s})$

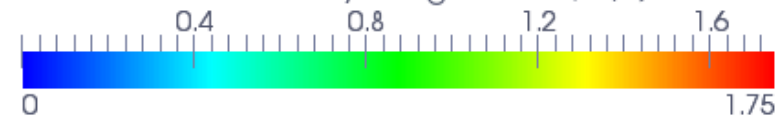

Solid pressure (Pa)

1000 2000

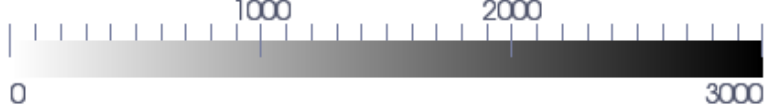

Figura 54 Snapshots da simulação de partículas - Onda longa - (a) $t=7,19 \mathrm{~s}$. (b) $t=8,11 \mathrm{~s}$. 
Finalmente, a Figura 55 mostra a série temporal da força de arrasto nas duas colunas para a condição de onda curta (acima) e onda longa (abaixo). O padrão de coportamento da força de arrasto é bastante similar à aquele observado no runup das colunas. Para a onda curta é possível observar que a força de arrasto é ligeiramente superior na primeira coluna do que na segunda coluna. Já para a onda longa, no perído transiente correspondente aos primeiros ciclos de onda, não é possível observar um comportamento bem definido relativamente a amplitude do módulo da força de arrasto nas colunas, mas observa-se claramente uma duração maior na primeira coluna do que na segunda coluna.

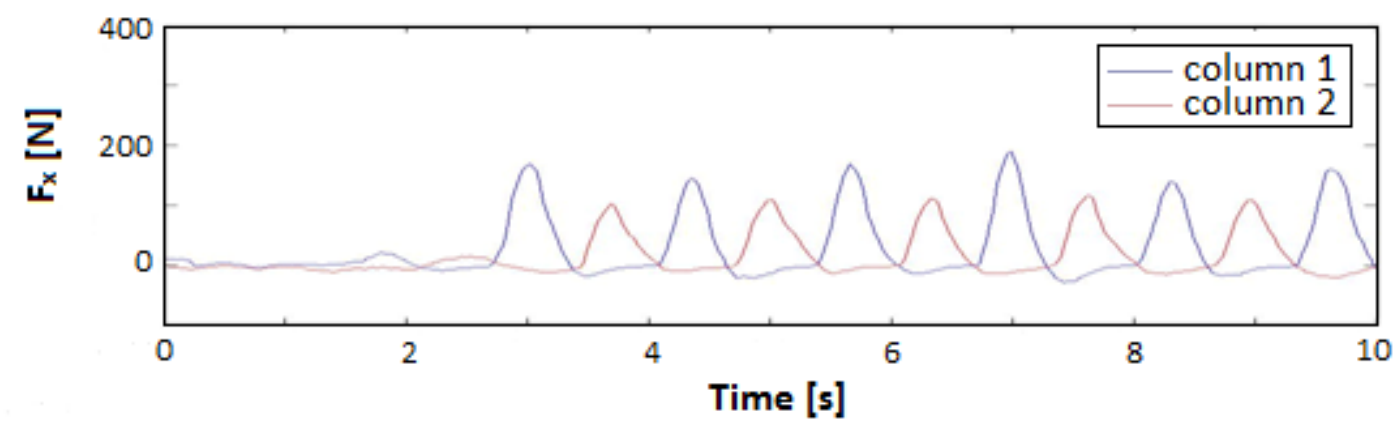

(a)

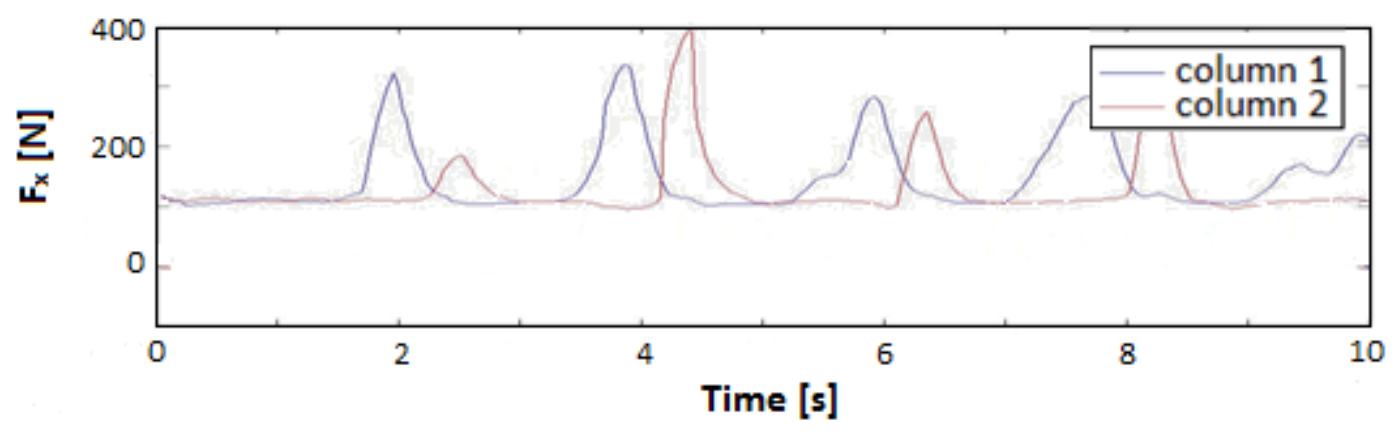

(b)

Figura 55 Força de arrasto nas colunas - (a) onda curta e (b) onda longa 


\subsection{Considerações finais}

No presente estudo o método MPS é adotado na modelagem do complexo fenômeno de interação fluído-estrutura de corpos flutuantes em ondas. Modelos simplificados de plataformas semi-submersíveis com duas colunas alinhadas foram empregados. As simulações numéricas em modelo fixo de colunas de seção quadrada mostraram boa aderência aos resultados experimentais. Para a estrutura flutuante com condição de mar de proa com os movimentos de heave e pitch acoplados, o impacto de ondas nas colunas 1 e 2, assim como o embarque de água e a difração das ondas puderam ser observados. $O$ runup calculado numericamente mostrou alternância entre as colunas para onda com $\lambda / L \approx 1$ e instantes em que simultaneamente as colunas estão totalmente imersas e totalmente emersas para $\lambda / L \approx 2$. Além disto, nas duas situações o runup nas segunda coluna é ligeiramente mais curto do que na primeira coluna. Desenvolvimentos futuros baseado neste estudo contemplam simulações de alta resolução empregando-se o simulador com memória híbrida. 


\section{SLOSHING}

O fenômeno de sloshing, dentre os três fenômenos de impacto hidrodinâmico estudados neste trabalho, é o único que ocorre de forma indireta devido à ação das ondas. O sloshing consiste no movimento violento dentro de tanques parcialmente preenchidos. O movimento de sloshing gera impactos hidrodinâmicos de magnitude significativa nas paredes dos tanques e para os quais os mesmos não costumam ser projetados. Além disso, com o aumento das dimensões dos tanques em estruturas offshore como navios petroleiros, LNG, plataformas FPSO e as novas plataformas tipo FLNG, a frequência natural do primeiro modo de oscilação para o fenômeno de sloshing se aproxima do peródo das ondas. Isto resulta em uma combinação perigosa por meio da qual o próprio fenômeno de sloshing pode estimular um movimento ainda maior da estrutura flutuante sob a ação das ondas, o que prejudica a operação das mesmas.

Nesta seção é analisado o fenômeno de sloshing em tanques tradicionais, em forma de paralelepípedo, e o emprego de anteparaas e elementos estruturais como forma de modificar a dinâmica do fenômeno, deslocando a frequência natural para outra região do espectro de frequência ou, simplesmente, amortecendo as respostas na área de ressonância. Estudos sobre a aplicação de um supressor de sloshing baseado em uma estrutura móvel, empregando o método de partículas como uma das ferrementas de análise, é apresentado em Tsukamoto et al. (2011), Tsukamoto et al. (2010) e Tsukamoto (2011).

\subsection{Validação}

A primeira etapa do estudo do fenômeno de sloshing compreende a validação do método numérico, por meio da comparação dos resultados experimentais e numéricos apresentados em Arai et al. (1992).

\subsubsection{Modelagem}

As dimensões principais dos modelos empregados na etapa de validação são baseados em Arai et al. (1992), no qual são apresentados resultados experimentais e numéricos empregando-se método SOLA-SURF. A configuração dos tanques e as 
variáveis do movimento são apresentadas na Figura 56, retirada do trabalho de (Arai, et al., 1992).

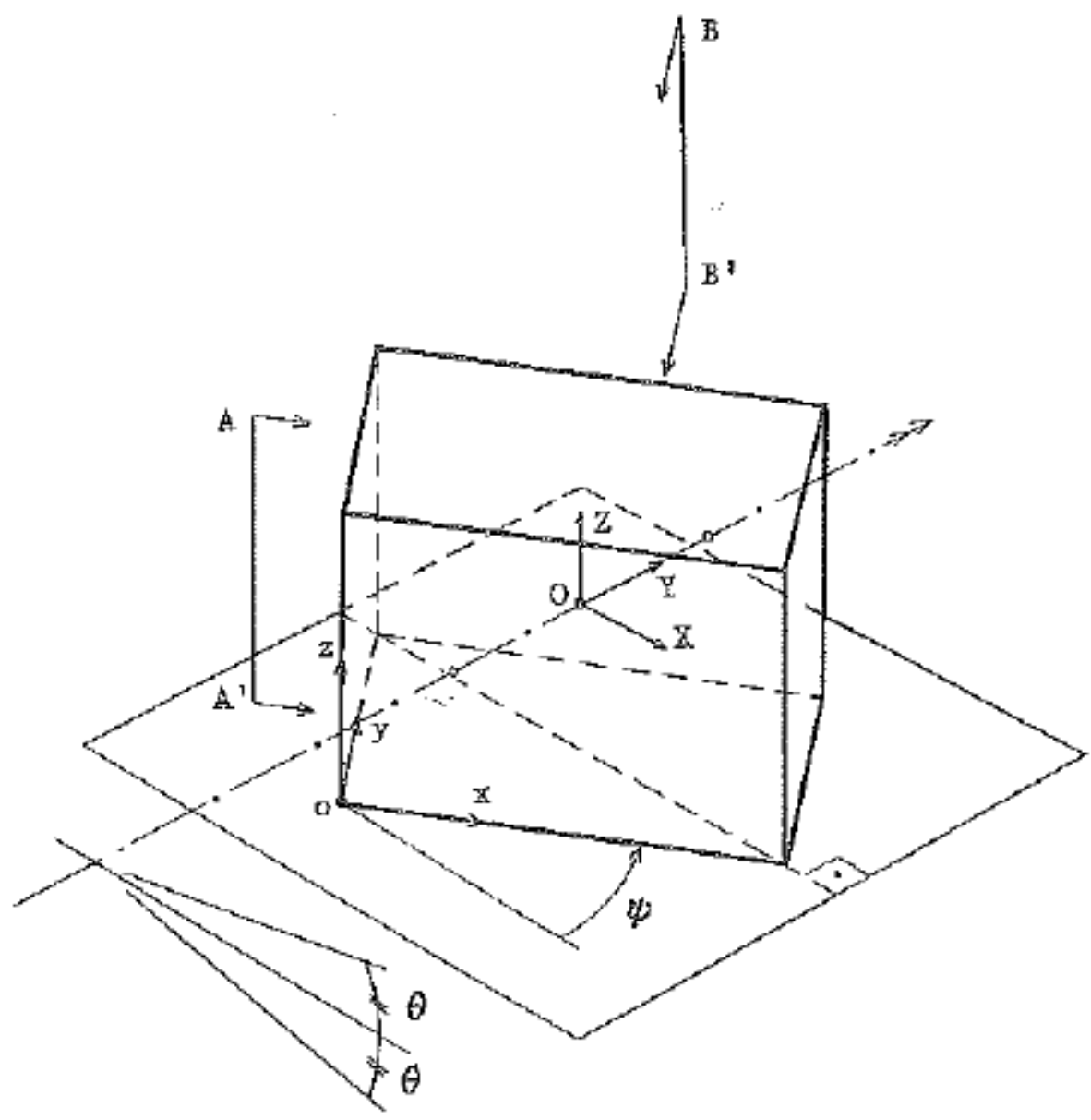

Model tank motion and coordinate systems

$O-X Y Z$ : Fixed coordinate system

$O$ : Center of tank

$o^{-} x y z$ : Moving coordinate system

$\phi:$ Setting angle

$\theta$ : Forced pitch amplitude

Figura 56 Configuração do tanque e principais variáveis do movimento (Arai et. al., 1992a)

O modelo possui um sistema de coordenadas local o-xyz e o movimento de rotação se dá em um relação à um plano de coordenadas global $O-X Y Z$, conforme apresentado na Figura 56. O plano $A A^{\prime}$ ' representa a componente longitudinal da rotação do tanque, de pitch, e o plano $B B^{\prime}$ representa a componente transversal da rotação do tanque, de roll. A base do tanque se encontra no plano $X Y$ no instante de tempo inicial. $O$ ângulo $\phi$ consiste naquele formado entre o plano $X Y$ e o plano $x y \mathrm{e}$ 
estabelece a inclinação do eixo de rotação, já o ângulo $\theta$ representa a amplitude do movimento oscilatório de rotação do tanque. O movimento oscilatório é dado pela Eq. 9.

$$
\theta(t)=\theta_{0} \cdot \sin (\omega \cdot t)
$$

Para a validação são empregados tanques com diferentes medidas e diferentes níveis de preenchimento. Os tanques utilizados na etapa de validação são apresentados na Figura 57.

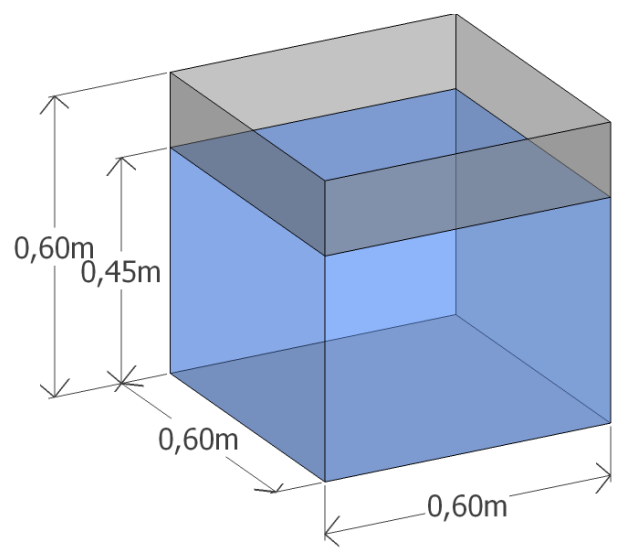

\section{Caso A}

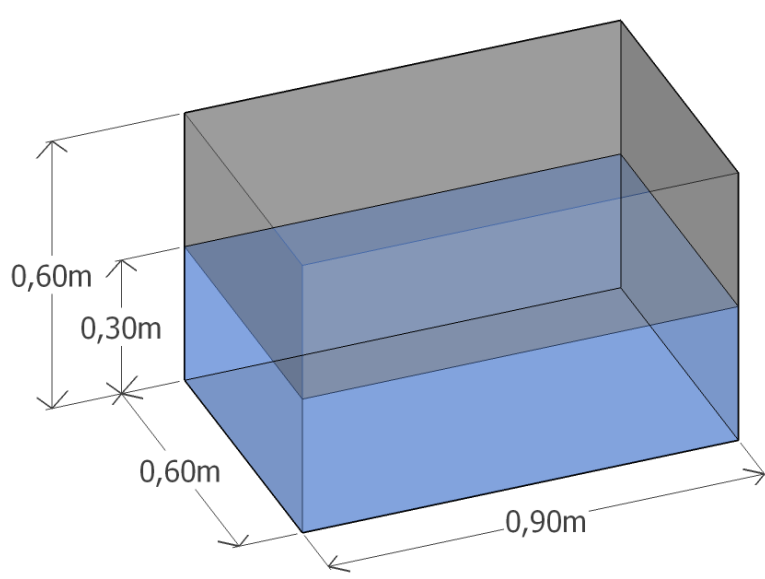

Caso C

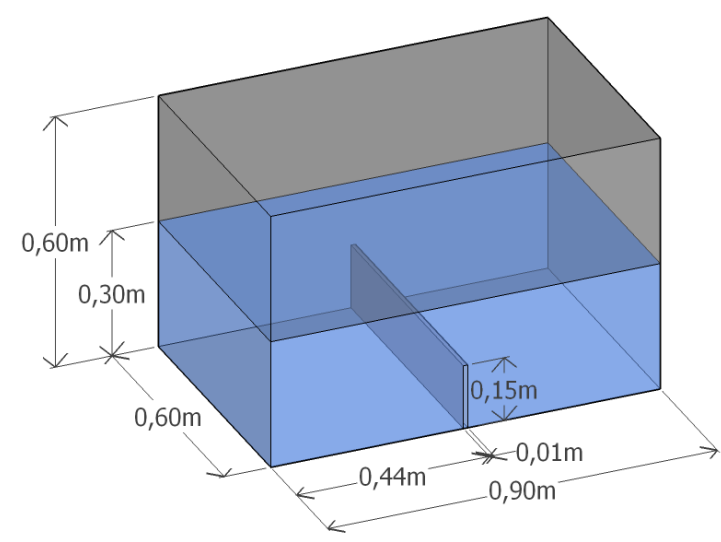

Caso D

Figura 57 Dimensões e tipos de tanque 


\subsubsection{Convergência}

A primeira etapa do estudo contempla a análise de convergência, por meio da determinação da resolução necessária para a obtenção de resultados com precisão adequada ao menor custo computacional. Nesta etapa os resultados serão baseados em simulações empregando-se o Caso A com preenchimento de $75 \%$ ( $h=450 \mathrm{~mm}$ ), com o movimento de rotação oscilatório de amplitude de 6ำ, período de 0,9 segundos e ângulo $\phi=45^{\circ}$, em uma rotação bidimensional. As resoluções avaliadas e os respectivos tempos de processamento, para a simulação de 20 segundos, são apresentados na Tabela 11.

Tabela 11 Parâmetros da análise de convergência

\begin{tabular}{|c|c|c|c|c|}
\hline $\begin{array}{c}\text { Razão entre } \\
\text { largura e } \\
\text { distância entre } \\
\text { partículas } \\
(B / d s)\end{array}$ & $\begin{array}{c}\text { Distância } \\
\text { entre } \\
\text { partículas } \\
\text { [mm] }\end{array}$ & $\begin{array}{l}\text { Número de } \\
\text { partículas }\end{array}$ & $\begin{array}{c}\text { Incremento } \\
\text { de tempo } \\
{[\mathrm{s}]}\end{array}$ & $\begin{array}{l}\text { Tempo de } \\
\text { simulação }\end{array}$ \\
\hline 15 & 40 & 6.600 & 0,002 & $1 \mathrm{~min}$. \\
\hline 20 & 30 & 17.000 & 0,0015 & $5 \mathrm{~min}$. \\
\hline 30 & 20 & 31.000 & 0,001 & $30 \mathrm{~min}$. \\
\hline 40 & 15 & 77.500 & 0,00075 & $1,5 \mathrm{hrs}$. \\
\hline 60 & 10 & 175.000 & 0,0005 & $5 \mathrm{hrs}$. \\
\hline
\end{tabular}

Os tempos de processamento são para nós do cluster compostos por 20 processadores AMD Shanghai de 2,66GHz com memória compartilhada de $128 \mathrm{~GB}$.

Na Figura 58 é apresentado o resultado de elevação da superfície livre nas paredes do tanque. Os resultados mostram boa concordância entre todas as curvas, apenas os resultados para a resolução mais grosseira mostram diferença significativa em relação aos demais, com uma curva senoidal de amplitude menor. 


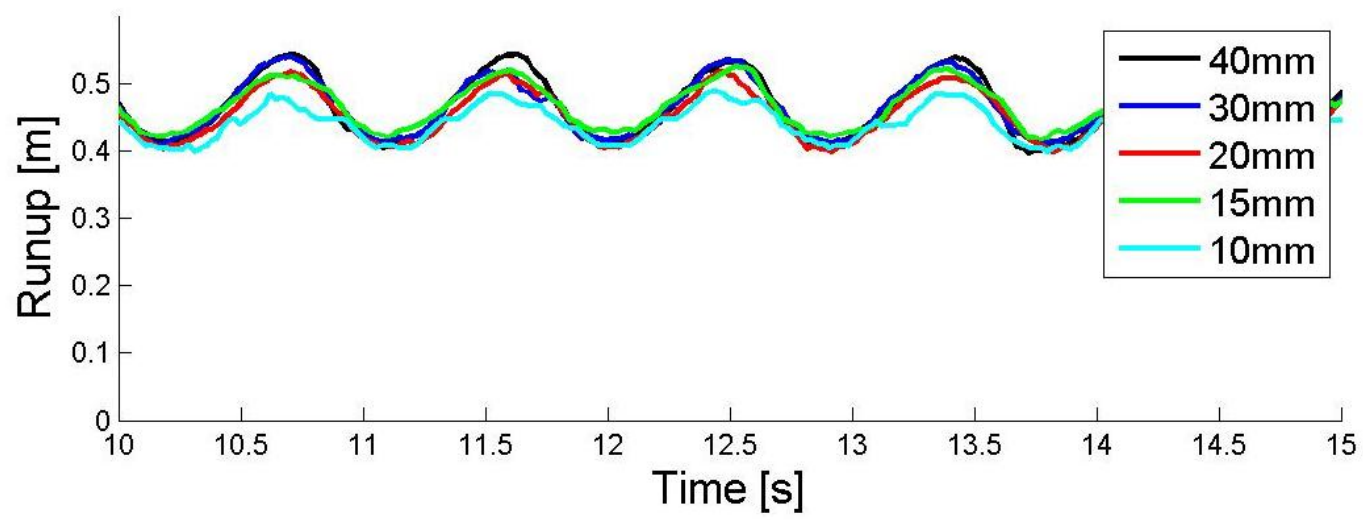

(a)

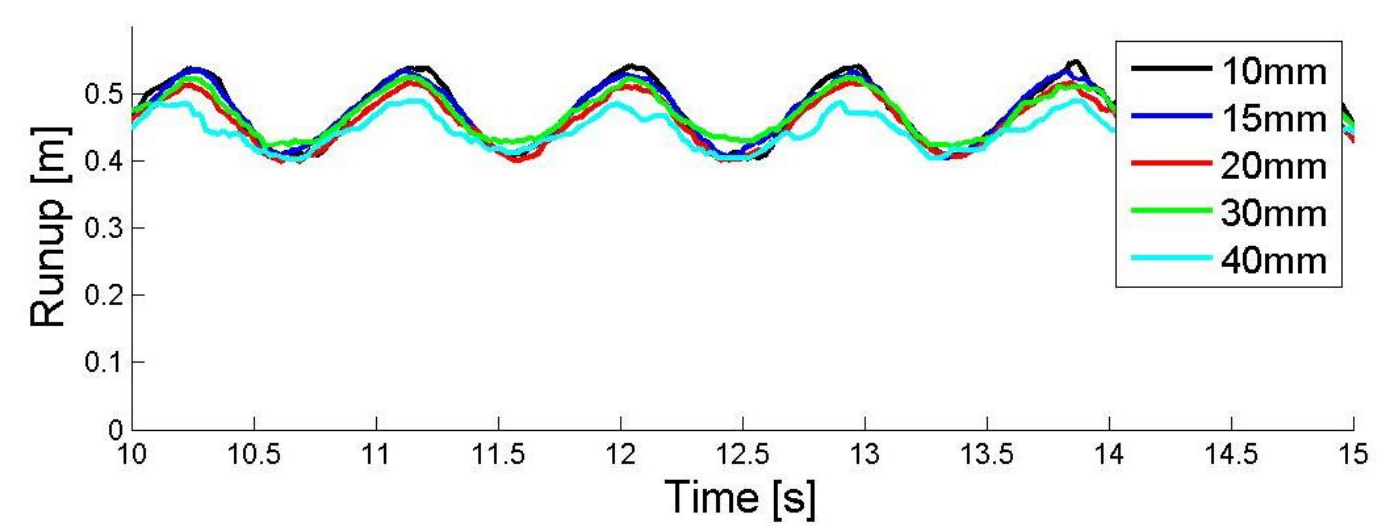

(b)

Figura 58 Eevação de superfície livre nas paredes (a) esquerda e (b) direita

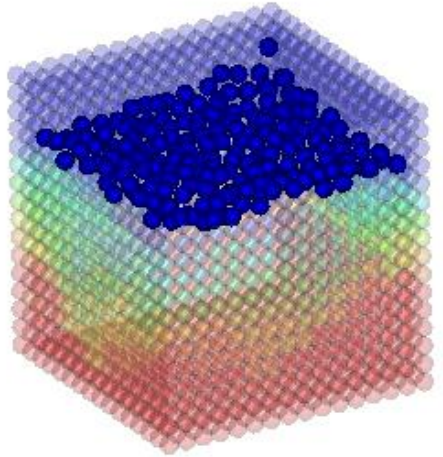

(a)

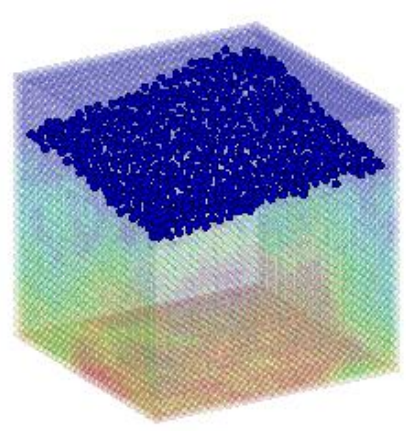

(b)

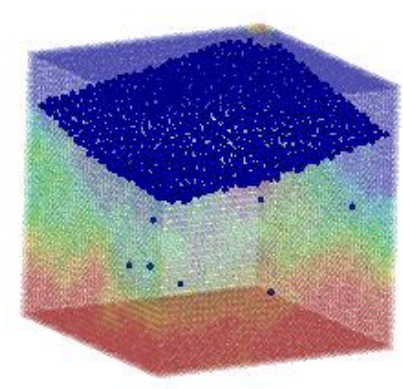

(c)

Figura 59 Snapshot das simulações de convergência com o método de partículas - Distância entre partículas de (a) $B / d s=15$, (b) $B / d s=30$ e (c) $B / d s=60$ 
A Figura 59 mostra snapshots das simulações com método de partículas para as três resoluções avaliadas. Observa-se que há impacto no topo para a maior resolução mostrada, enquanto que para a segunda a superfície livre se aproxima bastante do topo do tanque. No entanto, é possível observar uma diferença significativa no ferfil de superfície livre para a resolução mais grosseira.

Para concluir a análise de convergência são analisadas as séries temporais de pressão em sensores colocados ao longo das paredes dos tanques. A localização dos sensores no Caso A é apresentada na Figura 60, presente em Arai et al. (1992). Já os registros de pressão para os sensores P1 e P2 são apresentados na Figura 61.

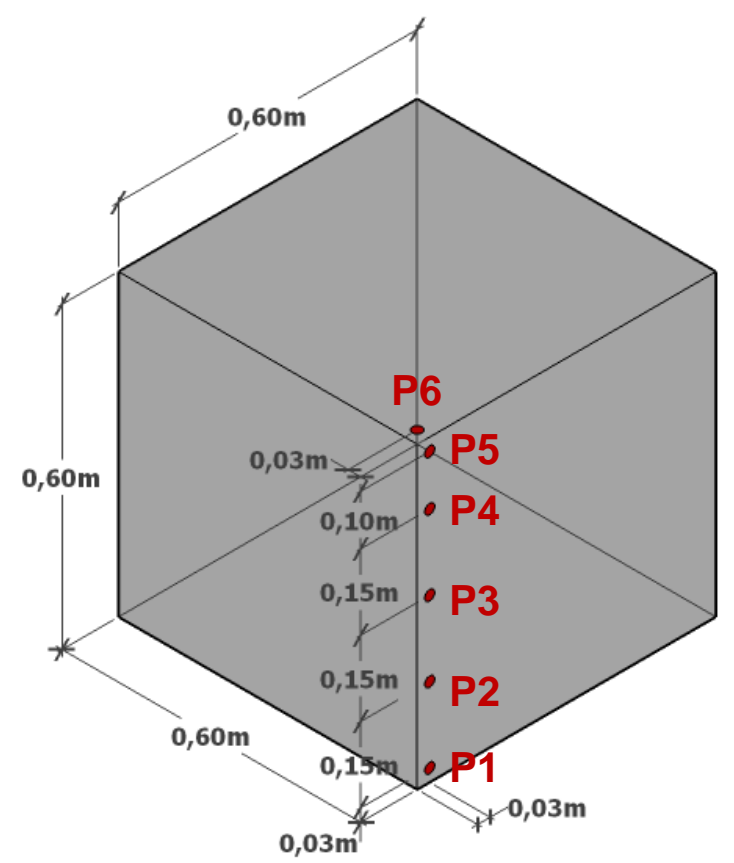

Figura 60 Posição dos sensores de pressão para o Caso A e o Caso B 


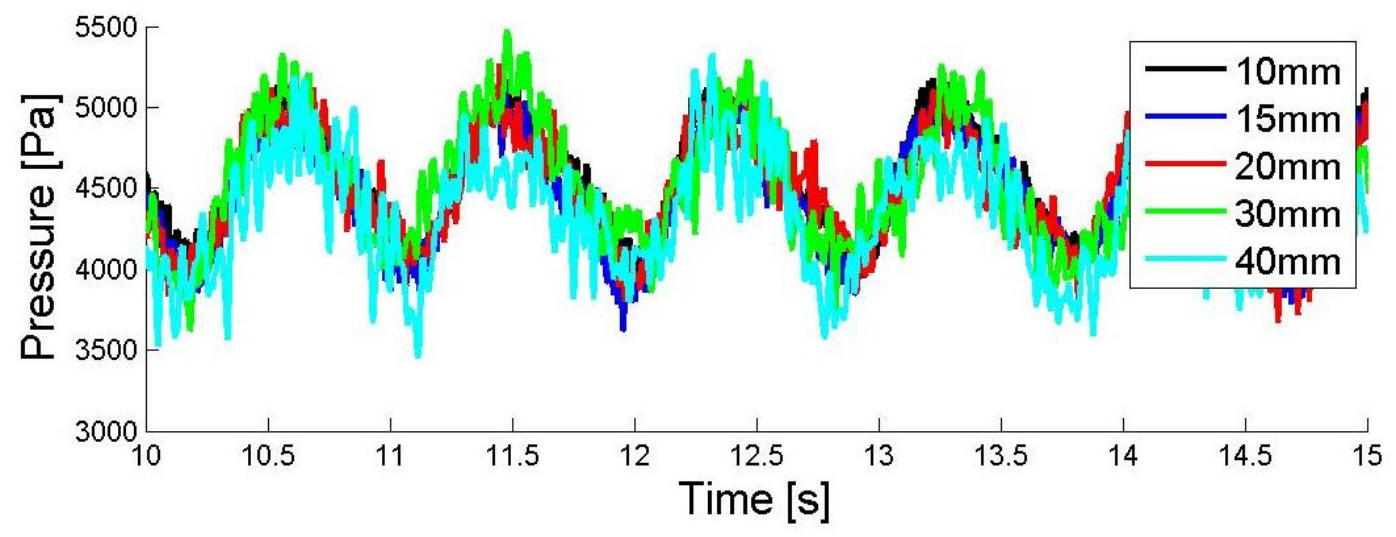

(a)

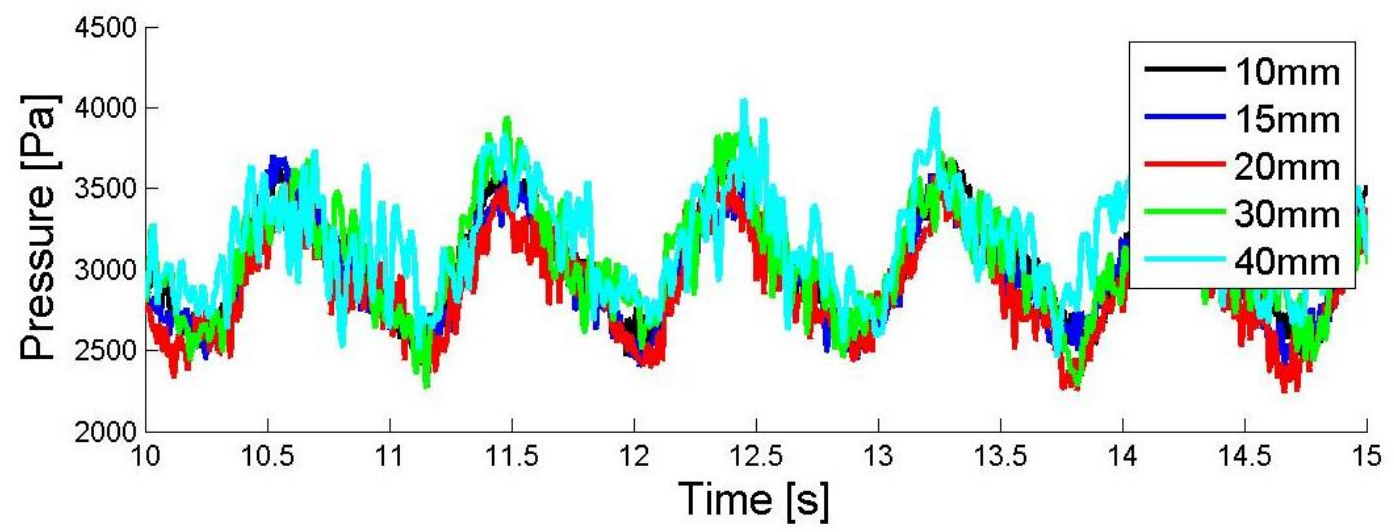

(b)

Figura 61 Pressão ns sensores (a) P1 e (b) P2 no Caso A

De acordo com os gráficos da Figura 61 se observa que o comportamento da curva de pressão para as resolução de distância entre partículas de 2 e 1 centímetros são bastante similares. No entanto, a discretização mais grosseira, com ditância entre partículas de 4 centímetros apresenta diferenças consideráveis em relação aos demais.

Observa-se também que a diferença é maior para o sensor de pressão P2, mais próximo à região de superfície livre. Os primeiros estudos abordando a suavização nas flutuações de pressão do método de partículas adotaram melhoramentos no algoritmo de detecção de superfície livre, como por exemplo em (Lee, et al., 2010), o que reflete o papel da superfície livre nas oscilações de pressão registradas. 
Outro ponto importante é uma grande influência da resolução empregada na estabilidade do cálculo da pressão, conforme já observado também no caso de validação de dam break apresentado anteriormente. Mesmo os modelos com resoluções mais grosseiros, em todos os casos de validação, geralmente apresentarem o escoamento e o comportamento tridimensional do fluído próximos aos observados com as resoluções mais altas. Por outro lado, uma grande diferença foi observada nos registros de pressão, para os quais um refinamento maior se mostra necessário a fim de obter resultados mais precisos.

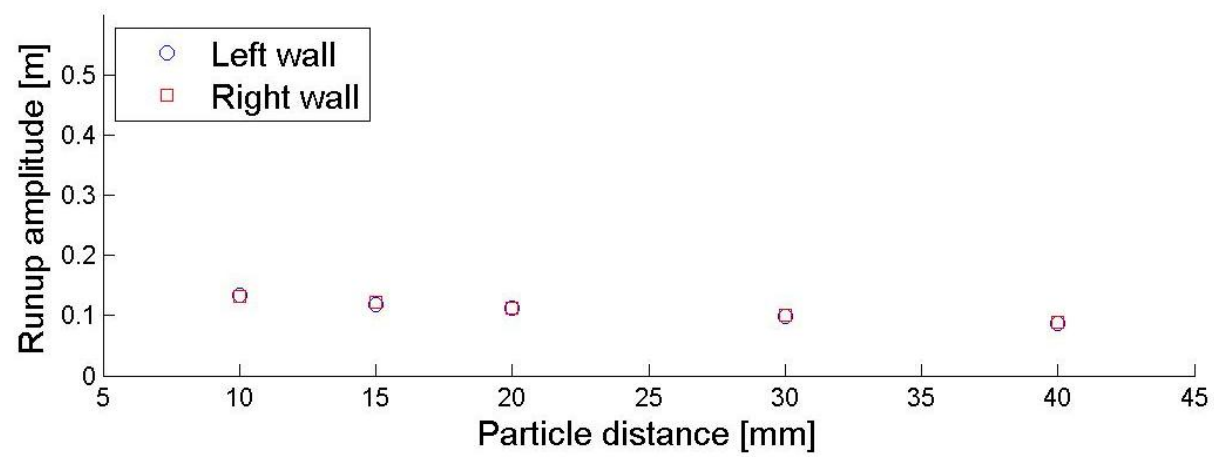

Figura 62 Amplitude do runup em função da resolução

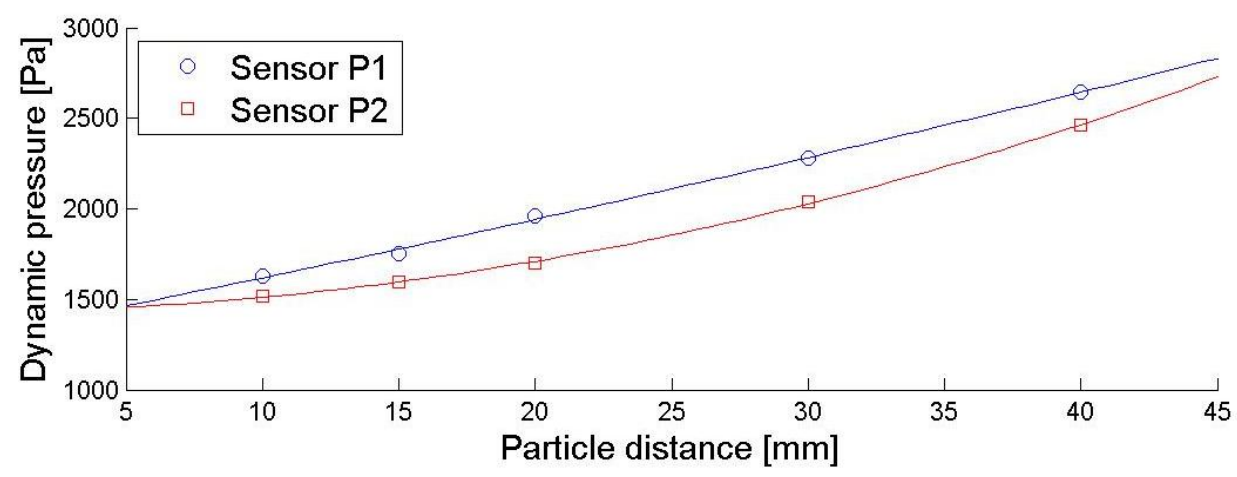

Figura 63 Pressão dinâmica nos sensores P1 e P2 em função da resolução

A Figura 62 mostra a amplitude do runup nas paredes laterais do tanque em função da resolução. Já a Figura 63 mostra a pressão dinâmica nos sensores P1 e P2 em função da resulação. Na Figura 62 é possível observar, assim como já mostrado pela série temporal apresentada na Figura 58, que o movimento do fluído, mesmo para as resoluções mais grosseiras, mostra bons resultados. O aumento da resolução leva a um maior movimento da superfície livre. Na Figura 62 o aumento da resolução mostra uma convergência, atingida pelos modelos com distância entre partículas de 15 e 10 centímetros. 
Por meio dos resultados apresentados e análises da Figura 58 a Figura 62, optou-se por empregar o modelo com distância entre partículas de 1 centímetro, por apresentar resultados suficiente precisos e apresentarem um tempo de processamento adequado. Desta maneira, para os subsequentes estudos de sloshing nesta seção são empregados modelos com aproximada 170 mil partículas para as análise preliminares, as quais envolvem grande números de simulações e um tempo de processamento reduzido passa a possuir importância primária.

\subsubsection{Validação}

$\mathrm{Na}$ validação será empregado o modelo com distância entre partículas de 2 centímetros, valor reste obtido na etapa anterior segundo o estudo de convergência. Os casos a serem simulados são baseado nos tanques $C$ e D. A comparação entre os resultados numéricos e os resultados experimentais presentes em Arai et al. (1992) se dará por meio das séries temporais da pressão e do diagrama no domínio da frequência da pressão dinâmica. A pressão dinâmica consiste na amplitude da oscilação de pressão em um ciclo de movimento do tanque. O posicionamento dos sensores de pressão nos Casos C e D é análogo ao do Caso $A$ e é apresentado na Figura 64.

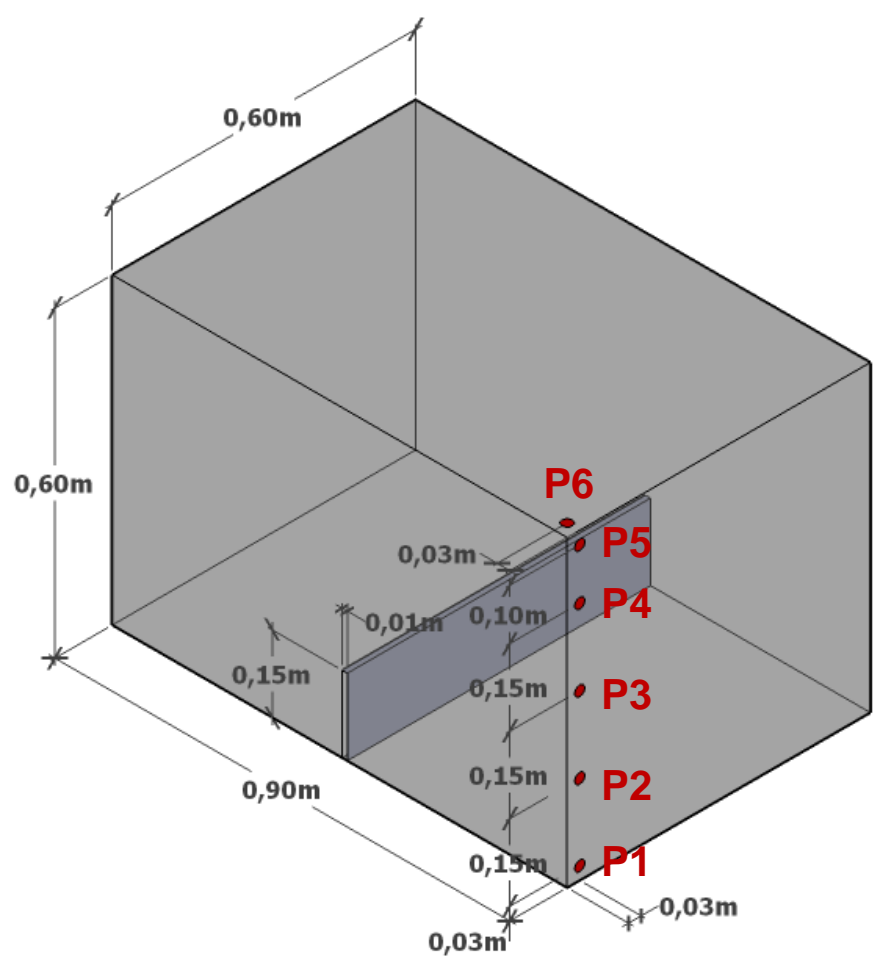

Figura 64 Posição dos sensores de pressão para o Caso C - tanque com antepara 
A comparação das séries temporais de pressão é apresentada na Figura $65 \mathrm{e}$ na Figura 66. Na Figura 65 é mostrado o resultado para o Caso A com preenchimento de $75 \%(h=450 \mathrm{~mm})$ para os sensores de pressão P4, P5 e P6, na condição de movimento de amplitude $\theta=6^{\circ}$ e ângulo de $\phi=45^{\circ}$. Já a Figura 66 mostra a série temporal da pressão para o Caso $D$, para os sensores $P 1, P 2$ e $P 3$, na condição de movimento de $\theta=6^{\circ}$ e ângulo de $\phi=33,7^{\circ}$.
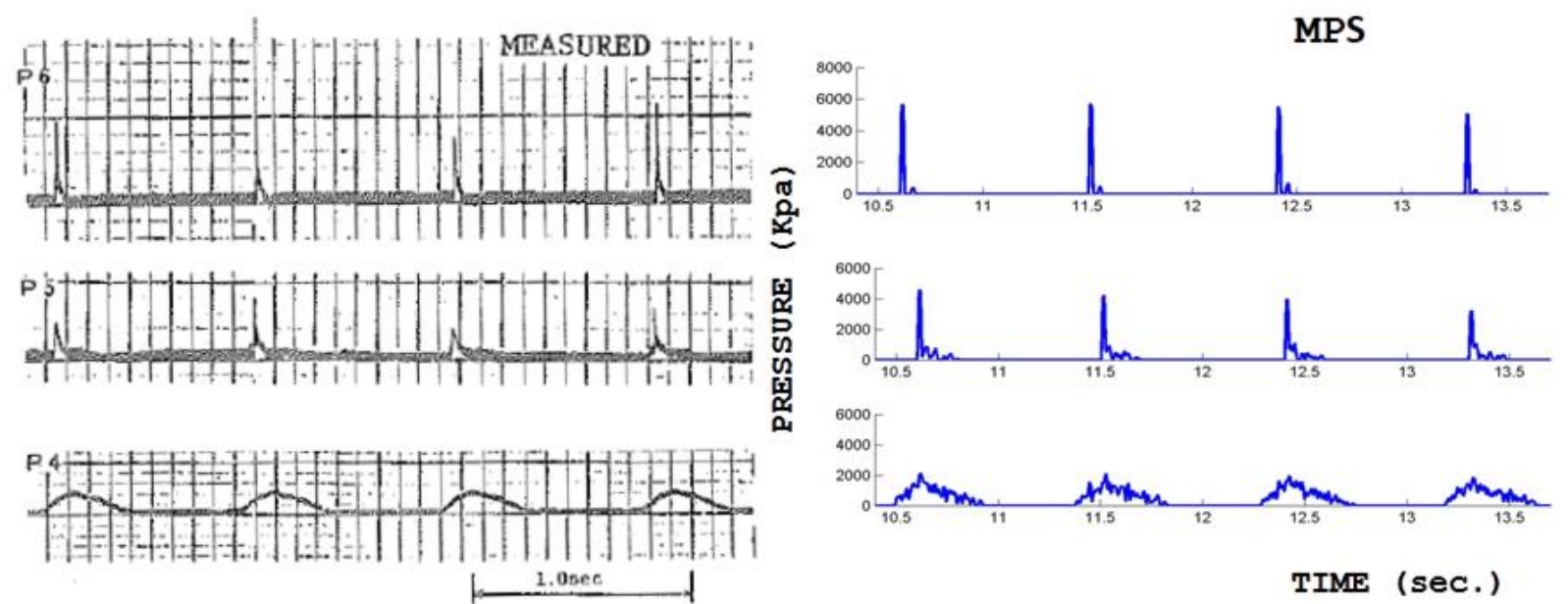

Figura 65 Pressão no tanque A ( $h=450 \mathrm{~mm})$ - Sensores P4 (abaixo), P5 (centro) e P6 (acima) - MPS $x$ experimental - adaptado de (Arai, et al., 1992)
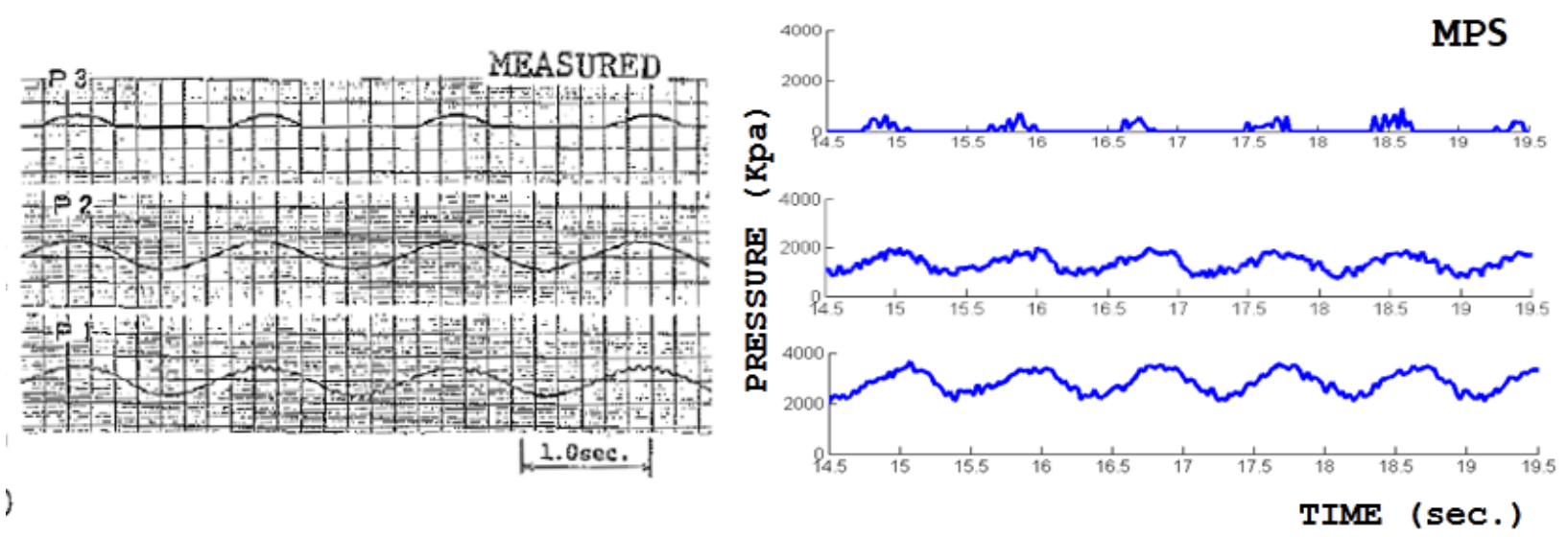

Figura 66 Pressão no Caso D - Sensores P1 (abaixo), P2 (centro) e P3 (acima) - MPS x experimental - adaptado de (Arai, et al., 1992)

E ambas as séries temporais, o método de partículas mostra boa aderência aos resultados experimentais apresentados em Arai et al. (1992). Ocorre uma diferença significativa apenas para os sensores P4 e P5 na Figura 65, que 
correspondem aos sensores de pressão localizados na região próxima à parede do topo do tanque e registram os impactos hidrodinâmicos do fluído no topo, de curta duração e grande magnitude.

A segunda comparação se dá em termos do diagrama no domínio da frequência da pressão dinâmica. O diagrama comparado leva em conta a pressão dinâmica para o sensor de pressão P1, para o Caso C, com a antepara na região central, nas condições de movimento de $\theta=6^{\circ}$ e ângulo de $\phi=33,7^{\circ}$. As frequências para as quais o fenômeno é simulado são apresentadas na Tabela 12.

\begin{tabular}{cc} 
Tabela 12 Frequência de movimento do Caso \\
\hline Frequência [Hz] & Período [s] \\
\hline 0,5 & 2,00 \\
0,75 & 1,33 \\
1,0 & 1,0 \\
1,25 & 0,8 \\
1,5 & 0,67 \\
1,75 & 0,57 \\
2,0 & 0,5 \\
\end{tabular}

Na Figura 67 é a presentada a comparação entre os resultados da pressão hidrodinâmica em função da frequência obtida numericamente, com o emprego do métode MPS, e os resultados experimentais e numéricos de Arai et al. (1992) obtidos com o método baseado no SOLA-SURF. O diagrama mostra a boa aderência entre o método de partículas e os resultados experimentais, com os resultados estando muito próximos e coincidindo em diversos pontos, como para as frequência de $0,75 \mathrm{~Hz}, 1,0 \mathrm{~Hz}$ e $1,25 \mathrm{~Hz}$. 


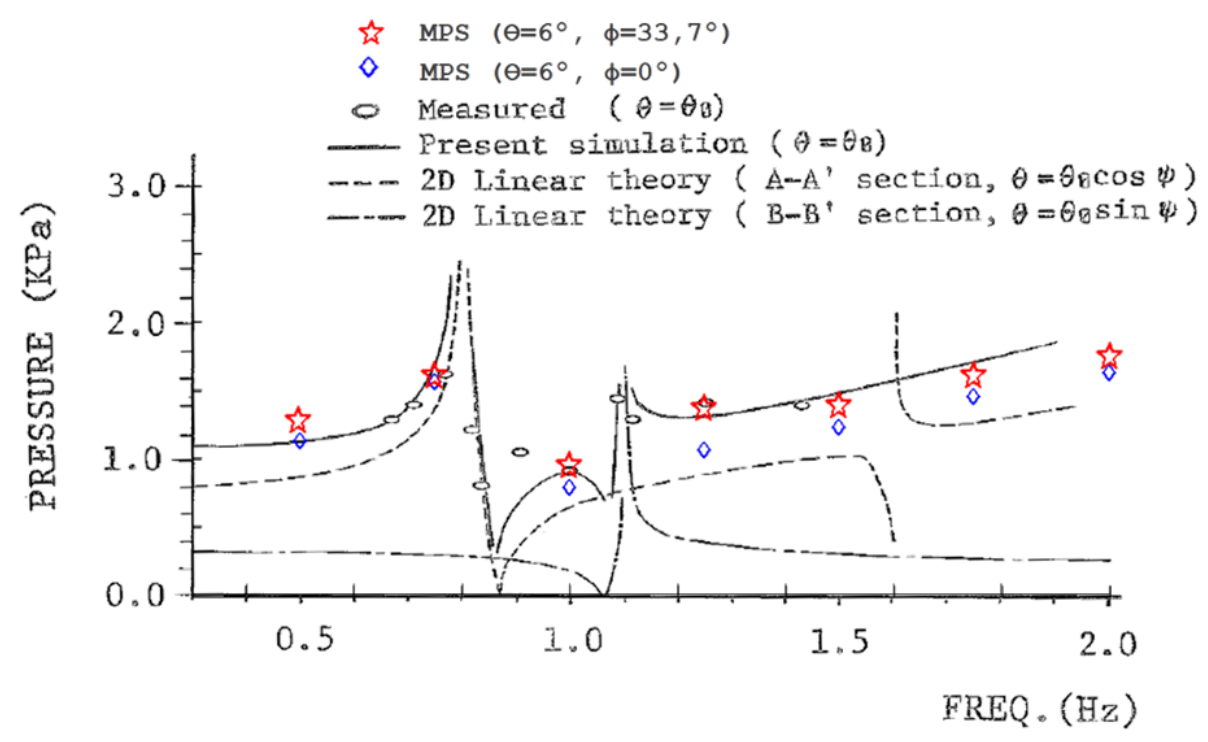

Figura 67 Pressão hidrodinâmica em função da frequência (Caso C, $\theta=6^{\circ}, \varphi=33,7^{\circ}$ ) - MPS x experimental (adaptado de Arai et. al., 1992)

\subsection{Estudo de supressor de sloshing com anteparas fixas}

O fenômeno de sloshing em tanques em forma de paralelepípedo apresenta período naturais bem defidos que variam de acordo com a dimensão e o nível de preenchimento. Dadas as dimensões médias dos tanques presentes em estruturas offshore, em muitos casos a frequência natural do fenômeno de sloshing se aproxima do período típico da região na qual a estrutura se encontra ancorada. Então, com o objetivo de modificar o comportamento do fenômeno de sloshing, de deslocar a posição da frequência natural no diagrama de pressão dinâmica ou simplesmente amortecer o fenômeno, são estudadas várias maneiras de se suprimir o movimento do fluído dentro dos tanques.

A aplicação do método de partículas na análise de um problema de engenharia relacionado ao fenômeno de sloshing é analisada a atuação de dispositivos de supressão de sloshing baseados em anteparas fixas horizontais. Neste estudo são analisadas diferentescondições de preenchimento e diferentes formas de posicionar a antepara na região central do tanque. Os modelos empregados e as suas dimensões são apresentados na Figura 68, que mostra o modelo sem antepara (a), o modelo com antepara na região do fundo (baffle A) (b), o modelo com antepara no centro (baffle B)(c) e o modelo com antepara no topo do tanque (baffle $\mathrm{C})(\mathrm{d})$. 


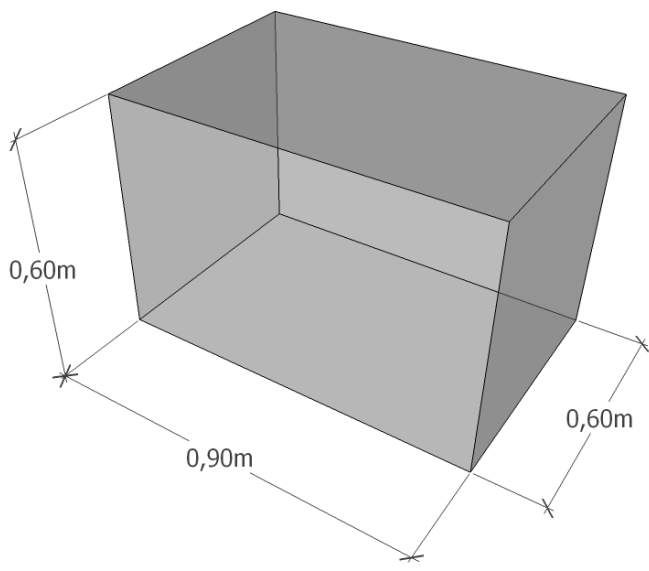

(a)

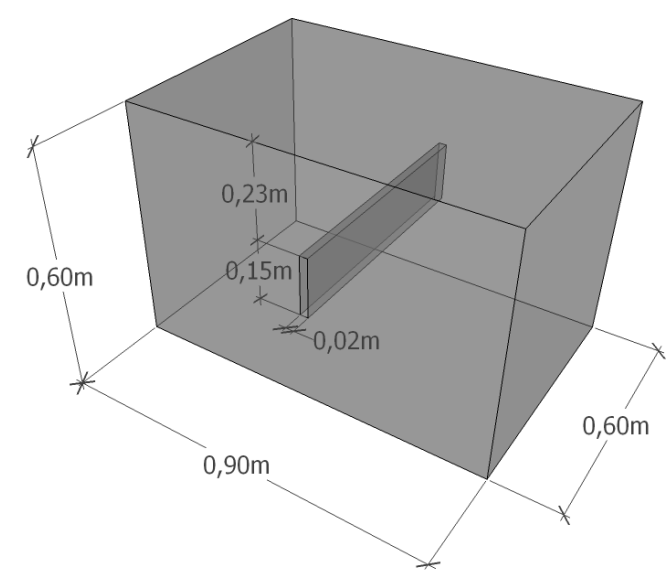

(c)

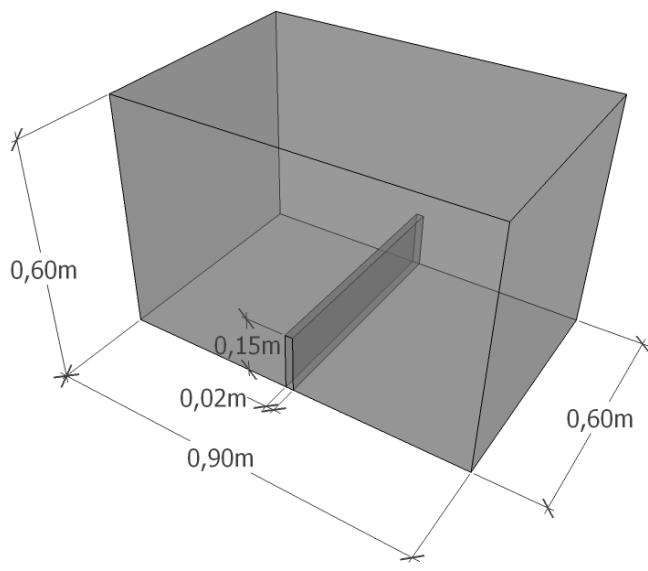

(b)

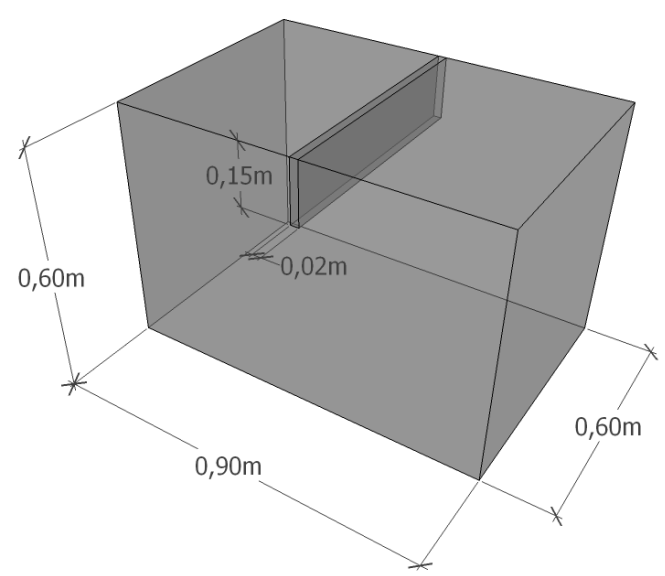

(d)

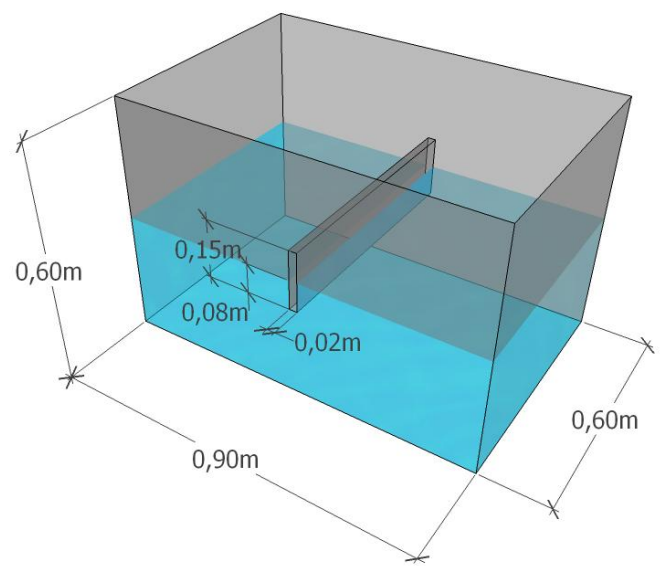

(e)

Figura 68 Modelos de tanque para o estudo de supressão de sloshing - Modelo sem antepara (a), modelo com antepara no fundo (Modelo A) (b), modelo com antepara no centro (Modelo B)(c), modelo com antepara no topo (Modelo C) e modelo com antepara flutuante (e) 
Com o objetivo de possuir um mecanismo supressor que esteja sempre próximo à superfície livre do fluído no tanque, é proposta a análise do emprego de uma antepara flutuante horizontal, mostrada na Figura 68-(e). A antepara possui $1,35 \mathrm{~kg}$ e densidade equivalente a metade da densidade da água. O movimento da antepara é restrito a translação na direção vertical em relação ao plano de coordendas oxyz local do tanque.

Neste estudo são avaliadas 5 diferentes condições de preenchimento. Para as condições de menor preenchimento poderão não ser analisadas a situações em que seja colocada antepara no centro (baffle B) e no topo do tanque (baffle C). A combinação entre os diferentes modelos e os níveis de preenchimento a serem simulados são apresentados na Tabela 13.

Tabela 13 Combinação dos modelos de tanque e níveis de preenchimento

Modelos

\begin{tabular}{c|c|cccc}
\hline $\begin{array}{c}\text { Nível de } \\
\text { preenchimento } \\
{[\mathrm{mm}]}\end{array}$ & $\begin{array}{c}\text { Razão entre } \\
\text { altura e } \\
\text { preenchimento } \\
(\mathrm{H} / \mathrm{h})\end{array}$ & $\begin{array}{c}\text { s/ } \\
\text { antepara }\end{array}$ & $\begin{array}{c}\text { Antepara } \\
\text { Antepara }\end{array}$ & $\begin{array}{c}\text { Antepara } \\
\text { An }\end{array}$ \\
\cline { 3 - 5 } 200 & $33 \%$ & $\mathrm{X}$ & $\mathrm{X}$ & \\
300 & $50 \%$ & $\mathrm{X}$ & $\mathrm{X}$ & $\mathrm{X}$ \\
400 & $67 \%$ & $\mathrm{X}$ & $\mathrm{X}$ & $\mathrm{X}$ \\
450 & $75 \%$ & $\mathrm{X}$ & $\mathrm{X}$ & $\mathrm{X}$ \\
\end{tabular}

Para cada uma das combinações entre modelo e nível de preenchimento enumeradas na Tabela 13 são simuladas 24 diferentes frequências com o objetivo de traçar a curva de pressão dinâmica ao longo da frequência. A combinação entre estes valores resulta no número de 384 simulações. As frequências, tempo de simulação e janela de impressão são apresentados pela Tabela 14. 


\begin{tabular}{|c|c|c|c|}
\hline \multicolumn{2}{|c|}{ Frequência [Hz] } & $\begin{array}{c}\text { Tempo de } \\
\text { simulação [s] }\end{array}$ & $\begin{array}{c}\text { Tempo de } \\
\text { impressão [s] }\end{array}$ \\
\hline \multicolumn{2}{|c|}{0,05} & & \\
\hline \multicolumn{2}{|c|}{0,1} & & \\
\hline \multicolumn{2}{|c|}{0,15} & 80 & 0,1 \\
\hline \multicolumn{4}{|c|}{0,2} \\
\hline \multicolumn{2}{|c|}{0,25} & & \\
\hline 0,3 & 0,575 & & \\
\hline 0,35 & 0,6 & & \\
\hline 0,4 & 0,625 & & \\
\hline 0,45 & 0,65 & 40 & 0,05 \\
\hline 0,5 & 0,675 & & \\
\hline 0,525 & 0,7 & & \\
\hline 0,55 & 0,725 & & \\
\hline 0,75 & 0,95 & & \\
\hline 0,8 & 0,975 & & \\
\hline 0,825 & 1,0 & & \\
\hline 0,85 & 1,25 & 20 & 0,025 \\
\hline 0,875 & 1,5 & & \\
\hline 0,9 & 1,75 & & \\
\hline 0,925 & 2,0 & & \\
\hline
\end{tabular}

O movimento forçado do tanque continua como a rotação oscilatória baseada na função senoidal apresentada na Eq. 13, com amplitude de $\theta=6^{\circ}$ e ângulo $\phi=33.3^{\circ}$. O deslocamento do eixo de rotação se dá com o objetivo de simular um fenômeno de sloshing completamente tridimensional, tanto com a componente de pitch quanto a componente de heave.

São empregados modelos com distância entre partículas de 1 centímetro, com modelos de aproximadamente 175 mil partículas para o menor nível de preenchimento (25\%) e 300 mil partículas para o maior nível de preenchimento (75\%). O incremento de tempo é de 0,0005 segundos e a constante suavizadora de 
pressão é de 0,05 . Para a simulação de 20 segundos (para as frequências de $0,8 \mathrm{HZ}$ a 2,0Hz) é necessário cerca de 12 horas de tempo de prcessamento.

A análise dos dispositivos de supressão de sloshing se dá em termos, sobretudo, da pressão dinâmica nos sensores de pressão distribuídos ao longo do tanque. $\mathrm{Na}$ análise que segue serão considerados os resultados para o sensor de pressão $\mathrm{P} 1$. A posição e as dimensões para o posicionamento dos sensores são apresentados na Figura 69.

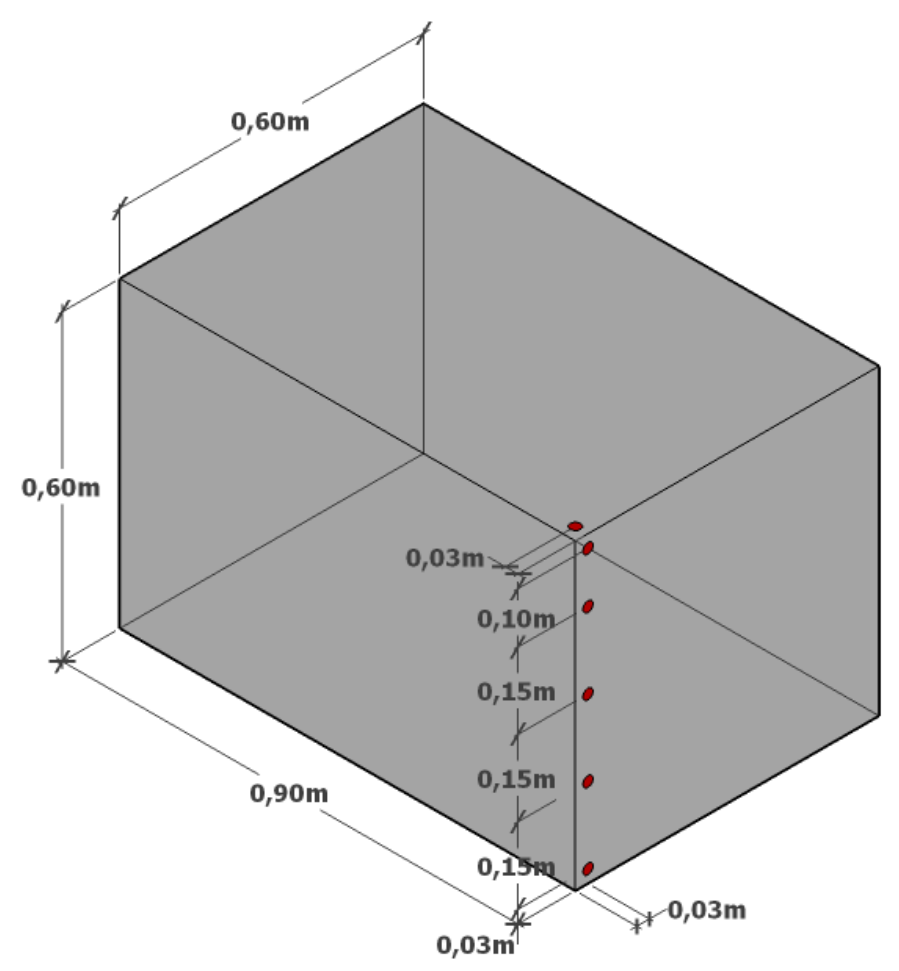

Figura 69 Distribuição dos sensores de pressão

\subsubsection{Resultados}

Em primeiro lugar, baseado no esquema apresentado na Figura 70, onde são apresentados os modos naturais do fenômeno de sloshing em tanque, é mostrada na Eq. 10 a fórmula analítica para o período natural de sloshing bidimensional. 


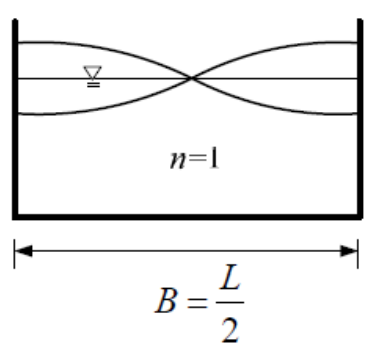

(a)

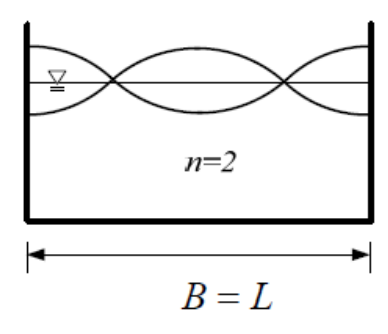

(b)

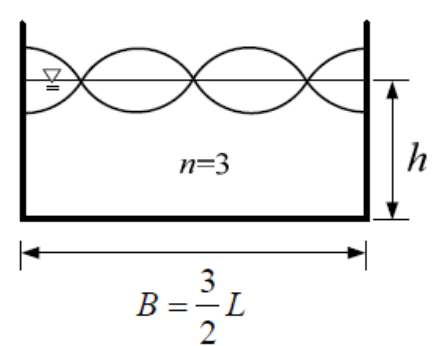

(c)

Figura 70 Modos naturais de sloshing bidimensional (a) $n=1$ (b) $n=2$ (c) $n=3$

$$
T_{n}=\frac{2 \sqrt{\pi B}}{n \sqrt{g \tanh \left(\frac{n \pi}{B} h\right)}}
$$

$\mathrm{Na}$ Figura 71 é apresentado o diagrama de pressão dinâmica para o preenchimento de $25 \%$, para o qual são simulados apenas o tanque sem antepara, o tanque com antepara no fundo e o tanque com antepara flutuante. A ressonância para o movimento de pitch ocorre por volta de $0,65 \mathrm{~Hz}$, enquanto que para 0 movimento de roll para $0,9 \mathrm{~Hz}$. A ressonância obtida para o movimento tridimensional foi observada por volta de $0,7 \mathrm{~Hz}$, mostrando predominância da componente de pitch. O emprego da antepara (tanto fixa quanto flutuante) reduz de maneira significativa a pressão dinâmica na região da frequência natural.

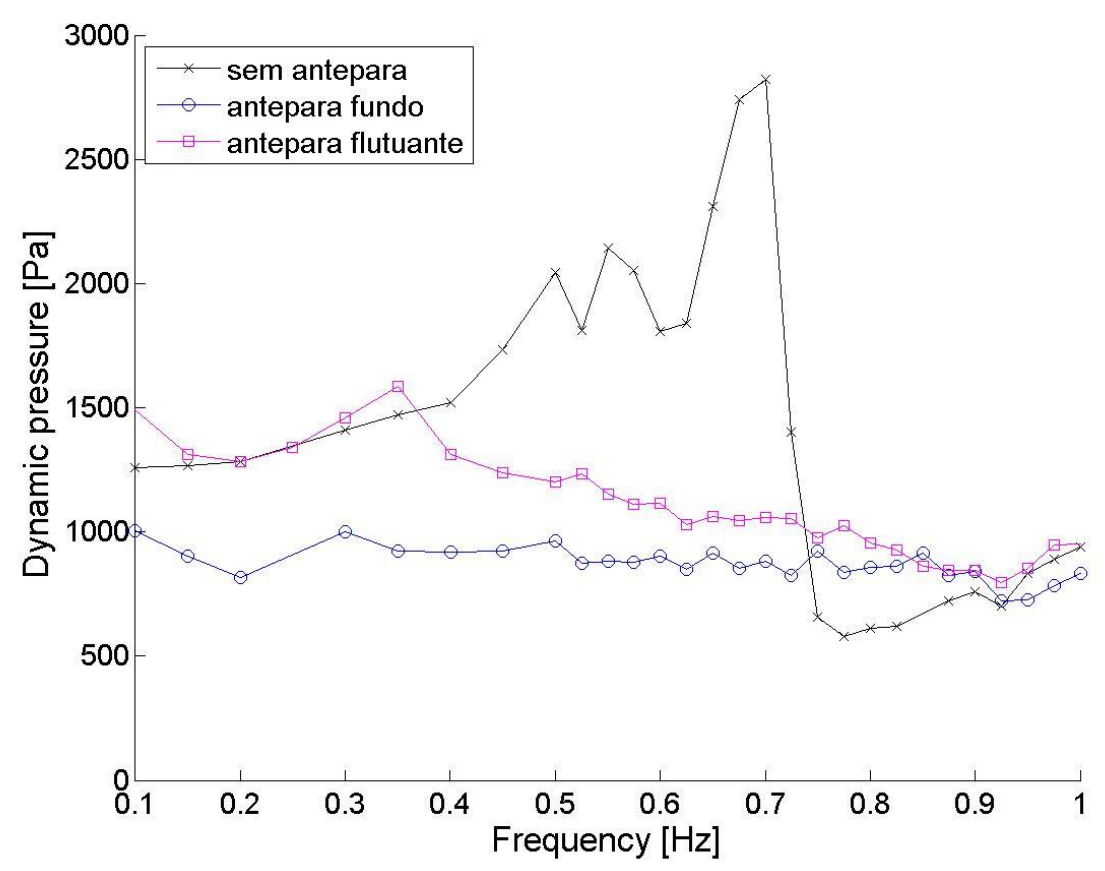

Figura 71 Diagrama de pressão dinâmica - nível de preenchimento de 25\% - P1 

(a) $f=0,6 \mathrm{~Hz}$
(b) $f=0,7 \mathrm{~Hz}$
(c) $f=0,75 \mathrm{~Hz}$

$\infty$
0
$\stackrel{N}{N}$
$\infty$
$\stackrel{\infty}{I I}$
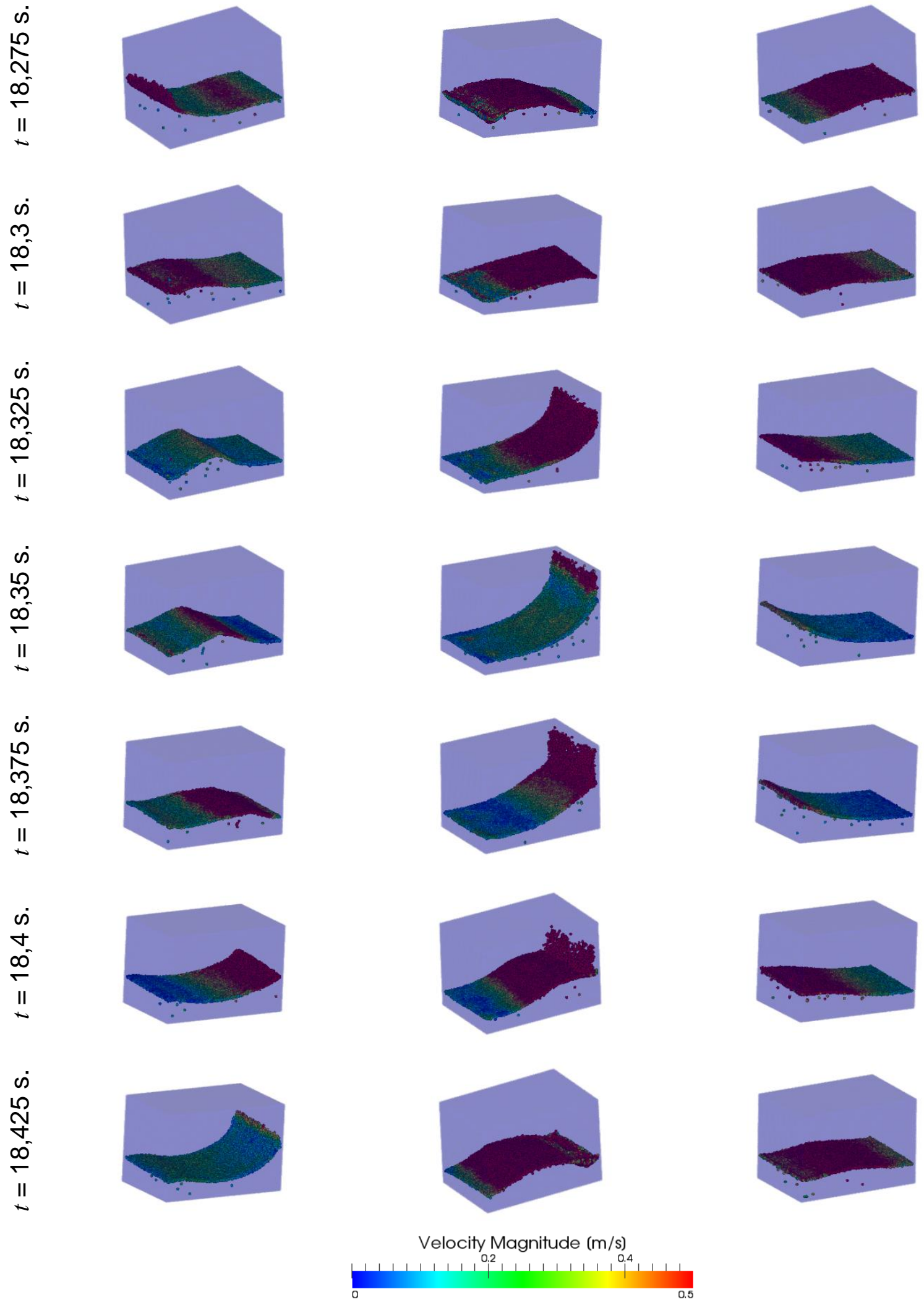

Figura 72 Snapshots da simulação por método de partículas - nível de preenchimento de $25 \%$ -

(a) $f=0,6 \mathrm{~Hz}$ (b) $f=0,7 \mathrm{~Hz}$ (c) $f=0,75 \mathrm{~Hz}$ 
A Figura 72 mostra snapshots da simulação numérica para as frequências próximas ao pico de ressonância. Na frequência de ressonância, para o fenômeno de sloshing em tanque com baixo preenchimento, é possível observar a formação da chamada "onda solitária" (travelling wave). A ressonância ocorre quando a onda solitária quebra na região próxima a parede, como para a frequência de $0,7 \mathrm{~Hz}$. Para frequências mais baixas a onda solitária quebra antes do contato com a parede, enquanto que para frequências maiores a onda solitária nem chega a quebrar.

Na Figura 73 é apresentada a série temporal da pressão no sensor P1 para a frequência de $0,7 \mathrm{~Hz}$. Observa-se que a utilização tanto da antepara horizontal fixa no fundo quanto da antepara flutuante reduzem a amplitude da oscilação de pressão. Tal redução inclusive muda a dinâmica do fenômeno, pois é possível observar dois picos de pressão na curva do tanque sem antepara, a primeira devido ao aumento da coluna d'água e a segunda devido ao colapso da mesma.

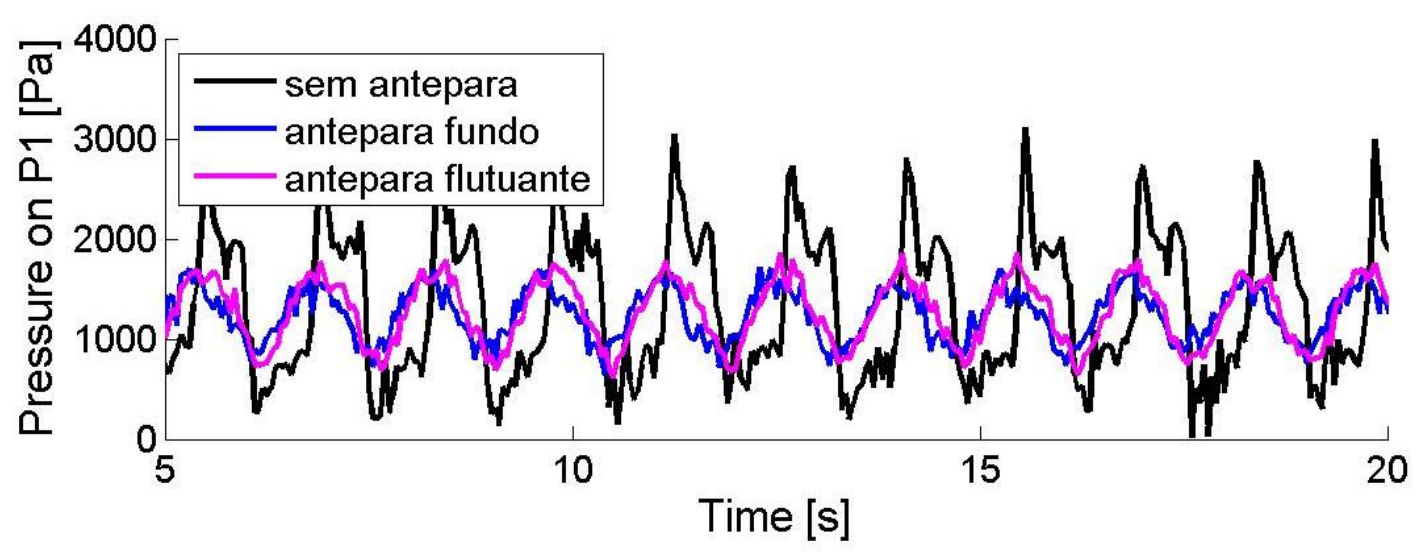

Figura 73 Série temporal de pressão no sensor P1- nível de preenchimento $25 \%$ - frequência $0,7 \mathrm{~Hz}$

$\mathrm{Na}$ Figura 74 é mostrada a série temporal da pressão máxima registrada em toda a superfície interna das paredes (acima) e a posição vertical do tanque na qual ocorre a pressão máxima (abaixo), para a frequência de $0,7 \mathrm{~Hz}$, aquela que registrou a maior pressão dinêmica e apresenta maior probabilidade de ter impacto de fluído nas paredes do topo. Os resultados mostra que o modelo sem antepara apresenta picos de pressão máxima maiores, da ordem de $3,0 \mathrm{kPa}$, enquanto o modelo com antepara fixa no fundo (baffle A) e o modelo com antepara flutuante mostram pressão máxima de cerca de 2,0kPa. 


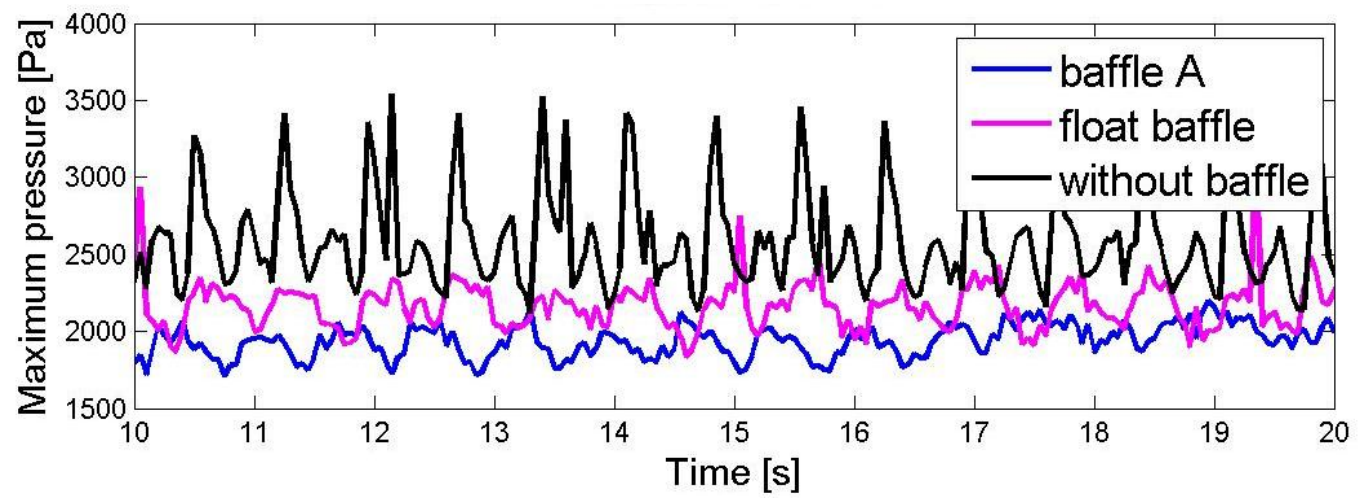

Figura 74 Série temporal da pressão máxima (a) e posição vertical no tanque de ocorrência da pressão máxima (b) - nivel de preenchimento $25 \%$

Por fim, na Figura 75 são mostrados os snapshots da simulação numéricos para a frequência de ressonância comparando o tanque sem anteparas ao tanque com antepara fixo no fundo e o tanque com antepara flutuante. A escala de cores da superfície livre do fluído vai do azul ao vermelho e mostra a velocidade das partículas. Observa-se que o uso de anteparas confina o fluído, reduzindo o seu movimento. As maiores velocidades são, conforme o esperado, observadas para o caso do tanque sem anteparas. 
(a) Sem antepara
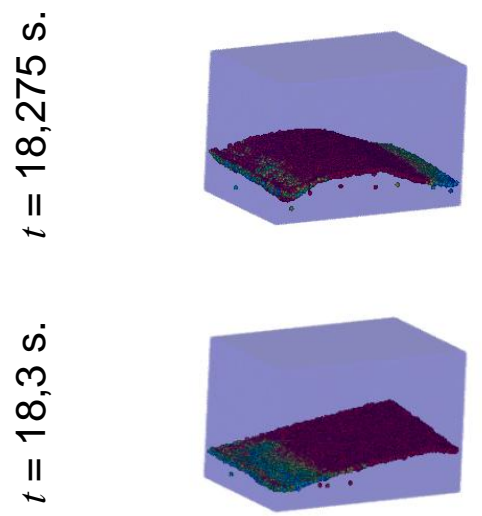

ம)

$\stackrel{\infty}{\infty}$

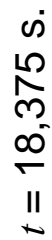

$\stackrel{\infty}{+}$

ஸ்
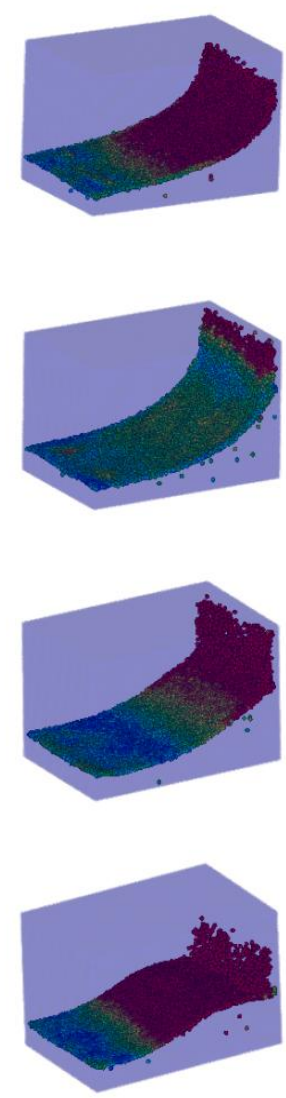

(b) Antepara fixa no fundo
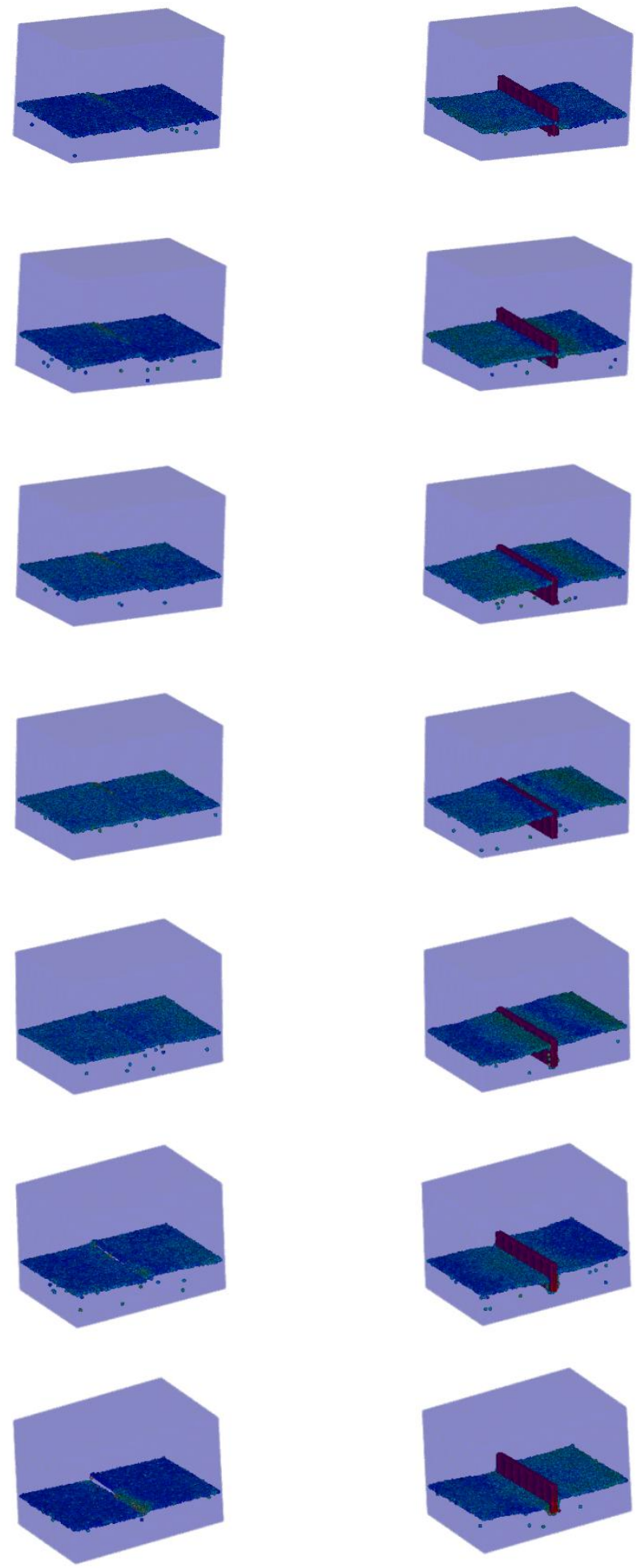

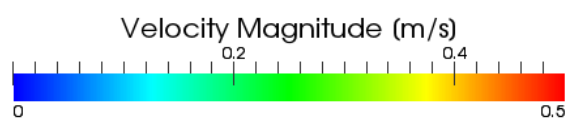

Figura 75 Snapshots da simulação por método de partículas - nível de preenchimento de $25 \%$ frequência $0,7 \mathrm{~Hz}$ - (a) sem antepara (b) antepara fixa no fundo (c) antepara flutuante 
Na Figura 76 é apresentado o diagrama no domínio da frequência para a pressão dinâmica na condição de preenchimento de 33\%, na qual são mostrados os resultados para o tanque de geometria tradicional, o tanque com antepara no fundo e o tanque com antepara ao centro.

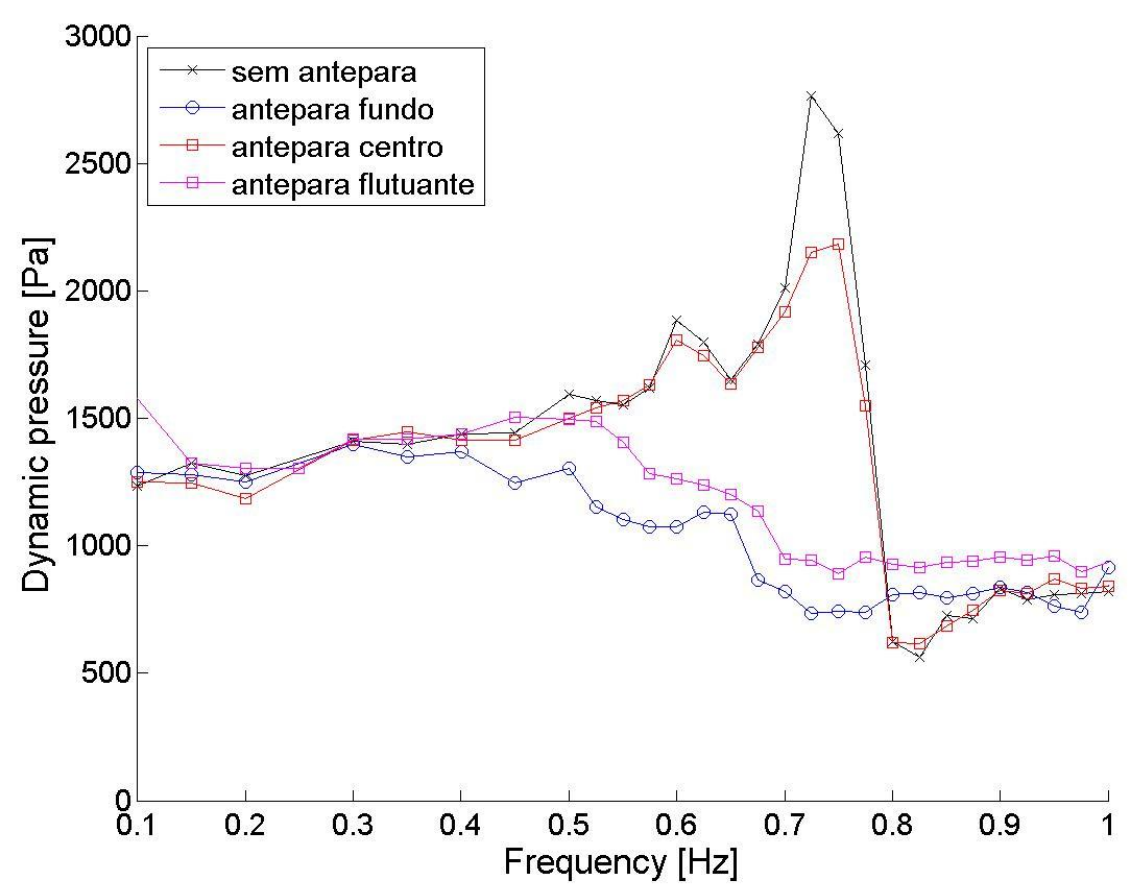

Figura 76 Diagrama de pressão dinâmica - nível de preenchimento de 33\% - P1

O intervalo no qual são verificadas as maiores pressões dinâmicas, relacionado a frequência natural do primeiro modo do fenômeno de sloshing, fica em torno da frequência de $0,7 \mathrm{~Hz}$ e é mais estreito em relação a região de ressonância do preenchimento de $25 \%$. A frequência natural de pitch, para este preenchimento, é de $0,72 \mathrm{~Hz}$, enquanto que a frequência natural de roll é de $1,0 \mathrm{~Hz}$. Mais uma vez observa-se a predominancia da componente de pitch.

Em uma visão geral, o resultado obtido para o preenchimento de $33 \%$ é bastante similar ao daquele obtido para o preenchimento de $25 \%$, no qual o emprego da antepara no fundo do tanque reduz significativamente a pressão dinâmica na região da frequência natural. A antepara ao centro do tanque (baffle $\mathrm{B}$ ) mostra apenas uma pequena redução na pressão dinâmica somente para a frequência mais crítica, de $0,75 \mathrm{~Hz}$. Mais uma vez, a antepara flutuante mostra redução na pressão dinâmica na região de ressonância. 
Na Figura 77 é mostrada a série temporal da pressão pra o sensor P1 e o preenchimento de 33\%. Assim como no caso anterior, é possível observar os dois picos nas curvas do tanque sem antepara e no tanque com antepara fixa no centro, que suprime apenas ligeiramente o sloshing. Já para o tanque com antepara fixa no fundo e o tanque flutuante, a redução na amplitude da pressão é considerável e deixa de haver o segundo pico.

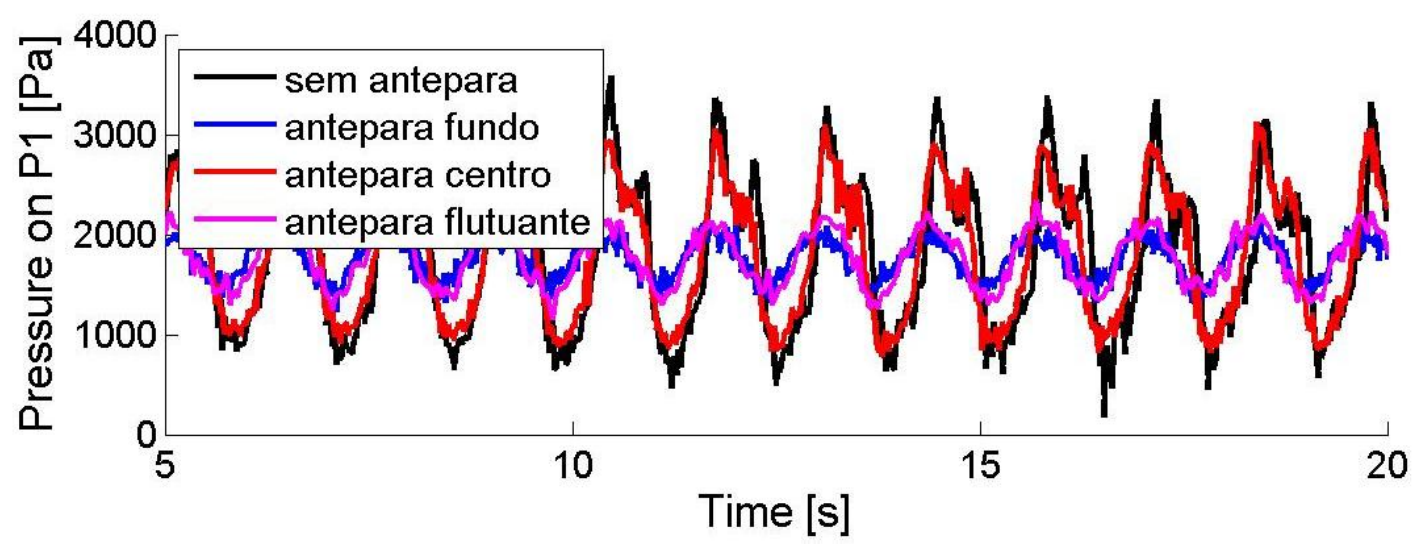

Figura 77 Série temporal de pressão - sensor P1 - nível de preenchimento $33 \%$ - frequência $0,75 \mathrm{~Hz}$

A Figura 78 apresenta a série tempral para a pressão máxima registrada em todo o domínio computacional, para o preenchimento de $33 \%$ e a frequência de $0,75 \mathrm{~Hz}$. O resultado, mais uma vez, é bastante próximo ao obtido para preenchimento de $25 \%$, no qual os picos do registro de pressão máxima são associados ao impacto hidrodinâmico do fluído nas paredes do topo do tanque, fato que acontece com o tanque tradicional e é evitado por meio do emprego das antepara fixa no fundo e flutuante.

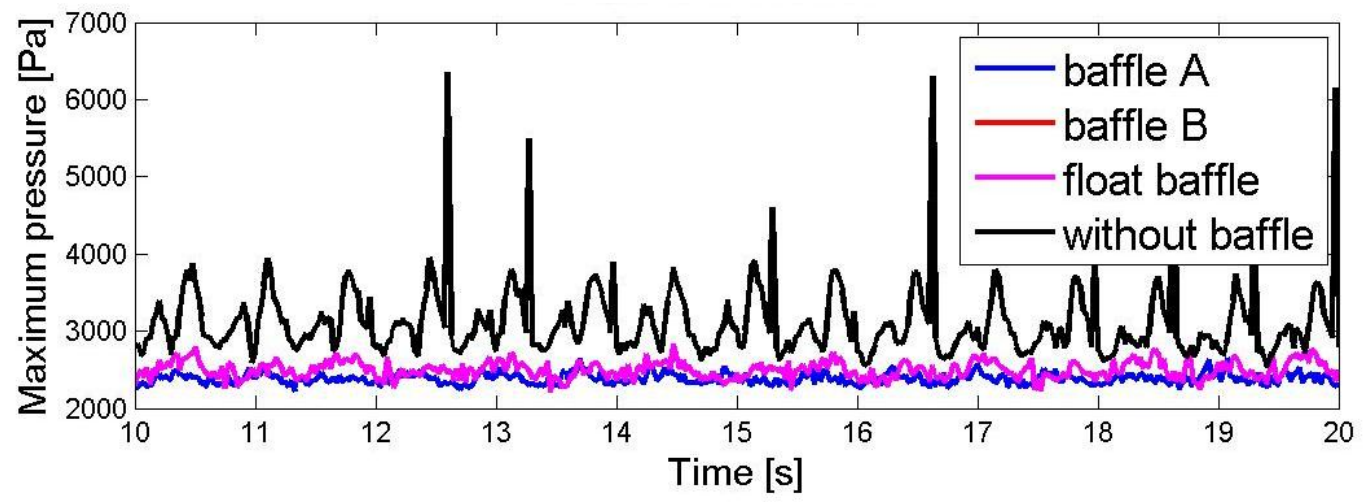

Figura 78 Série temporal da pressão máxima (a) e posição vertical no tanque de ocorrência da pressão máxima (b) - nivel de preenchimento $33 \%$ 
Na Figura 79 apresenta o diagrama de pressão dinâmica para o nível de preenchimento de 50\%. Observa-se o deslocamento da região associada à frequência natural para $0,8 \mathrm{~Hz}$, próximo da frequência natural de pitch, de cerca de $0,82 \mathrm{~Hz}$. Desta vez, diferentemente do resultado obtido para o nível de preenchimento anterior, o emprego da antepara ao centro (baffle B) apresenta resultados de supressão de sloshing similares aos obtido pelo emprego da antepara no fundo do tanque (baffle A). Neste resultado o emprego de antepara, nas duas posições, significou uma redução significativa na pressão dinâmica na região da frequência natural em relação ao modelo tradicional, sem mecanismo de supressão do fenômeno de sloshing. O emprego de antepara flutuante, mais uma vez, também apresentou bons resultados reduzindo a pressão dinâmica na região da ressonância.

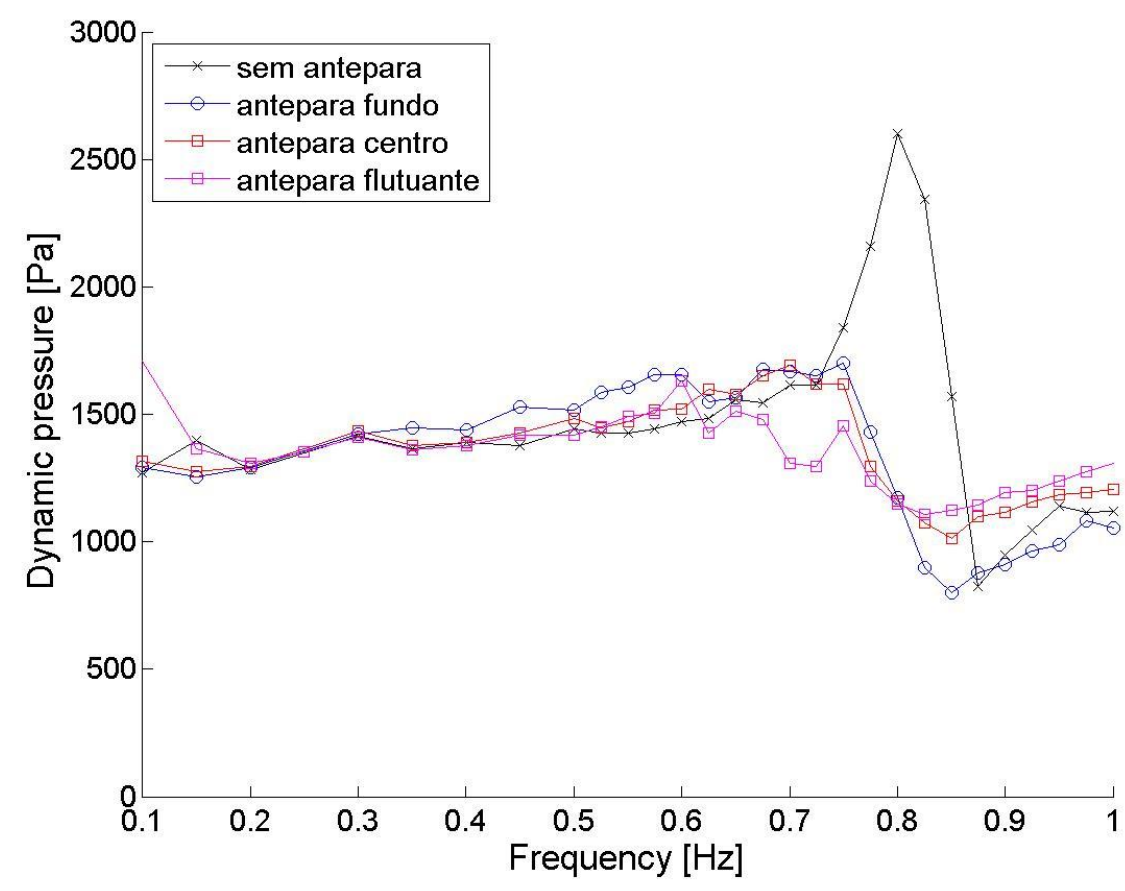

Figura 79 Diagrama de pressão dinâmica - nível de preenchimento de 50\% - P1

A Figura 80 apresenta a série temporal da pressão no sensor P1 para a frequência de $0,8 \mathrm{~Hz}$, aquela associada ao maior valor obtido para a pressão dinâmica. Em primeiro lugar, a amplitude da senoide relativa ao modelo tradicional possui amplitude maior do que aquela dos modelos com antepara; em segundo lugar, o emprego da antepara muda em parte o comportamento da curva de pressão, na qual deixa-se de observar a existência um segundo pico de pressão, característica do fenômeno de sloshing e observado no resultado com uso do tanque 
tradicional.

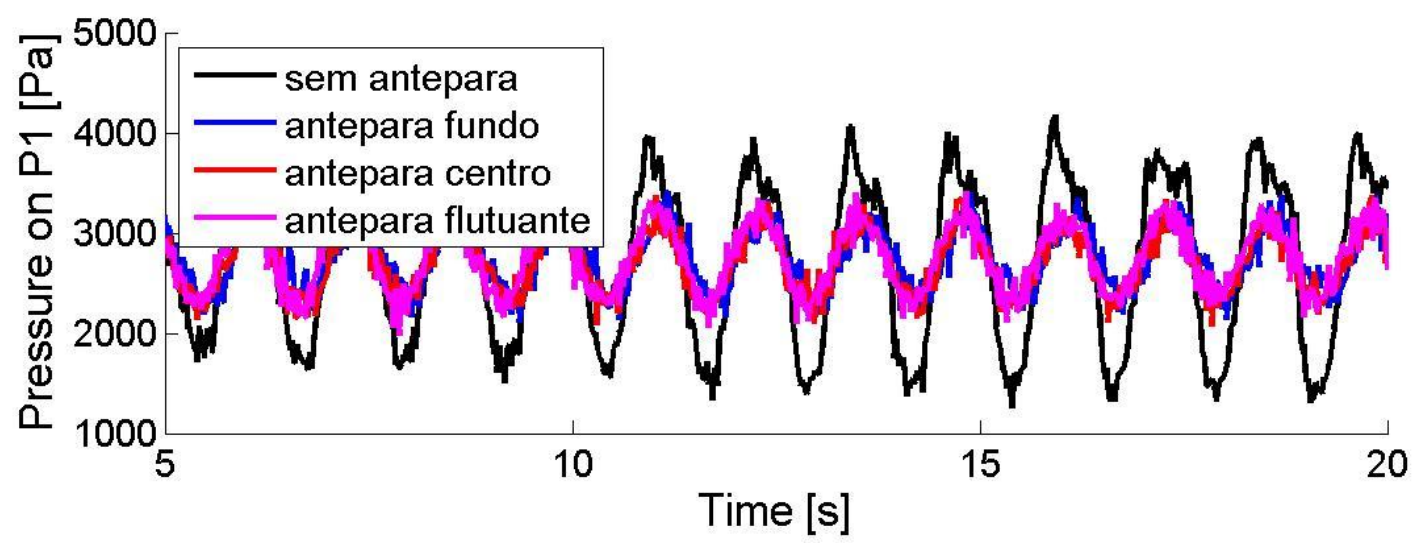

Figura 80 Série temporal de pressão no sensor P1- nível de preenchimento $50 \%$ - frequência $0,8 \mathrm{~Hz}$

A Figura 81 apresenta as séries temporais da pressão máxima registrada nas paredes do tanque e a posição vertical de ocorrência do máximo valor de pressão, ambas para a frequência de $0,8 \mathrm{~Hz}$, na qual observa-se maior pressão dinâmica. Neste nível de preenchimento não ocorreu impacto de fluído na parede de topo do tanque, portanto, todas as pressões máximas obtidas são referentes ao fundo do tanque. Apesar de não ocorrer impacto, os modelos com uso de anteparas, devido a menor pressão dinâmica, também mostram menor registro da pressão máxima ao longo do tempo em relação ao modelo tradicional.

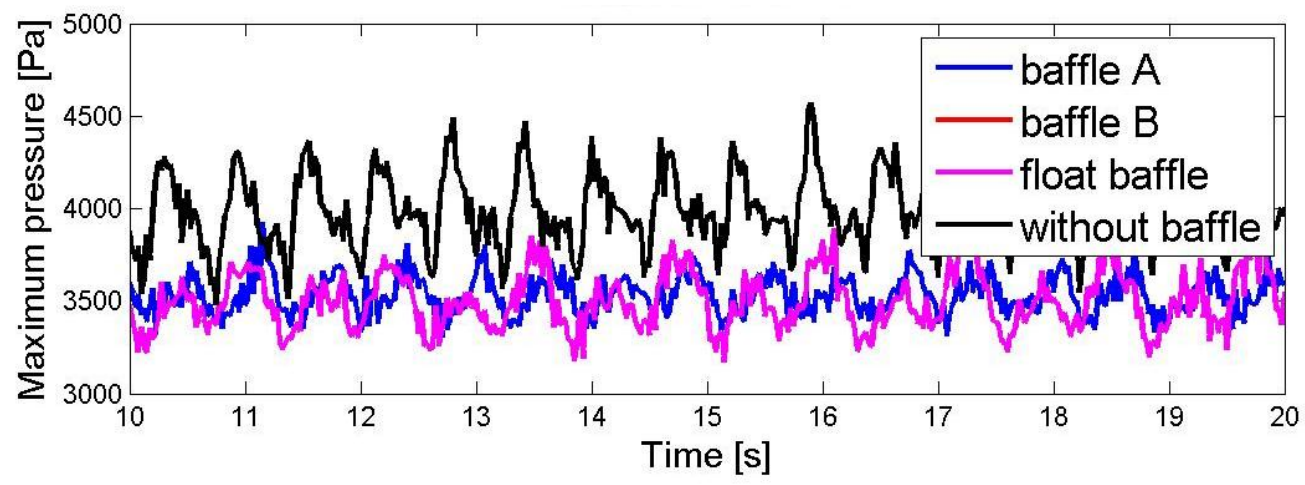

Figura 81 Série temporal da pressão máxima (a) e posição vertical no tanque de ocorrência da pressão máxima (b) - nivel de preenchimento $50 \%$

A Figura 82 mostra os snapshots da simulação numérica para 0 preenchimento de 50\%, com o tanque sem anteparas, o tanque com antepara fixa no fundo e o tanque com antepara flutuante. Pela escala de cores da velocidade das partículas na superfície livre observa-se as maiores velocidades, assim como o maior deslocamento da superfície livre, para o caso do tanque sem antepara. 
(a) Sem antepara
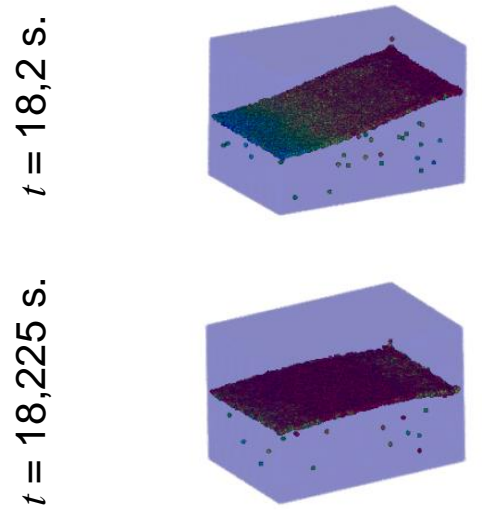

ஸึ

$\stackrel{\infty}{n} \stackrel{\infty}{N}^{\infty}$

i

$\infty$

$\stackrel{\infty}{-\infty}$

II

$\infty$

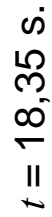

(b) Antepara fixa no centro
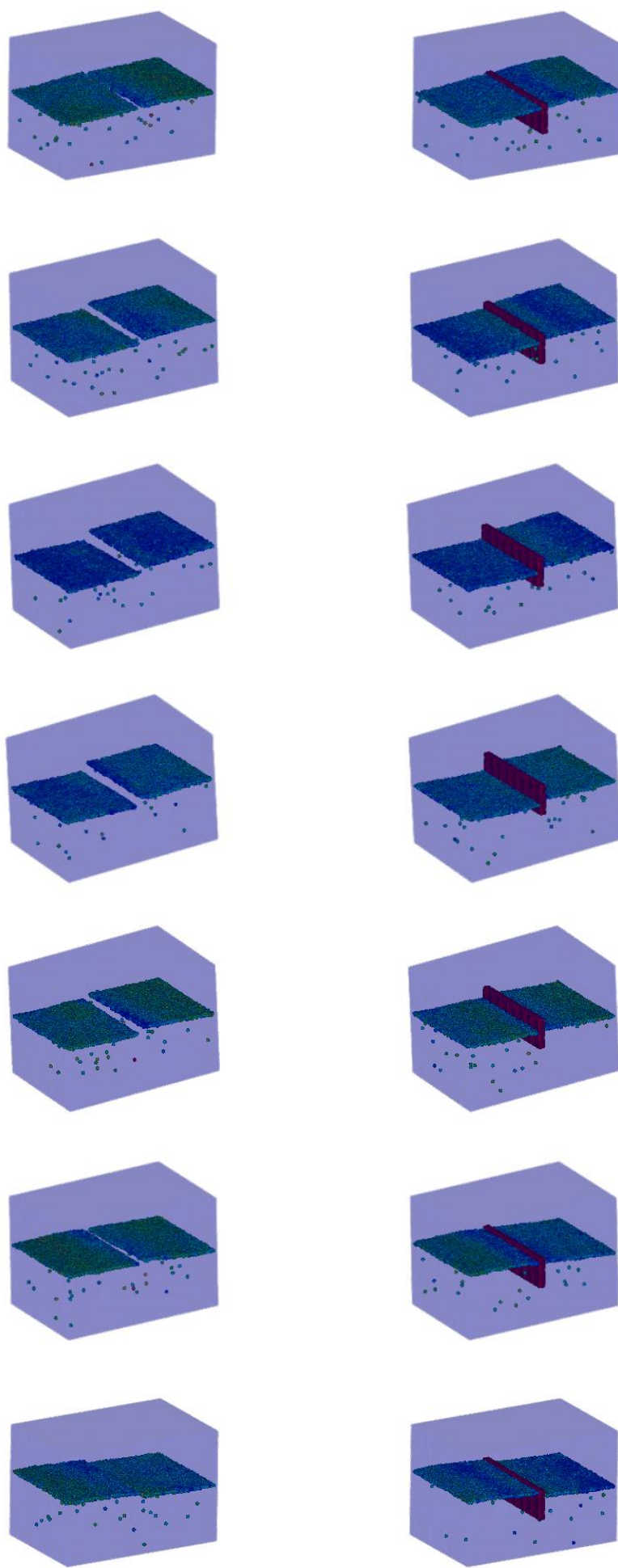

(c) Antepara flutuante
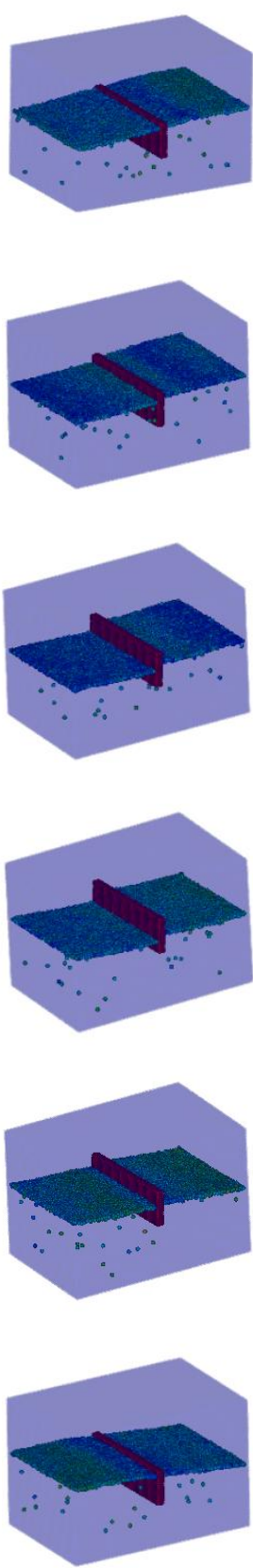

Velocity Magnitude (m/s)

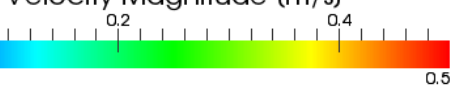

Figura 82 Snapshots da simulação por método de partículas - nível de preenchimento de $50 \%$ frequência $0,8 \mathrm{~Hz}$ - (a) sem antepara (b) antepara fixa no centro (c) antepara flutuante 
A Figura 83 apresenta o diagrama da pressão dinâmica para o preenchimento de $67 \%$ no domínio da frequência; são apresentados resultados para o uso da antepara nas três diferentes posições: no fundo (baffle A), ao centro (baffle B), no topo do tanque (baffle $\mathrm{C}$ ) e para a antepara flutuante. Para este preenchimento o efeito do emprego da antepara no topo é desprezível, de forma que a curva associada a este modelo é idêntica a curva do tanque tradicional e se sobrepõe a ela. O emprego da antepara no fundo e da antepara ao centro mostram, para ambas, redução na pressão dinâmica na região da frequência natural, com o modelo de antepara ao centro mostrando resultado significativamente melhor que a antepara ao fundo. Apesar de reduzir ligeiramente a pressão dinâmica na região de ressonância, a antepara no fundo apresenta um aumento, ainda mais ligeiro, da pressão dinâmica para as pressões entre $0,5 \mathrm{~Hz}$ e $0,8 \mathrm{~Hz}$. Por fim, a antepara flutuante mostra redução na pressão dinâmica na região de ressonância.

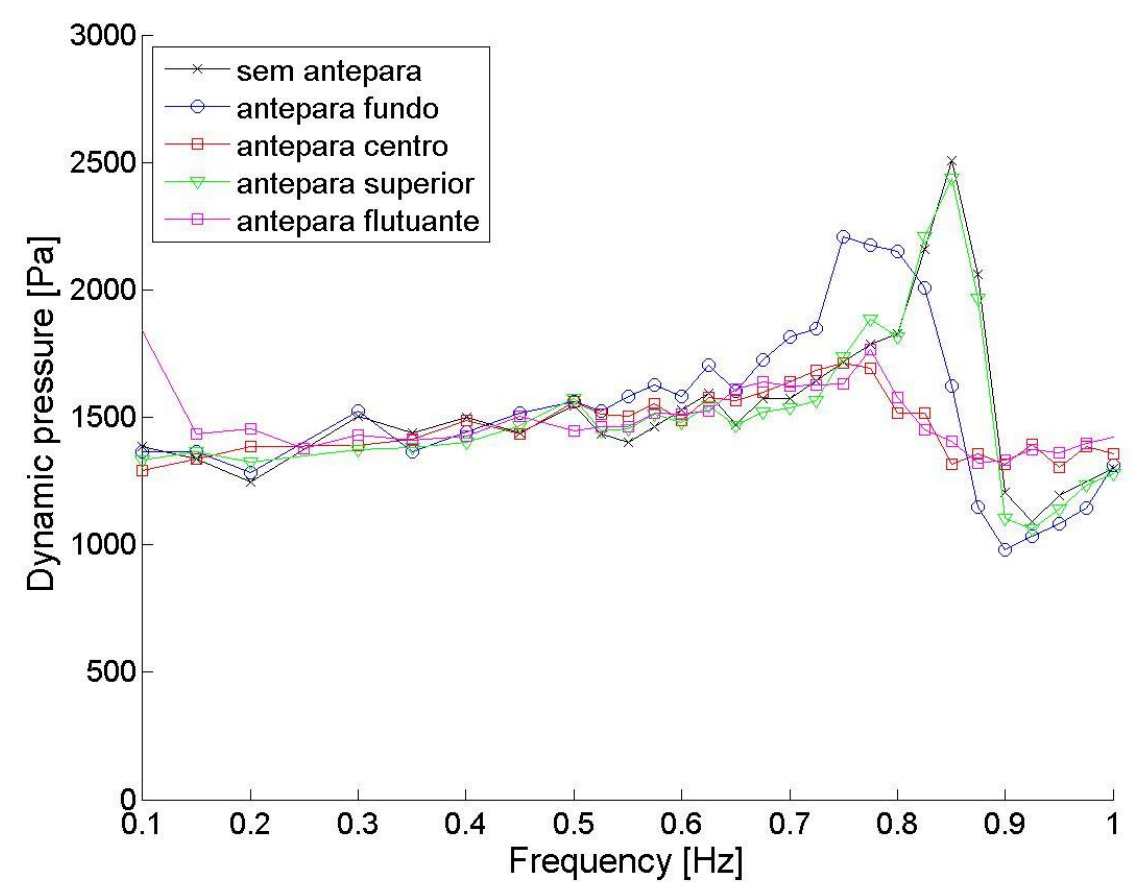

Figura 83 Diagrama de pressão dinâmica - nível de preenchimento de 67\%

A Figura 84 mostra a série temporal da pressão registrada no sensor P1 para a frequência de $0,85 \mathrm{~Hz}$, próxima da ressonância do tanque sem antepara. Observase redução da amplitude para os casos de anteparas fixas no fundo e no centro, assim como para a antepara flutuante. 


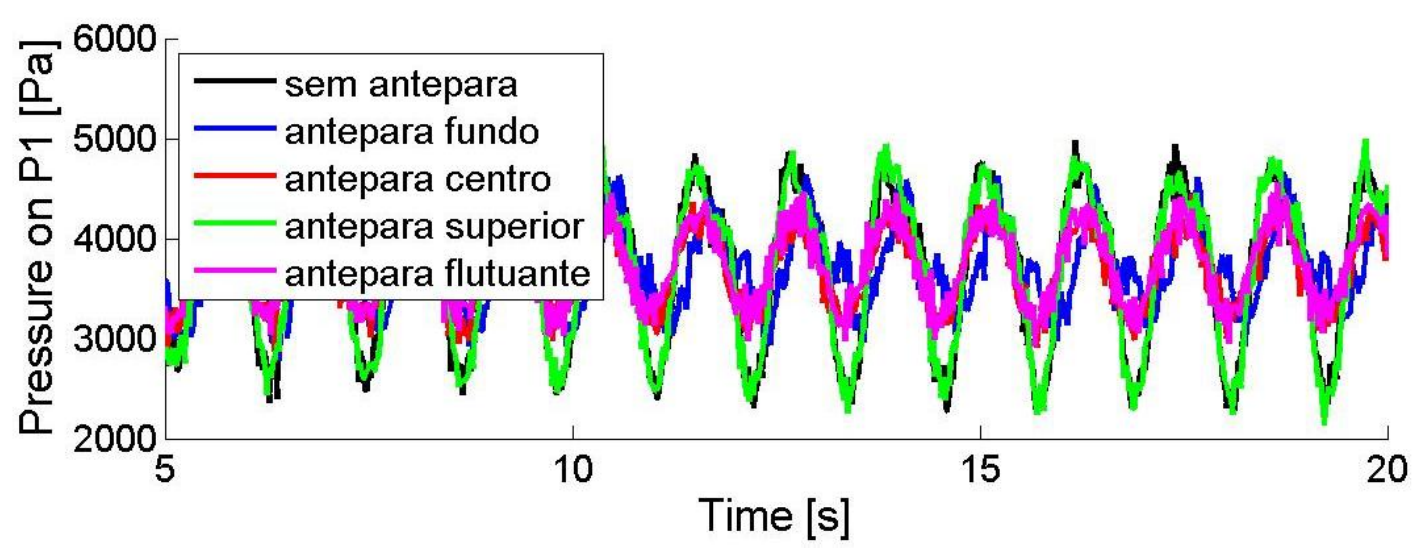

Figura 84 Série temporal de pressão - sensor P1 - nível de preenchimento $67 \%$ - frequência $0,85 \mathrm{~Hz}$ A Figura 85 mostra as séries temporais da pressão máxima e do osição vertical de registro da pressão máxima para as frequência de $0,85 \mathrm{~Hz}$.

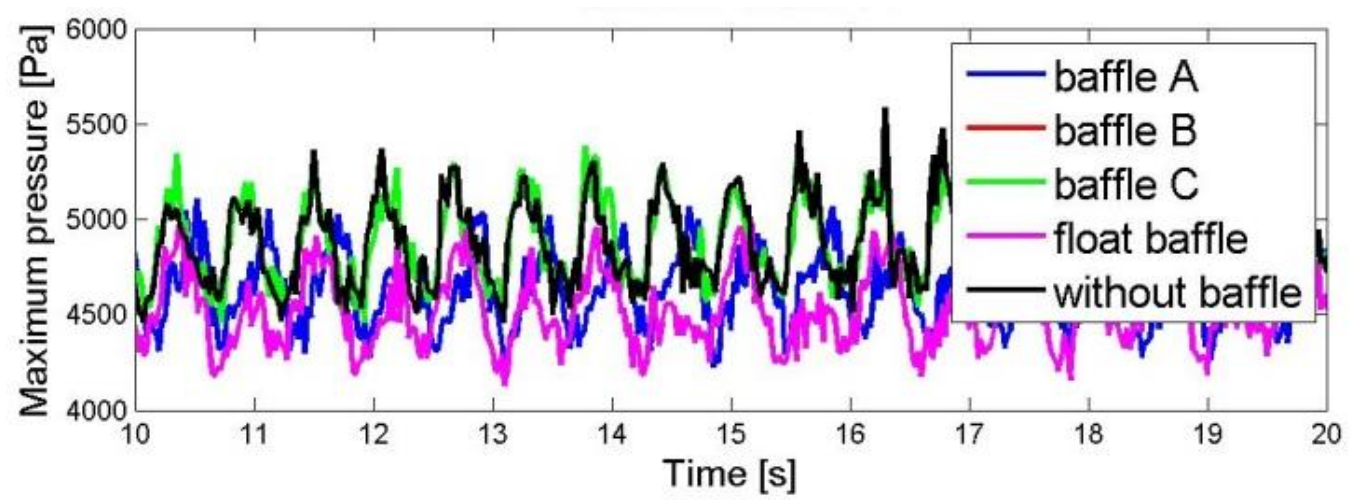

Figura 85 Série temporal da pressão máxima - frequência de $0,85 \mathrm{~Hz}$ - nível de preenchimento $67 \%$

Para $0,85 \mathrm{~Hz}$ se observa uma queda significativa na pressão máxima obtida com a antepara ao fundo e a antepara flutuante, menor do que aquela observada no tanque tradiconal. Ocorre impacto no topo apenas para o tanque sem supressor na frequência de $0,85 \mathrm{~Hz}$ e o emprego da antepara ao centro mostrou os melhores resultados para ambas as situações.

A Figura 86 apresenta o diagrama de pressão dinâmica para o maior nível de preenchimento analisado no presente estudo, de 75\%. Assim como no resultado para o nível de preenchimento de $67 \%$, a antepara no topo do tanque não apresentou nenhuma diferença significativa em relação ao tanque sem mecanismo de supressão. A frequência natural para a componente de pitch do tanque é de $0,9 \mathrm{~Hz}$, enquanto que a frequência natural para a componente de roll é de $1,1 \mathrm{~Hz}$, predominando a primeira componente. 


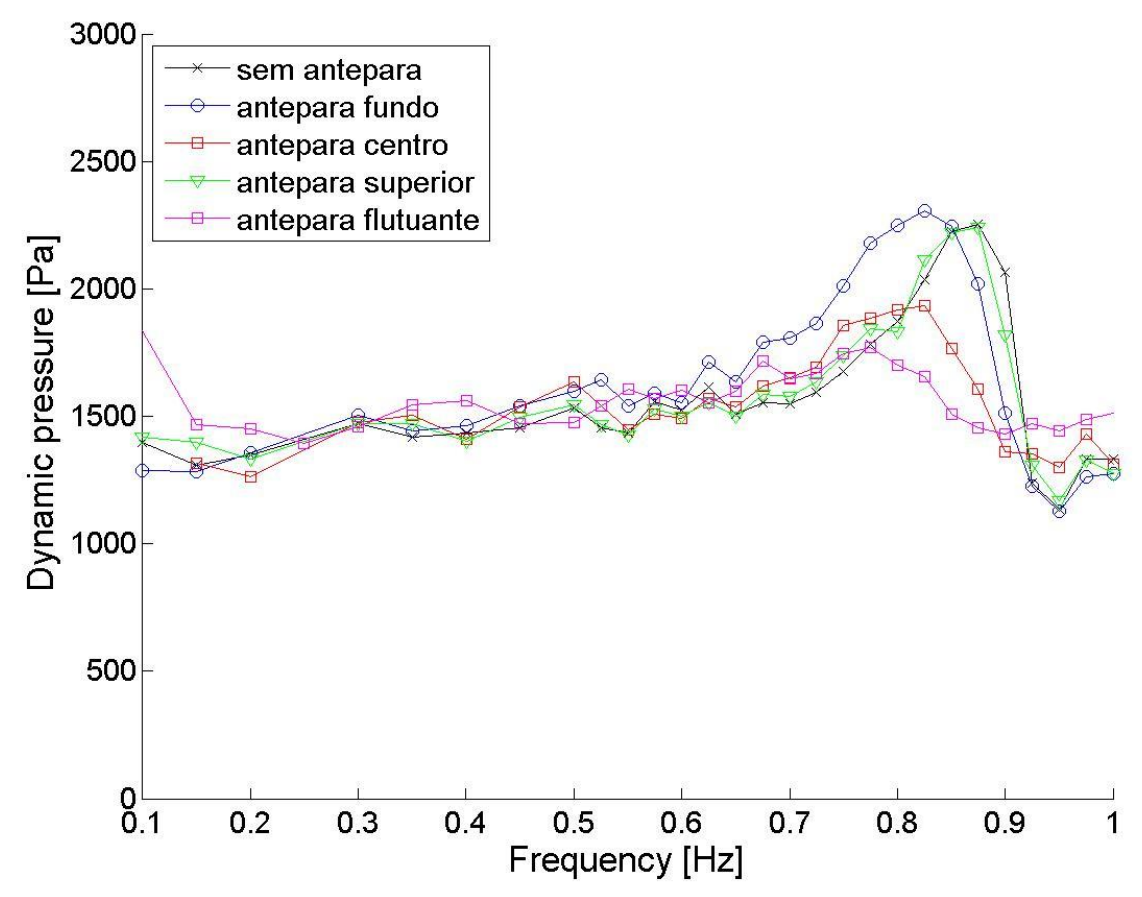

Figura 86 Diagrama de pressão dinâmica - nível de preenchimento de 75\% - P1

No entanto, diferentemente dos casos anteriores, o emprego de antepara no fundo do tanque mostrou aumento da pressão dinâmica inclusive ne região da frequência natural, tornando o fenômeno de sloshing ainda mais violento. Além disso, semelhante ao preenchimento anterior, a antepara posicionada ao centro do tanque mostrou bons resultados em relação a redução da pressão dinâmica.

Resultados bons de supressão para este preenchimento também são observados para a antepara flutuante. O uso de anteparas também parece modificar a dinâmica do sistema de modo que a frequência natural se desloca para frequência menores que $0,9 \mathrm{~Hz}$, sendo de cerca de $0,82 \mathrm{~Hz}$ para a antepara fixa no fundo e 0,78 para a antepara flutuante.

A Figura 87 mostra a série temporal da pressão no sensor $\mathrm{P} 1$ para 0 preenchimento de $75 \%$. Observa-se que a amplitude da curva para o modelo com antepara fixa no fundo é ligeiramente maior que os demais, enquanto que aamplitude da curva para o modelo com antepara flutuante é ligeiramente menor. 


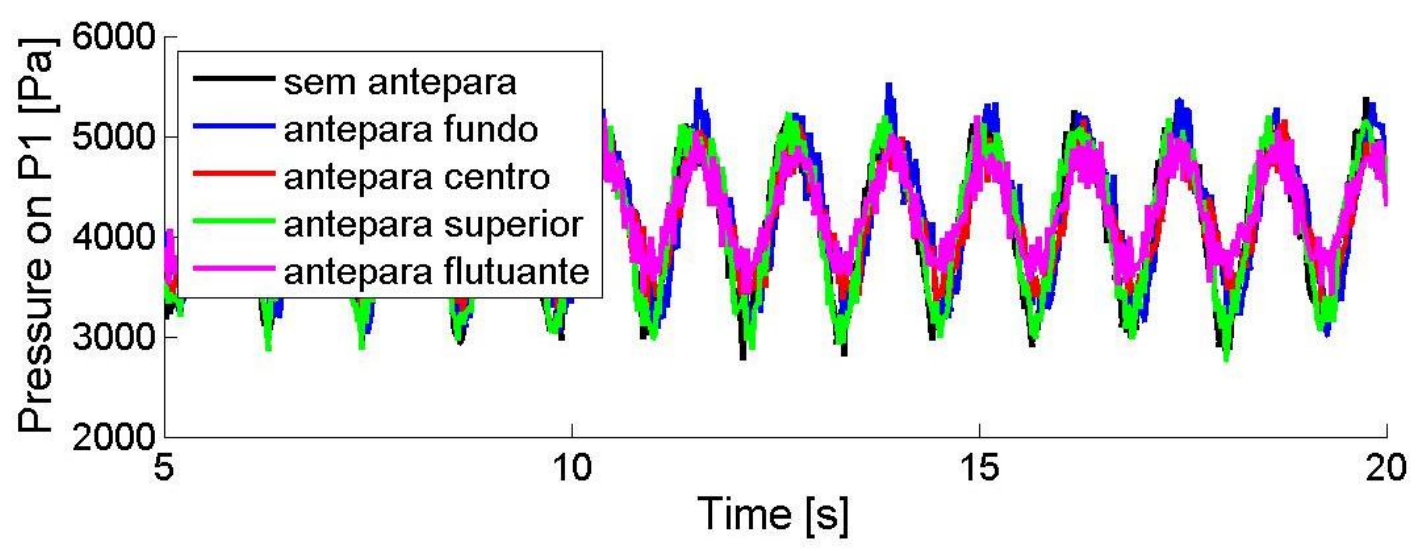

Figura 87 Série temporal de pressão - sensor P1 - nível de preenchimento $75 \%$ - frequência $0,85 \mathrm{~Hz}$

$\mathrm{Na}$ Figura 88é mostrada a série temporal da pressão máxima para a frequência de $0,85 \mathrm{~Hz}$. Para a frequência de $0,85 \mathrm{~Hz}$ o modelo com antepara no fundo aumenta a pressão dinâmica e é o únicoque apresenta impacto de fluído no topo, resultando em pressões máximas que chegam a ser o dobro da pressão máxima registrada no fundo do tanque, por volta de $10 \mathrm{kPa}$. Observa-se, neste caso, que o pico de pressão resultante do impacto hidrodinâmico no topo do tanque pode ser crítico.

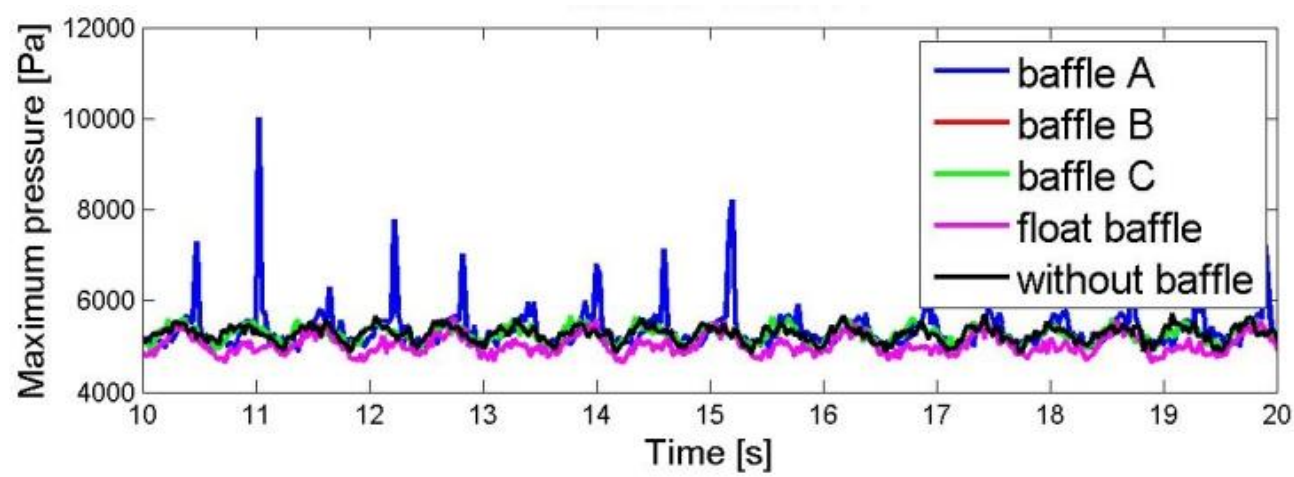

Figura 88 Série temporal da pressão máxima - frequência de $0,85 \mathrm{~Hz}$ - nível de preenchimento $75 \%$

Por fim, os snapshots da simulação numérica para o preenchimento de $75 \%$ são apresentados na Figura 89, com o tanque sem antepara, tanque com antepara fixa no fundo e tanque com antepara flutuante. Tanto no caso do tanque sem antepara quanto no tanque com antepara no fundo observa-se o impacto de fluído no topo do tanque, assim como a escala de cores indica maior velocidade das partículas da superfície livre. A supressão obtida pelo modelo com antepara flutuante também pode ser observada. 
(a) Sem antepara
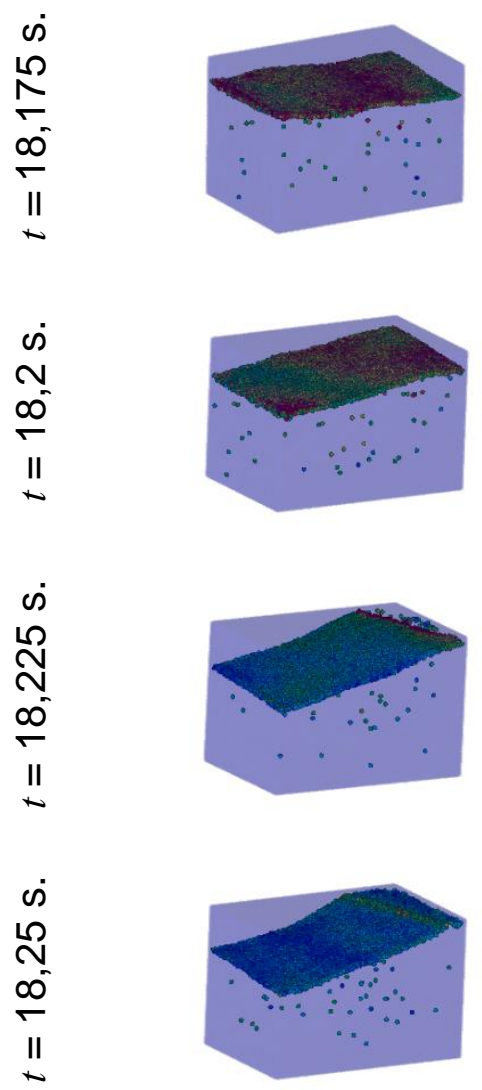

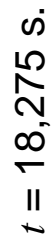
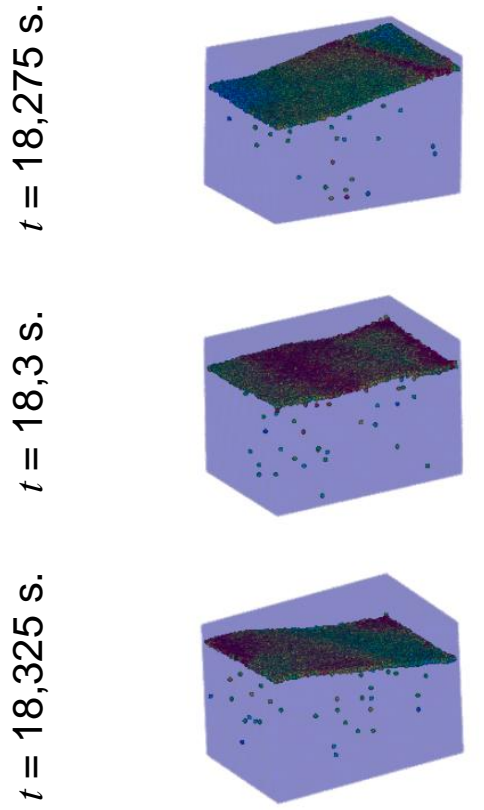

(b) Antepara fixa no fundo
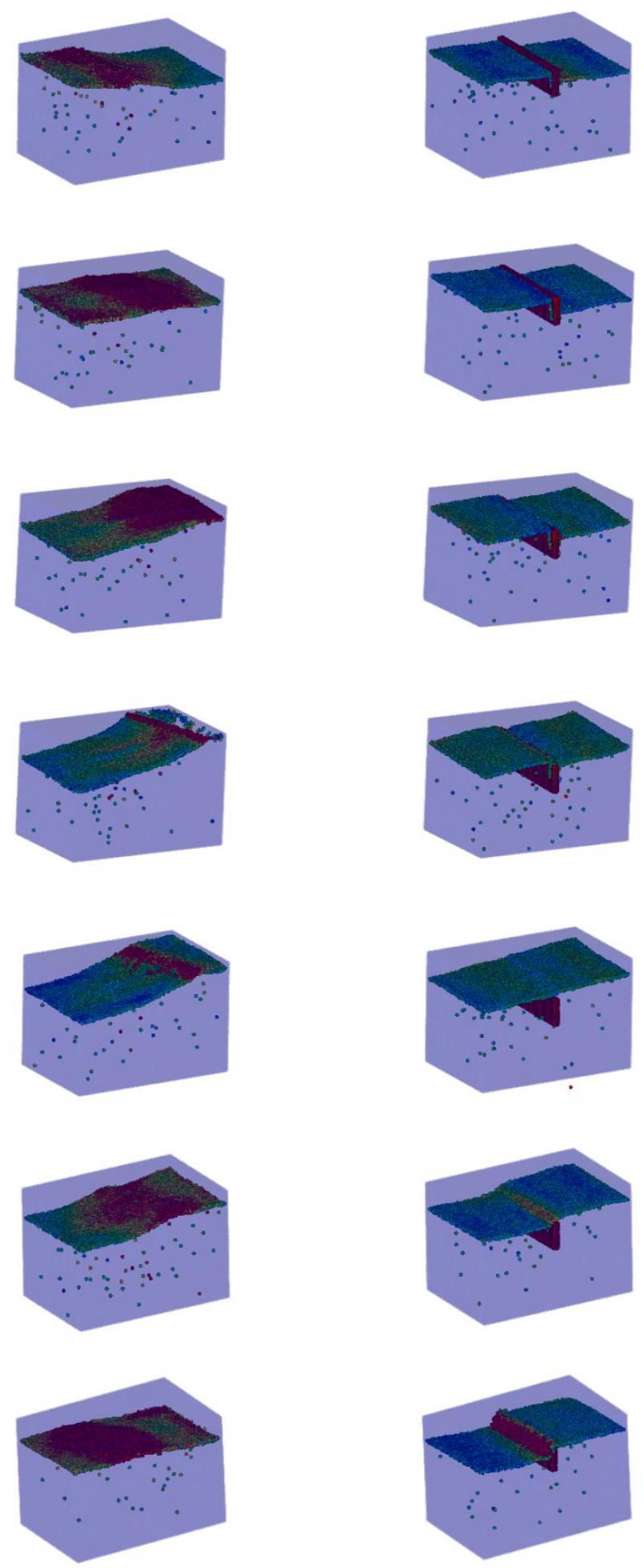

Velocity Magnitude (m/s)

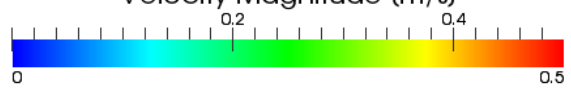

Figura 89 Snapshots da simulação por método de partículas - nível de preenchimento de $75 \%$ frequência $0,85 \mathrm{~Hz}$ - (a) sem antepara (b) antepara fixa no fundo (c) antepara flutuante 


\subsection{Considerações finais}

De acordo com os resultados apresentados na etapa de aplicação, as pressões resultantes do impacto hidrodinâmico da coluna de fluído no topo dos tanque, fruto do sloshing, implicam em pressões de magnitude muito maior a aquelas que o fundo do tanque está sujeito e para as quais os mesmos costumam ser projetados. $\mathrm{O}$ emprego de supressores fixos conseguiu com sucesso reduzir a pressão dinâmica e o fenômeno de sloshing na sua região mais crítica, na região de ressonância do primeiro modo de oscilação, para todos os níveis de preenchimento. No entanto, para cada nível de preenchimento um dos modelos de antepara fixa se mostrou mais efetivo e, em algumas situações, algum dos modelos resultou inclusive em um perigoso aumento do fenômeno de sloshing. Além disso, os supressores fixos são mais eficazes na supressão dos menores níveis de preenchimento, não possuindo a mesma efetividade para os maiores preenchimentos, efeitos já observados em Tsukamoto (2011).

Observando a dinâmica do fenômeno de sloshing e os resultados da análise dos supressores fixos notou-se que aqueles que apresentavam melhores resultados de supressão estavam na região próxima a superfície livre que, inclusive, consistia na região na qual as partículas de fluído apresentavam maiores velocidades. Desta forma foi analisada a aplicação de um dispositivo supressor de sloshing baseado em uma antepara flutuante. O dispositivo flutuante mostrou reduzir o fenômeno de sloshing na região da frequência natural para todos os níveis de preenchimento, apesar de não mostrar os resultados de maior supressão para alguns deles.

A utilização do supressor baseado em antepara flutuante pode encontrar complicações de natureza prática, como instalação e manutenção. No entanto, pode ser uma solução na redução dos impacto hidrodinâmico promovido pelo fenômeno de sloshing. 


\section{CONCLUSÃo}

A conclusão deste trabalho é dividida em uma primeira parte geral e em uma segunda parte específica, na qual são apresentadas as considerações finais próprias de cada um dos fenômenos estudados. Quanto às conclusões gerais, estas serão divididas nas etapas típicas deste trabalho: a validação, a simulação por processamento paralelo por memória distribuída e a aplicação.

A etapa de validação é baseada na comparação entre os resultados numéricos obtidos pelo método de partículas e os resultados experimentais presentes na literatura. A validação mostrou boa aderência entre os resultados numéricos e experimentais, com o método de partículas sendo capaz de representar adequadamente os complexos fenômenos de impacto hidrodinâmico.

O emprego do simulador com processamento paralelo por meio de partição dinâmica do domínio computacional permitiu a superação da limitação de hardware imposta pela utilização do simulador serial. Desta forma, foi possível usar modelos com grande número de partículas que melhora da resolução dos mesmos. O aumento da resolução levou a um ganho na precisão dos resultados obtidos e, ao mesmo tempo, resultou na redução da oscilação numérica de pressão própria do método MPS. É importante observar que a redução da oscilação numérica de pressão é fruto de uma combinação cuidadosa dos parâmetros numéricos de simulação, não bastando apenas o aumento da resolução.

A etapa de aplicação mostrou a flexibilidade do simulador baseado no método de partículas como ferramenta para a análise dos fenômenos de impacto hidrodinâmico. As análises realizadas neste trabalho demandariam mais tempo e recursos caso fossem realizadas por meio de experimentos. Por outro lado, os métodos numéricos tradicionais baseados em malhas apresentariam dificuldade na modelagem dos violentos fenômenos de impacto hidrodinâmico e na interação entre fluído e estrutura, como no caso das anteparas flutuantes.

Passando às considerações finais específicas, a validação do método de partículas para o fenômeno de green water, por meio da comparação com o resultado experimental obtido para o impacto de onda em modelo fixo, apresentou 
boa aderência. A tendência média da curva de pressão na região central da antepara, na qual ocorre o esforço mais intenso, mostrou comportamento semelhante à curva experimental. Os resultados numéricos da pressão no convés, em frente à antepara, permitiram observar os dois picos de pressão. O primeiro é associado à junção das colunas de água vindas da proa e das laterais e o segundo ao colapso da coluna de água. O emprego do simulador paralelizado por memória distribuída permitiu a obtenção de resultados mais precisos, observando-se a diferença de magnitude entre os dois picos de pressão, e uma menor oscilação numérica de pressão.

A comparação entre os resultados obtidos empregando-se modelo flutuante e modelo fixo mostrou a importância de se considerar o movimento relativo entre a embarcação e a superfície livre da onda. Desta forma, as modelagens que optam, por simplicidade, em utilizar modelos fixos, podem incorrer em erros substanciais ao avaliar o fenômeno de green water.

A análise de green water para diferentes ângulos de aproamento também mostrou a importância da consideração do movimento da estrutura flutuante. Foram observadas situações críticas de movimento da estrutura flutuante para ondas de través e ondas de bochecha. Para as ondas de proa, o movimento do modelo resultou em um maior embarque de água, enquanto que, para as ondas de través, o movimento do modelo resultou em um embarque menor de água.

Por fim, a análise dos diferentes formatos de proa, avaliando-se modelos hidrodinâmicos como cunhas e parábolas e modelos com inclinação da proa (bow flare), mostrou a eficiência do último na redução do embarque de água. Tal solução já é empregada na indústria naval, com o aumento do ângulo de flare para defletir a onda incidente e reduzir o embarque de água. Os modelos de geometria de proa hidrodinâmicas resultaram em maior impacto hidrodinâmico nas estruturas posicionadas sobre o convés do modelo.

A validação do fenômeno de wave runup pela comparação do impacto de onda em modelo fixo de semi-submersível com colunas quadradas mostrou boa aderência. Foi observado nas simulações numéricas um pico de pressão local acima da base das colunas como resultado do impacto da região de alta velocidade do pico das ondas diretamente na coluna. Também foram observadas as diferenças na 
duração do runup nas duas colunas para diferentes comprimentos de onda, como resultado da difração da onda na primeira coluna.

A validação do fenômeno de sloshing mostrou boa aderência entre o método de partículas e os experimentos. O método de partículas representou os fenômenos de sloshing característicos dos diferentes níveis de preenchimento, como a formação de onda solitária (travelling wave) para os baixos preenchimentos e a formação de onda estacionária para os maiores preenchimentos. Observou-se nas simulações numéricas as regiões nas quais são registradas as maiores velocidades no escoamento durante o fenômeno de sloshing, geralmente próximas à superfície livre. Esta observação permitiu a elaboração da proposta da antepara flutuante.

A análise do emprego de anteparas horizontais fixas em diferentes alturas mostrou que, para diferentes preenchimentos, as anteparas em diferentes posições mostram os melhores resultados. Para os preenchimentos baixos apresenta os melhores resultados a antepara posicionada próxima ao fundo do tanque enquanto que, para os maiores preenchimentos, a antepara posicionada no centro do tanque mostrou os melhores resultados. Nos maiores preenchimentos, o emprego de antepara no fundo do tanque resultou na intensificação do fenômeno de sloshing. Já o emprego da antepara horizontal flutuante mostrou mitigação de sloshing, próximo à frequência natural, para todos os níveis de preenchimento. 


\section{BIBLIOGRAFIA}

Amsden, A. A. \& Harlow, F. H., 1968. Transport of Turbulence in Numerical Fluid Dynamics. J. Comput. Phys., pp. 94-110.

Arai, M., Cheng, L. Y. \& Inoue, Y., 1992. 3D Numerical Simulation of Impact Load due to Liquid Cargo Sloshing. Journal of the Naval Societ of Japan, Volume 171, pp. pp. 317-324.

Baarholm, R., 2009. Experimental and Theoretical Study of Three-dimensional Effects on Vertical Wave-in-deck Forces. 30th International Conference on Ocean, Offshore and Artic Engineering.

Bellezi, C. A., Marcus, F. A., Liang-Yee, C. \& Nishimoto, K., 2009. Análise de Hidrodinâmica Não-linear por Método MPS: Suavização da Flutuação de Pressão. $30^{\circ}$ Iberian-Latin-American Congress on Computational Methods in Engineering.

Blackbill, J. U., Kothe, D. B. \& Ruppel, H. M., 1988. FLIP: A Low-Dissipation, Particlein-Cell Method for Fluid Flow. Comp. Phys. Comm., pp. 25-38.

Buchner, B., 2002. Green water on ship-type structures. s.l.:Delft University of Technology.

Cheng, L.-Y., 1995. Evaluation of Water Impact Load by Numerical Simulation and Its Application to Ship Design. Yokohama, Japan: PhD Thesis on Hydrodynamics, Yokohama National University.

Chorin, A. J., 1968. Numerical Solution of the Navier-Stokes Equations. s.I.:s.n.

Colagrossi, A. \& Landrini, M., 2003. Numerical simulation of interfacial flow by smoothing particles hydrodynamics. s.l.:Elsevier.

Colicchio, G., Colagrossi, A., Greco, M. \& Landrini, M., 2002. Free Surface Flow after a Dam Break. s.l.:s.n.

Crank, J. \& Nicolson, P., 1947. A Pratical Method for Numerical Evaluation of solutions of Partial Differential Equations of the Heat-Conduction Type. Proc. Camb. Phi. Soc., pp. 50-67. 
Cummins, S. J. \& Rudman, M., 1999. An SPH Projection Method. s.I.:Academic Press.

Dean, R. G. \& Dalrymple, R. A., 1991. Water Wave Mechanics for Engineers and Scientists. 1st ed. s.I.:World Scientific Publication.

Faltinsen, O. M., Greco, M. \& Landrini, M., 2002. Green Water Loading on a FPSO. s.I.:American Society of Mechanical Engineers.

Fernandes, D. T., 2013. Implementação de Framework Computacional de Paralelização Híbrida do Moving Particles Semi-Implicit Method para Modelagem de Fluídos Incompressíveis. São Paulo(São Paulo): Departamento de Engenharia Naval e Oceânica, Escola Politécnica, Universidade de São Paulo.

Gingold, R. \& Monaghan, J. J., 1977. Smoothed Particle Hidrodynamics: Theory and Application to Non-Spherical Stars. Monthly Notices of the Royal Astronomical Society, pp. 375-389.

Gotoh, S., 2009. 3D-CMPS method for improvement of water surface tracking in breaking waves, Simulation of the SPHERIC benchmark test 2, '3D schematic dam break and evolution of the free surface', by an improved parallelized particle method and SPHysics. Nantes: s.n.

Greco, M., 2001. A Two-Dimensional Study of Green Water Loading. s.I.:Norwegian University of Science and Technology.

Greco, M., Faltinsen, O. M. \& Landrini, M., 2005. Shipping of water on a twodimensional structure. Journal of Fluid Mechanics, pp. 309-332.

Harlow, F. H., Ellison, M. A. \& Reid, J. H., 1964. The Particle-in-Cell Computing Method for Fluid Dynamics. J. Methods Comput. Phys., pp. 319-343.

Harlow, F. W. \& Welch, J. E., 1965. Numerical Calculation of Time-Dependent Viscous Incompressible Flow of Fluid with Free Surface. Physics of Fluids, pp. 21822189.

Hibi, S. \& Yabushita, K., 2004. A Study on Reduction of Unusual Pressure Fluctuation of MPS Method. J. Kansai Soc., pp. 125-131.

Hirt, C. W. \& Cook, J. L., 1972. Calculating Three-Dimensional Flows around Structures and over Rough Terrain. J. Comput. Phys., pp. 324-430. 
Ikari, H. \& Gotoh, H., 2008. Parallelization of MPS method for 3D wave analysis. Nagoya, s.n.

Iribe, T., Fujizawa, T. \& Koshizuka, S., 2010. Redution of Communication on Parallel Computing of Particle Method for Flow Simulation at Seaside Areas. Coastal Enginnering Journal, pp. 261-285.

Issa, R. \& Violeau, D., 2006. 3D dambreaking - Test Case 2, s.l.: Laboratoire National d'Hydraulique et Evironnement.

Iwanowski, B., Lefranc, M. \& Wemmenhove, R., 2009. CFD Simulation of Wave Runup on a semi-Submersible and Comparison with Experiment. Honolulu, Hawaii, USA, s.n.

Kendon, T. E. et al., 2010. wave-in-deck impact: comparing CFD, simple methods, and model tests. Shanghai, s.n.

Khayyer, A. \& Gotoh, H., 2008. Development of CMPS Method for Accurate Water Surface Tracking on Breaking Waves. Coastal Engineering.

Khayyer, A. \& Gotoh, H., 2009. Modified MPS Method for Prediction of 2D Wave Impact Pressure. Coastal Engineering.

Khayyer, A. \& Gotoh, H., 2012. A 3D Higher Order Laplacian Model for Enhancement ad Stabilization of Pressure Calculation in 3D MPS-BAsed Simulations. s.I.:Elsevier.

Kleefsman, K. M. T. et al., 2005a. A volume-of-fluid based simulation method for wave impact problems. Journal of Computational Physics, Volume 206, pp. 363-393.

Kleefsman, T. K. M. et al., 2005b. The Numerical Simulation of Green Water Loading Including Vessel Motions and the Incoming Wave Field. Halkidiki: American Society of Mechanical Engineers (ASME).

Koh, C. G., Gao, M. \& Luo, C., 2012. A New Particle Method for Simulation od Incompressible Fee Surface Flow Problems. s.I.:Wiley \& Sons.

Kondo, M. \& Koshizuka, S., 2010. Improvement of Stability of Moving Particle SemiImplicit Method. International Journal of Numerical Methods on Fluids. 
Koshizuka, S., Nobe, A. \& Oka, Y., 1998a. Numerical Analisys of Breaking Waves Using the Moving Particle Semi-Implicit Method. International Journal of Numerical Methods in Fluids, pp. 751-769.

Koshizuka, S., Ohta, K. \& Oka, Y., 1998b. Development of a 3D Scheme Using Moving Particles Semi-Implicit for Thermal Hydraulics. s.l., American Society of Mechanical Engineering.

Koshizuka, S. \& Oka, Y., 1996. Moving particles semi-impliciti method for fragmentation of incompressible fluid. Nuclear Science and Engineering, Volume 123, pp. 421-434.

Koshizuka, S. \& Oka, Y., 1997. A Particle Method for Complex Fluid Dynamics with Interfaces. Tokyo, The Japan society of Mechanical Engineers.

Koshizuka, S., Tamako., H. \& Oka, Y., 1995. A Particle Method for Incompressible Viscous Flow with Fluid Fragmentation. Journal of Computational Fluid Dynamics, pp. 29-46.

Le Touzé, D. et al., 2010. SPH Simulation of Green Water and Shipping Flooding Scenarios. s.I.:Elsevier.

Lee, B.-H., Park, J.-C. \& Kim, M., 2010. Two-dimensional vessel-motion/liquidsloshing interactions and impact loadings by using a particle method. Shanghai, China, s.n.

Lee, H.-H., Lim, H.-J. \& Rhee, S. H., 2012. Experimental Investigation of Green Water on Deck for a CFD Validation Database. Ocean Engineering, Volume 42, pp. p. 47-60.

Liebmann, L., 1918. Die Angenäherte Ermittelung Harmonischer Funktionen und Konformer Abbildungen. Sitzungsber. Math. Phys. Kl. Bayer. Akad. Wiss. , p. 385.

Lu, H., Yang, C. \& Löhner, R., 2010. Numerical Studies of Green Water Impact on Fixed and Moving Bodies. Shanghai: International Society of Offshore and Polar Engineers - ISOPE.

Monaghan, J. J. \& Gingold, R., 1983. Shock Simulation by the Particle Method SPH. Journal of computational Physics, pp. 374-389. 
Nichols, B. D. \& Hirt, C. W., 1973. Calculating Three-Dimensional Flows in the Vicinity of submerged and Exposed Structures. J. Comput. Phys., pp. 234-246.

$\mathrm{Ni}, \mathrm{T}$. et al., 2011. State-of-the-art of Green Water on FPSO in Harsh Environment. Key Engineering Materials, Volume Vol. 464, pp. 465-468.

Pakozdi, C., Östman, A., Stansberg, C. T. \& Silva, D. F. d. C., 2014. Green Water on FPSO Analyzed by a Coupled Potential-Flow-NS-VOF Method. San Francisco(California): American Society of Mechanical Engineers - ASME.

Patankar, S. V., 1980. Numerical Heat Transfer and Fluid Flows. Nova York: Hemisphere Publishing Co..

Peaceman, D. W. \& Rachford, H. H., 1955. The Numerical Solution of Parabolic and Ellipitic Partial Differential Equations. J. Soc. Ind. Appl. Math., pp. 28-41.

Premoze, S., Tasdizen, T., Lefohn, J. \& Whitaker, T., 2003. Particle Based Simulation of Fluids. s.l., Eurographics.

Richardson, L. F., 1910. The Approximate Arithmetic Soluton by Finite Differences of Physical Problems Involving Differential Equations with an Application to the Stresses in a Masonry Dam. Phil. Trans. R. Soc., pp. 307-357.

Rudman, M. et al., 2008. Rogue Wave Impact on a Semi-Submersible Offshore Platform. Estoril, Portugal, s.n.

Ryu, Y., Chang, K.-A. \& Mercier, R., 2007. Application of Dam-Break Flow to Green Water Prediction. s.l.:Elsevier.

Schiller, R. V., Pâkozdi, C., Stansberg, C. T. \& Silva, D. F. C. e., 2014a. Green Water and Wave Impact on FPSOs in Santos Basin: Challenges and Prediction Tools. San Francisco(California): s.n.

Schiller, R. V. et al., 2014b. Green Water on FPSO Predicted by a Practical Engineering Method and Validated Againist Model Tests Data for Irregular Waves. San Francisco(California): s.n.

Shibata, K. \& Koshizuka, S., 2007. Numerical Analysis of Shipping Water Impact on a Deck Using a Particle Method. Ocean Engineering, Volume 34, p. 585-593. 
Shibata, K., Koshizuka, S., Sakai, M. \& Tanizawa, K., 2012. Lagrangian Simulations of Ship-Wave Interactions in Rough Seas. Ocean Engineering.

Shibata, K., Koshizuka, S. \& Tanizawa, K., 2009. Three-dimensional Numerical Analysis of Shipping Water Onto a Moving Ship Using a Particle Method. Journal of Marine Science and Technology, pp. 214-227.

Shibata, K., Tanizawa, K. \& Koshizuka, S., 2007. Numerical Analysis of Coupling between Ship Motion and Green Water on Deck using MPS Method. Fukuoka: s.n.

Silva, D. F. C. e. \& Rossi, R. R., 2014. Green Water Loads Determination for FPSO Exposed to Beam Sea Conditions. San Francisco(California): American Society of Mechanical Engineers - ASME.

Souto-Iglesias, A., Macià, F., González, L. M. \& Cercos-Pita, J. L., 2013. On the consistency of MPS. s.l.:Elsevier.

Sueyoshi, M., 2006. Validation of a Numerical Prediction Method of Impulsive Pressure by Particle Method. s.I., The Society of Naval Archtects of Japan.

Sueyoshi, M. \& Naito, S., 2002a. Aplication of MPS for Violent Free Surface Problems on Marine Engineering, Tokyo: Department of Naval and Ocean Enginnering.

Sueyoshi, M. \& Naito, S., 2002b. A Numerical Study of Very Large Motion of Floating Body by Particle Method. Kobe, Japan, Asia and Pacific Workshop on Marine Hydrodinamics.

Tamai, T., Shibata, K. \& Koshizuka, S., 2013. Development of Least Squares Moving Particle Semi-Implicit Method. s.l.:s.n.

Tanaka, M. \& Matsunaga, T., 2010. Stabilization and Smoothing of Pressure in MPS Method by Quasi-Compressibility. s.l.:Elsevier.

Thom, A., 1933. The Flow Past Circular Cylinders at Low Speed. Proc. Roy. Soc. A., pp. 651-669.

Tsukamoto, Márcio Michiharu; Cheng, Liang-Yee; Nishimoto, Kazuo, 2010. Numerical Study of the Effectiveness of Moving a Sloshing Supression Device. Shanghai, China, s.n. 
Tsukamoto, M. M., 2006. Desenvolvimento do Método de Partículas na Representação de Corpos Flutuantes em Ondas Altamente Não-lineares. São Paulo: s.n.

Tsukamoto, M. M., 2011. Modelagem analítica e simulação numérica de um sistema móvel de supressão de sloshing, São Paulo, SP, Brazil: Doctorate thesis in naval and ocean engineering, University of São Paulo.

Tsukamoto, M. M., Cheng, L.-Y. \& Nishimoto, K., 2011. Analytical and numerical study of the effects of an elastically-linked body on sloshing. Computer \& Fluids, Volume 49, pp. 1-21.

Vogel, M. et al., 2010. Metocean Measurements of Northern Santos Basin - Brazil. Houston(Texas): s.n.

Von Karman, T., 1929. The Impact on Seaplane Floats During Landing. s.I.:s.n.

Wood Group Mustang, 2011. 2011 Worldwide Survey of Semi-FPSs and FPUs. s.l.:Offshore Magazine.

Wood Group Mustang, 2013. 2013 Worldwide Survey of Floating, Production, Storage and Offloading (FPSO) Units. s.l.:Offshore Magazine.

Xiao, L., Tao, L., Yang, J. \& Li, X., 2014. An Experimental Investigation on Wave Runup Along the Broadside of a Single Point Moored FPSO Exposed to Oblique Waves. s.l.:Elsevier.

Zhang, Y., Wang, X., Tang, Z. \& Wan, D., 2013. Numerical Simulation of Green Water Incidents Based on Parallel MPS Method. Anchorage(Alaska): International Society of Offshore and Polar Engineers (ISOPE). 